\title{
RECENT ADVANCES TOWARDS THE DEVELOPMENT OF ENANTIO- AND DIASTEREOSELECTIVE PALLADIUM CATALYZED NITROGEN ARYLATION REACTIONS
}

\author{
by \\ Augusto Matarazzo \\ Bachelor of Science, Chemistry, \\ Ryerson University, Toronto, Ontario, Canada, 2009
}

\begin{abstract}
A thesis presented to Ryerson University
in partial fulfillment of the requirements for the degree of

Master of Science in the Program of Molecular Science
\end{abstract}

Toronto, Ontario, Canada, 2011

(C) Augusto Matarazzo 2011 


\section{Author's Declaration}

I hereby declare that I am the sole author of this thesis.

I authorize Ryerson University to lend this thesis to other institutions or individuals for the purpose of scholarly research.

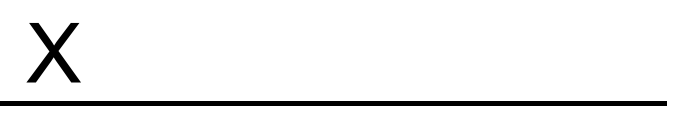

Augusto Matarazzo

I further authorize Ryerson University to reproduce this thesis by photocopying or other means, in total or in part, at the request of other institutions or individuals for the purpose of scholarly research.

\section{$X$}

Augusto Matarazzo 


\title{
Abstract \\ RECENT ADVANCES TOWARDS THE DEVELOPMENT OF ENANTIO- AND DIASTEREOSELECTIVE PALLADIUM CATALYZED NITROGEN ARYLATION REACTIONS
}

by Augusto Matarazzo

Molecular Science

Master of Science, Ryerson University, 2011

\begin{abstract}
A non-commercially available ligand, (R)-2(Dicyclohexylphosphino)-2'-methoxy-1,1'binaphthyl), $(R)-\mathrm{Cy}_{2} \mathrm{MOP}$, has been synthesized and demonstrated to be very effective in the palladium catalyzed intramolecular desymmetrization of di-nitrogen malonamides. Additionally an enantio- and diastereoselective Buchwald-Hartwig reaction has been developed through the desymmetrization of 2-(2-bromobenzyl)- $N^{1}, N^{3}$-bis(2-(tert-butyl)phenyl)-2-methylmalonamide using palladium/ $\mathrm{Cy}_{2} \mathrm{MOP}$ as the catalyst system to produce $N, 1$-bis(2-(tert-butyl)phenyl)-3methyl-2-oxo-1,2,3,4-tetrahydroquinoline-3-carboxamide in excellent yield, with high enantioand diastereoselectivity $(99 \%, 88 \% e e)$. This serves as the first example of its kind whereby an enantio- and diastereoselective Buchwald-Hartwig reaction occurs in a single step from the preferential $\mathrm{N}$-arylation of prochiral di-nitrogen malonamides. Application of the palladium/ $\mathrm{Cy}_{2} \mathrm{MOP}$ catalyst system in the intramolecular desymmetrization reaction also resulted in the formation of six membered ring benzomorpholinone and seven membered ring benzodiazepineone heterocycles. Furthermore several synthetic routes towards the synthesis of five membered ring oxindoles are thoroughly discussed. Lastly the synthesis of a precatalyst was also attempted using $\mathrm{Cy}_{2} \mathrm{MOP}$ and $\mathrm{Pd}(\mathrm{II}) \mathrm{Me}_{2} \mathrm{TMEDA}$.
\end{abstract}




\section{Acknowledgements}

I would like to start off by thanking my supervisor Dr. Russell Viirre for giving me the opportunity to work in his lab. He is a phenomenal supervisor and this project would not have been possible if not for his guidance and expertise. Not only was he an outstanding mentor and teacher, he also inspired me to pursue my graduate studies in synthetic organic chemistry.

I would like to thank my committee members Dr. Steve Wylie and Dr. Robert Gossage for their help and expertise as well as everyone in the synthetic group at Ryerson University. I would like to thank Dr. Alan Lough for collaborating with us and carrying out the x-ray crystallography.

Next I must say that I have had the pleasure of working with a fantastic group of people in the Viirre lab throughout the years. I want to thank all past and present members of the Viirre research group, especially Salma Al-Karmi, Julian Kwok, Joanne Bogojeski, Robert Denning, Bashar Alkhouri, Salma Elmallah and Salman Ansari, you guys truly made this experience one that I will never forget. I would also like to extend a special thanks to Lukasz Porosa for starting this work and helping me get acquainted with this project.

I want to thank all my family members here in Canada and in Italy, especially my parents Gianni and Elvira Matarazzo for giving me the opportunity to pursue my post-secondary studies and always being there for me over the years. I would also like to thank my sisters Stefania and Linda Matarazzo for all their encouragement and support throughout the years. I want to extend an extremely special thanks to Adriana Cimo for being such a wonderful person. This project would not have been possible if not for her continuous patience, support and understanding. I would also like to thank the Cimo family for all their warmth, compassion and support during this time. 
Table of Contents

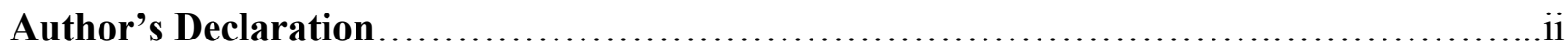

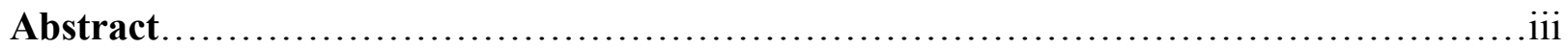

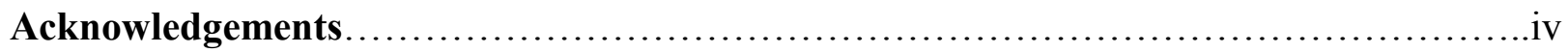

List of Tables.................................................................. vii

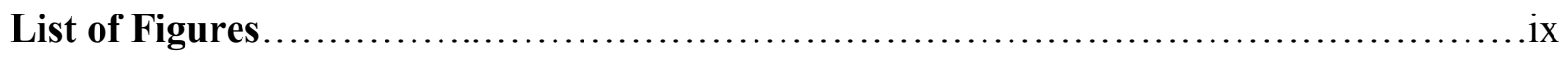

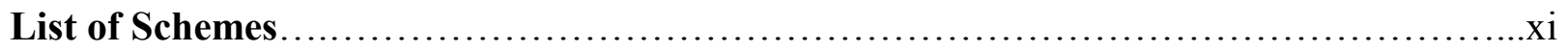

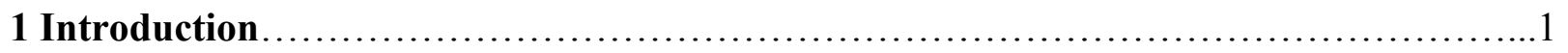

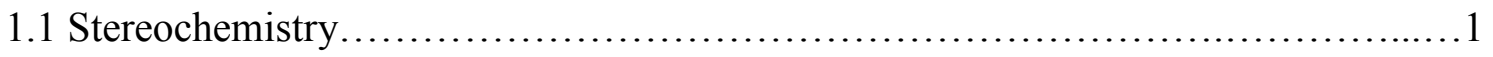

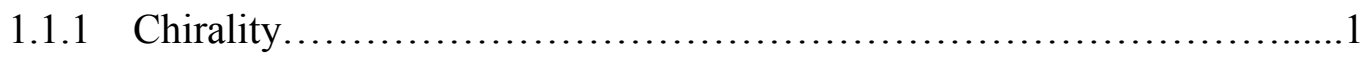

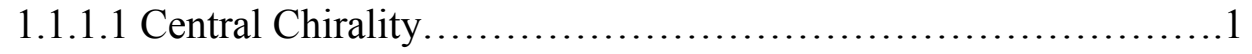

1.1.1.2 Axial Chirality............................................

1.1.1.3 Planar Chirality................................................

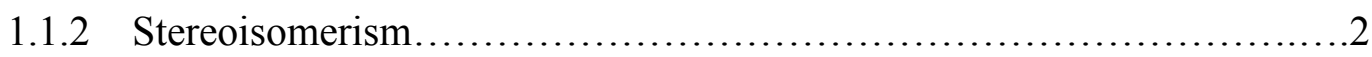

1.1.2.1 Enantiomers...........................................

1.1.2.2 Diastereomers........................................... 3

1.1.3 Stereoselective Reactions.........................................4

1.2 The Buchwald-Hartwig Reaction...........................................4

1.2.1 Mechanism of the Buchwald - Hartwig Reaction.......................5

1.2.2 Chiral Bisphosphine Ligands in the Buchwald-Hartwig Reaction...........6

1.2.3 Retention of Chirality in Buchwald-Hartwig Reactions...................8

1.2.4 Enantioselective Buchwald-Hartwig Reactions..........................9

1.2.4.1 Kinetic Resolution.........................................9

1.2.4.2 Chiral Plane Formation.......................................14

1.2.4.3 Chiral Centre Formation....................................... 18

1.2.4.4 Chiral Axis Formation.........................................20

1.3 Synthesis of MOP and MOP Type Ligands.................................23

1.4 Synthesis of Palladium Precatalysts for C-N Cross-coupling Reactions..............27

1.5 Research Goals and Objectives...........................................28 
2.1 Towards the Synthesis of 5 membered ring Oxindole Heterocycles................29

2.1.1 Decarboxylation of 2-(2-bromophenyl)-2-methylmalonic acid............32

2.1.2 Alternate synthetic route towards $N^{1}, N^{2}$-dibenzyl-2-methyl-2-

phenylmalonamide.......................................... 32

2.1.2.1 $N^{1}, N^{2}$-dibenzyl-2-methyl-2-phenylmalonamide Synthesis using trimethyl aluminum....................................32

2.1.2.2 Decarbonylation of Barbituric acids...........................34

2.1.2.3 Base catalyzed ester hydrolysis followed by immediate activation

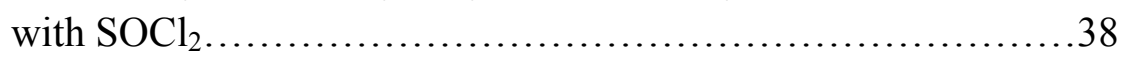

2.1.2.3.1 $N^{1}, N^{2}$-dibenzyl-2-methyl-2-phenylmalonamide Synthesis using benzyl isocyanate............................39

2.1.2.3.2 Temperature experiments on base catalyzed ester hydrolysis....................................40

2.1.2.4 Base catalyzed ester hydrolysis re-revisited...................40

2.1.2.5 $N^{1}, N^{2}$-dibenzyl-2-methyl-2-phenylmalonamide synthesis using HBTU..................................................41

2.1.2.6 $N^{1}, N^{2}$-dibenzyl-2-methyl-2-phenylmalonamide synthesis using BuLi..............................................42

2.2 Synthesis of six membered ring Benzomorpholinone Heterocycles.................43

2.3 Synthesis of Seven Membered Ring Benzodiazepinone Heterocycles...............49

2.4 Development of an enantio- and diastereoselective Buchwald-Hartwig reaction.....53

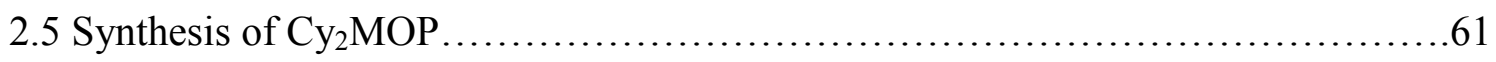

2.6 Palladium Precatalyst Synthesis..........................................64

2.6.1 Palladium Precatalyst Synthesis via orthopalladated complexes..........65

2.6.2 Palladium Precatalyst Synthesis using Pd(II)Me $\mathrm{M}_{2}$ TMEDA..............66

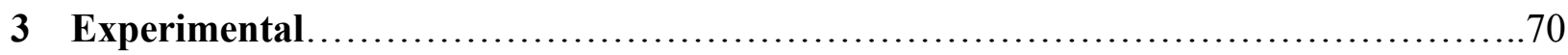

3.1 General Considerations................................................ 70

3.2 Towards the Synthesis of Oxindole Heterocycles............................. 70

3.3 Towards the Synthesis of Benzomorpholinone Heterocycles.....................76

3.3.1 General Procedure for the Synthesis of 21 .............................79

3.4 Towards the Synthesis of Benzodiazepinone Heterocycles......................80

3.5 Towards the Synthesis of $t$-butyl substituted Quinolinone.........................85

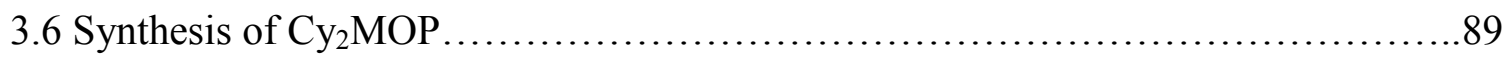




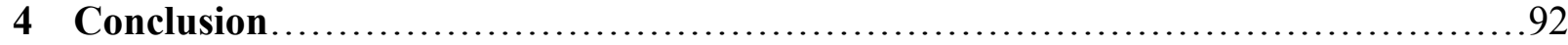

5 Appendix: NMR spectra $\left({ }^{1} \mathrm{H},{ }^{13} \mathrm{C},{ }^{11} \mathrm{~B},{ }^{31} \mathrm{P}\right)$, HPLC chromatograms and x-ray crystallographic data........................................................... 93

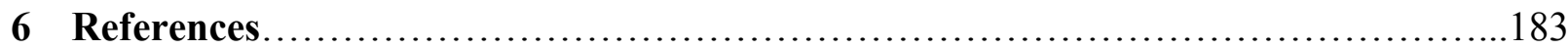


List of Tables:

Table 1: Desymmetrization of di-nitrogen malonamides via an intramolecular Buchwald-Hartwig reaction to produce benzomorpholinone heterocycles....

Table 2: Desymmetrization of di-nitrogen malonamides via an intramolecular Buchwald-Hartwig reaction to produce benzodiazepinone heterocycles.................52

Table 3: Desymmetrization of di-nitrogen malonamides via an intramolecular Buchwald-Hartwig reaction to produce $t$-butyl substituted quinolinone...................55 
List of Figures:

Figure 1) The two enantiomers of 2-bromobutane...................................

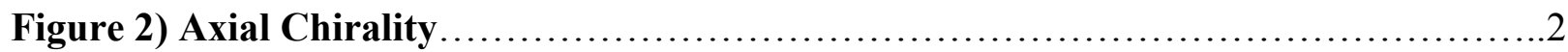

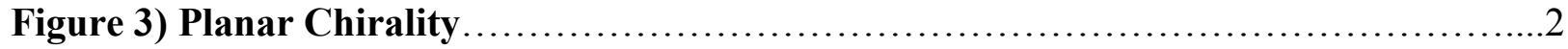

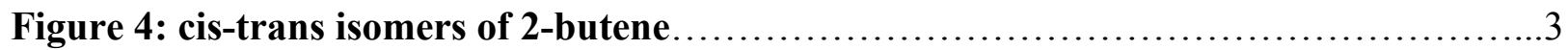

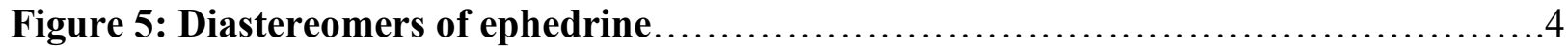

Figure 6: Equation for calculating enantiomeric excess.............................4

Figure 7:A General Buchwald-Hartwig reaction ..................................

Figure 8: Coupling of aryl halides with secondary phosphines......................26

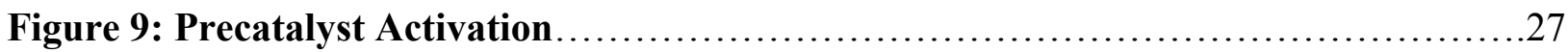

Figure 10: Desymmetrization of di-nitrogen malonamides to form oxindole

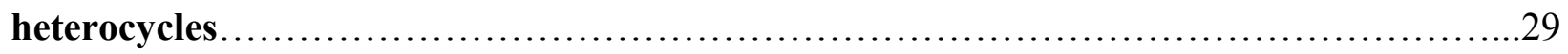

Figure 11: Desymmetrization of malonamides to form benzomorpholinone

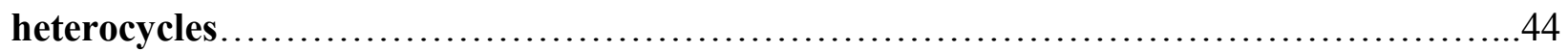

Figure 12: Desymmetrization of malonamides to form benzodiazepinone

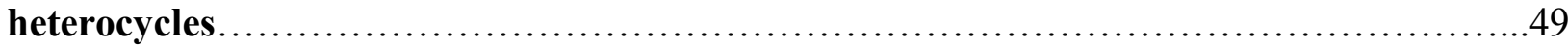

Figure 13: Development of an enantio- and diastereoselective Buchwald-Hartwig

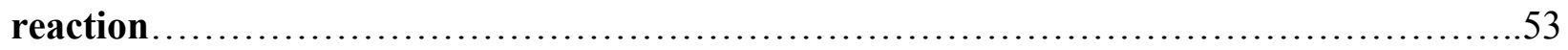

Figure 14: X-ray crystal structure of $t$-butylphenyl substituted quinolinone.............57

Figure 15a: HPLC chromatogram of racemic compound 36.........................59

Figure 15b: HPLC chromatogram of compound 36 cyclized with $\mathrm{Cy}_{2} \mathrm{MOP}$ using

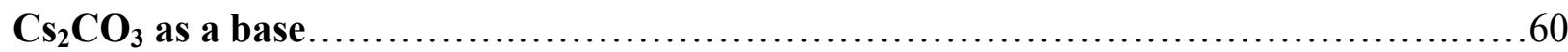

Figure 15c: HPLC chromatogram of compound 36 cyclized with $\mathrm{Cy}_{2} \mathrm{MOP}$ using

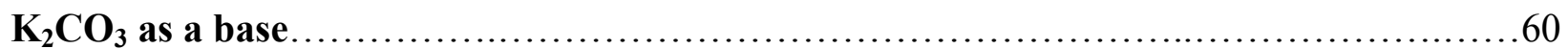

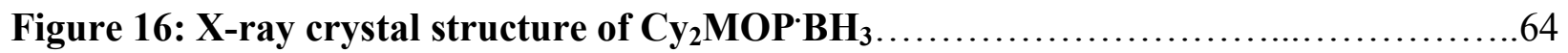


Figure 17: An axially chiral, enantiopure palladium precatalyst....................65

Figure 18: Reaction of tertiary phosphines with orthopalladated complexes.............65

Figure 19: Buchwald's Palladium precatalyst synthesis using Pd(II)Me 2 TMEDA.......66 
List of Schemes:

Scheme 1: Intermolecular coupling of aryl halides with secondary amines...............5

Scheme 2: General mechanism of the Buchwald-Hartwig reaction......................6

Scheme 3a: Incorporation of chiral bisphosphine ligands in the Buchwald/Hartwig

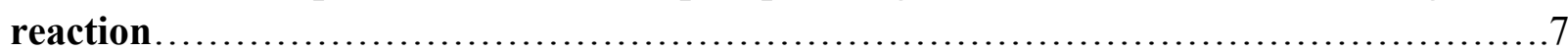

Scheme 3b: Incorporation of chiral bisphosphine ligands in the Buchwald/Hartwig

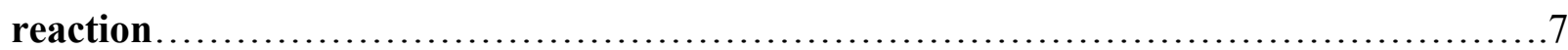

Scheme 4a: intermolecular coupling of an amine with an aryl halide..................8

Scheme 4b: intramolecular coupling of an amine with an aryl halide $\ldots \ldots \ldots \ldots \ldots \ldots \ldots . . \ldots$

Scheme 5: Enantiopure mono-N-arylation of (1R,2R)-(-)-1,2-diaminocyclohexane.........9

Scheme 6: Kinetic resolution of racemic planar chiral bromides...................... 10

Scheme 7a: Kinetic resolution of a racemic axially chiral amino alcohol.................11

Scheme 7b: Kinetic resolution of a racemic axially chiral diamine.................... 12

Scheme 8: Kinetic resolution of optically active aniline derivatives....................12

Scheme 9: Enantio- and diastereoselective Buchwald-Hartwig reaction...................13

Scheme 10a: Azamacrocycle synthesis via enantioselective Buchwald-Hartwig

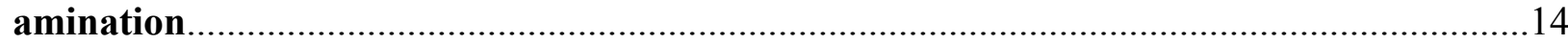

Scheme 10b:Azamacrocycle synthesis via enantioselective Buchwald-Hartwig amination.

Scheme 11a:Azamacrocycle synthesis via enantioselective Buchwald-Hartwig amination

Scheme 11b:Azamacrocycle synthesis via enantioselective Buchwald-Hartwig

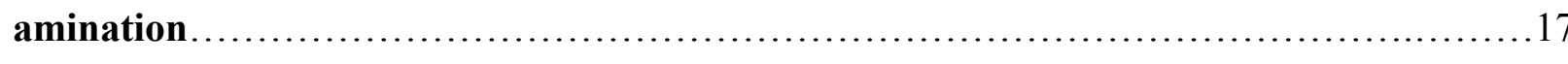

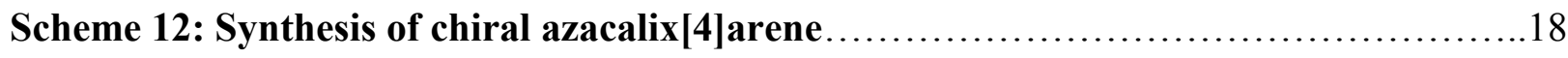

Scheme 13: Desymmetrization of malonamide derivatives via an enantioselective intramolecular Buchwald-Hartwig reaction.

Scheme 14: Synthesis of $C_{2}$-symmetric spirobilactams via an enantioselective intramolecular Buchwald-Hartwig reaction. 
Scheme 15: Enantioselective intermolecular nitrogen arylation of $t$-butylanilides........21

Scheme 16: Enantioselective intramolecular nitrogen arylation of $t$-butylanilides.........22

Scheme 17: Atropisomeric lactam chemistry as a chiral auxiliary in the synthesis of key

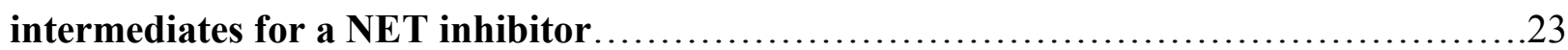

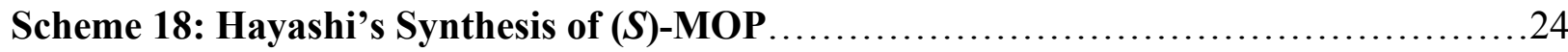

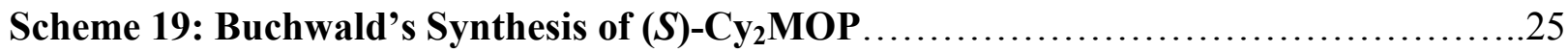

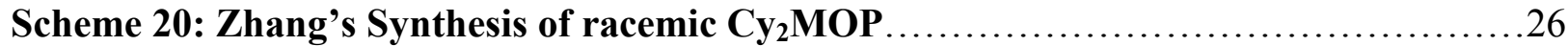

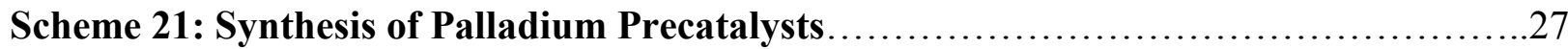

Scheme 22: Coupling of electron deficient anilines with unactivated aryl chlorides.......28

Scheme 23: Initial synthetic protocol for the synthesis of oxindole precursors.............30

Scheme 24: An Improved Synthetic Protocol for the Synthesis of Oxindole Precursors....31

Scheme 25: Decarboxylation of 2-(2-bromophenyl)-2-methylmalonic acid................32

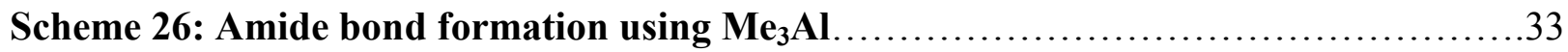

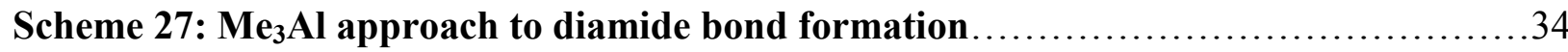

Scheme 28: decarbonylation of tetrasubstituted barbituric acids....................... 34

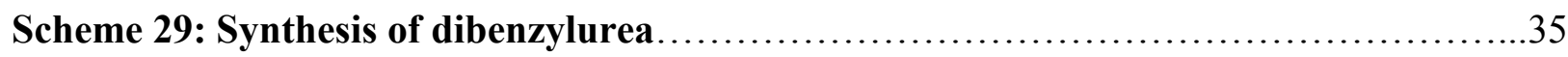

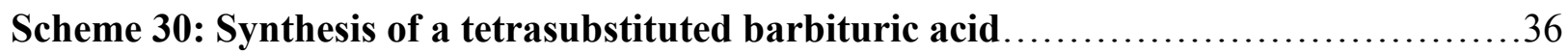

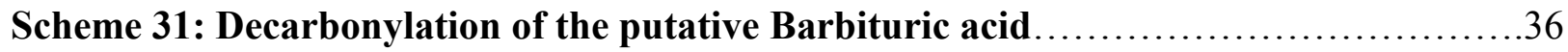

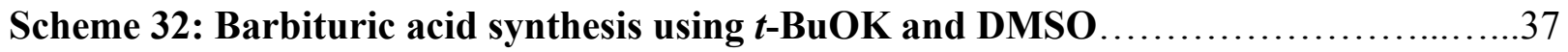

Scheme 33: Barbituric acid synthesis using TMSCI and Hunig's base....................37

Scheme 34: Barbituric acid synthesis using potassium bis(trimethylsilyl)amide............38

Scheme 35:Base catalyzed ester hydrolysis followed by immediate activation with

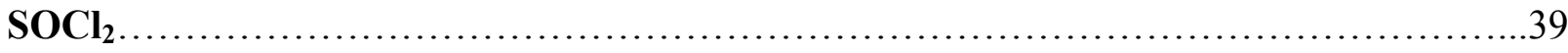

Scheme 36:Synthesis of compound 10 using benzyl isocyanate.....................40

Scheme 37: Amide bond formation in the absence of heat............................ 41

Scheme 38: Base-catalyzed ester hydrolysis using KOH $\ldots \ldots \ldots \ldots \ldots \ldots \ldots \ldots \ldots \ldots \ldots . \ldots \ldots$ 
Scheme 39: HBTU coupling of mono-acid mono-ester with benzylamine .42

Scheme 40: Amide bond formation using Butyl-Lithium.........................43

Scheme 41: Towards the Synthesis of Benzomorpholinone Heterocycles...............45

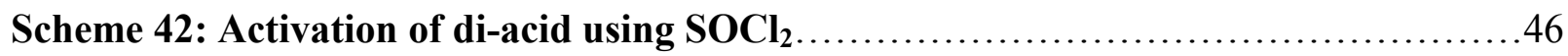

Scheme 43: Activation of di-acid using HBTU............................... 46

Scheme 44: Synthesis of benzodiazapineone precursors..........................50

Scheme 45: Towards the Synthesis of benzodiazepinone heterocycles.................51

Scheme 46: Debromination under cross-coupling conditions........................52

Scheme 47: Towards the synthesis of $t$-butyl quinolinone........................54

Scheme 48: Initial cross-coupling experiments using $(R)-M O P$ and $(R)-M O P \cdot B H_{3} \ldots \ldots .56$

Scheme 49: Synthesis of racemic $t$-butyl quinolinone using an S-PHOS precatalyst........58

Scheme 50: Synthesis of (R)-2(Dicyclohexylphosphino)-2'-methoxy-1,1'-binaphthyl)......61

Scheme 51: Intramolecular desymmetrization using $\mathbf{C y}_{2}$ MOP .....................62

Scheme 52: Synthesis of $\mathrm{Cy}_{2} \mathrm{MOP}^{-\mathrm{BH}_{3}}$ via complexation with borane-THF.............63

Scheme 53: Attempted orthopalladation of (2-Phenylethyl)amine ...................66

Scheme 54: Cross coupling reaction using putative $\mathrm{Cy}_{2} \mathrm{MOP}$ precatalyst...............67

Scheme 55:Cross coupling reaction using putative $(R)-$ MOP precatalyst................68

Scheme 56: Cross coupling reaction using another putative precatalyst................69 


\section{Introduction}

\subsection{Stereochemistry}

Stereochemistry is a branch of chemistry that deals with the three dimensional structure of molecules. ${ }^{1}$ Stereoisomers are isomers that have the same connectivity but differ in their three dimensional orientation. ${ }^{1}$

\subsubsection{Chirality}

A molecule is said to be chiral if it is nonsuperimposable on its mirror image. ${ }^{2}$ An example of a chiral molecule is shown in figure 1.

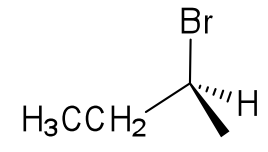

(S)-configuration

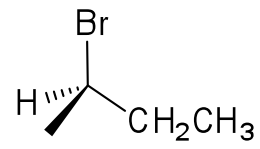

$(R)$-configuration

\section{Figure 1: The two enantiomers of 2-bromobutane}

A molecule can possess three different types of stereogenic elements: a chiral centre, chiral axis or chiral plane.

\subsubsection{Central chirality}

The presence of a tetrahedral carbon atom attached to four different groups usually makes a molecule chiral. ${ }^{1}$ The carbon atom which is attached to the four different groups is called a chiral carbon or a chiral centre. ${ }^{1}$ An example of a molecule that exhibits this type of chirality is shown in figure 1.

\subsubsection{Axial Chirality}

Axial chirality results from the non planar arrangement of four groups in pairs about a chiral axis. ${ }^{3}$ A chiral axis can be generated due to restricted rotation around a single bond, pi bonds or rings and is usually observed in allenes, biphenyls and binaphthyls. ${ }^{3}$ Some examples of axial chirality are shown in figure 2. 

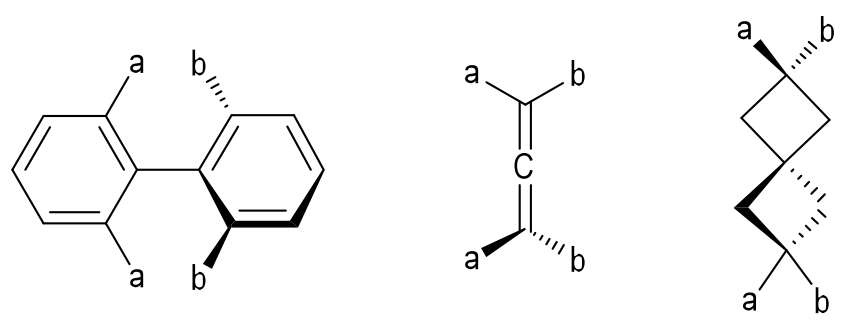

Figure 2: Axial Chirality

\subsubsection{Planar Chirality}

Planar chirality results from the arrangement of out of plane groups with respect to a plane. ${ }^{3}$ The most common class of molecules that possess chiral planes are bridged aromatic molecules ${ }^{3}$ in which a linker-chain, extending above or below the chiral plane, restricts rotation in the molecule. An example of a molecule exhibiting planar chirality is shown in figure 3.

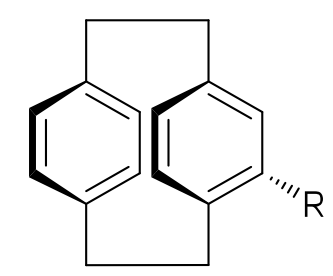

Figure 3: Planar Chirality

\subsubsection{Stereoisomerism}

Stereoisomers are isomers that have the same molecular formula and sequence of bonded atoms but differ in the three dimensional orientation of their atoms in space. ${ }^{1}$ Stereoisomers can be subdivided into two classes: enantiomers and diastereomers.

\subsubsection{Enantiomers}

Enantiomers are a pair of stereoisomers that are nonsuperimposable mirror images. ${ }^{1}$ An example of a pair of enantiomers is shown in figure 1. The chemical properties of enantiomers are identical when reacting with achiral molecules and differ when reacting with chiral molecules, 
i.e. a reaction that forms enantiomers from achiral starting material will form a racemic mixture of enantiomers unless there is some chiral influence on the reaction (for example a chiral catalyst). ${ }^{1}$ The physical properties of enantiomers are identical except for the direction in which they rotate plane polarized light. ${ }^{1}$

\subsubsection{Diastereomers}

Diastereomers are a special type of stereoisomer that are not mirror images of each other but differ in their spatial arrangement of atoms. ${ }^{1}$ Diastereomers often have different chemical reactions and different physical properties. ${ }^{1}$ Furthermore some reactions produce only one diastereomer and not the other and some reactions only occur with one diastereomer and not the other. ${ }^{1}$ Diastereomers can be divided into two categories: cis-trans stereoisomers, i.e. the stereoisomers differ in the placement of groups on one side or the other of a double bond (see figure 4), and stereoisomers with multiple stereogenic elements, i.e. two chiral centers, a chiral center and a chiral axis, a chiral centre and a chiral plane, etc. (see figure 5). ${ }^{1}$
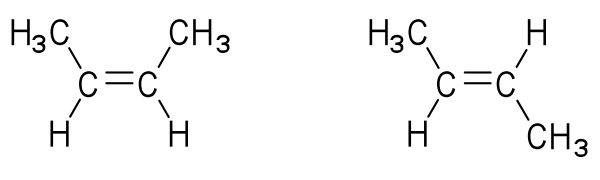

cis2-Butene

trans-2-Butene

Figure 4: cis-trans isomers of 2-butene 


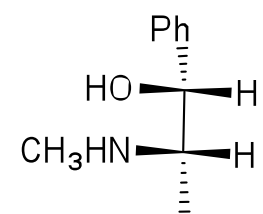

$(R, S)$-configuration

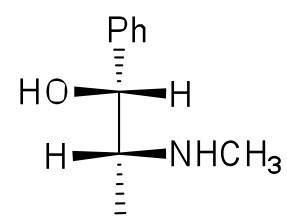

$(R, R)$-configuration

\section{Figure 5: Diastereomers of ephedrine}

\subsubsection{Stereoselective Reactions}

Stereoselective reactions can be broadly defined as reactions that favor the production of one enantiomer or diastereomer over another. ${ }^{2}$ Stereoselective reactions include enantioselective reactions and diastereoselective reactions. The enantiomeric excess is a measure of how much of an excess of one enantiomer is in a mixture of enantiomers and is calculated using the equation shown in figure 6 (presuming, in this case, that the $(R)$-enantiomer is the major product).

$$
e e=\frac{[(R)-(S)]}{[(R)+(S)]} \times 100 \%
$$

\section{Figure 6: Equation for calculating enantiomeric excess}

\subsection{The Buchwald - Hartwig Reaction}

The Buchwald-Hartwig reaction is a palladium catalyzed cross-coupling reaction of an aryl halide with a nitrogen nucleophile resulting in the formation of a new carbon-nitrogen bond. ${ }^{4-12}$ This reaction is a very useful synthetic tool for the construction of arylamines. A general Buchwald-Hartwig reaction is shown in figure 6.

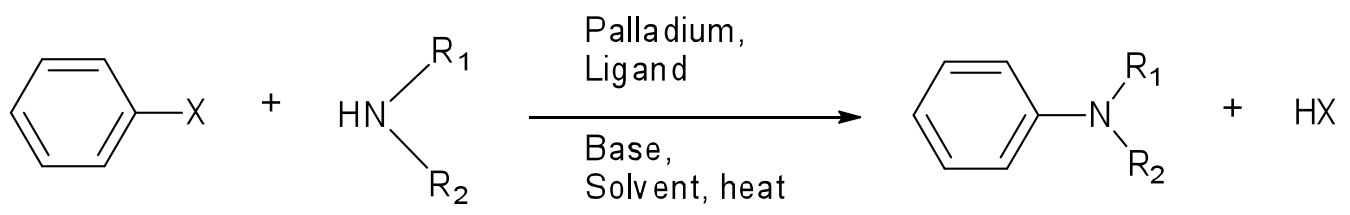

Figure 7: A General Buchwald-Hartwig reaction 
In 1995 both Buchwald and Hartwig independently reported the intermolecular coupling of aryl halides with secondary amines using a small amount of palladium, a base and $\mathrm{P}(o-\mathrm{Tol})_{3}$ as a ligand (scheme 1). ${ }^{13,14}$

Buchwald:
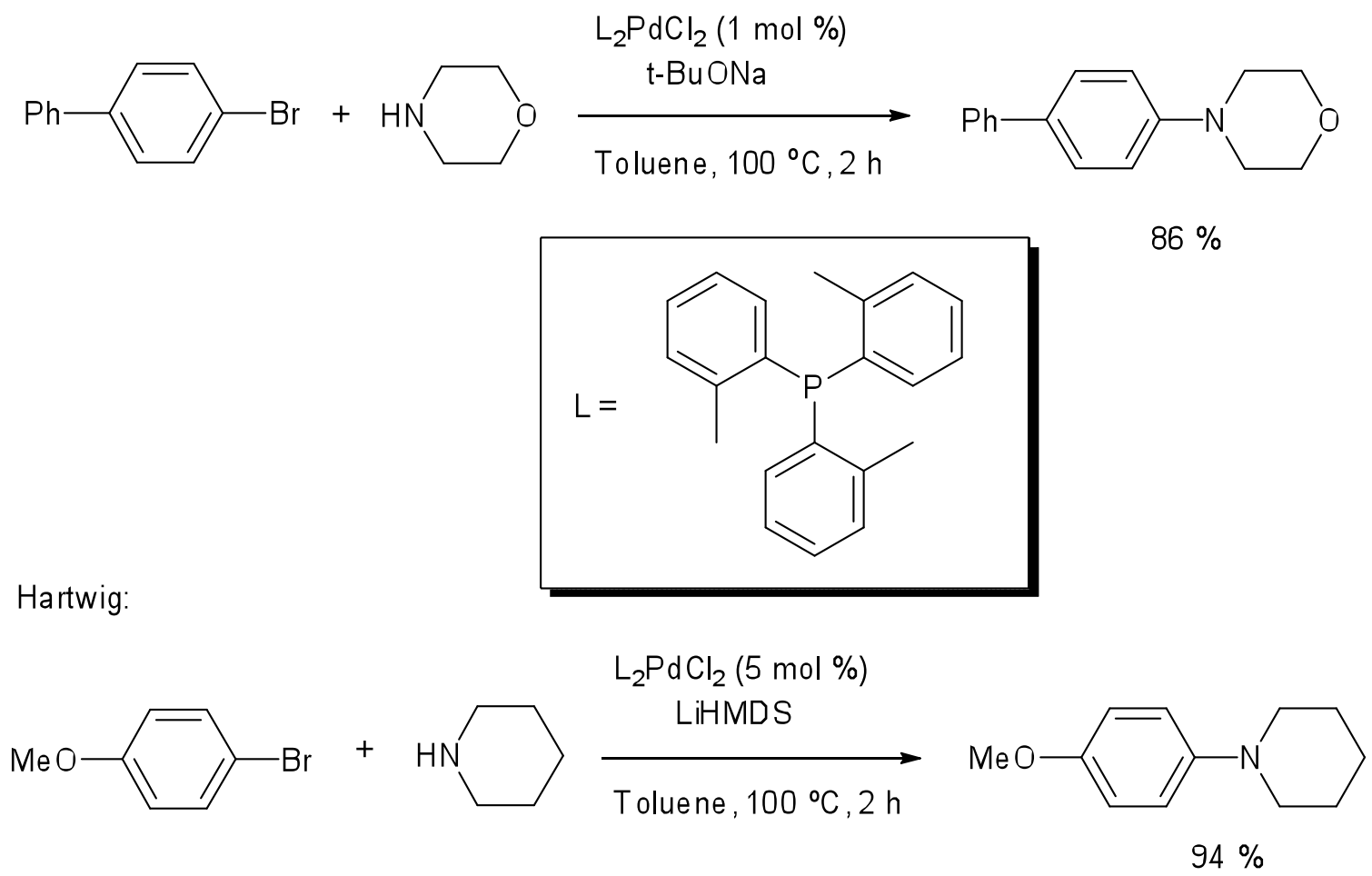

\section{Scheme 1: Intermolecular coupling of aryl halides with secondary amines}

\subsubsection{Mechanism of the Buchwald - Hartwig Reaction}

The mechanism of the Buchwald-Hartwig reaction has been extensively studied and is well

understood. ${ }^{15-20}$ A general mechanism of the Buchwald-Hartwig reaction is shown in scheme 2. Upon formation of the active palladium(0) complex, palladium inserts into the carbon halogen bond in a step called oxidative addition. Palladium then coordinates to the nitrogen atom of the amine and ligand exchange occurs with bromine, a base is also added to alleviate the positive 
charge generated on nitrogen. The last step of the cycle is a reductive elimination which produces the coupled product and regenerates the catalyst thus enabling the cycle to repeat.

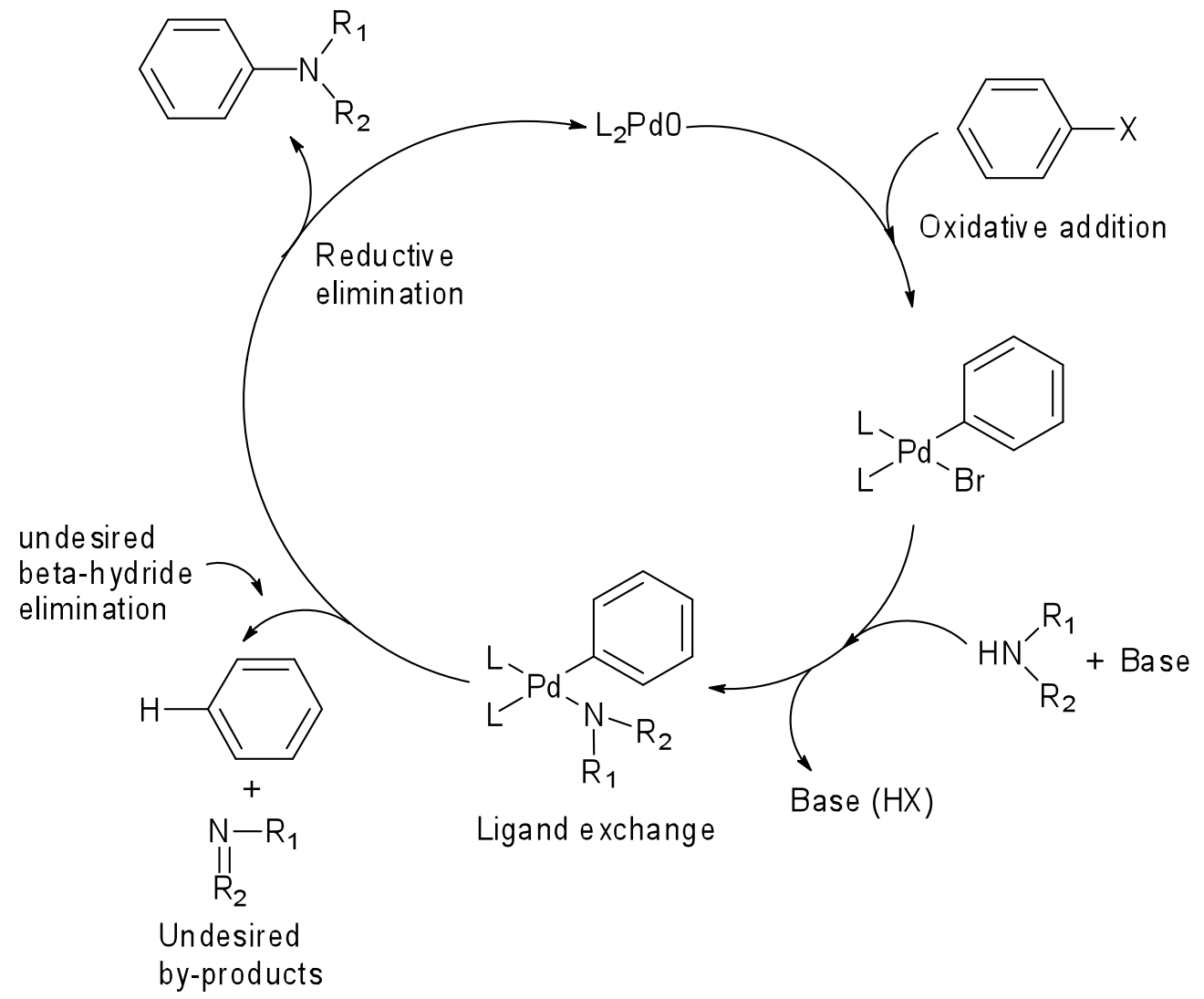

\section{Scheme 2: General mechanism of the Buchwald-Hartwig reaction}

\subsubsection{Chiral Bisphosphine Ligands in the Buchwald-Hartwig Reaction}

In these early experiments, especially when $\mathrm{P}(o-\mathrm{Tol})_{3}$ was used as a ligand both Buchwald and Hartwig reported a significant amount of by-products arising from $\beta$-hydride elimination (scheme 2, bottom left). Soon after in 1996 Buchwald demonstrated that the amount of byproducts could be substantially reduced by employing $\operatorname{Pd}_{2}(\mathrm{dba})_{3}$ (tris(dibenzylideneacetone)dipalladium(0))/BINAP as the catalyst system (scheme $3 a){ }^{21}$ Similarly in 1998, Hartwig also reported a reduction in $\beta$-hydride elimination products by using a ferrocene based racemic, chiral, bulky, electron-rich phosphine ligand (scheme $3 \mathrm{~b}){ }^{22}$ 
Buchwald:
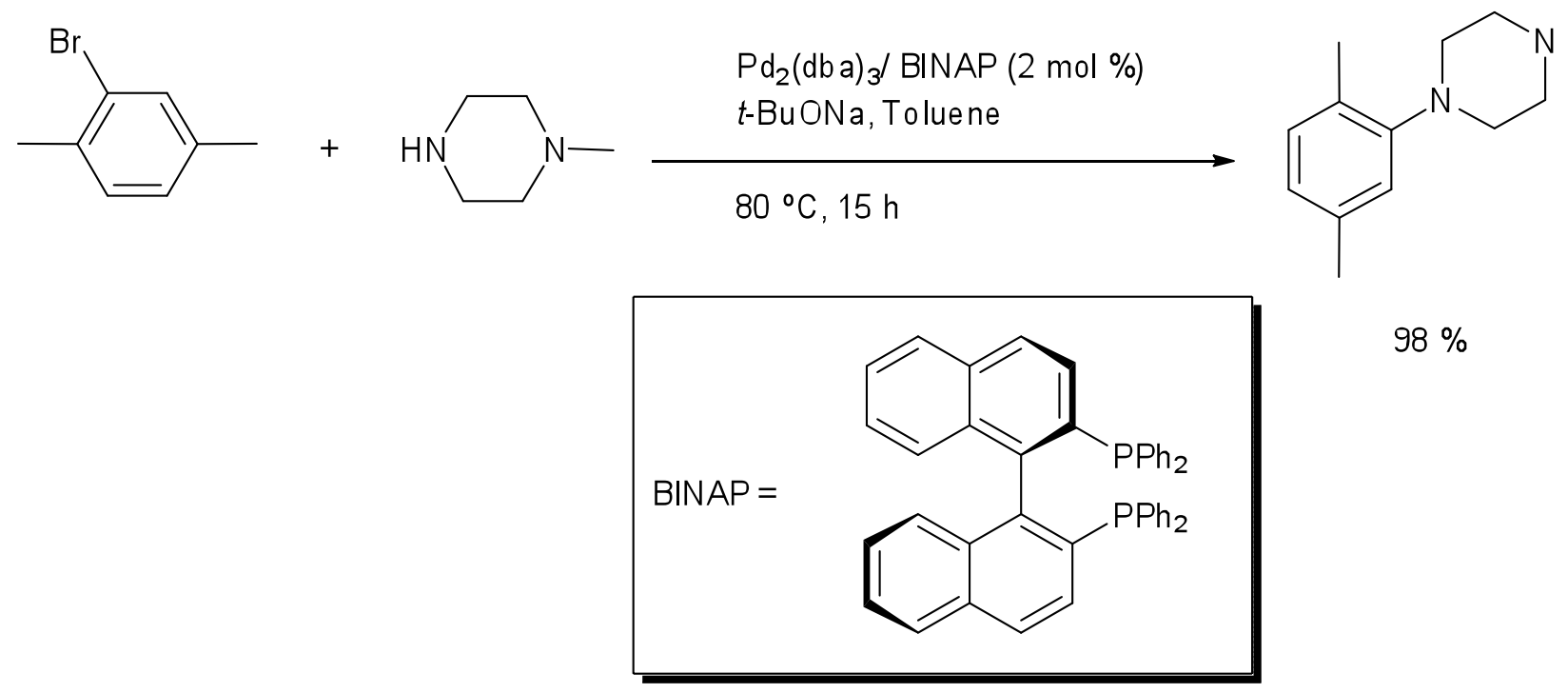

$98 \%$

Scheme 3a: Incorporation of chiral bisphosphine ligands in the Buchwald-Hartwig reaction

Hartwig:
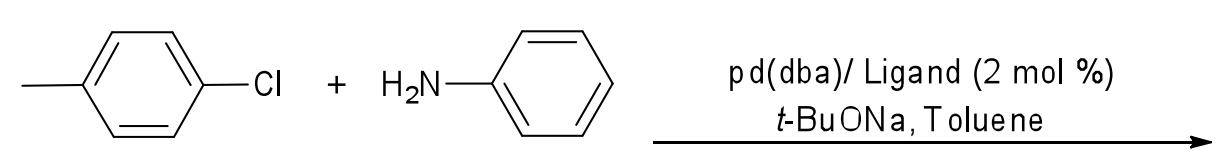<smiles>Cc1ccc(Nc2ccccc2)cc1</smiles>

$110^{\circ} \mathrm{C}, 16 \mathrm{~h}$

$96 \%$

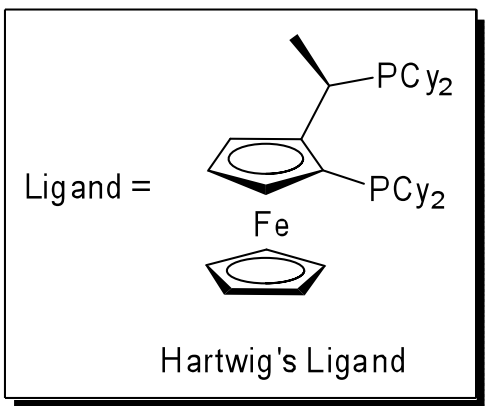

Scheme 3b: Incorporation of chiral bisphosphine ligands in the Buchwald/Hartwig reaction

Although many of the ligands used in these transformations are chiral, only a few groups have tried to exploit the chirality of the ligand to develop an enantioselective variant of the BuchwaldHartwig reaction. 


\subsubsection{Retention of Chirality in Buchwald-Hartwig Reactions}

Palladium-catalyzed intermolecular and intramolecular coupling of amines with aryl halides has proven to be an efficient method for the synthesis of various aniline derivatives. ${ }^{23}$ In a paper written by Wagaw et al. enantiomerically enriched aniline derivatives were prepared by coupling aryl bromides with enantiomerically enriched amines (scheme 4a). ${ }^{23}$ The authors also report the intramolecular coupling of amines with aryl halides as shown in scheme $4 \mathrm{~b}$.

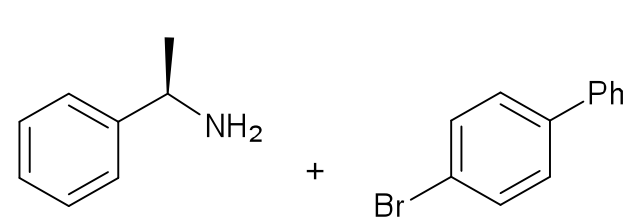

$>99 \%$ ee

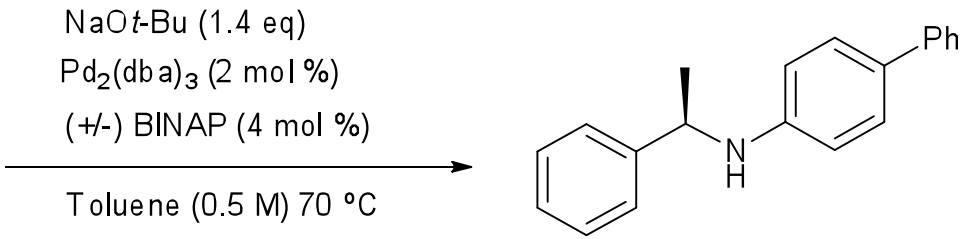

$86 \%,>99 \%$ ee

Scheme 4a: intermolecular coupling of an amine with an aryl halide

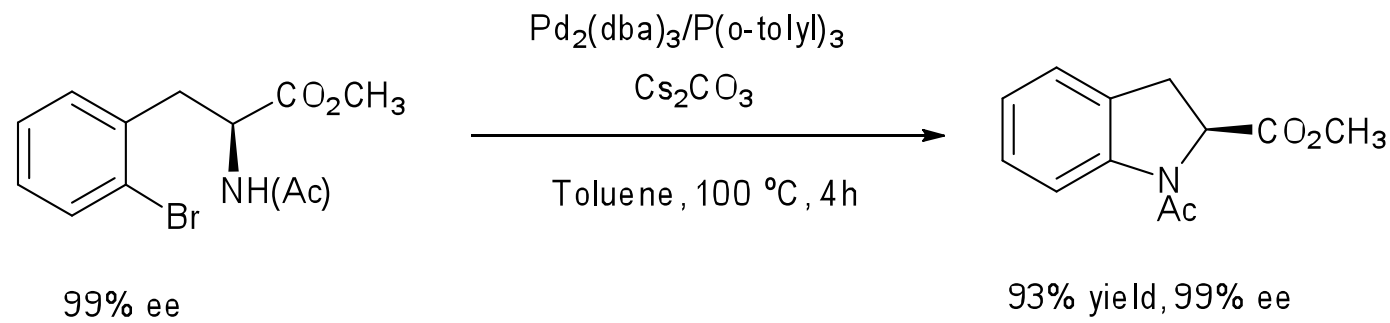

Scheme 4b: intramolecular coupling of an amine with an aryl halide

It is important to note that a new chiral centre is not formed in the products of the above reactions, the original stereochemistry is retained. 
In a paper written by Frost \& Mendonca, palladium catalyzed arylation of amines is used to selectively prepare various mono-N-arylated, enantiopure diamine ligands. ${ }^{24}$ The catalytic crosscoupling of enantiopure amines with aryl bromides using $\operatorname{Pd}(0) / \operatorname{dppf} \quad\left(\mathrm{dppf}=1,1^{\prime}\right.$ bis(diphenylphosphino)ferrocene) or Pd(0)/BINAP (2,2'-Bis( $N$-diphenylphosphinoamino-1,1'binaphthyl) produces products in moderate yields with no loss of enantiopurity. ${ }^{24}$ The use of BINAP as a ligand resulted in a considerable increase in yield. ${ }^{24}$ An example of the crosscoupling of $(1 R, 2 R)-(-)-1,2$-diaminocyclohexane with an aryl bromide is shown in scheme 5 .

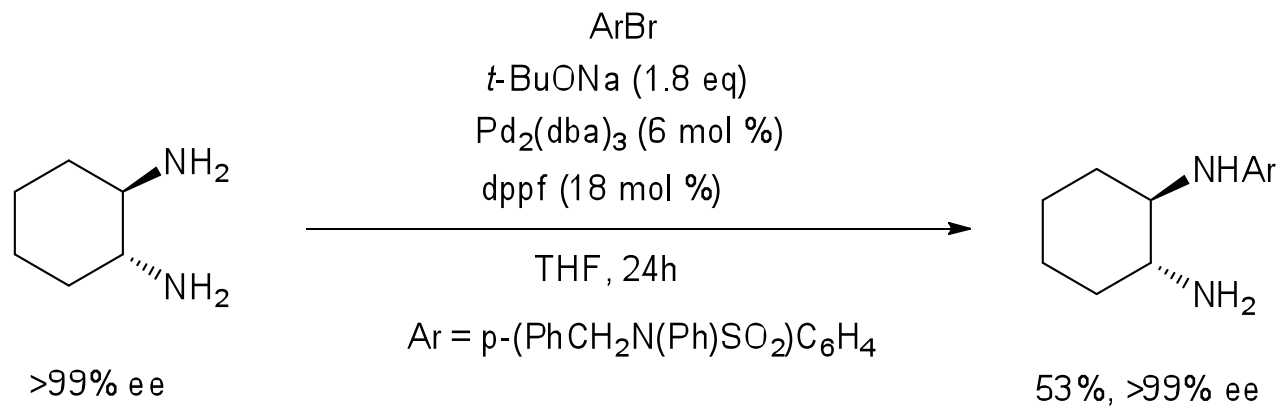

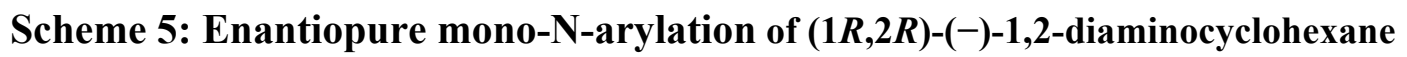

\subsubsection{Enantioselective Buchwald-Hartwig Reactions}

\subsubsection{Kinetic Resolution}

The first example of an enantioselective Buchwald-Hartwig reaction was reported by Rossen and Pye in which the authors demonstrated kinetic resolution of planar chiral bromides (scheme 6) ${ }^{25}$ 


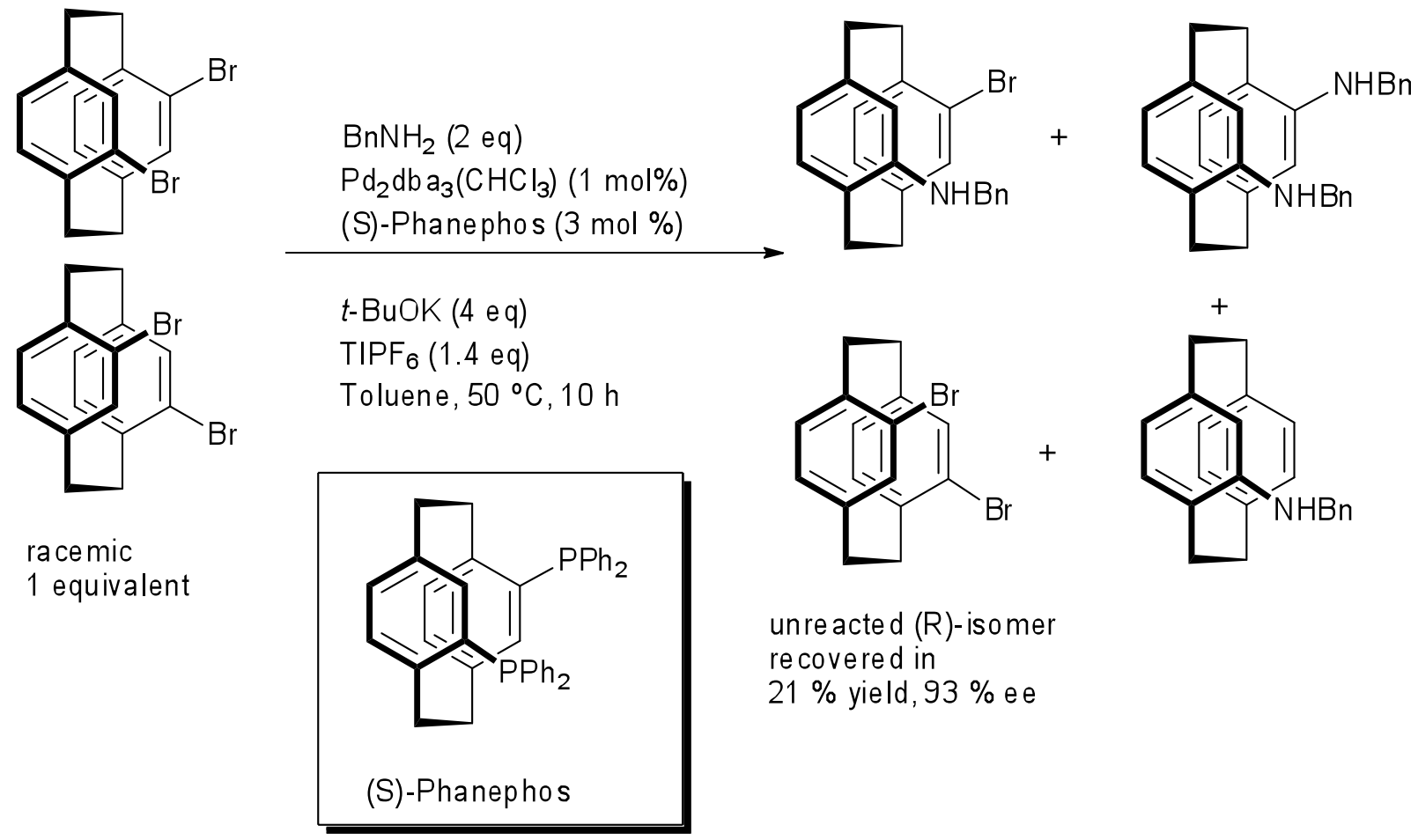

\section{Scheme 6: Kinetic resolution of racemic planar chiral bromides}

The catalyst system employed in these reactions was palladium/(S)-PHANEPHOS. Although the cross-coupling reaction produced a variety of products, i.e. mono-aminated, di-aminated, debrominated, mono-aminated de-brominated, no efforts were made to recover these products. The authors were interested in the unreacted di-bromide starting material and when they determined the enantiomeric excess $(e e)$ of this starting material they discovered that a kinetic resolution had taken place. The $(R)$-dibromide proved to be a poorer substrate for the $(S)$-PHANEPHOS palladium catalyst complex with the $(S)$ isomer of the dibromide reacting 3-4 times faster. Addition of the halide scavenger $\mathrm{TlPF}_{6}$ resulted in an increase in selectivity with the $(S)$ dibromide reacting 10-13 times faster than the $(R)$ isomer. When the reaction was pushed to 79 $\%$ conversion this led to a $21 \%$ recovery of the $(R)$-dibromide with a $93 \%$ ee. 
Another early example illustrating an enatioselective intermolecular Buchwald-Hartwig reaction via kinetic resolution was reported by Kocovsky et $a l^{26}$ The authors demonstrated partial kinetic resolution of racemic axially chiral amines using palladium/(S)-BINAP as the catalyst system. When the amino alcohol NOBIN (scheme 7a) was used as a coupling partner with bromobenzene, preferential arylation of the $(R)$-enantiomer resulted in a $27 \%$ ee at $35 \%$ conversion and an $11 \%$ ee at $60 \%$ conversion (scheme $7 \mathrm{a}$ ). Similarly the cross-coupling reaction of a binaphthyl diamine BINAM (scheme $7 \mathrm{~b}$ ) with bromobenzene also resulted in preferential arylation of the $(R)$-enantiomer with $17 \%$ ee at $45 \%$ conversion and $10 \%$ ee at 70 $\%$ conversion for the monoarylated product (scheme $7 \mathrm{~b}$ ). In these reactions the $(R)$-amino alcohol/diamine is a better substrate for the palladium/(S)-BINAP catalyst complex.<smiles>Nc1ccc2ccccc2c1-c1c(O)ccc2ccccc12</smiles><smiles>Nc1ccc2ccccc2c1-c1c(O)ccc2ccccc12</smiles>

racemic NOBIN

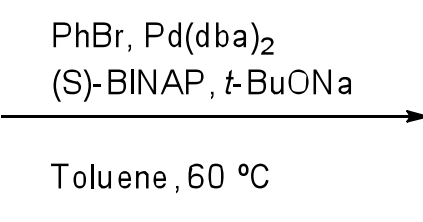<smiles>Oc1ccc2ccccc2c1-c1c(Nc2ccccc2)ccc2ccccc12</smiles>

(R)-isomer arylated in slight preference

\section{Scheme 7a: Kinetic resolution of a racemic axially chiral amino alcohol}


<smiles>Nc1ccc2ccccc2c1-c1c(N)ccc2ccccc12</smiles>

race mic BINAM<smiles>Nc1ccc2ccccc2c1-c1c(N)ccc2ccccc12</smiles>

$\mathrm{PhBr}, \mathrm{Pd}(\mathrm{dba})_{2}$

(S)-BINAP, $t$-BuONa

Toluene, $60^{\circ} \mathrm{C}$<smiles>Nc1ccc2ccccc2c1-c1c(Nc2ccccc2)ccc2ccccc12</smiles>

$(R)$-isomer arylated in slight preference

Scheme 7b: Kinetic resolution of a racemic axially chiral diamine

A more recent example of an enantioselective Buchwald-Hartwig reaction involving kinetic resolution of amines was reported by Ohta et $a l .{ }^{27}$ The authors employed palladium/(S)-TolBINAP as the catalyst system for the kinetic resolution of 1-(1-napthyl)ethylamine which furnished the arylated product in good yield and relatively high selectivity, $70 \%$ yield and $80 \%$ ee respectively (scheme 8 ). Although the selectivity of the reaction is good it should be noted that 19 equivalents of racemic amine and 8.4 equivalents of a crown ether additive were required.<smiles>COc1ccccc1I</smiles>

19 eq
$\mathrm{Pd}_{2}(\mathrm{dba})_{3}(2 \mathrm{~mol} \%)$

$(S)$-tol-BINAP

8.4 eq $\mathrm{NaOMe}$

8.4 eq 18 -crown-6

Toluene, it, $24 \mathrm{~h}$<smiles>COc1ccccc1NC(C)c1cccc2ccccc12</smiles>

$70 \%$ yield, $80 \%$ ee

Scheme 8: Kinetic resolution of optically active aniline derivatives 
In 2005 Bräse et al. reported the first example of a diastereoselective Buchwald-Hartwig reaction through coupling of racemic [2.2]paracyclophane bromide with $(S)-1$-phenylethylamine. ${ }^{28}$ The catalyst system employed was palladium $/\left(S_{\mathrm{p}}, R\right)$-Walphos 1 which furnished the desired product in excellent yield and diastereoselectivity, $92 \%$ yield, $86 \%$ de (scheme 9). Additionally since the authors use half an equivalent of amine relative to the racemic [2.2]paracyclophane bromide a kinetic resolution also takes place when $(S)$-1-phenylethylamine is used resulting in the excess diastereomer with configuration $\left(R_{\mathrm{p}}, S\right)$ and the excess $(S)$-enantiomer of [2.2]paracyclophane bromide, making the reaction enantioselective as well as diastereoselective (scheme 9).

$(R)$<smiles>Brc1ccc2c(c1)-c1ccc(Br)c(Br)c1CC2</smiles>

(S)

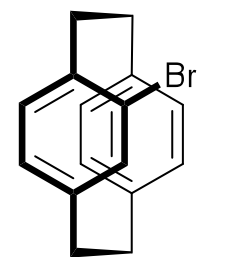

(S)-isomer $0.5 \mathrm{eq}$<smiles>CC(N)C(=O)c1ccc(N)cc1</smiles>

racemic $1 \mathrm{eq}$
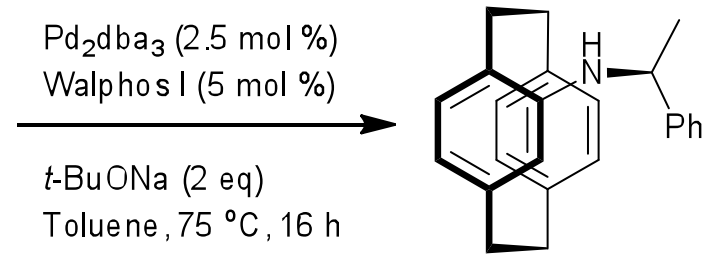

$(\mathrm{Rp}, \mathrm{S}) 92 \%, 86 \% \mathrm{de}$

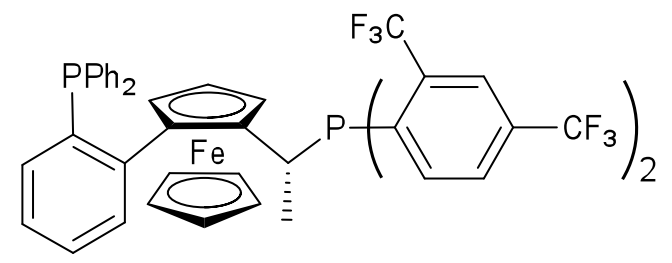

$\left(S_{p}, R\right)$-Walphos I

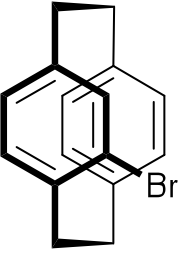

unre acted (S)-isomer

\section{Scheme 9: Enantio- and diastereoselective Buchwald-Hartwig reaction}




\subsubsection{Chiral plane Formation}

A more recent example of an enantioselective Buchwald-Hartwig reaction involving planar chirality was reported by Ranyuk et al. where the authors were successful in coupling 1,5dichloroanthraquinone with dioxadiamine to produce an azamacrocycle (scheme 10a). ${ }^{29}$ Palladium/Josiphos SL-J002-1 was the catalyst system used and the corresponding azamacrocycle was obtained in $31 \%$ yield and $60 \%$ ee. Recrystallization of the mixture of enantiomers from dichloromethane/petroleum ether resulted in an enantiopure azamacrocycle in $19 \%$ yield.
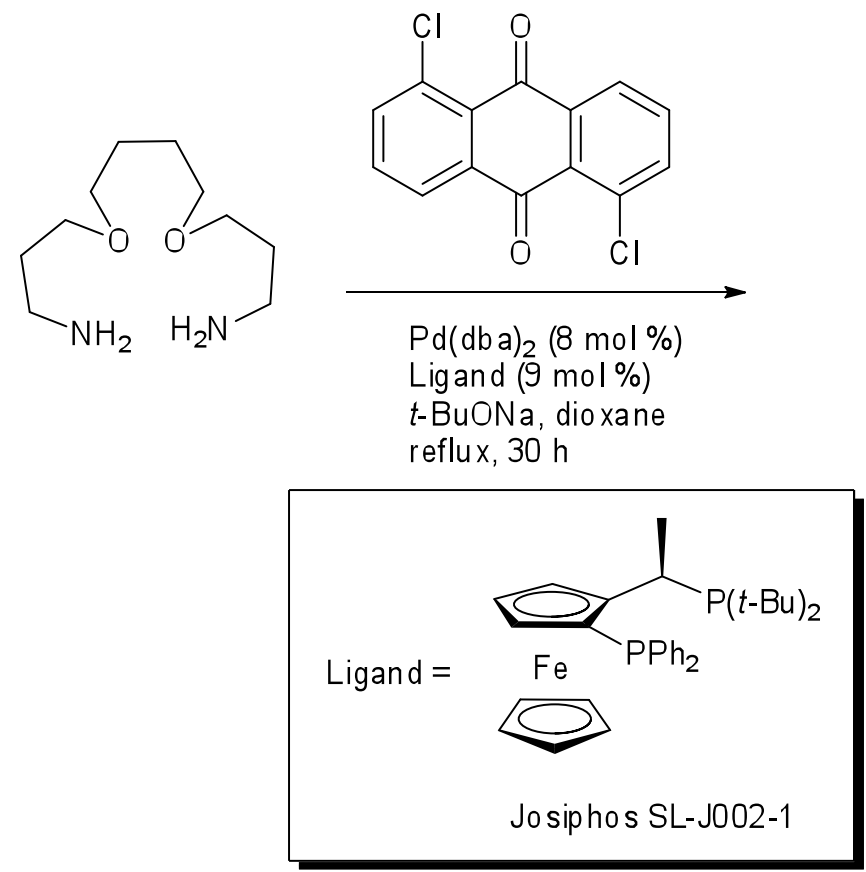

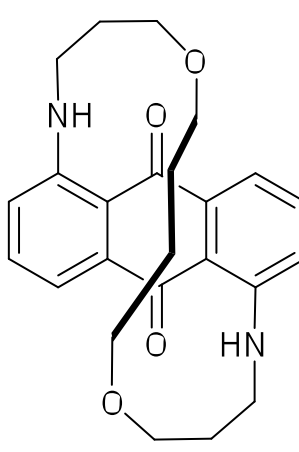

(S)-isomer

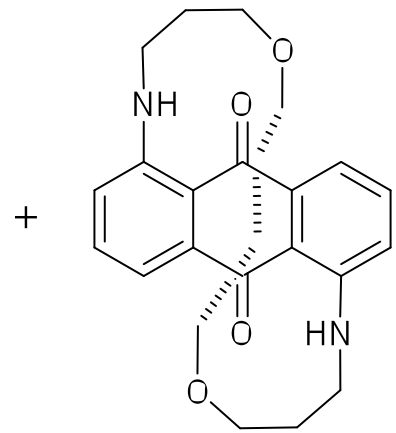

$(R)$-isomer

\section{Scheme 10a: Azamacrocycle synthesis via enantioselective Buchwald-Hartwig amination}

The authors followed up on this work and again were successful in coupling 1,5dichloroanthraquinone with trioxadiamine using Palladium/Josiphos SL-J002-1 to produce the 
corresponding azamacrocycles in $27 \%$ yield and $58 \%$ ee (scheme 10b) ${ }^{29}$ However in this case the azamacrocycle could not be recrystallized to enantiopurity but rather $88 \%$ ee in $11 \%$ yield.

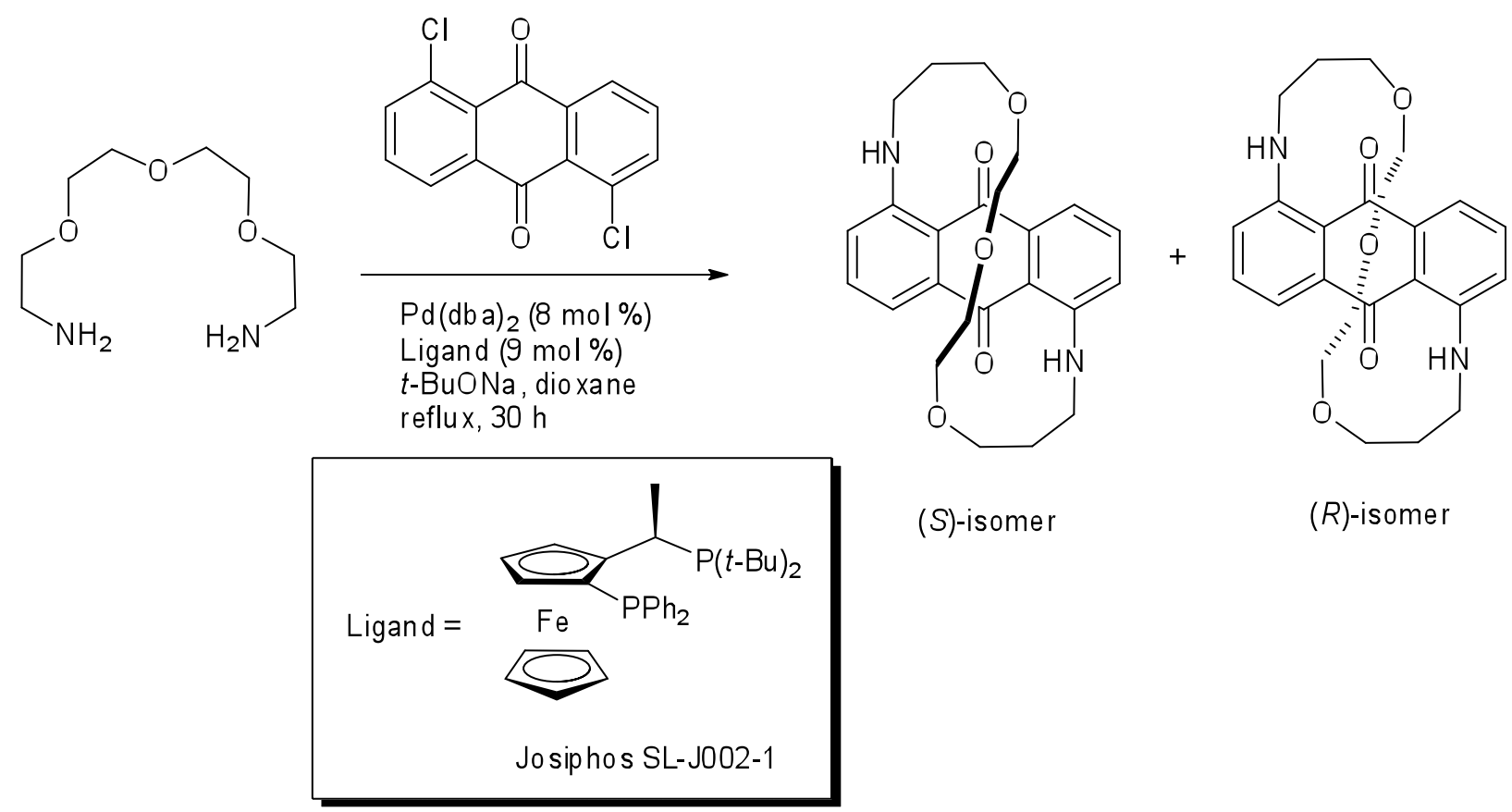

Scheme 10b: Azamacrocycle synthesis via enantioselective Buchwald-Hartwig amination

Next the authors investigated the coupling of 1,5-dichloroanthracene with dioxadiamine. Again palladium/Josiphos SL-J002-1 was the ideal catalyst system furnishing the azamacrocycle in 30 $\%$ yield, $34 \% e e$ (scheme 11a). ${ }^{29}$ In this case however recrystallization of the azamacrocycle could not be achieved to increase enantiopurity. 

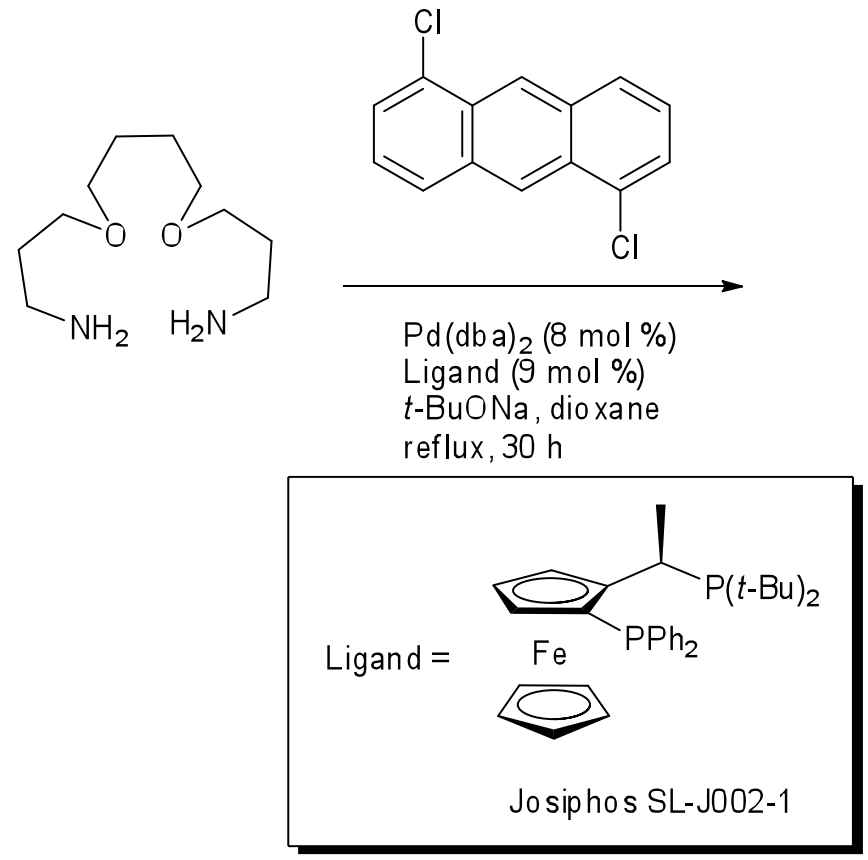

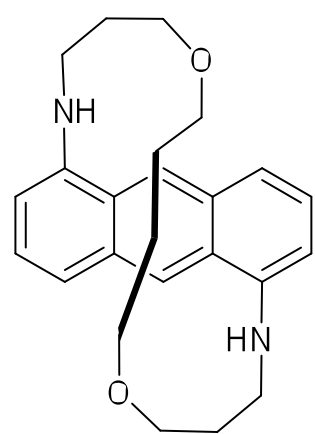

$(S)$-isomer

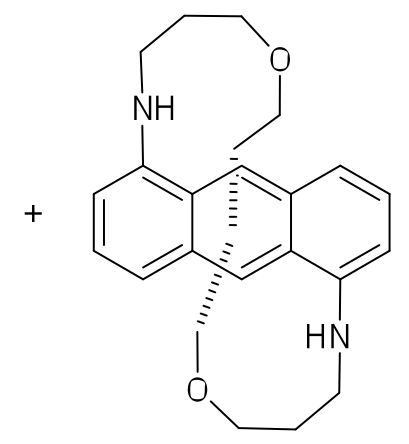

$(R)$-isomer

Scheme 11a: Azamacrocycle synthesis via enantioselective Buchwald-Hartwig amination

Lastly the authors successfully coupled 1,5-dichloroanthracene with trioxadiamine using palladium/Josiphos SL-J002-1 to produce the corresponding azamacrocycle in $29 \%$ yield, $45 \%$ $e e$ (scheme $11 \mathrm{~b}) .{ }^{29}$ This azamacrocycle also could not be recrystallized to enantiopurity. 


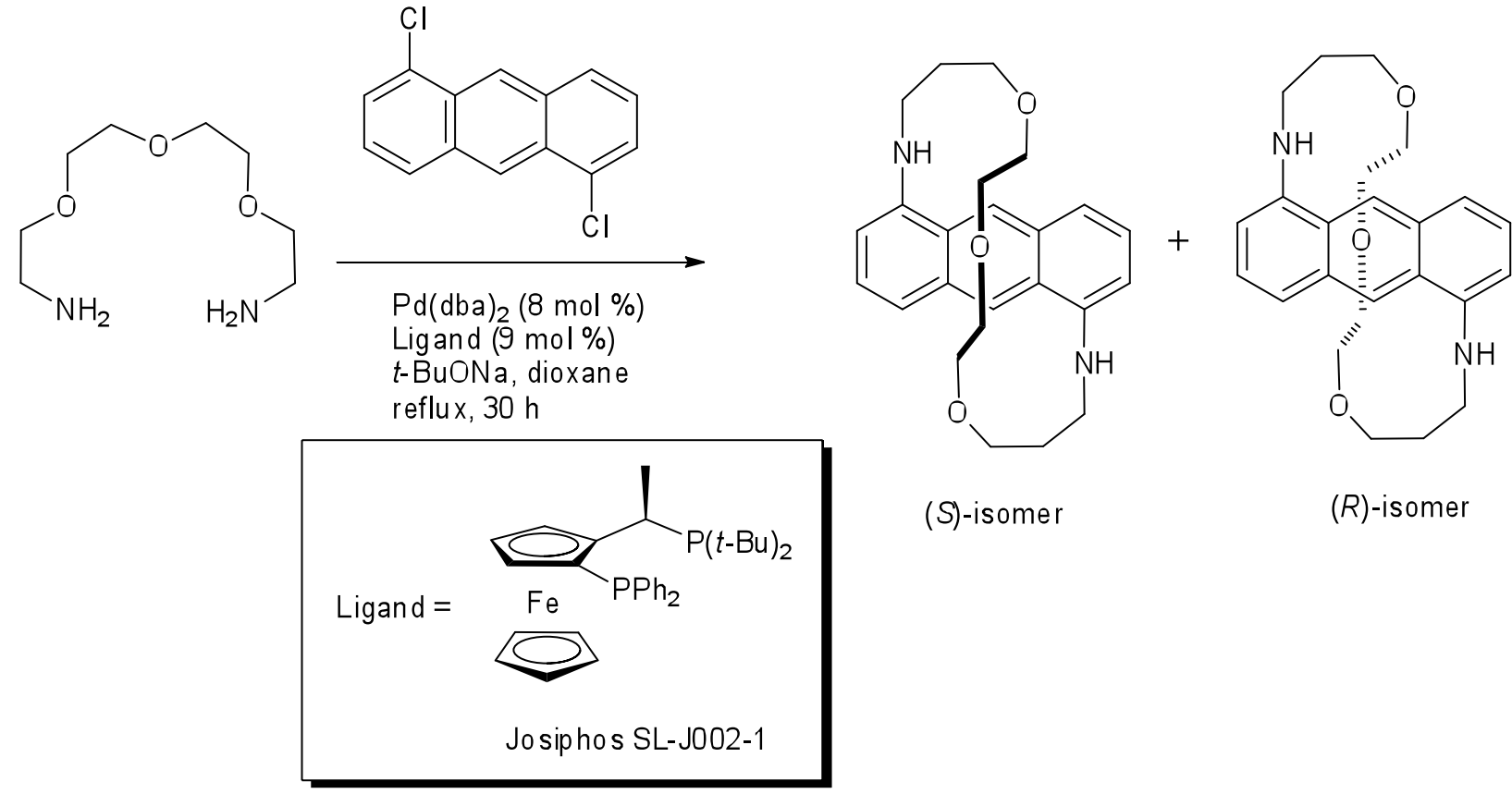

Scheme 11b: Azamacrocycle synthesis via enantioselective Buchwald-Hartwig amination

Another interesting example reported by Ishibashi et al. involves the synthesis of chiral azacalix[4]arene via enantioselective intramolecular Buchwald-Hartwig amination. ${ }^{30}$ When palladium/(R)-SEGPHOS was used as the catalyst system the product was obtained in $78 \%$ yield and $35 \%$ ee (scheme 12). More importantly these enantiomerically enriched compounds were obtained in enantiopure form through multiple recrystallizations due to preferential crystallization of the racemic product. 


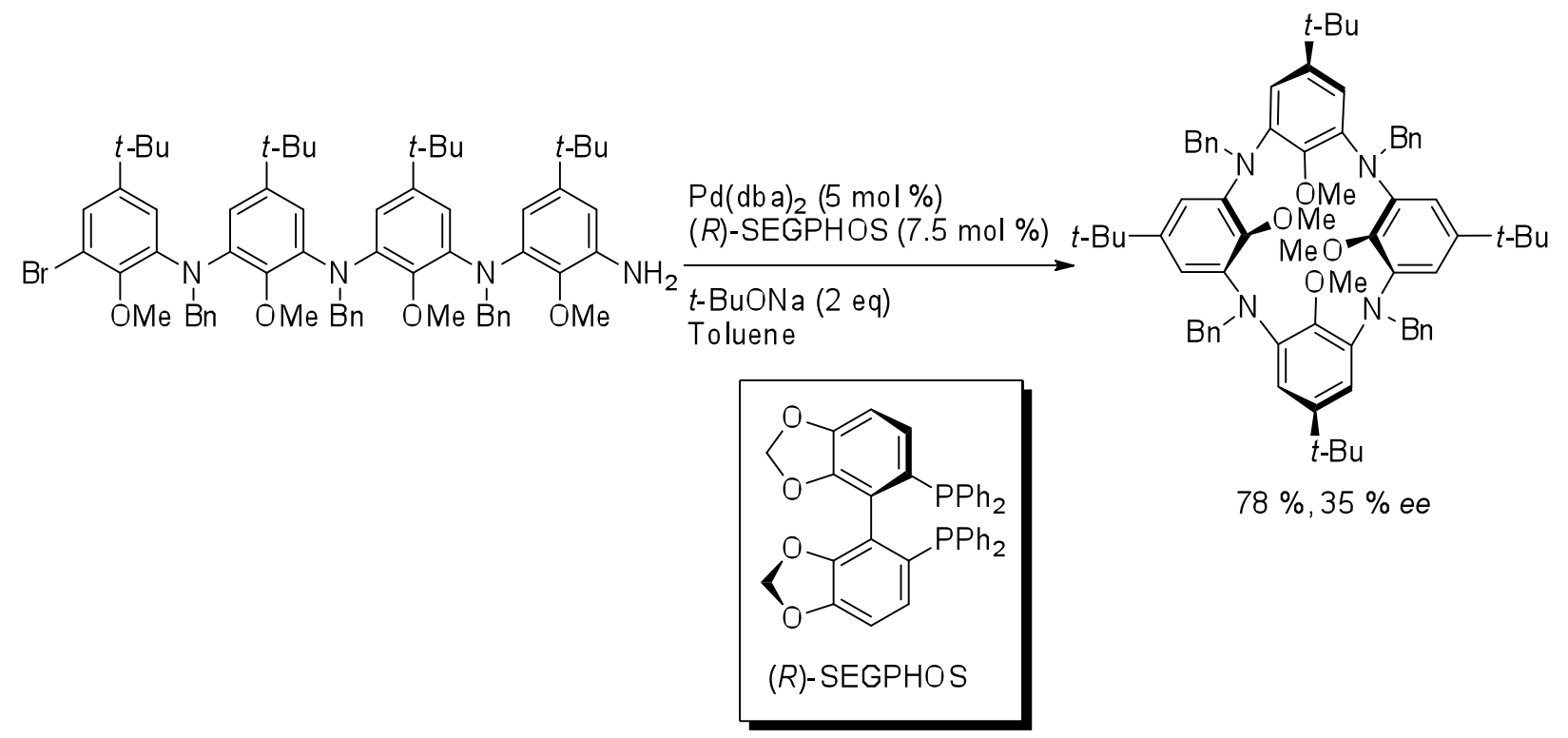

\section{Scheme 12: Synthesis of chiral azacalix[4]arene}

\subsubsection{Chiral Centre Formation}

In 2009 Porosa and Viirre reported an enantioselective intramolecular Buchwald-Hartwig reaction via desymmetrization of di-nitrogen malonamides. ${ }^{31,32}$ The chiral catalyst employed in these reactions was palladium/ $(R)$-MOP which furnished various six-membered quinolinone heterocycles in excellent yield, 90-99\%, with moderate to high enantiomeric excess, 38-96 \% ee (scheme 13). Additionally the six-membered quinolinone heterocycle containing a 4-chloro-2methylbenzyl substituent was obtained in enantiopure form by preferential recrystallization of the racemate, leaving behind the enantiopure mother liquor. ${ }^{32}$ 
<smiles>[R]NC(=O)C(C)(Cc1ccccc1Br)C(=O)N[R]</smiles><smiles>[R]NC(=O)[C@]1(C)Cc2ccccc2N([R])C1=O</smiles><smiles>COc1ccc2ccccc2c1-c1c(-c2ccccc2)ccc2ccccc12</smiles>

\section{Scheme 13: Desymmetrization of malonamide derivatives via an enantioselective intramolecular Buchwald-Hartwig reaction}

Also in 2009 Sasai et al. reported a similar enantioselective intramolecular Buchwald-Hartwig reaction to produce spirobi(3,4-dihydro-2-quinolone) derivatives via double cyclization of various malonamides (scheme 14). ${ }^{33}$ The catalyst system employed in these reactions was palladium/(S)-BINAP.<smiles>[R]NC(=O)C(Cc1ccccc1Br)(Cc1ccccc1Br)C(=O)N[R]</smiles>
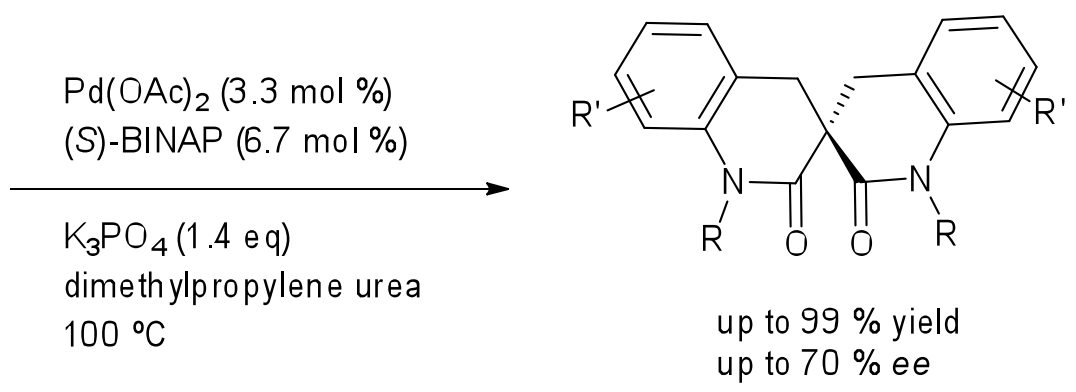

Scheme 14: Synthesis of $C_{2}$-symmetric spirobilactams via an enantioselective intramolecular Buchwald-Hartwig reaction 
Furthermore the dimethyl, diethyl and dibenzyl derivatives were obtained in enantiopure form through a single recrystallization. Interestingly when the authors used palladium/(R)-MOP as the catalyst system, which worked well for Porosa and Viirre, the resulting spirobilactam was isolated as a racemic mixture in $69 \%$ yield.

\subsubsection{Chiral Axis Formation}

In 2005 Taguchi et al. demonstrated a very impressive intermolecular enantioselective Buchwald-Hartwig reaction by $\mathrm{N}$-arylation of bulky achiral $t$-butyl anilide derivatives (scheme 15). ${ }^{34}$ There is free rotation around the $\mathrm{C}-\mathrm{N}$ bond in the starting material of the reaction shown in scheme 15 however upon arylation at the nitrogen atom the rotation becomes locked in the product thus forming a chiral axis. The authors employed palladium/(R)-DTBM-SEGPHOS as a catalyst system which furnished the coupled products in high yields and enantioselectivity, $>80$ $\%$ yield and $>90 \%$ ee (scheme 15 ). 
<smiles>[R2]C(=O)Nc1cc([R2])ccc1C(C)(C)C</smiles>

Free rotation around $\mathrm{C}-\mathrm{N}$ bond $\mathrm{R}_{2}=\mathrm{H}, t-\mathrm{Bu}$
Ar-I

$\mathrm{Pd}(\mathrm{OAc})_{2}(3.3 \mathrm{~mol} \%)$

$(R)$-DTBM-SEGPHOS (5 mol \%)

$t$-BuOK (1.4 eq)

Toluene, $80^{\circ} \mathrm{C}, 2-6 \mathrm{~h}$

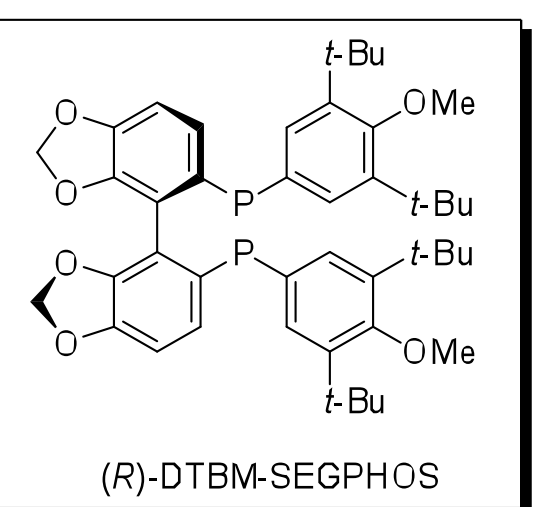<smiles>[R]C(=O)N([Al])c1cc([R2])ccc1C(C)(C)C</smiles>

Conformationally<smiles>[R2]c1ccc([R18]([H])([H])[H])c(N([Ga])C(=O)CC2CC2)c1</smiles>

locked

$>80 \%$ yields

$>90 \%$ ee

\section{Scheme 15: Enantioselective intermolecular nitrogen arylation of $t$-butylanilides}

The authors also successfully applied this chemistry to intramolecular systems resulting in the formation of six-membered ring lactams. ${ }^{34-37}$ Interestingly the palladium/(R)-DTBM-SEGPHOS catalyst complex was not ideal for the intramolecular $\mathrm{N}$-arylation reaction, resulting in racemic lactam product in low, $12 \%$, yield. Instead palladium/(S)-BINAP proved to be the optimal catalyst system resulting in the highest enantioselectivity, $70 \% e e$, and good yield, $95 \%$, for the formation of lactam product (scheme 16). When 2,5-bis-t-butylanilide was used as the substrate for N-arylation using palladium/(S)-BINAP as the catalyst system the corresponding lactam was obtained in high yield, $95 \%$, with a remarkable increase in enantioselectivity, $96 \%$ ee (scheme 16). 

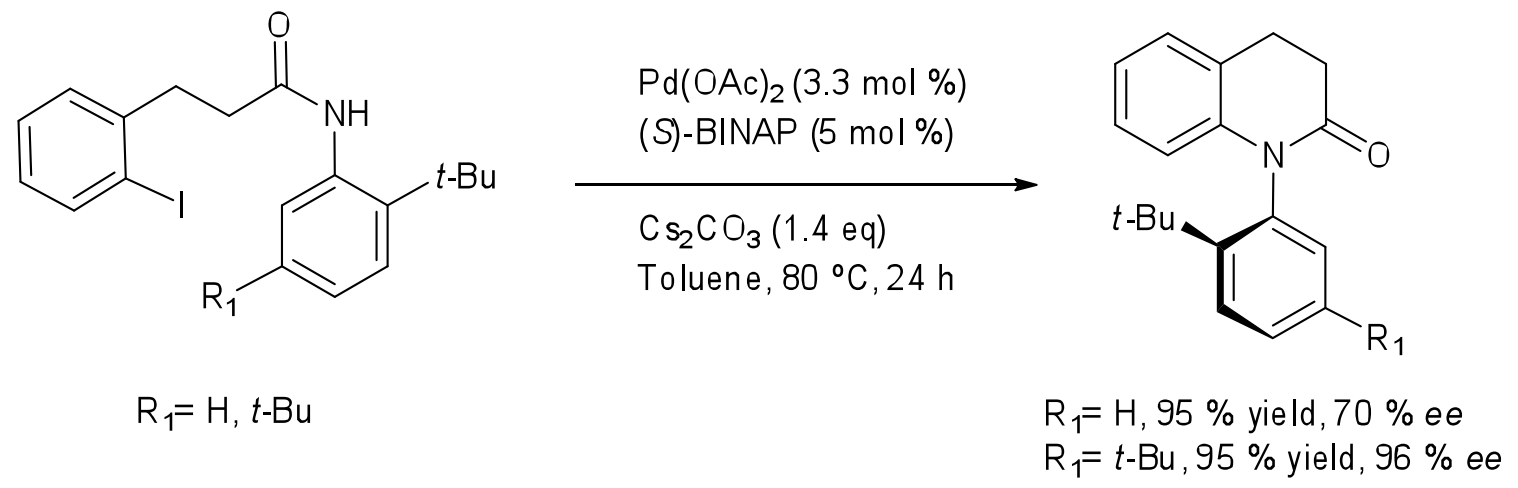

\section{Scheme 16: Enantioselective intramolecular nitrogen arylation of $t$-butylanilides}

Additionally the anilide products from the intermolecular $\mathrm{N}$-arylation reactions and lactam products from the intramolecular $\mathrm{N}$-arylation reactions have been applied to asymmetric enolate chemistry ${ }^{34-37}$ The chiral axis of these products is what dictates the chirality at the $\alpha$-carbon because attack of alkyl halides to either the anilide or lactam enolate preferentially occurs from the opposite face of the ortho-t-butyl group. These highly diastereoselective reactions were used in the synthesis of a key intermediate for a norepinephrine transporter (NET) inhibitor. The first step in the synthesis of the NET inhibitor involves an intramolecular asymmetric $\mathrm{N}$-arylation reaction using palladium/(R)-SEGPHOS as the catalyst complex. This yields the desired lactam product in excellent yield and enantioselectivity, $95 \%$ yield and $93 \%$ ee (scheme 17). Subsequent $\alpha$-methylation of the $t$-butyl lactam product proceeded in high yield, $82 \%$, with high diastereoselectivity, $d r=31: 1$. Construction of the quaternary $\alpha$-carbon atom was achieved by $\alpha-$ allylation which again resulted in remarkably high diastereoselectivity, $d r=50: 1$, and good yield, $86 \%$. The final steps toward the NET inhibitor was removal of the ortho-t-butyl group of lactam product via a retro-Friedel-Crafts reaction followed by anti-Markovnikov hydration and 
installation of the amine to furnish the product in moderate yield, $57 \%$, but more importantly with retention of chirality, $93 \% e e$, from the original starting lactam.

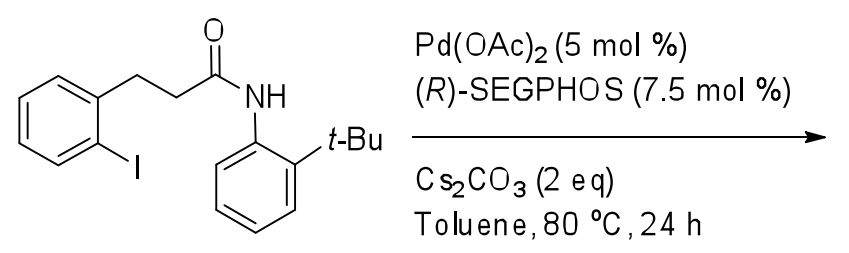<smiles>CNCCC[C@H]1Cc2ccccc2N(c2ccccc2)C1=O</smiles>

NET inhibitor
$95 \%, 93 \%$ ee
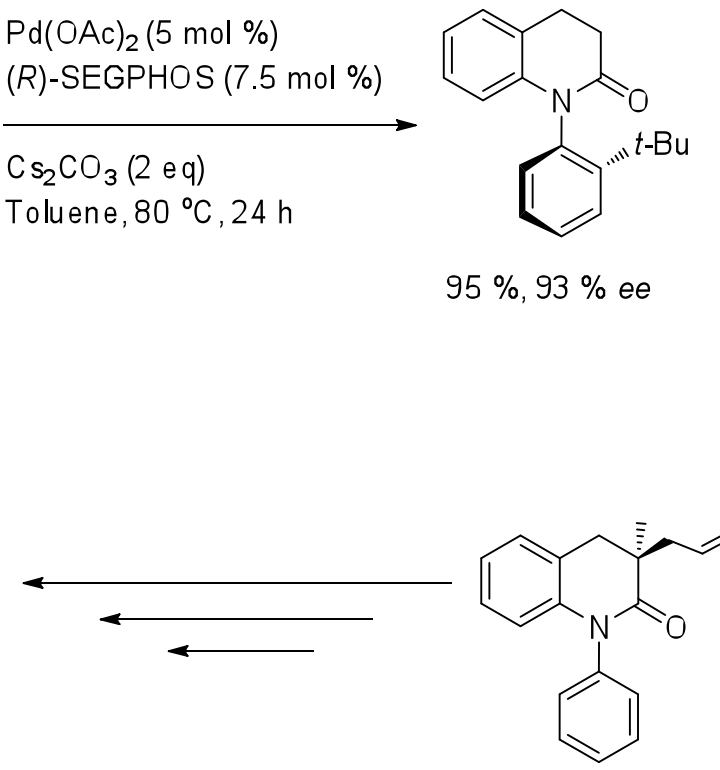

$57 \%, 93 \%$ ee

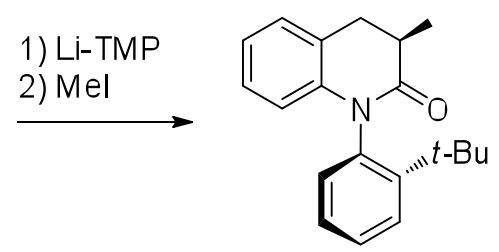

$82 \%, d r=31: 1$

1) Li-TMP

2) allyl-Br

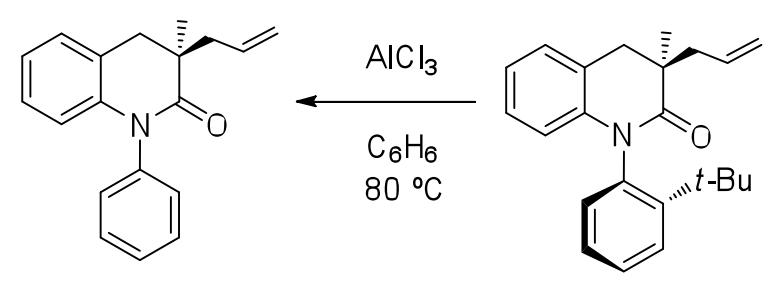

$83 \%, d r=50: 1$

\section{Scheme 17: Atropisomeric lactam chemistry as a chiral auxiliary in the synthesis of key intermediates for a NET inhibitor}

\subsection{Synthesis of MOP and MOP Type Ligands}

In 1993 Hayashi et al. reported the synthesis of enantiopure 2-(Diarylphosphino)-1,1'-binaphthyl ligands for use in asymmetric transition metal catalyzed reactions (scheme 18 ) ${ }^{38}$ The first step in the synthesis involved the monophosphinylation of the ditriflate with diphenylphosphine oxide using palladium/dppb as the catalyst system. Next hydrolysis of the monotriflate was accomplished using aqueous $\mathrm{NaOH}$ in 1,4-dioxane and methanol. The phenolic hydroxyl moiety was then alkylated by treatment with iodomethane and $\mathrm{K}_{2} \mathrm{CO}_{3}$ to produce the corresponding phosphine oxide. Reduction of the phosphine oxide was achieved using trichlorosilane and triethylamine to obtain the free phosphine. 


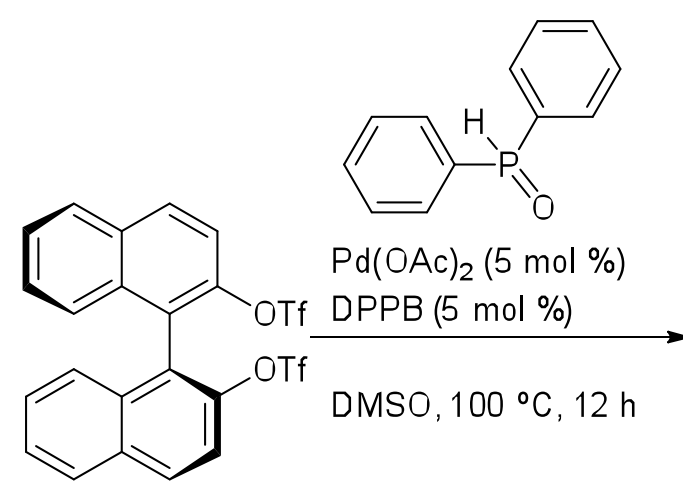

(S)<smiles>Oc1ccc2ccccc2c1-c1c(O)ccc2ccccc12</smiles>

(S)- $-95 \%$
(S)-99\%<smiles>COc1ccc2ccccc2c1-c1c(OC)ccc2ccccc12</smiles>

(S)-99\%

\section{Scheme 18: Hayashi's Synthesis of (S)-MOP}

In 2002 Buchwald et al. reported the synthesis of novel, enantiopure 2-alkoxy-2'dialkylphosphino-1,1'-binaphthyl ligands which are used in palladium-catalyzed asymmetric arylation reactions of enolates. ${ }^{39}$ The synthetic protocol used to access these ligands was similar to that reported by Hayashi et al. in the preparation of enantiopure 2-(diarylphosphino)-1,1'binaphthyls (scheme 19). ${ }^{38,39}$ 


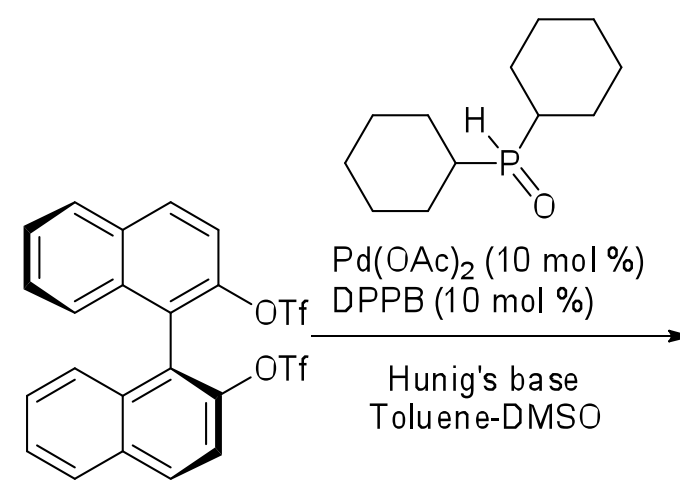

(S)

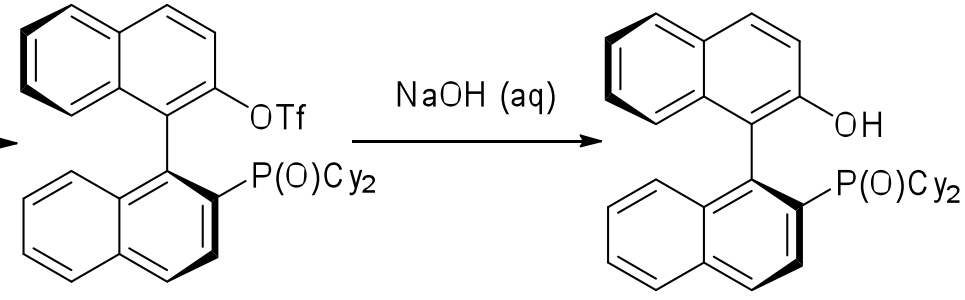

(S)-24\%

(S)-99\%<smiles>CCOc1ccc2ccccc2c1-c1c(OC)ccc2ccccc12</smiles>

(S)-80 \%<smiles>COc1ccc2ccccc2c1-c1c(OC)ccc2ccccc12</smiles>

(S)-50 \%

\section{Scheme 19: Buchwald's Synthesis of (S)-Cy 2 MOP}

About five years later Zhang and his group reported the synthesis of racemic 2-alkoxy-2'dialkylphosphino-1,1'-binaphthyl ligands and demonstrated their utility in intermolecular palladium catalyzed carbon-nitrogen bond forming reactions. ${ }^{40}$ The synthetic route towards the synthesis of these ligands differs from that reported by Hayashi and Buchwald (scheme 20). The first step in the synthesis involved dehydration of 1,1'-bi(2-binaphthol) using an HY zeolite to form a dinaphthofuran ring. Next reductive opening of the dinaphthofuran ring was accomplished with lithium metal to form the dilithium salt which reacted with chlorodicyclohexyl phosphine to produce racemic 2-dicyclohexylphosphino-2'hydroxybinaphthyl. This compound was oxidized using hydrogen peroxide followed by treatment with sodium hydride to form a soluble sodium salt which was then alkylated using dimethyl sulfate. Lastly the alkylated phosphine oxide was reduced to the free phosphine using trichlorosilane and triethylamine. 

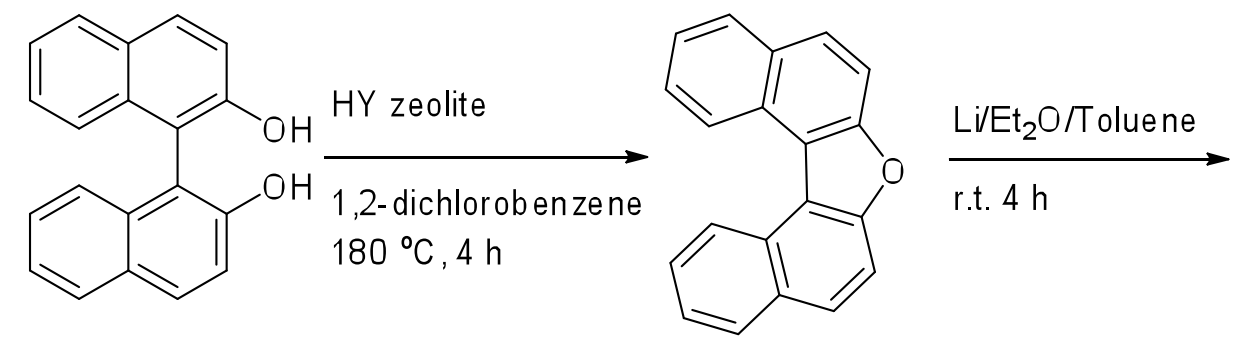<smiles>Clc1ccc2ccccc2c1-c1c(Cl)ccc2ccccc12</smiles>

$94 \%$<smiles>Clc1ccc2ccccc2c1-c1c(Cl)ccc2ccccc12</smiles>

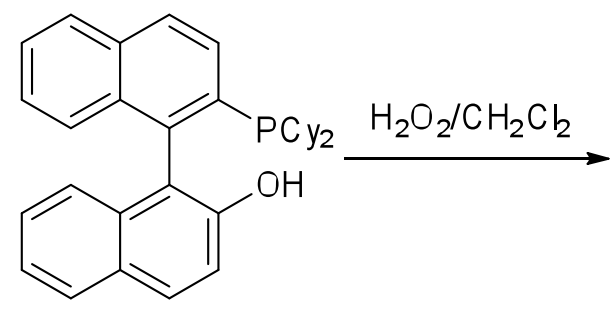

$83 \%$ (3 steps)<smiles>Oc1ccc2ccccc2c1-c1c(O)ccc2ccccc12</smiles>

$90 \%$

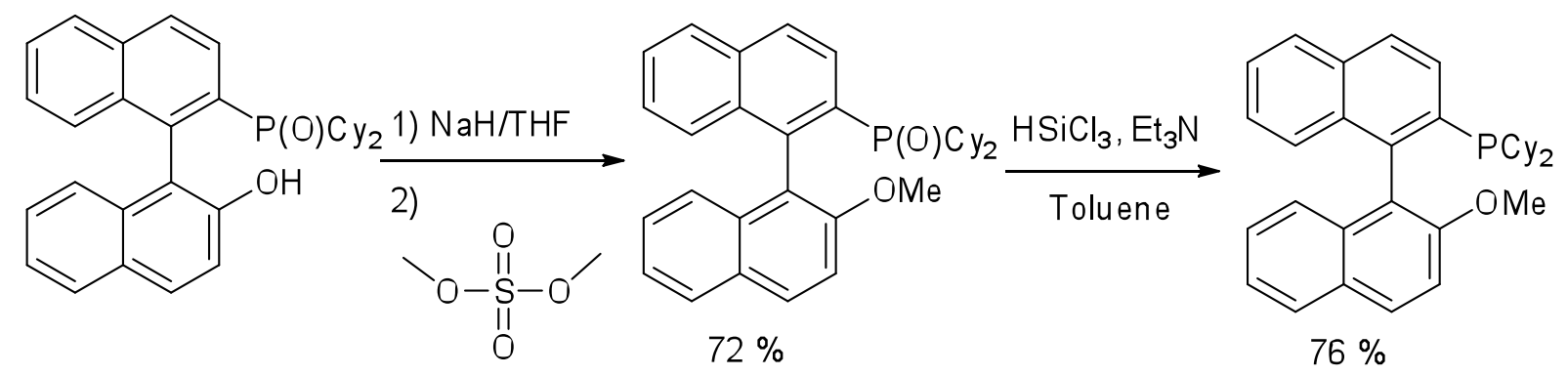

\section{Scheme 20: Zhang's Synthesis of racemic $\mathrm{Cy}_{2} \mathrm{MOP}$}

In 2004 Buchwald et al. reported the coupling of thiols with aryl halides using palladium/dippf as a catalyst system. ${ }^{41}$ The substrate scope of the reaction was quite broad making it possible to couple various aryl bromides/chlorides with aliphatic and aromatic thiols. More importantly this catalyst system was also useful for accessing tertiary phosphines via coupling of aryl bromides/chlorides with secondary phosphines (figure 8).

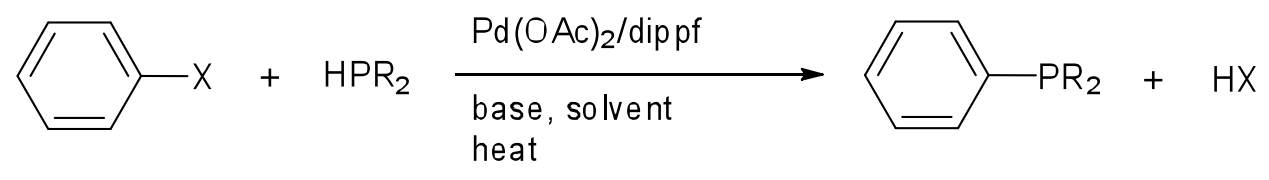

\section{Figure 8: Coupling of aryl halides with secondary phosphines}




\subsection{Synthesis of Palladium Precatalysts for C-N Cross-coupling Reactions}

In 2008 Buchwald et al. reported the synthesis of a new class of palladium precatalysts and demonstrated their utility in carbon-nitrogen cross-coupling reactions. ${ }^{42,43}$ The synthetic outline for the synthesis of these palladium precatalysts is shown in scheme 21 . The precatalysts are easily activated by treatment with base to produce indoline and the active $\operatorname{Pd}(0)$ catalyst (Figure 9).

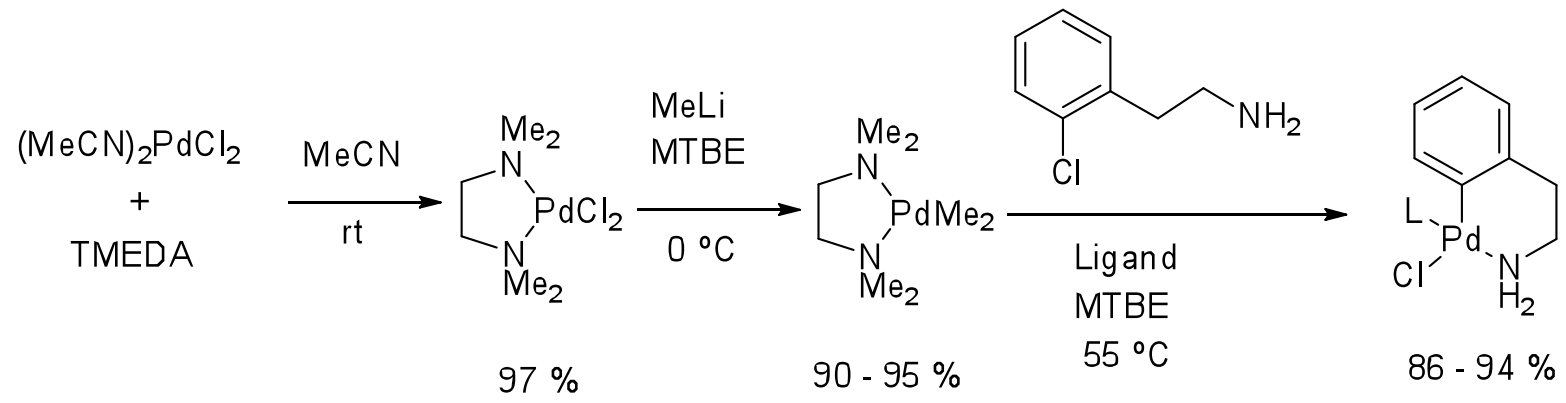

Scheme 21: Synthesis of Palladium Precatalysts

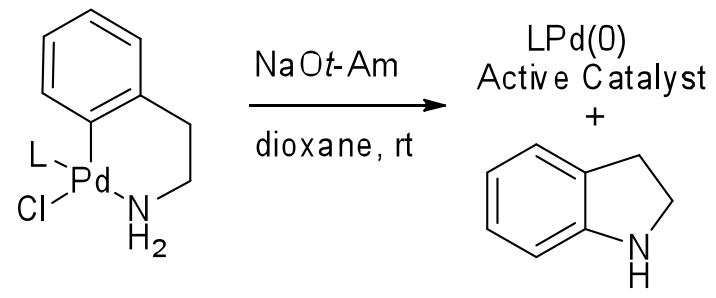

Figure 9: Precatalyst Activation

Products of cross-coupling reactions were obtained in high yield using low catalyst loadings with short reaction times thus implying that these precatalysts act as highly reactive palladium sources in C-N cross-coupling reactions. Even electron deficient anilines, which are usually difficult coupling partners in C-N cross-couplings due to their low nucleophilicity, were coupled with unactivated aryl chlorides in high yields (scheme 22). 


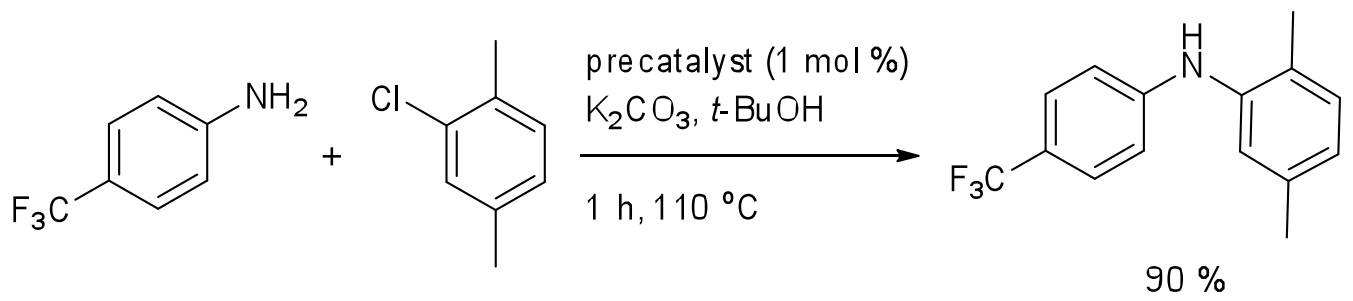

\section{Scheme 22: Coupling of electron deficient anilines with unactivated aryl chlorides}

\subsection{Research Goals and Objectives}

This thesis paper entails the synthesis of (R)-2(Dicyclohexylphosphino)-2'-methoxy-1,1'binaphthyl), $(R)-\mathrm{Cy}_{2} \mathrm{MOP}$, which appears to be a very efficient ligand for the palladium catalyzed intramolecular desymmetrization of di-nitrogen malonamides. Additionally an enantioand diastereoselective Buchwald-Hartwig reaction has been developed through the desymmetrization of 2-(2-bromobenzyl)- $N^{1}, N^{3}$-bis(2-(tert-butyl)phenyl)-2-methylmalonamide using palladium $/ \mathrm{Cy}_{2} \mathrm{MOP}$ as the catalyst system to produce $\left(3 R, S_{\mathrm{a}}\right)-N, 1$-bis $(2$-(tertbutyl)phenyl)-3-methyl-2-oxo-1,2,3,4-tetrahydroquinoline-3-carboxamide in excellent yield, with high enantio- and diastereoselectivity $(99 \%, 88 \% e e)$. The absolute configuration of the formed diastereomer was determined by $\mathrm{x}$-ray crystallography. The $\mathrm{Cy}_{2} \mathrm{MOP} /$ Palladium catalyst system has also been effective in the cyclization of six membered ring benzomorpholinone and seven membered ring benzodiazepineone heterocycles. Furthermore various synthetic routes towards the synthesis of five membered ring oxindoles have been explored and each method is thoroughly discussed. Lastly the synthesis of a precatalyst was also attempted using $\mathrm{Cy}_{2} \mathrm{MOP}$ and $\mathrm{Pd}(\mathrm{II}) \mathrm{Me}_{2}$ TMEDA. 


\section{Results and Discussion:}

\subsection{Towards the Synthesis of 5 membered ring Oxindole Heterocycles}

In order to extend the work carried out by Porosa in $2009^{31,32}$ to include smaller ring sizes an intramolecular Buchwald-Hartwig reaction was envisioned which would furnish five-membered ring oxindole heterocycles (Figure 10).<smiles>CC(C(=O)NCc1ccccc1)(C(=O)NCc1ccccc1)c1ccccc1Br</smiles>

(10)

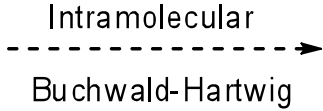

Buchwald-Hartwig<smiles>CNCc1ccccc1</smiles>

(11)

\section{Figure 10: Desymmetrization of di-nitrogen malonamides to form oxindole heterocycles}

The initial synthetic protocol towards the synthesis of oxindole heterocycles is shown in scheme 23. The first step entailed a Fischer esterification reaction between compound 1 (2-(2bromophenyl) acetic acid) and ethanol using a Dean-Stark apparatus. The reaction was catalyzed by $\mathrm{H}_{2} \mathrm{SO}_{4}$, heated to $85{ }^{\circ} \mathrm{C}$ and refluxed for two hours. Under these reaction conditions the desired ethyl ester 2 (ethyl 2-(2-bromophenyl)acetate) was obtained in $50-70 \%$ yield. Next an ethoxycarbonylation reaction was carried out by deprotonation of $\mathbf{2}$ in diethyl carbonate using $\mathrm{NaH}$. The reaction was left stirring overnight at room temperature and compound 3 (diethyl 2-(2bromophenyl)malonate) was obtained in $40-60 \%$ yield. Methylation of 3 at the $\alpha$-carbon was attempted by deprotonation of $\mathbf{3}$ in THF using NaH followed by the addition of iodomethane. The reaction was heated to $85{ }^{\circ} \mathrm{C}$ and refluxed overnight. The reaction was checked by TLC and showed no disappearance of the starting material, thus another half equivalent of sodium hydride and iodomethane were added to the reaction mixture and the reaction was refluxed overnight. The reaction was checked by TLC and again showed no disappearance of the starting material. 
This methylation procedure was repeated twice more however the desired compound 4 (diethyl 2-(2-bromophenyl)-2-methylmalonate) was not obtained, in each case TLC of the reaction mixture showed unreacted starting material.<smiles>CCOC(=O)Cc1ccccc1Br</smiles>

(1)

(2)

(3)

$50-70 \%$ $40-60 \%$<smiles>CCOC(=O)C(C(=O)OCC)c1ccccc1Br</smiles>

(3)
1) $\mathrm{THF}, \mathrm{NaH}, \mathrm{O}^{\circ} \mathrm{C}, 30 \mathrm{~min}$

2) $\mathrm{Mel}, \mathrm{O}^{\circ} \mathrm{C}-$ r.t. $85^{\circ} \mathrm{C}, 24 \mathrm{~h}$<smiles>CCOC(=O)C(C)(C(=O)OCC)c1ccccc1Br</smiles>

(4)

\section{Scheme 23: Initial synthetic protocol for the synthesis of oxindole precursors}

An improved synthetic protocol was established for these three steps and is shown in scheme 24 . The first step entailed a Fischer esterification reaction between $\mathbf{1}$ and methanol. The reaction was catalyzed by $\mathrm{H}_{2} \mathrm{SO}_{4}$, heated to $85{ }^{\circ} \mathrm{C}$ and refluxed for two hours. The reaction worked exceptionally well and furnished the desired product 5 (methyl 2-(2-bromophenyl)acetate) in 95 $\%$ yield. Next a methoxycarbonylation reaction was carried out by deprotonation of $\mathbf{5}$ in dimethyl carbonate using $\mathrm{NaH}$. The reaction was left stirring overnight at room temperature and compound 6 (dimethyl 2-(2-bromophenyl)malonate) was obtained in $85 \%$ yield. Methylation of 6 at the $\alpha$-carbon was accomplished by deprotonation of $\mathbf{6}$ in THF using $\mathrm{NaH}$ followed by the 
addition of either iodomethane or dimethylsulfate. The reaction was heated to $85{ }^{\circ} \mathrm{C}$ and refluxed overnight. Compound 7 (dimethyl 2-(2-bromophenyl)-2-methylmalonate) was obtained in good yield, 82 and $95 \%$, when using iodomethane or dimethylsulfate respectively.<smiles>COC(=O)Cc1ccccc1Br</smiles>

(1)

(5)

(6)

$95 \%$

$85 \%$<smiles>COC(=O)C(C(=O)OC)c1ccccc1Br</smiles>

(6)

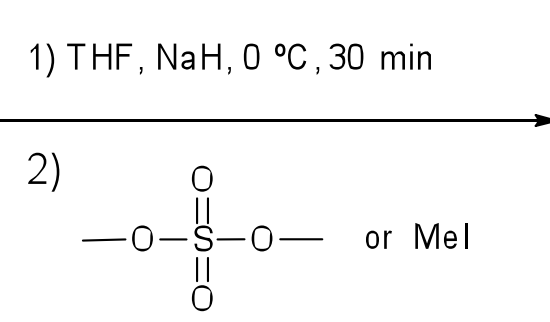

$85^{\circ} \mathrm{C}, 24 \mathrm{~h}$<smiles>COC(=O)C(C)(C(=O)OC)c1ccccc1Br</smiles>

(7)

$95 \%$ with DMS

$82 \%$ with Mel

\section{Scheme 24: An Improved Synthetic Protocol for the Synthesis of Oxindole Precursors}

Thus there is a distinct increase in yield for the Fischer esterification reaction when using methanol as opposed to ethanol. This is likely due to the decreased steric bulk of a methyl group compared to an ethyl group thus making it a better nucleophile. Interestingly the methoxycarbonylation reaction shows a similar trend with a dramatic increase in yield when using dimethyl esters as opposed to diethyl esters. The most striking comparison is observed with the methylation reaction whereby alkylation at the $\alpha$-position was never accomplished using 
compound $\mathbf{3}$ as the starting material, however when compound $\mathbf{6}$ was used as the starting material the desired $\alpha$-methylated product was obtained in high yield.

\subsubsection{Decarboxylation of 2-(2-bromophenyl)-2-methylmalonic acid}

Synthesis of 2-(2-bromophenyl)-2-methylmalonic has proven to be quite tricky due to the propensity of this compound to undergo rapid decarboxylation. Base catalyzed ester hydrolysis of dimethyl 2-(2-bromophenyl)-2-methylmalonate followed by subsequent acidification resulted in $65 \%$ yield of racemic 2-(2-bromophenyl)propanoic acid (8) and $0 \%$ of the desired 2-(2bromophenyl)-2-methylmalonic acid (9) (scheme 25). The reaction was repeated twice more using 2.2 equivalents of $2 \mathrm{M} \mathrm{NaOH}$ followed by acidification with $2 \mathrm{M} \mathrm{HCl}$ resulting in $75 \%$ and $67 \%$ yield of racemic 8 respectively. In each case the desired compound 9 was not obtained.<smiles>COC(=O)C(C)(C(=O)OC)c1ccccc1Br</smiles>

(7)
1) $4 \mathrm{M} \mathrm{NaOH}, 65^{\circ} \mathrm{C}, 0 / \mathrm{n}$ $\mathrm{MeOH}$

2) $0^{\circ} \mathrm{C}, 6 \mathrm{M} \mathrm{HCl}$<smiles>C[C@H](C(=O)O)c1ccccc1Br</smiles>

(8)<smiles>CC(C(=O)O)(C(=O)O)c1ccccc1Br</smiles>

(9)

$$
\begin{aligned}
& \text { decarb oxylated } \\
& \text { product } 65-75 \%
\end{aligned}
$$

Scheme 25: Decarboxylation of 2-(2-bromophenyl)-2-methylmalonic acid

\subsubsection{Alternate synthetic route towards $N^{1}, N^{2}$-dibenzyl-2-methyl-2-phenylmalonamide}

\subsubsection{1 $N^{1}, N^{2}$-dibenzyl-2-methyl-2-phenylmalonamide Synthesis using trimethyl aluminum}

Since the production of $\mathbf{9}$ was not working via the base catalyzed ester hydrolysis route due to rapid decarboxylation of the desired product, an alternate approach towards the synthesis of $\mathbf{1 0}$ $\left(N^{1}, N^{2}\right.$-dibenzyl-2-methyl-2-phenylmalonamide) was explored. In 2010 Taguchi et al. reported a reaction between 12 (2-t-butyl-4-methoxyaniline) and 13 (3-(2-iodophenyl)propanoate) to 
produce 14 ( $N$-(2-t-butyl-4-methoxyphenyl)-3-(2-iodophenyl)propanamide) using $\mathrm{Me}_{3} \mathrm{Al}$ (scheme 26). ${ }^{37}$<smiles>COC(=O)CCc1ccccc1I</smiles>

(13)<smiles>COc1ccc(N)c(C(C)(C)C)c1</smiles>

(12)

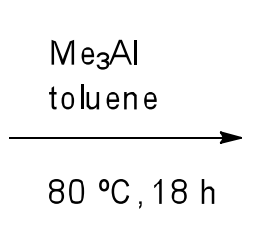

$80^{\circ} \mathrm{C}, 18 \mathrm{~h}$<smiles>COc1ccc(NC(=O)CCc2ccccc2I)c(C(C)(C)C)c1</smiles>

(14)

$61 \%$

\section{Scheme 26: Amide bond formation using $\mathrm{Me}_{3} \mathrm{Al}$}

The reaction required an atmosphere of argon and entailed dissolving $\mathbf{1 3}$ in toluene followed by the addition of $\mathrm{Me}_{3} \mathrm{Al}$ on ice. After stirring for 20 minutes at $0{ }^{\circ} \mathrm{C} \mathbf{1 2}$ was added and the reaction was stirred at $80{ }^{\circ} \mathrm{C}$ for $18 \mathrm{~h}$. After an aqueous work-up followed by purification via column chromatography the desired compound was obtained in $61 \%$ yield.

Application of this method towards the synthesis of $\mathbf{1 0}$ seemed very appealing since compound $\mathbf{9}$ was not required as the starting material. Thus under an atmosphere of argon, benzylamine was dissolved in toluene followed by the addition of $\mathrm{Me}_{3} \mathrm{Al}$ on ice (scheme 27). After stirring for 20 minutes at $0{ }^{\circ} \mathrm{C}$ compound 7 was added and the reaction was stirred at $80{ }^{\circ} \mathrm{C}$ for $18 \mathrm{~h}$. The reaction was then checked by TLC and showed no disappearance of the starting material, therefore another half equivalent of $\mathrm{Me}_{3} \mathrm{Al}$ was added to the reaction and the mixture was stirred overnight at $80{ }^{\circ} \mathrm{C}$. Once again the reaction was checked by TLC and still there appeared to be no disappearance of starting material. After a quick mini work-up ${ }^{1} \mathrm{H}-\mathrm{NMR}$ confirmed that there was only starting material in the reaction mixture. 


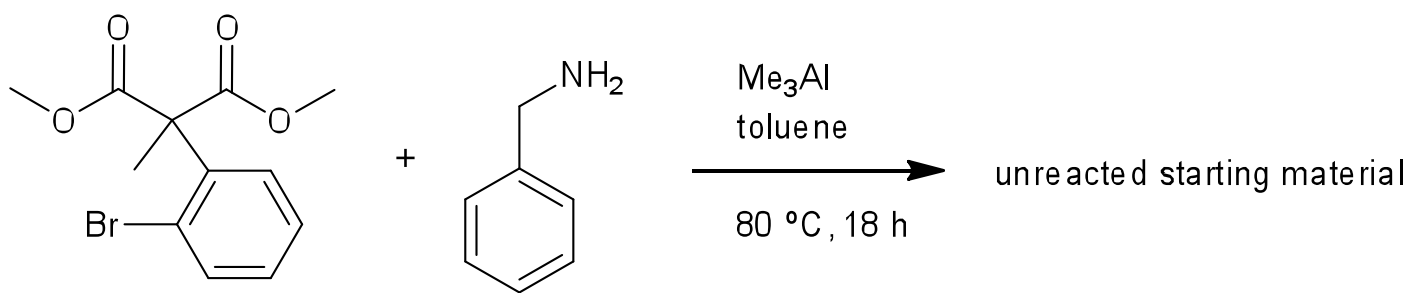

(7)

\section{Scheme 27: $\mathrm{Me}_{3} \mathrm{Al}$ approach to diamide bond formation}

\subsubsection{Decarbonylation of Barbituric acids}

In 2000 Jursic reported a versatile and convenient procedure for the preparation of $N, N-2,2-$ tetrasubstituted malonamides by decarbonylation of tetrasubstituted barbituric acids (scheme 28). ${ }^{44}$<smiles>[R]N1C(=O)N([R3])C(=O)C([R])([R])C1=O</smiles>
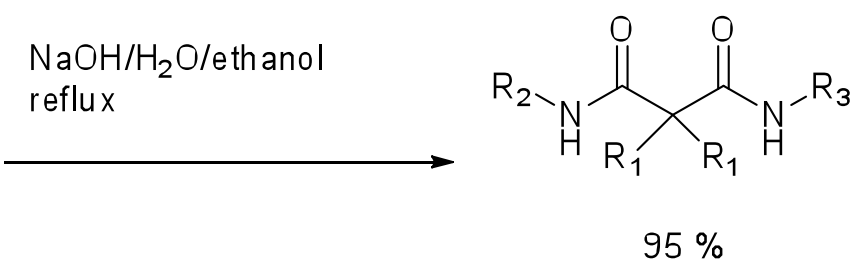

\section{Scheme 28: decarbonylation of tetrasubstituted barbituric acids}

Since the synthesis of $\mathbf{1 0}$ proved to be problematic, decarbonylation of tetrasubstituted barbituric acids appeared to be a reasonable method for obtaining this compound. The first step towards the synthesis of tetrasubstituted barbituric acids was to synthesize 15 (dibenzylurea) which was accomplished by reacting benzylamine with 1,1'-carbonyldiimidazole in DCM at room temperature for 12 hours. The reaction worked extremely well and compound $\mathbf{1 5}$ was obtained in $86 \%$ yield (scheme 29$)$. 


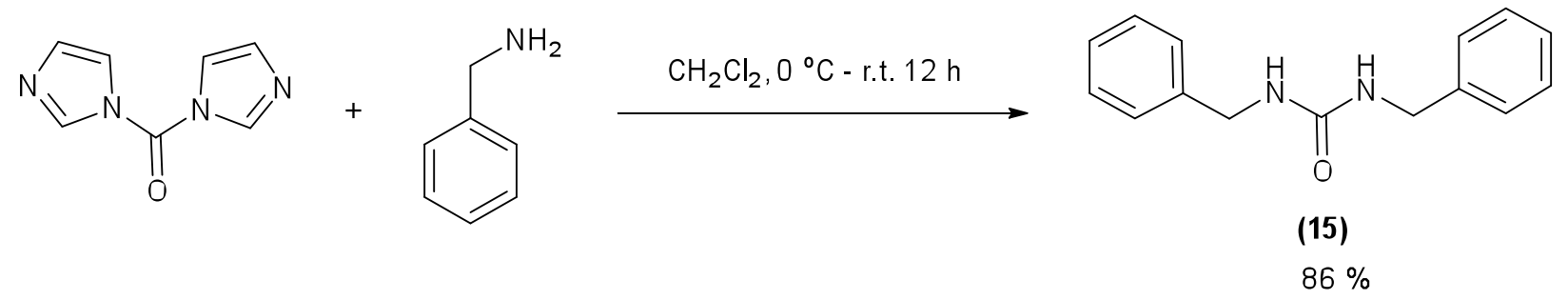

\section{Scheme 29: Synthesis of dibenzylurea}

The next step was to synthesize the corresponding barbituric acids. The first attempt towards the synthesis of these compounds was based on a literature procedure reported by Bose et al. in which the authors reacted various carbodiimides with substituted malonic acids to obtain the desired barbiturates. ${ }^{45}$ Thus compounds $\mathbf{7}$ and $\mathbf{1 5}$ were dissolved in a solution of NaOEt/ethanol and the reaction mixture was heated to $70{ }^{\circ} \mathrm{C}$ (scheme 30). After refluxing overnight the reaction was checked by TLC and showed complete disappearance of the starting material. Furthermore the appearance of a broad streak on the TLC plate became evident. After an acidic work-up, ${ }^{1} \mathrm{H}$ NMR of the crude product looked encouraging however it was clear that the compound needed to be purified in order to determine if it was indeed the desired barbituric acid. The sample would always appear as a broad streak on the TLC plate regardless of the various different solvents and solvent conditions used in attempt to see distinct spots on the TLC plate. Thus column chromatography was carried out using $60 \%$ EtOAc: $40 \%$ Hexanes, and the broad streak was isolated in $76 \%$ yield, however ${ }^{1} \mathrm{H}-\mathrm{NMR}$ of this sample still showed that the compound was not pure. 


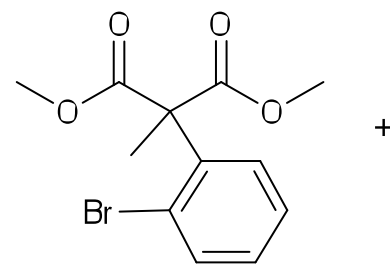

(7)<smiles>O=C(NCc1ccccc1)NCc1ccccc1</smiles>

(15)

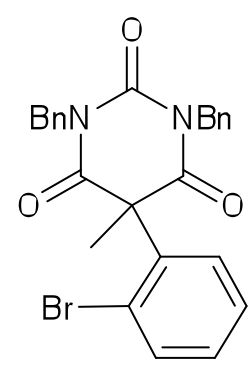

$76 \%$

(16)

\section{Scheme 30: Synthesis of a tetrasubstituted barbituric acid}

Nevertheless a reaction was set up to decarbonylate the putative barbituric acid based on the procedure reported by Jursic et al ${ }^{44}$ in which the crude compound $\mathbf{1 6}$ was dissolved in $\mathrm{MeOH}$ followed by the addition of $0.2 \mathrm{M} \mathrm{NaOH}$, the reaction was heated to $70{ }^{\circ} \mathrm{C}$ and left refluxing overnight (scheme 31). The reaction was checked by TLC and showed that the broad streak was still present along with another spot that had an $\mathrm{R}_{\mathrm{f}}$ corresponding to that of dibenzyl urea. An aqueous work-up followed by recrystallization of the organic phase resulted in $40 \%$ recovery of dibenzylurea. Decarbonylation of the putative barbituric acid was repeated twice more resulting in $50 \%$ and $40 \%$ recovery of dibenzylurea respectively (scheme 31 ).

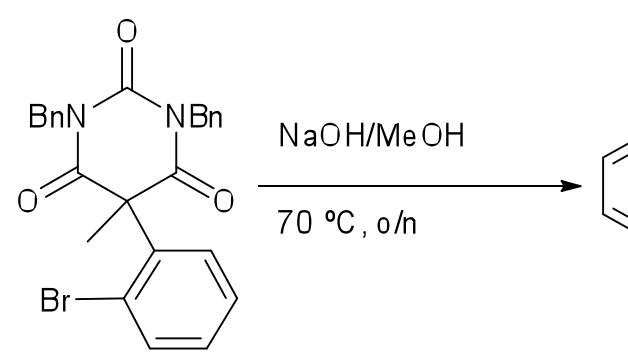

(16)

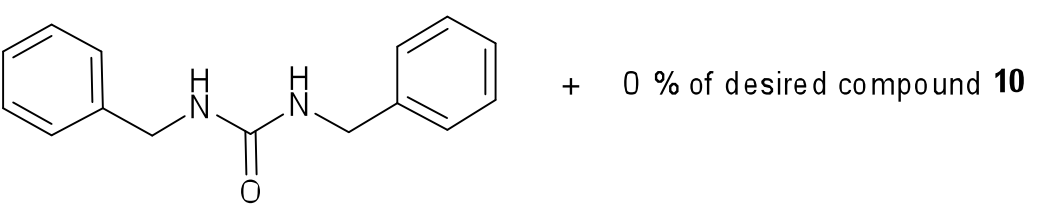

$40-50 \%$

(15)

\section{Scheme 31: Decarbonylation of the putative Barbituric acid}

Barbituric acid synthesis was also attempted using $t$ - $\mathrm{BuOK}$ as a base instead of $\mathrm{NaOEt}$, thus to a solution of $t$-BuOK in DMSO was added a solution of dibenzyl urea in DMSO at $0{ }^{\circ} \mathrm{C}$. After 10 
minutes of stirring, a solution of compound 7 in DMSO was added and the reaction was left stirring at room temperature overnight (scheme 32). The reaction was checked by TLC and again the appearance of a broad streak was evident. Once again the crude product was subjected to column chromatography however in this case the crude compound either decomposed or was strongly retained on the column because only $16 \%$ of the crude product was recovered.

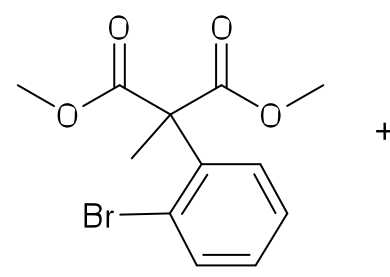

(7)<smiles>O=C(NCc1ccccc1)NCc1ccccc1</smiles>

(15)

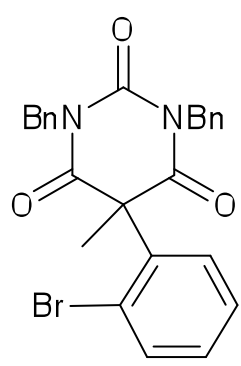

$16 \%$

(16)

\section{Scheme 32: Barbituric acid synthesis using $t$-BuOK and DMSO}

Another attempt towards the synthesis of barbituric acids was explored using TMSCl (scheme 33). In this procedure dibenzylurea, $\mathrm{TMSCl}$ and Hunig's base were stirred in a concentrated solution of THF for thirty minutes. Compound 7 was then added to the reaction mixture and the reaction was stirred at room temperature for two hours. After seeing no disappearance of starting material by TLC the reaction was heated to $70{ }^{\circ} \mathrm{C}$ and left refluxing overnight. The reaction was checked by TLC and again showed no disappearance of starting material.<smiles>COC(=O)C(C)(C(=O)OC)c1ccccc1Br</smiles>

(7)<smiles>O=C(NCc1ccccc1)NCc1ccccc1</smiles>

TMSCl/Hunig's base

THF , r.t. $70^{\circ} \mathrm{C}, \mathrm{o} / \mathrm{n}$

(15) unreacted starting material

Scheme 33: Barbituric acid synthesis using TMSCI and Hunig's base 
A similar reaction was set up using $\left[\left(\mathrm{CH}_{3}\right)_{3} \mathrm{Si}\right]_{2} \mathrm{NK}$ (potassium bis(trimethylsilyl)amide) in which dibenzylurea and $\left[\left(\mathrm{CH}_{3}\right)_{3} \mathrm{Si}\right]_{2} \mathrm{NK}$ were stirred in a concentrated solution of THF for thirty minutes. Compound 7 was then added to the reaction mixture and the reaction was stirred at room temperature for two hours (scheme 34). The reaction was monitored by TLC and showed no disappearance of starting material after two hours, therefore the reaction was heated to $70{ }^{\circ} \mathrm{C}$ and left refluxing overnight. Once again only starting material was visible after the reaction was checked by TLC.

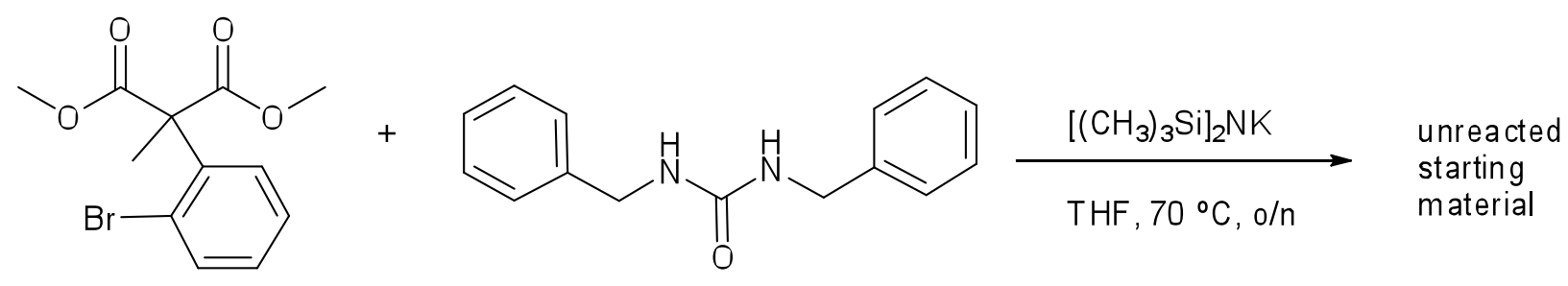

(7)

(15)

\section{Scheme 34: Barbituric acid synthesis using potassium bis(trimethylsilyl)amide}

\subsubsection{Base catalyzed ester hydrolysis followed by immediate activation with $\mathrm{SOCl}_{2}$}

Having had no success in synthesizing compound $\mathbf{1 0}$ using the $\mathrm{Me}_{3} \mathrm{Al}$ protocol or through decarbonylation of barbituric acids, base catalyzed ester hydrolysis was reinvestigated. This time compound 7 was dissolved in THF upon addition of three equivalents of $\mathrm{NaOH}$. The reaction was heated to $70{ }^{\circ} \mathrm{C}$ and left refluxing overnight in THF. The reaction mixture was evaporated to dryness (without acidification) cooled to $0{ }^{\circ} \mathrm{C}$ and transferred to ice cold $\mathrm{SOCl}_{2}$ in THF. The reaction was stirred for four hours at $60{ }^{\circ} \mathrm{C}$, evaporated to dryness, redissolved in THF and evaporated to dryness once again. This process of redissolving the crude product in THF and evaporating to dryness was repeated four more times to get rid of any excess $\mathrm{SOCl}_{2}$. The crude product was redissolved in THF and treated with benzylamine and $\mathrm{Et}_{3} \mathrm{~N}$. The reaction mixture was heated to $70{ }^{\circ} \mathrm{C}$ and left refluxing overnight (scheme 35). TLC of the crude reaction mixture 
showed the appearance of a new spot which was isolated in $21 \%$ yield and found to be the mono-substituted benzylamide. This reaction was repeated once more with freshly distilled $\mathrm{SOCl}_{2}$ and once again the mono-substitued product was obtained in low $25 \%$ yield. So even under these reaction conditions decarboxylation of compound 9 was still occurring.<smiles>COC(=O)C(C)(C(=O)OC)c1ccccc1Br</smiles>

(7)
1) $\mathrm{NaOH}, \mathrm{THF}, 70{ }^{\circ} \mathrm{C}, \mathrm{o} / \mathrm{n}$

2) $\mathrm{SOCl}_{2}, 0-60^{\circ} \mathrm{C}, 4 \mathrm{~h}$

3)<smiles>NCc1ccccc1</smiles>

$\mathrm{NEt}_{3}, \mathrm{THF}, 70{ }^{\circ} \mathrm{C}, \mathrm{o} / \mathrm{n}$<smiles>CC(C(=O)NCc1ccccc1)c1ccccc1Br</smiles>

(17)

$21-25 \%$

Scheme 35: Base catalyzed ester hydrolysis followed by immediate activation with $\mathrm{SOCl}_{2}$

\subsubsection{1 $N^{1}, N^{2}$-dibenzyl-2-methyl-2-phenylmalonamide synthesis using benzyl isocyanate}

With compound 17 ( $N$-benzyl-2-(2-bromophenyl)propanamide) in hand, a reaction using benzyl isocyanate was envisioned which would afford $\mathbf{1 0}$. Thus a solution of $\mathbf{1 7}$ in THF was added to a suspension of $\mathrm{NaH}$ in THF and the reaction was heated to $70{ }^{\circ} \mathrm{C}$ (scheme 36). The reaction was refluxed for one hour and cooled to room temperature, followed by the addition of benzyl isocyanate on ice. The reaction was stirred at room temperature and monitored by TLC. After two hours of stirring at room temperature, TLC of the reaction mixture showed no disappearance of starting material and no appearance of a new spot. Therefore the reaction was heated to $70{ }^{\circ} \mathrm{C}$ and left refluxing overnight. Once again TLC of the reaction mixture showed that no reaction had occurred. 


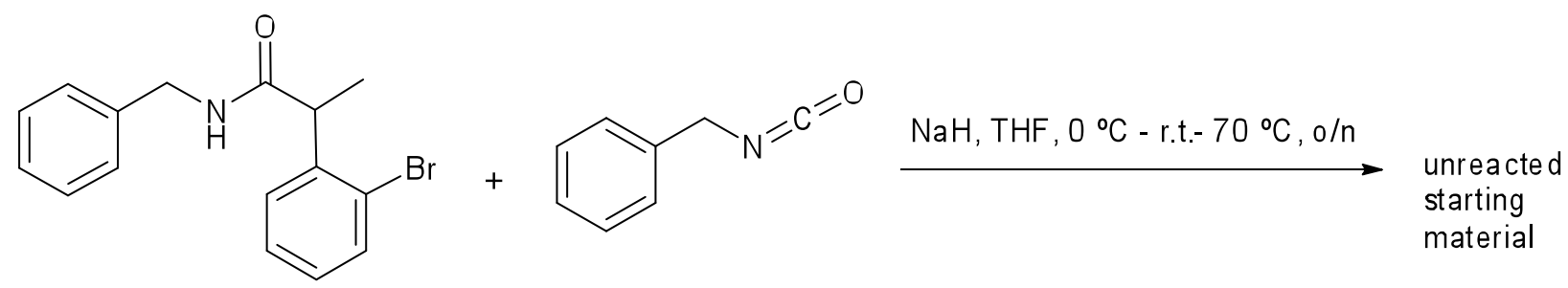

(17)

\section{Scheme 36: Attempted synthesis of compound 10 using benzyl isocyanate}

\subsection{Temperature experiments on base catalyzed ester hydrolysis}

A small scale heating experiment was performed on compound 7. In this experiment compound 7 was dissolved in $\mathrm{MeOH}$ and treated with 3 eq of $4 \mathrm{M} \mathrm{NaOH}$. The reaction was left stirring overnight at room temperature. After the reaction was evaporated to dryness ${ }^{1} \mathrm{H}-\mathrm{NMR}$ showed complete disappearance of the ester signals of the starting material and peaks corresponding to a 3:1 ratio of the disodium salt to the decarboxylated compound. This experiment was taken one step further whereby this sample was redissolved in methanol, heated to $70{ }^{\circ} \mathrm{C}$ and left stirring

overnight at this temperature. Interestingly ${ }^{1} \mathrm{H}-\mathrm{NMR}$ of this sample revealed that the only product in the reaction after heating overnight at $70{ }^{\circ} \mathrm{C}$ was in fact the decarboxylated compound. Therefore heat was found to be the culprit for decarboxylation.

\subsubsection{Base catalyzed ester hydrolysis re-revisited}

Since the disodium salt of compound 7 could be obtained by treatment with $\mathrm{NaOH} / \mathrm{MeOH}(1: 3)$ and stirring overnight at room temperature, synthesis of compound $\mathbf{1 0}$ could potentially be achieved by treatment of the disodium salt with $\mathrm{SOCl}_{2}$ followed by subsequent addition of benzylamine and Hunig's base. Thus compound 7 was dissolved in $\mathrm{MeOH}$ and treated with $\mathrm{NaOH}$ and the reaction was stirred overnight at room temperature (Scheme 37). The reaction mixture was checked by TLC and showed complete disappearance of the starting material. At this point the reaction was evaporated to dryness then re-dissolved in toluene and evaporated to 
dryness once again. This process of re-dissolving in toluene and evaporating to dryness was repeated four more times to get rid of any remaining water. After keeping the product overnight under vacuum the disodium salt was dissolved in cold THF and transferred to ice cold $\mathrm{SOCl}_{2}$. The reaction was stirred for four hours at room temperature then evaporated to dryness, redissolved in THF and evaporated to dryness once again. This process of re-dissolving in THF and evaporating to dryness was repeated four more times to get rid of any remaining $\mathrm{SOCl}_{2}$. Next the crude product was dissolved in THF and treated with benzylamine and Hunig's base. The reaction was left stirring overnight at room temperature. TLC of the reaction mixture did not show the appearance of a new spot but rather unreacted benzylamine indicating that the amide bond forming reaction needs heat.

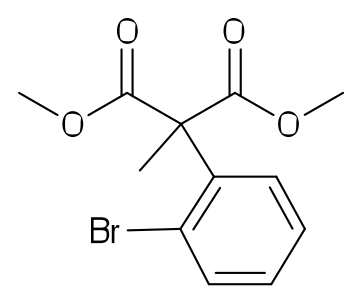

(7)
1) $\mathrm{NaOH} / \mathrm{MeOH}$, r.t. o/n

2) $\mathrm{THF}, \mathrm{SOCl}_{2}, \mathrm{O}^{\circ} \mathrm{C}$ - r.t. $4 \mathrm{~h}$

3)<smiles>NCc1ccccc1</smiles>

Hunig's base, THF, r.t. o/n

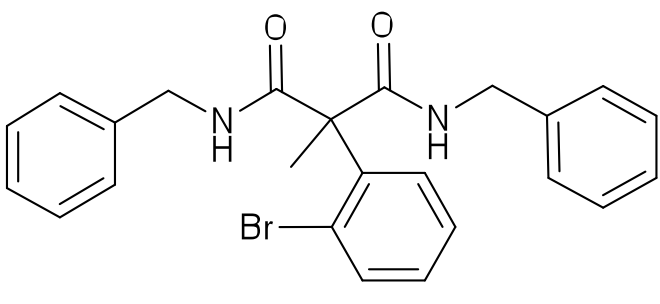

(10)

$0 \%$

\section{Scheme 37: Amide bond formation in the absence of heat}

\subsubsection{5 $N^{1}, N^{2}$-dibenzyl-2-methyl-2-phenylmalonamide synthesis using HBTU}

It became evident that mild conditions were necessary for the synthesis of compound $\mathbf{1 0}$ and HBTU (2-(1H-benzotriazole-1-yl-1,1,3,3-tetramethyl uronium hexafluorophosphate) appeared to be a good candidate for promoting mild amide couplings. Having the disodium salt in hand a coupling reaction with benzylamine using HBTU was envisioned however even at low reaction concentrations, $<0.001 \mathrm{M}$, the disodium salt would not dissolve in DMF. 
In order to increase the solubility of the starting material in DMF, a base catalyzed ester hydrolysis was set up using $\mathrm{KOH}$ instead of $\mathrm{NaOH}$. Interestingly only one side of the molecule reacted resulting in a mono-potassium salt mono-ester compound (scheme 38).

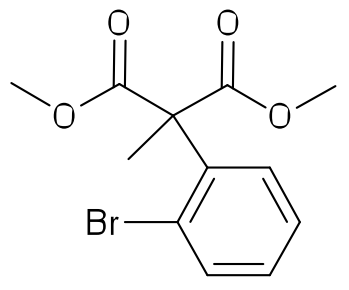

(7)

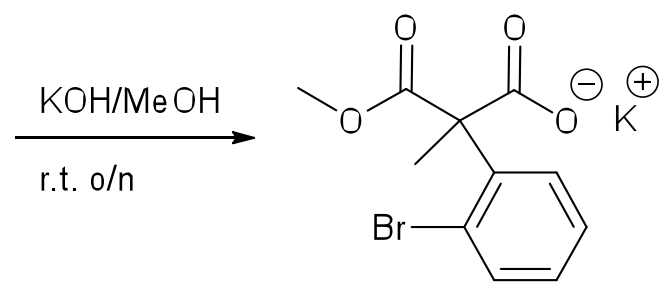

$85 \%$

(18)

\section{Scheme 38: Base-catalyzed ester hydrolysis using $\mathrm{KOH}$}

Nevertheless this compound was subjected to a coupling reaction using HBTU as the coupling agent (scheme 39). Thus the starting material was dissolved in DMF followed by the addition of HBTU and benzylamine. The reaction was stirred at room temperature overnight. TLC of the crude reaction mixture showed the appearance of several new spots however any attempt at purifying this compound via column chromatography was unsuccessful.

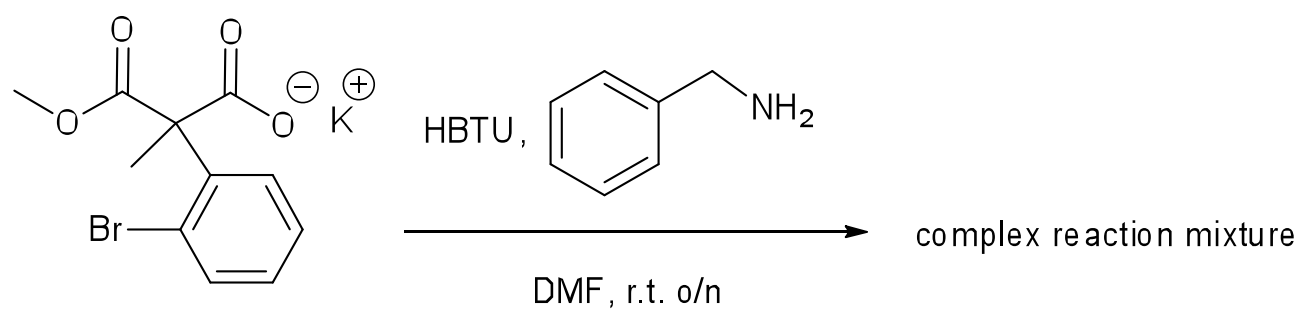

(18)

\section{Scheme 39: HBTU coupling of mono-acid mono-ester with benzylamine}

\subsubsection{6 $N^{1}, N^{2}$-dibenzyl-2-methyl-2-phenylmalonamide synthesis using BuLi}

The last procedure attempted for the synthesis of $\mathbf{1 0}$ entailed using BuLi to deprotonate benzylamine, thus creating an extremely strong nucleophile which should theoretically undergo di-substitution with compound 7. In this method benzylamine was dissolved in dry THF and 
cooled to $0{ }^{\circ} \mathrm{C}$ followed by the slow dropwise addition of BuLi under a stream of argon. The reaction was stirred for fifteen minutes at $0{ }^{\circ} \mathrm{C}$ before the addition of a solution of compound 7 in THF at $0{ }^{\circ} \mathrm{C}$. The reaction was stirred overnight at room temperature. TLC of the crude reaction mixture at $40 \%$ EtOAc:Hexanes showed many spots however it looked encouraging due to the appearance of a spot with a strikingly similar $\mathrm{R}_{\mathrm{f}}$ to the six and seven membered ring precursor di-substituted benzylmalonamides. This spot was easily isolated by column chromatography eluting at $40 \%$ EtOAc:Hexanes, however ${ }^{1} \mathrm{H}-\mathrm{NMR}$ of this compound showed too much signal in the methylene region of the spectrum. Perhaps what happened was lithium exchange with bromide resulting in the compound shown in scheme 40 . The reaction was repeated with the addition of BuLi at $-78{ }^{\circ} \mathrm{C}$ instead of $0{ }^{\circ} \mathrm{C}$ and this also resulted in the isolation of a compound with peaks corresponding to 19 by ${ }^{1} \mathrm{H}-\mathrm{NMR}$.

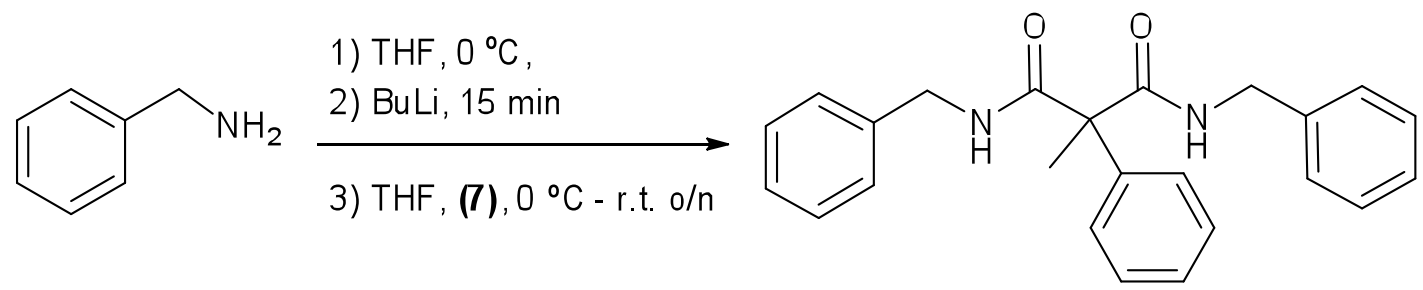

(19)

\section{Scheme 40: Amide bond formation using Butyl-Lithium}

\subsection{Synthesis of six membered ring Benzomorpholinone Heterocycles}

In order to further investigate the work carried out by Porosa in $2009^{31,32}$ to include six membered rings with more than one heteroatom in the ring an intramolecular Buchwald-Hartwig reaction was envisioned which would furnish six-membered ring benzomorpholinone heterocycles (Figure 11). 


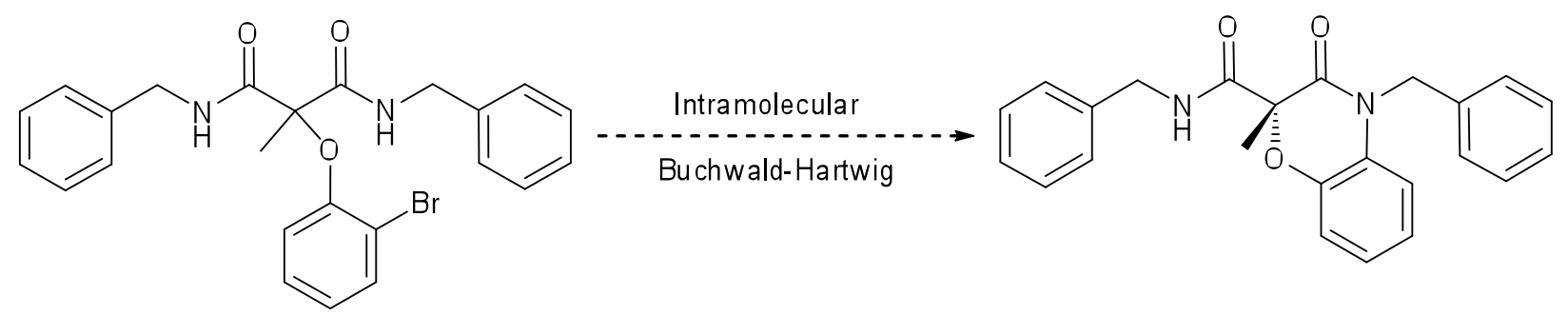

(20)

(21)

Figure 11: Desymmetrization of malonamides to form benzomorpholinone heterocycles

The synthesis of six membered ring benzomorpholinone heterocycles began with a substitution reaction between 2-bromophenol and diethyl 2-bromo-2-methylmalonate (scheme 41). The reaction worked reasonably well and the desired product 22 (diethyl 2-(2-bromophenoxy)-2methylmalonate) was obtained in $66 \%$ yield. The next step entailed base catalyzed ester hydrolysis of 22 followed by subsequent acidification with a $\mathrm{pH} 3$ phosphate buffer which furnished compound 23 (2-(2-bromophenoxy)-2-methylmalonic acid) in $80 \%$ yield (scheme 41). 
<smiles>Oc1ccccc1Br</smiles>

1) t-BuOK, DMF, 30 min, r.t.<smiles>CCOC(=O)C(C)(Oc1ccccc1Br)C(=O)OCC</smiles>

(22)

$16 \mathrm{hr}$, r.t.

$66 \%$<smiles>CCOC(=O)C(C)(Oc1ccccc1Br)C(=O)OCC</smiles>

(22)
1) $\mathrm{NaOH}, \mathrm{MeOH}$, reflux

2) $0^{\circ} \mathrm{C}$, $\mathrm{pH} 3$ phosphate buffer<smiles>CC(Oc1ccccc1Br)(C(=O)O)C(=O)O</smiles>

(23)

$80 \%$

\section{Scheme 41: Towards the Synthesis of Benzomorpholinone Heterocycles}

Initially the base catalyzed ester hydrolysis of $\mathbf{2 2}$ was followed by acidification with $6 \mathrm{M} \mathrm{HCl}$ which produced the corresponding di-acid $\mathbf{2 3}$ in $50 \%$ yield. Thus the rationale for switching from $6 \mathrm{M} \mathrm{HCl}$ to a $\mathrm{pH} 3$ phosphate buffer was that the buffer would be a less harsh way to protonate the di-sodium salt and ultimately lead to a decrease in decarboxylation.

Coupling of $\mathbf{2 3}$ with benzylamine to form $\mathbf{2 0}$ ( $N^{1}, N^{3}$-dibenzyl-2-(2-bromophenoxy)-2methylmalonamide) was originally attempted by activation of the di-carboxcylic acid with $\mathrm{SOCl}_{2}$ followed by the addition of benzylamine but this route yielded only $16 \%$ of compound $24(\mathrm{~N}$ benzyl-2-(2-bromophenoxy)propanamide) the undesired decarboxylated compound (scheme 42). 
<smiles>CC(Oc1ccccc1Br)(C(=O)O)C(=O)O</smiles>

(23)
1) $\mathrm{SOCl}_{2}$

2)<smiles>NCc1ccccc1</smiles>

$\mathrm{NEt}_{3}, \mathrm{CHCl}_{3}$, reflux, o/n<smiles>C[C@H](Oc1ccccc1Br)C(=O)NCc1ccccc1</smiles>

(24)

$16 \%$ unde sired de carb oxylated compound

\section{Scheme 42: Activation of di-acid using $\mathrm{SOCl}_{2}$}

Activation of $\mathbf{2 3}$ with $\mathrm{HBTU}$ proved superior to $\mathrm{SOCl}_{2}$ and the desired diamide compound $\mathbf{2 0}$ was obtained in $38 \%$ yield (scheme 43 ). One of the benefits of using $\mathrm{HBTU}$ over $\mathrm{SOCl}_{2}$ is the ability to run reactions at room temperature, this is important because heat is a factor that increases the rate of decarboxylation.<smiles>CC(Oc1ccccc1Br)(C(=O)O)C(=O)O</smiles>

(23)<smiles>CC(OC(=O)OCc1ccccc1)C(=O)NCc1ccccc1</smiles>

(20)

$38 \%$

\section{Scheme 43: Activation of di-acid using HBTU}

With the desired dibenzylamide in hand a series of cross coupling reactions were carried out to find optimal cyclization conditions (Table 1). 
<smiles>CC(Oc1ccccc1Br)(C(=O)NCc1ccccc1)C(=O)NCc1ccccc1</smiles>

(20)

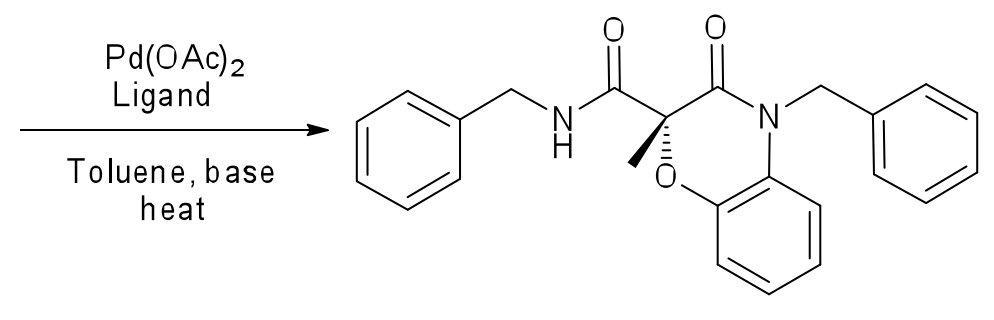

(21)

\begin{tabular}{|c|c|c|c|c|c|c|c|}
\hline Trial & Ligand & Base & $\begin{array}{l}\text { Temp } \\
\left({ }^{\circ} \mathrm{C}\right)\end{array}$ & $\begin{array}{l}\text { Time } \\
\text { (h) }\end{array}$ & $\begin{array}{l}\text { Conversion* } \\
(\%)\end{array}$ & $\begin{array}{l}\text { Isolated } \\
\text { yield } \\
(\%)\end{array}$ & $\begin{array}{l}e e \\
(\%)\end{array}$ \\
\hline 1 & $(+/-)$ BINAP & $\mathrm{K}_{2} \mathrm{CO}_{3}$ & 100 & 48 & 95 & 50 & 0 \\
\hline 2 & $(R)-\mathrm{Cy}_{2} \mathrm{MOP}^{\prime} \mathrm{BH}_{3}$ & $\mathrm{~K}_{2} \mathrm{CO}_{3}$ & 100 & 48 & 25 & nd & nd \\
\hline 3 & $(R)-\mathrm{Cy}_{2} \mathrm{MOP}$ & $\mathrm{K}_{2} \mathrm{CO}_{3}$ & 100 & 48 & 35 & nd & nd \\
\hline 4 & $(R)-\mathrm{MOP}$ & $\mathrm{K}_{2} \mathrm{CO}_{3}$ & 100 & 48 & $<10$ & nd & nd \\
\hline 5 & $(R)$-BINAP & $\mathrm{K}_{2} \mathrm{CO}_{3}$ & 100 & 48 & 100 & 88 & 20 \\
\hline 6 & $(R)-\mathrm{Cy}_{2} \mathrm{MOP}$ & $\mathrm{Cs}_{2} \mathrm{CO}_{3}$ & 100 & 48 & 100 & 90 & 12 \\
\hline 7 & $(R)$-BINAP & $\mathrm{Cs}_{2} \mathrm{CO}_{3}$ & 100 & 48 & 100 & 99 & 12 \\
\hline 8 & $(R)-\mathrm{MOP}$ & $\mathrm{Cs}_{2} \mathrm{CO}_{3}$ & 100 & 48 & 100 & 98 & 3 \\
\hline 9 & $(R)$-BINAP & $\mathrm{K}_{2} \mathrm{CO}_{3}$ & 60 & 96 & 0 & 0 & nd \\
\hline
\end{tabular}

Table 1: Desymmetrization of di-nitrogen malonamides via an intramolecular BuchwaldHartwig reaction to produce benzomorpholinone heterocycles ( ${ }^{1} \mathrm{H}-\mathrm{NMR}$ Conversion determined from the disappearance of $\mathrm{CH}_{2}$ signals in compound 20)

Initially compound $\mathbf{2 0}$ was cyclized using racemic BINAP as the ligand (Table 1, Trial 1). The reaction worked well showing $95 \%$ conversion by ${ }^{1} \mathrm{H}-\mathrm{NMR}$ however the cyclized product was only isolated in $50 \%$ yield. The reason for the low isolated yield of the cyclized product is because the crude product was purified by preparative plate TLC. Although this seemed to be an appropriate method for purification, since this reaction was done on a small scale $(0.05 \mathrm{mmol}, 25$ 
$\mathrm{mg}$ ), it proved to be inferior to purification via column chromatography. Next a series of reactions were set up in order to investigate the enantioselectivity of the desymmetrization reaction using chiral, enantiopure phosphine ligands. Application of $(R)-\mathrm{Cy}_{2} \mathrm{MOP}^{\circ} \mathrm{BH}_{3},(R)-$ $\mathrm{Cy}_{2} \mathrm{MOP}$ and $(R)$-MOP using $\mathrm{K}_{2} \mathrm{CO}_{3}$ as a base all demonstrated low conversion , $<10-35 \%$, to the desired cyclized product by ${ }^{1} \mathrm{H}-\mathrm{NMR}$ (Table 1, Trials 2,3,4). Cyclization of compound 20 using $(R)$-BINAP and $\mathrm{K}_{2} \mathrm{CO}_{3}$ resulted in $100 \%$ conversion to cyclized product 21 . This compound was isolated in good yield, $88 \%$, however the enantioselectivity was low, $20 \% e e$, (Table 1 , Trial 5). Interestingly application of $(R)-\mathrm{Cy}_{2} \mathrm{MOP},(R)$-BINAP and $(R)$-MOP using $\mathrm{Cs}_{2} \mathrm{CO}_{3}$ as a base instead of $\mathrm{K}_{2} \mathrm{CO}_{3}$ resulted in $100 \%$ conversion of compound $\mathbf{2 0}$ to compound 21 (Table 1, Trials 6,7,8). The crude product of these reactions was isolated in excellent yield, 90 $-99 \%$, however once again the enantioselectivity of the product was quite low, $3-12 \% e e$. It was thought that perhaps the high temperature of the cyclization reaction could be detrimental to the enantioselevtivity of the product thus a cross-coupling reaction was set-up using $(R)$-BINAP and $\mathrm{K}_{2} \mathrm{CO}_{3}$ at $60{ }^{\circ} \mathrm{C}$ instead of $100{ }^{\circ} \mathrm{C}$ (Table 1, Trial 9). After two days the reaction was monitored by ${ }^{1}$ H-NMR and showed no conversion of 20 to compound 21. Another catalyst loading of palladium and $(R)$-BINAP was added to the reaction mixture, since the catalyst tends to decompose after 2 days, and the reaction was left stirring for two more days. Even after four days however this reaction showed no conversion to compound 21 by ${ }^{1} \mathrm{H}-\mathrm{NMR}$ indicating that the high temperature is key for this cyclization to occur. 


\subsection{Synthesis of Seven Membered Ring Benzodiazepinone Heterocycles}

In order to extend the work carried out by Porosa in $2009^{31,32}$ to include larger ring sizes an intramolecular Buchwald-Hartwig reaction was envisioned which would furnish sevenmembered ring benzodiazepinone heterocycles (Figure 12).

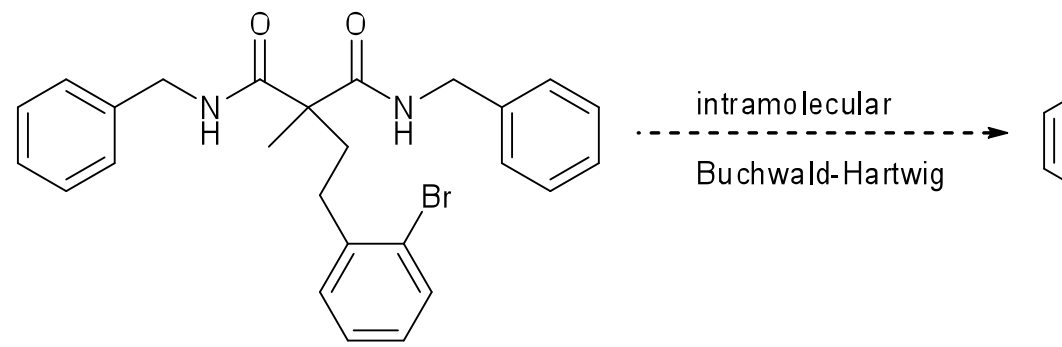

(31)

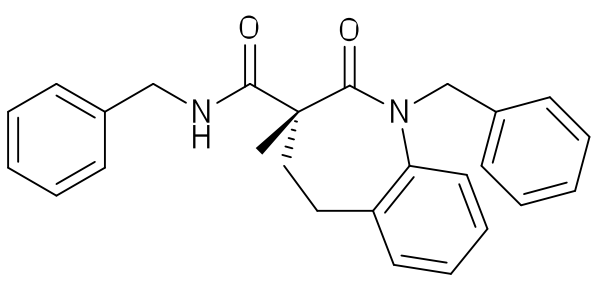

(32)

Figure 12: Desymmetrization of malonamides to form benzodiazepinone heterocycles

The first step towards the synthesis of benzodiazepinone heterocycles was a substitution reaction between 25 (2-bromophenethyl alcohol) and 26 (tosyl chloride) using triethylamine and DMAP which furnished the desired tosylate ester in $88 \%$ yield (scheme 44 ). Next the tosylate ester was reacted with 28 to produce compound 29 (diethyl-2-(2-bromophenethyl)-2-methylmalonate) in $50 \%$ yield (scheme 44 ). 


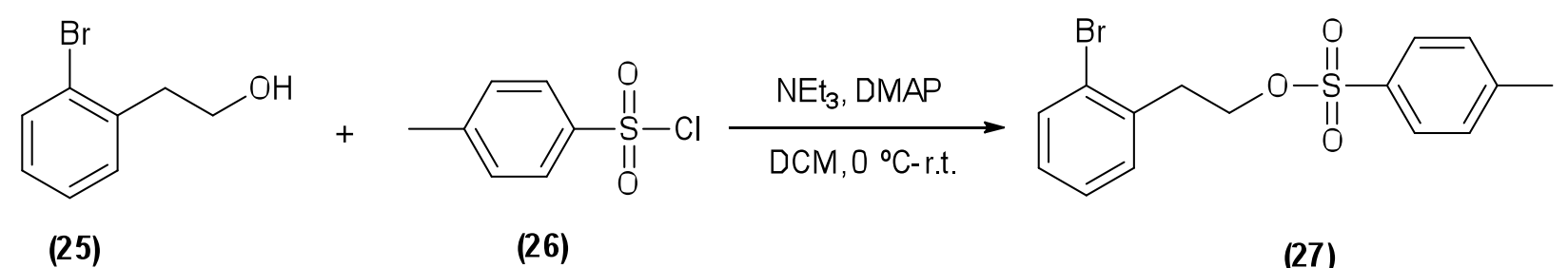

(26)

(27)

$88 \%$<smiles>CCOC(=O)C(C)C(=O)OCC</smiles>

(28)

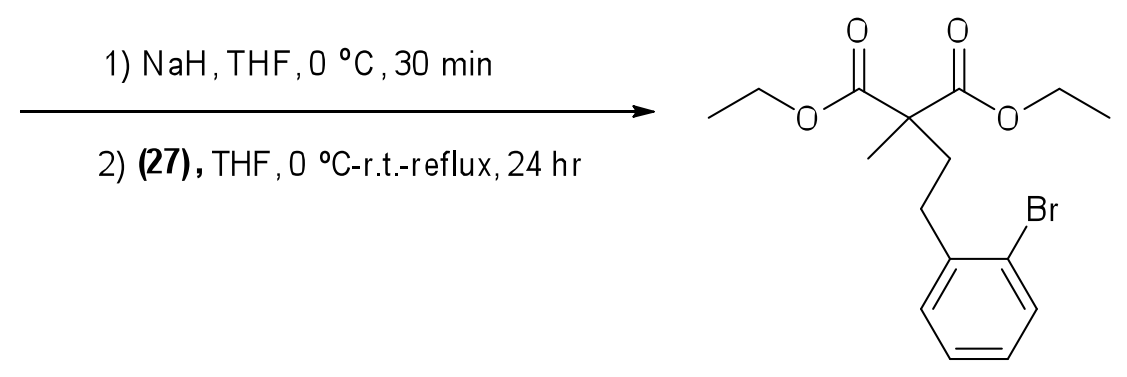

(29)

\section{Scheme 44: Synthesis of benzodiazapineone precursors}

The diethyl ester was then hydrolyzed using $\mathrm{NaOH}$ and acidified with $\mathrm{HCl}$ to produce 30 (2-(2bromophenethyl)-2-methylmalonic acid) in $55 \%$ yield (scheme 45). Activation of the dicarboxcylic acid with $\mathrm{SOCl}_{2}$ and subsequent treatment with benzylamine provided the desired dibenzylmalonamide $\mathbf{3 1}$ in $40 \%$ yield (scheme 45 ). 
<smiles>CCOC(=O)C(C)(CCc1ccccc1Br)C(=O)OCC</smiles>

(29)
1) $\mathrm{NaOH}, \mathrm{MeOH}$, reflux

2) $\mathrm{HCl}, \mathrm{O}^{\circ} \mathrm{C}$<smiles>CC(CCc1ccccc1Br)(C(=O)O)C(=O)O</smiles>

(30)

$55 \%$<smiles>CC(CCc1ccccc1Br)(C(=O)O)C(=O)O</smiles>

(30)
1) $\mathrm{SOCl}_{2}, 60^{\circ} \mathrm{C}, 4 \mathrm{~h}$

2)

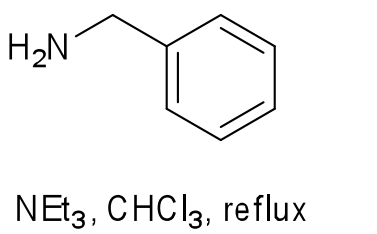

$\mathrm{NEt}_{3}, \mathrm{CHCl}_{3}$, reflux<smiles>CC(CCc1ccccc1Br)(C(=O)NCc1ccccc1)C(=O)NCc1ccccc1</smiles>

(31)

$40 \%$

\section{Scheme 45: Towards the Synthesis of benzodiazepinone heterocycles}

With the desired dibenzylmalonamide in hand a series of cross coupling reactions were carried out to find optimal cyclization conditions (Table 2). Initially the cyclization of $\mathbf{3 1}$ was attempted with racemic BINAP and $(R)-\mathrm{MOP}$ using $\mathrm{K}_{3} \mathrm{PO}_{4}$ as a base, in THF at $65{ }^{\circ} \mathrm{C}$ for twenty-four hours, however neither of these reactions showed any conversion to compound $\mathbf{3 1}$ by ${ }^{1} \mathrm{H}-\mathrm{NMR}$ (Table 2, Trials 1,2). Cyclization of 31 was also attempted with $(R)-\mathrm{MOP} \cdot \mathrm{BH}_{3}$ and $\mathrm{K}_{3} \mathrm{PO}_{4}$ in $t$ $\mathrm{BuOH}$ at $65{ }^{\circ} \mathrm{C}$, nonetheless this reaction still showed no conversion to compound 32 by ${ }^{1} \mathrm{H}-$ NMR (Table 2, Trial 3). Interestingly when the cyclization of compound $\mathbf{3 1}$ was attempted with (R)-MOP'BH $\mathrm{BH}_{3}$ using $\mathrm{Cs}_{2} \mathrm{CO}_{3}$, in THF at $65{ }^{\circ} \mathrm{C}$ for forty-eight hours, ${ }^{1} \mathrm{H}-\mathrm{NMR}$ of the crude reaction showed a 50:50 mixture of the starting material and compound $\mathbf{3 3}$, the debrominated compound (Table 2, Trial 4, scheme 46). 
<smiles>CC(CCc1ccccc1Br)(C(=O)NCc1ccccc1)C(=O)NCc1ccccc1</smiles>

(31)

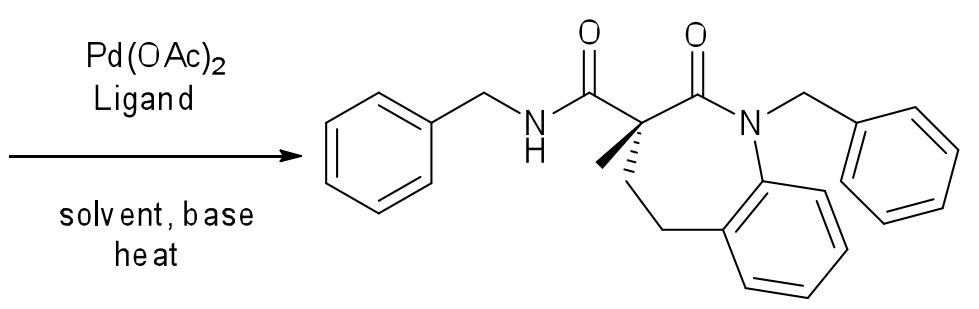

(32)

\begin{tabular}{|l|l|l|l|l|l|l|l|}
\hline Trial & Ligand & Solvent & Base & $\begin{array}{l}\text { Temp } \\
\left({ }^{\circ} \mathrm{C}\right)\end{array}$ & $\begin{array}{l}\text { Time } \\
(\mathrm{h})\end{array}$ & $\begin{array}{l}\text { Conversion* } \\
(\%)\end{array}$ & $\begin{array}{l}\text { Isolated } \\
\text { yield } \\
(\%)\end{array}$ \\
\hline 1 & $(+/-) \mathrm{BINAP}$ & THF & $\mathrm{K}_{3} \mathrm{PO}_{4}$ & 65 & 24 & 0 & 0 \\
\hline 2 & $(R)-\mathrm{MOP}$ & THF & $\mathrm{K}_{3} \mathrm{PO}_{4}$ & 65 & 24 & 0 & 0 \\
\hline 3 & $(R)-\mathrm{MOP}^{\circ} \mathrm{BH}_{3}$ & $t$-BuOH & $\mathrm{K}_{3} \mathrm{PO}_{4}$ & 65 & 24 & 0 & 0 \\
\hline 4 & $(R)-\mathrm{MOP}^{\circ} \mathrm{BH}_{3}$ & THF & $\mathrm{Cs}_{2} \mathrm{CO}_{3}$ & 65 & 48 & 0 & 0 \\
\hline 5 & $(R)-\mathrm{MOP}^{\circ} \mathrm{BH}_{3}$ & Toluene & $\mathrm{Cs}_{2} \mathrm{CO}_{3}$ & 100 & 48 & 75 & $\mathrm{nd}$ \\
\hline 6 & $(R)-\mathrm{Cy}_{2} \mathrm{MOP}$ & Toluene & $\mathrm{Cs}_{2} \mathrm{CO}_{3}$ & 100 & 48 & 100 & 50 \\
\hline
\end{tabular}

Table 2: Desymmetrization of di-nitrogen malonamides via an intramolecular BuchwaldHartwig reaction to produce benzodiazepinone heterocycles (* ${ }^{1} \mathrm{H}-\mathrm{NMR}$ Conversion determined from the disappearance of $\mathrm{CH}_{2}$ signals in compound 31)<smiles>CC(CCc1ccccc1)(C(=O)NCc1ccccc1)C(=O)NCc1ccc(-c2ccccc2)cc1</smiles>

(31)
(33)
50:50 mixture by ${ }^{1} \mathrm{H}-\mathrm{NMR}$ of debrominated 33 to unreacted starting material $\mathbf{3 1}$

Scheme 46: Debromination under cross-coupling conditions 
Having had no success in the synthesis of benzodiazepinone heterocycles thus far, it was believed that perhaps higher temperatures were required for this cyclization to happen. Indeed when compound 31 was cyclized using $(R)-\mathrm{MOP}^{3} \mathrm{BH}_{3}$ and $\mathrm{Cs}_{2} \mathrm{CO}_{3}$ in Toluene at $100{ }^{\circ} \mathrm{C}$ for forty-eight hours, ${ }^{1} \mathrm{H}-\mathrm{NMR}$ showed a $75 \%$ conversion of compound 31 to 32 (Table 2, Trial 5). Unfortunately the cyclized product could not be separated from the starting material because they appear to have a very similar $\mathrm{R}_{\mathrm{f}}$ by TLC. Application of $\mathrm{Cy}_{2} \mathrm{MOP}$ for the cyclization of compound $\mathbf{3 1}$ resulted in $100 \%$ conversion to the desired benzodiazapineone heterocycle (Table 2, Trial 6). The crude product was isolated in $50 \%$ yield because it was purified by preparative plate TLC which has proven not to be the optimal method of purification for these compounds. Nevertheless the seven-membered ring heterocycle has been synthesized and the isolated compound is being analyzed by chiral column HPLC to determine the enantiomeric excess.

\subsection{Development of an enantio- and diastereoselective Buchwald-Hartwig reaction}

To further expand the work carried out by Porosa in $2009^{31,32}$ and develop an enantio- and diastereoselective Buchwald-Hartwig reaction a desymmetrization reaction was envisioned which would generate a chiral centre as well as a chiral axis due to locked rotation around the Naryl bond (Figure 13).

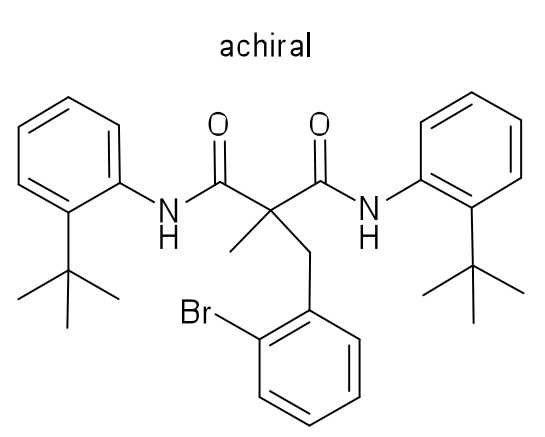

(35)

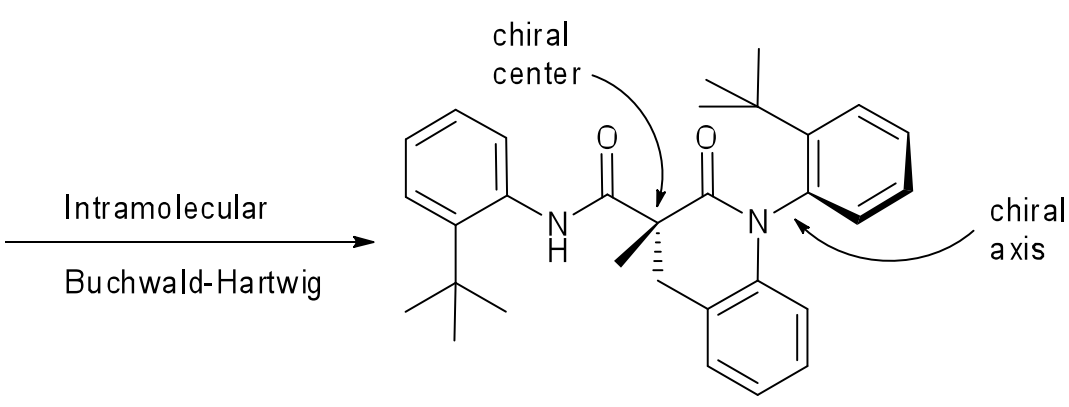

(36)

Figure 13: Development of an enantio- and diastereoselective Buchwald-Hartwig reaction 
The synthesis of $t$-butyl substituted quinolinone began with a substitution reaction between compound $\mathbf{2 8}$ and 2-bromobenzylbromide followed by base catalyzed ester hydrolysis using $\mathrm{NaOH}$ and subsequent acidification with concentrated $\mathrm{HCl}$. Activation of the dicarboxcylic acid was accomplished with $\mathrm{SOCl}_{2}$ followed by the addition of $t$-butyl aniline to obtain the desired diamide compound (scheme 47).

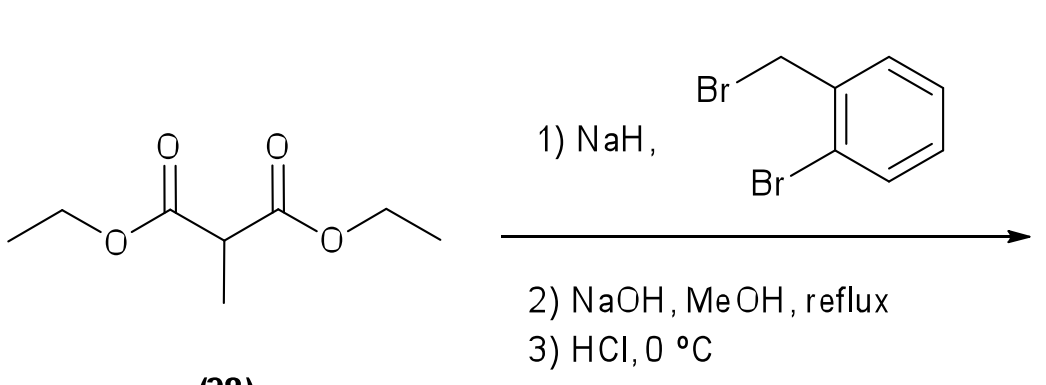

(28)<smiles>CC(Cc1ccccc1Br)(C(=O)O)C(=O)O</smiles>

(34)

$80 \%$ over 3 steps<smiles>CC(Cc1ccccc1Br)(C(=O)O)C(=O)O</smiles>

(34)
1) $\mathrm{SOCl}_{2}$

2)<smiles>CC(C)(C)c1ccccc1N</smiles>

$\mathrm{NEt}_{3}, \mathrm{CHCl}_{3}$, reflux<smiles>CC(Cc1ccccc1Br)(C(=O)Nc1ccccc1C(C)(C)C)C(=O)Nc1ccccc1C(C)(C)C</smiles>

(35)

$40 \%$

\section{Scheme 47: Towards the synthesis of $t$-butyl quinolinone}

The steric bulk created by the ortho t-butyl group made the substitution reaction between the acyl chloride and $t$-butylaniline difficult resulting in unreacted starting material as well as the mono-substituted decarboxylated compound. Nevertheless with the di-t-butylphenyl amide in hand a series of cross coupling reactions were carried out to find optimal cyclization conditions (Table 3). 
<smiles>CC(Cc1ccccc1Br)(C(=O)Nc1ccccc1C(C)(C)C)C(=O)Nc1ccccc1C(C)(C)C</smiles>

(35)

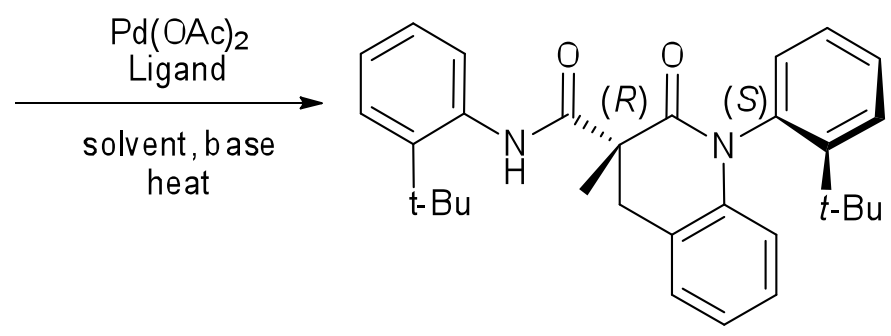

(36)

Ab solute stereochemistry $\left(3 R, S_{a}\right)$

\begin{tabular}{|l|l|l|l|l|l|l|l|}
\hline Trial & Ligand & Base & Solvent & $\begin{array}{l}\text { Temp } \\
\left({ }^{\circ} \mathrm{C}\right)\end{array}$ & $\begin{array}{l}\text { Time } \\
(\mathrm{h})\end{array}$ & $\begin{array}{l}\text { Conversion* } \\
(\%)\end{array}$ & $\begin{array}{l}\text { Isolated } \\
\text { Yield } \\
(\%)\end{array}$ \\
\hline 1 & $(R)$-MOP & $\mathrm{K}_{3} \mathrm{PO}_{4}$ & THF & 65 & 24 & 27 & 22 \\
\hline 2 & $(R)-\mathrm{MOP} \cdot \mathrm{BH} 3$ & $\mathrm{~K}_{2} \mathrm{CO}_{3}$ & THF & 65 & 24 & 15 & 10 \\
\hline 3 & $\begin{array}{l}(R)-\mathrm{DTBM}- \\
\text { SEGPHOS }\end{array}$ & $\mathrm{K}_{2} \mathrm{CO}_{3}$ & Toluene & 100 & 48 & 0 & 0 \\
\hline 4 & $\begin{array}{l}(R)-\mathrm{Cy} 2 \mathrm{MOP} \\
\mathrm{K}_{2} \mathrm{CO}_{3}\end{array}$ & Toluene & 100 & 48 & 50 & 48 \\
\hline 6 & $\begin{array}{l}(R)-\mathrm{Cy} \text { MOP } \\
(+/-)-\mathrm{BINAP}\end{array}$ & $\mathrm{Cs}_{2} \mathrm{CO}_{3}$ & Toluene & 100 & 48 & 100 & 99 \\
\hline 7 & $\begin{array}{l}\text { S-Phos } \\
\text { precatalyst } \\
\text { complex }\end{array}$ & $\mathrm{Cs}_{3} \mathrm{CO}_{3}$ & Toluene & 100 & 48 & $<10$ & $\mathrm{nd}$ \\
\hline
\end{tabular}

Table 3: Desymmetrization of di-nitrogen malonamides via an intramolecular BuchwaldHartwig reaction to produce $t$-butyl substituted quinolinone ( ${ }^{1}$ H-NMR Conversion determined from the disappearance of $\mathrm{CH}_{2}$ signals in compound 35)

Initially the cyclization of 35 was carried out with $(R)$-MOP using $\mathrm{K}_{3} \mathrm{PO}_{4}$, in THF at $65{ }^{\circ} \mathrm{C}$. Interestingly ${ }^{1} \mathrm{H}-\mathrm{NMR}$ of the crude reaction mixture showed unreacted $\mathbf{3 5}$, the debrominated compound 37, but more importantly only one diastereomer of $t$-butyl substituted quinolinone 36 (Table 3, Trial 1, scheme 48). When the cyclization of 35 was done using $(R)-\mathrm{MOP}^{-} \mathrm{BH}_{3}$ and $\mathrm{K}_{2} \mathrm{CO}_{3}$, with all other reaction parameters kept constant, the same three compounds $\mathbf{3 5}, \mathbf{3 6}$ and 37, were obtained (Table 3, Trial 2, scheme 48). 


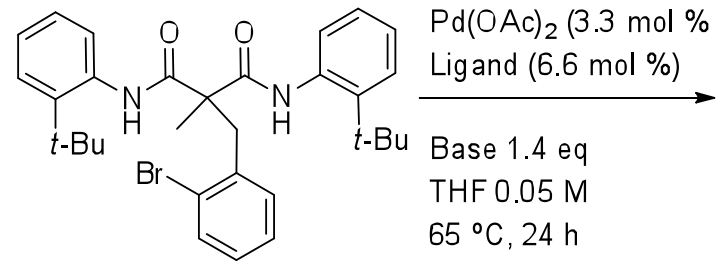

(35)

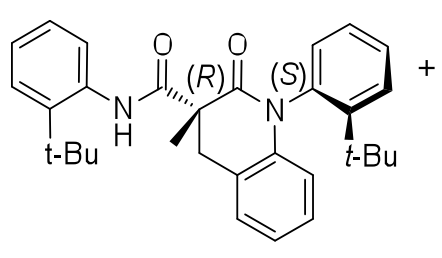

(36)

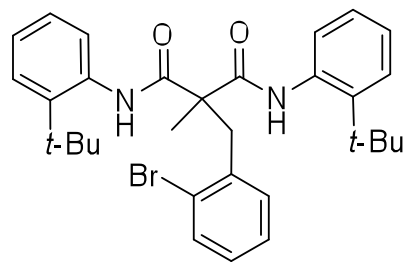

(35)

$27 \%$ using $(R)-\mathrm{MOP}, \mathrm{K}_{3} \mathrm{PO}_{4} \quad 24 \%$ using $(R)-\mathrm{MOP}, \mathrm{K}_{3} \mathrm{PO}_{4}$ $15 \%$ using (R)-MOP$\cdot \mathrm{BH}_{3}, \mathrm{~K}_{2} \mathrm{CO}_{3} \quad 50 \%$ using $(R)-\mathrm{MOP} \cdot \mathrm{BH}_{3}, \mathrm{~K}_{2} \mathrm{CO}_{3}$<smiles>CC(Cc1ccccc1)(C(=O)Nc1ccccc1C(C)(C)C)C(=O)Nc1ccccc1C(C)(C)C</smiles>

(37)

$22 \%$ using $(R)-\mathrm{MOP}, \mathrm{K}_{3} \mathrm{PO}_{4}$ $36 \%$ using $(R)-\mathrm{MOP} \cdot \mathrm{BH}_{3}, \mathrm{~K}_{2} \mathrm{CO}_{3}$

\section{Scheme 48: Initial cross-coupling experiments using $(R)-\mathrm{MOP}$ and $(R)-\mathrm{MOP} \cdot \mathrm{BH}_{3}$}

Cyclization of 35 using (R)-DTBM-SEGPHOS and $\mathrm{K}_{2} \mathrm{CO}_{3}$ in Toluene at $100{ }^{\circ} \mathrm{C}$ resulted in 100 $\%$ unreacted 35 (Table 3, Trial 3), this was an interesting result because even though the desired compound 36 was not produced neither was the undesired debrominated compound 37, indicating that THF may have been the culprit for debromination of the starting material. Amazingly when the cyclization of 35 was carried out using $(R)-\mathrm{Cy}_{2} \mathrm{MOP}$ and $\mathrm{K}_{2} \mathrm{CO}_{3}$ in Toluene at $100{ }^{\circ} \mathrm{C},{ }^{1} \mathrm{H}-\mathrm{NMR}$ of the crude reaction showed $50 \%$ conversion of $\mathbf{3 5}$ to $\mathbf{3 6}$ (Table 3, Trial 4). Furthermore when this same reaction was done using $\mathrm{Cs}_{2} \mathrm{CO}_{3}$ as a base instead of $\mathrm{K}_{2} \mathrm{CO}_{3}$, the reaction proceeded with $100 \%$ conversion of $\mathbf{3 5}$ to $\mathbf{3 6}$ and the crude product was isolated in excellent, $99 \%$, yield (Table 3, Trial 5). The purified compound was recrystallized once from chloroform:cyclohexane $(1: 1)$ and analyzed by x-ray crystallography. The absolute configuration of compound 36 determined by x-ray crystallography is $(R)$ at the chiral centre and $(S)$ at the chiral axis (figure 14). 


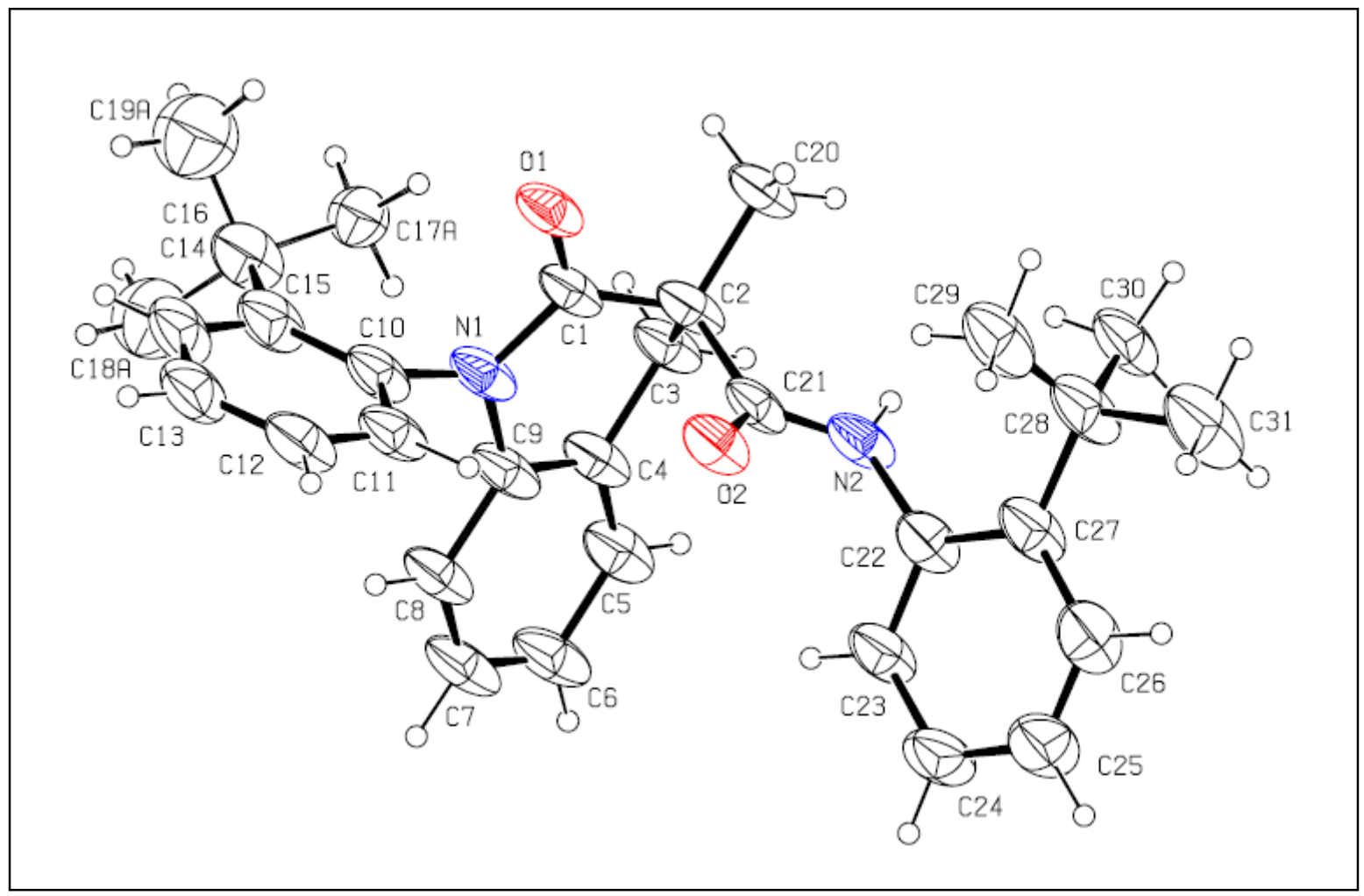

Figure 14: X-ray crystal structure of $t$-butylphenyl substituted quinolinone

In order to obtain racemic $\mathbf{3 6}$ a cross-coupling reaction was set up using racemic BINAP and $\mathrm{Cs}_{2} \mathrm{CO}_{3}$ in Toluene at $100{ }^{\circ} \mathrm{C}$, however this reaction resulted in poor, $<10 \%$ conversion, of compound 35 to 36 (Table 3, Trial 6). Nevertheless racemic 36 was obtained in $99 \%$ yield using the achiral S-Phos precatalyst complex (Table 3, Trial 7, scheme 49). 
<smiles>CC(Cc1ccccc1Br)(C(=O)Nc1ccccc1C(C)(C)C)C(=O)Nc1ccccc1C(C)(C)C</smiles>

(35)
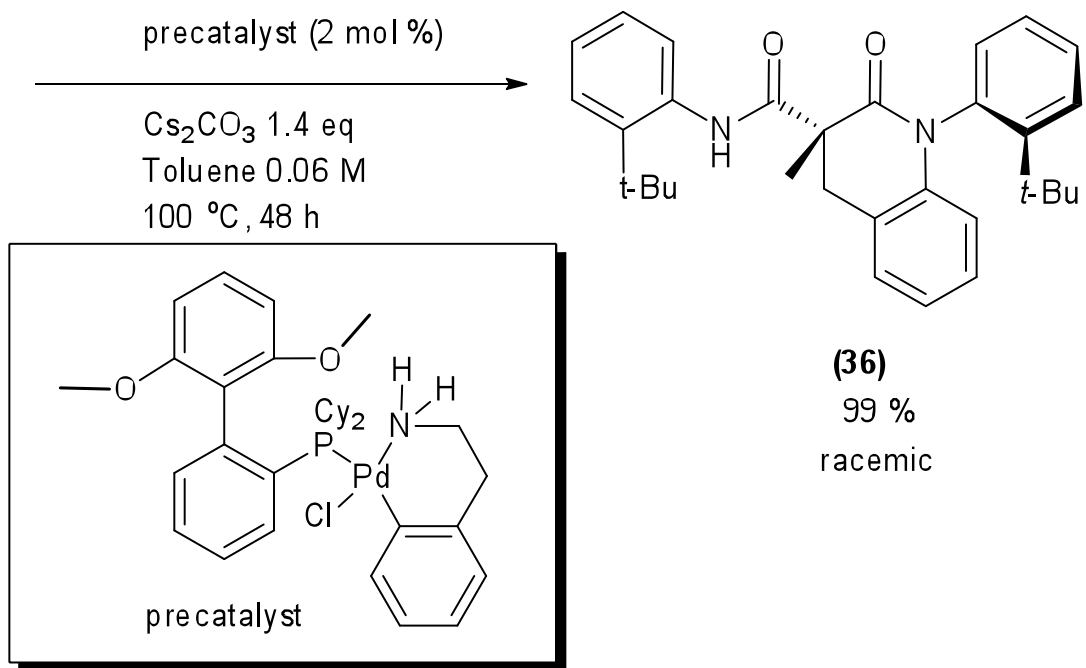

\section{Scheme 49: Synthesis of racemic $t$-butyl quinolinone using an S-PHOS precatalyst}

Interestingly TLC of the crude reaction showed a single spot and ${ }^{1} \mathrm{H}-\mathrm{NMR}$ analysis revealed only a single diastereomer was formed in this reaction. Furthermore it was proved by ${ }^{1} \mathrm{H}-\mathrm{NMR}$ that the diastereomer formed in this reaction is the same diastereomer that is formed when the cyclization of 35 was carried out using $(R)-\mathrm{Cy}_{2} \mathrm{MOP}$. Thus the reaction appears to be diastereoselective even when using an achiral catalyst. Additionally chiral column HPLC analysis of the racemic compound illustrated two peaks in an equal ratio to one another, signifying that the two enantiomers are formed in equal amounts in the absence of a chiral catalyst (figure 15a). Amazingly, chiral column HPLC analysis of compound 36 cyclized with $\mathrm{Cy}_{2} \mathrm{MOP}$ using $\mathrm{Cs}_{2} \mathrm{CO}_{3}$ or $\mathrm{K}_{2} \mathrm{CO}_{3}$ revealed a significant decrease in the peak with a retention time around 10.74 min (Figure $15 \mathrm{~b}$ and c). The ee of compound $\mathbf{3 6}$ cyclized with $\mathrm{Cy}_{2} \mathrm{MOP}$ using $\mathrm{Cs}_{2} \mathrm{CO}_{3}$ or $\mathrm{K}_{2} \mathrm{CO}_{3}$ was calculated to be $88 \%$. Although it is not certain that the crystal structure shown in figure 14 represents the major enantiomer formed in this reaction, there is a $94 \%$ probability that it does since the er (enantiomeric ratio) of compound $\mathbf{3 6}$ cyclized with $\mathrm{Cy}_{2} \mathrm{MOP}$ using $\mathrm{Cs}_{2} \mathrm{CO}_{3}$ or $\mathrm{K}_{2} \mathrm{CO}_{3}$ is $94: 6$. Nevertheless this serves as the first example of its kind whereby 
an enantio- and diastereoselective Buchwald-Hartwig reaction occurs in a single step through preferential $\mathrm{N}$-arylation of prochiral di-nitrogen malonamides.

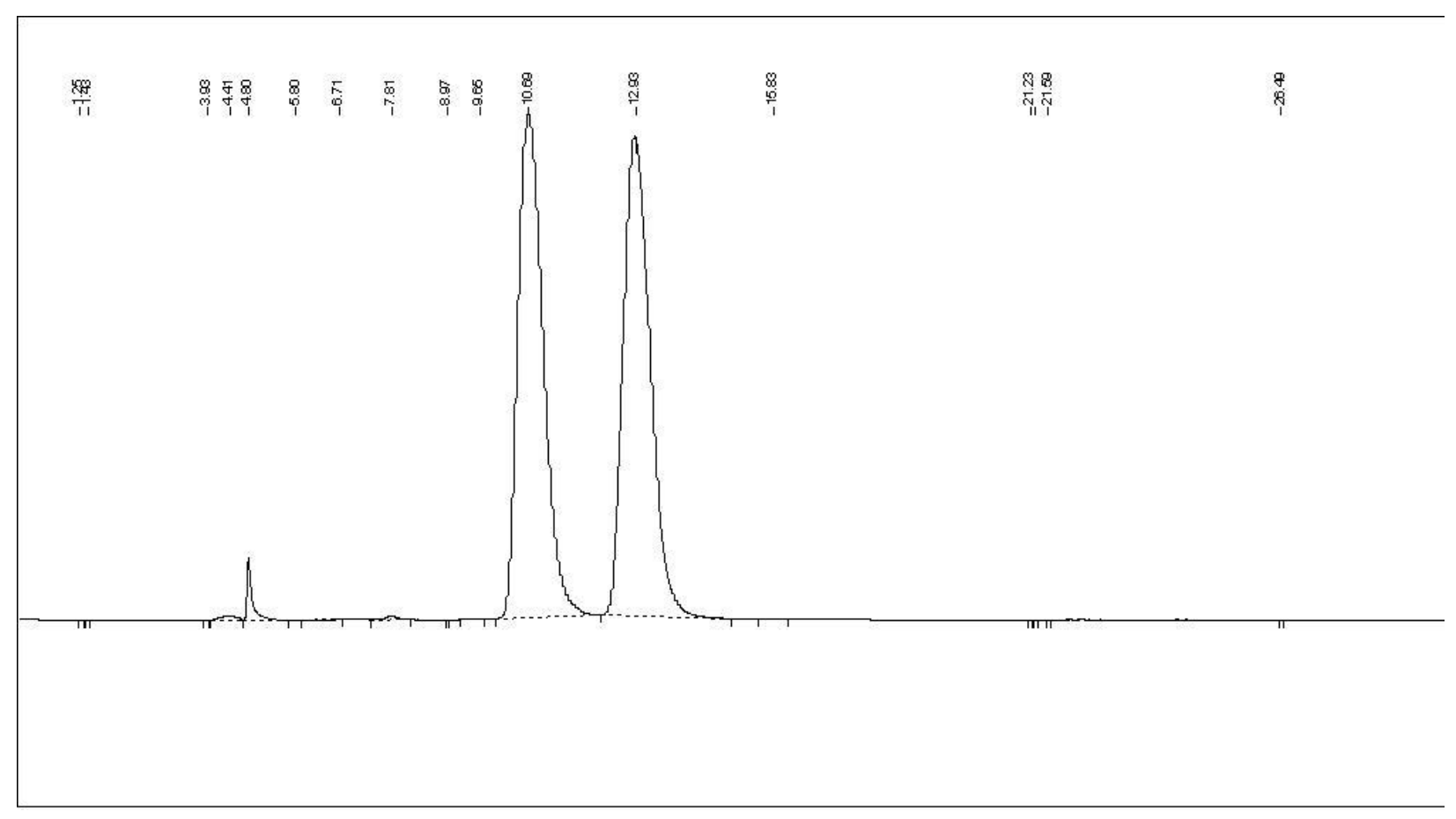

Figure 15a: HPLC chromatogram of racemic compound 36 


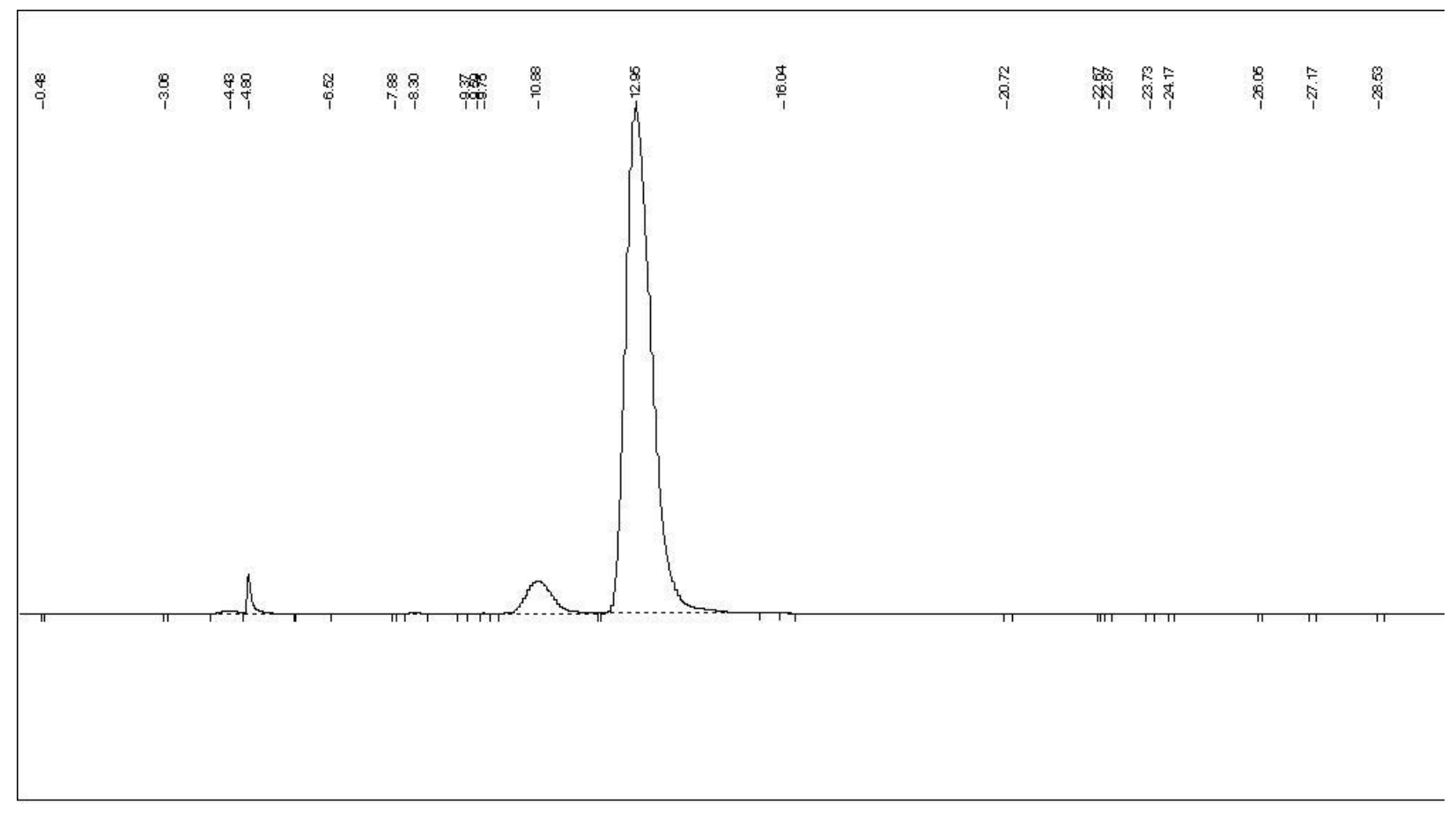

Figure 15b: HPLC chromatogram of compound 36 cyclized with $\mathrm{Cy}_{2} \mathrm{MOP}$ using $\mathrm{Cs}_{2} \mathrm{CO}_{3}$ as a base

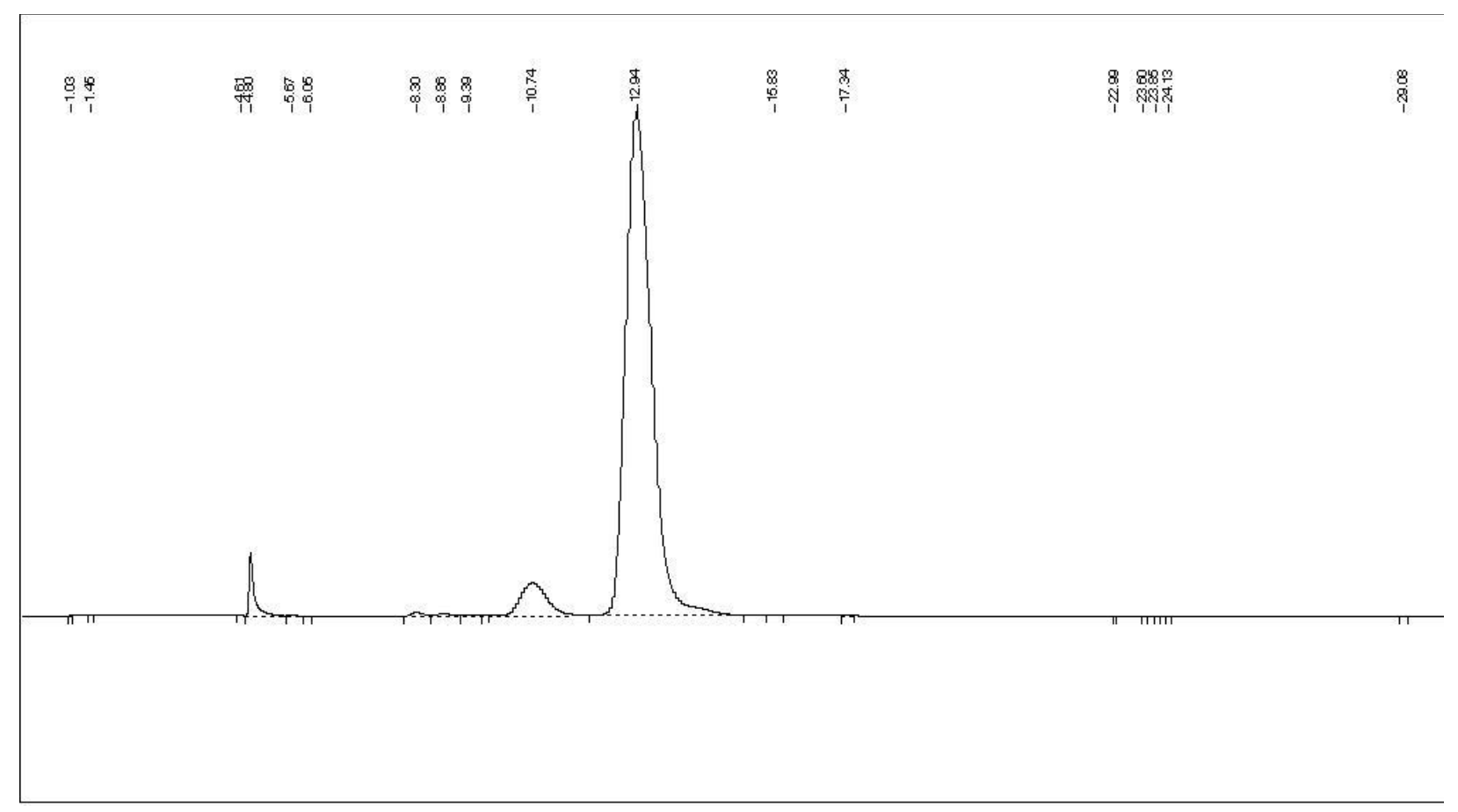

Figure 15c: HPLC chromatogram of compound 36 cyclized with $\mathrm{Cy}_{2} \mathrm{MOP}$ using $\mathrm{K}_{2} \mathrm{CO}_{3}$ as a base 


\subsection{Synthesis of $\mathrm{Cy}_{2} \mathrm{MOP}$}

In order to demonstrate the utility of chiral dialkylbiarylphosphines in the intramolecular desymmetrization of malonamides, a synthetic protocol was carried out to obtain the enantiopure, non-commercially available, ligand 41 ((R)-2(Dicyclohexylphosphino)-2'-methoxy1,1'-binaphthyl) (Scheme 50).

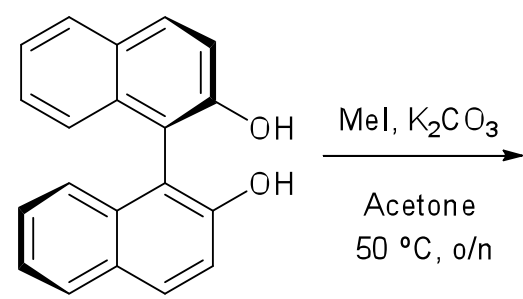

(38)<smiles>COc1ccc2ccccc2c1-c1c(O)ccc2ccccc12</smiles>

(39)

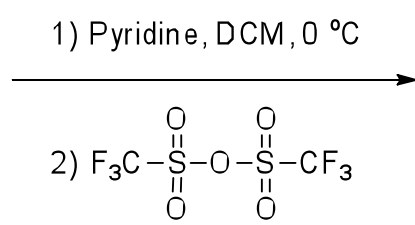

$0{ }^{\circ} \mathrm{C}, 6-8 \mathrm{~h}$<smiles>COc1ccc2ccccc2c1-c1c(OC)ccc2ccccc12</smiles>

(40)<smiles>COc1ccc2ccccc2c1-c1c(OC)ccc2ccccc12</smiles>

(40)

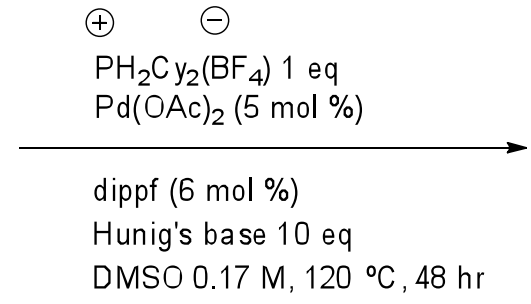

DMSO $0.17 \mathrm{M}, 120^{\circ} \mathrm{C}, 48 \mathrm{hr}$

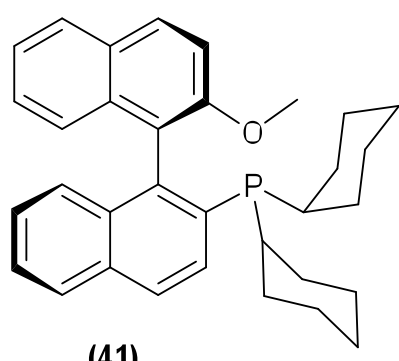

(41)

$56-85 \%$

\section{Scheme 50: Synthesis of (R)-2(Dicyclohexylphosphino)-2'-methoxy-1,1'-binaphthyl)}

The first two steps towards the synthesis of $\mathbf{4 1}$ were performed by Bashar Alkhouri and entailed treating compound 38 (BINOL, commercially available in the enantiopure $(R)$ form) with potassium carbonate in acetone followed by methylation, using iodomethane, which furnished $\mathbf{3 9}$ (Me-BINOL) in high yield (scheme 50). ${ }^{46}$ Next compound 39 was deprotonated using pyridine and reacted with triflic anhydride to produce 40 (Me-BINOL-OTf) in good yield (scheme 50). ${ }^{46}$ The final step was accomplished via a palladium catalyzed cross-coupling reaction between $\mathbf{4 0}$ 
and dicyclohexylphosphonium tetrafluoroborate using palladium/dippf as the catalyst system (scheme 50). This catalyst system was employed due to the successful coupling of aryl bromides/chlorides with secondary phosphines reported by Buchwald and co-workers in $2004 .{ }^{41}$ The reaction worked fairly well and the desired tertiary phosphine was obtained in moderate to high yield. Two factors which increased the yield of $\mathbf{4 1}$ were the use of ten equivalents of Hunig's base as opposed to six equivalents, in order to ensure complete deprotonation of dicyclohexylphosphonium tetrafluoroborate and keeping the reaction solvent, DMSO, under vacuum for one hour followed by purging with argon for another half hour before use.

Initially compound $\mathbf{4 1}$ was utilized in the desymmetrization of $\mathbf{4 5}$ in order to compare the yield and selectivity of this reaction with $(R)$-MOP (Scheme 51). Interestingly the ee of the desired product 46 was identical, $56 \%$ ee when cyclized with $\mathrm{Cy}_{2} \mathrm{MOP}$ or $(R)-\mathrm{MOP}^{47}$, however the yield of compound 46 was somewhat lower, $80 \%$ when cyclized with $\mathrm{Cy}_{2} \mathrm{MOP}$ compared to quantitative when cyclized with $(R)$-MOP. ${ }^{47}$<smiles>CC(Cc1ccccc1Br)(C(=O)NCc1ccccc1)C(=O)NCc1ccccc1</smiles>

(45)

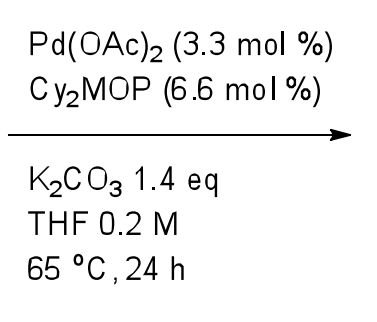

$65^{\circ} \mathrm{C}, 24 \mathrm{~h}$

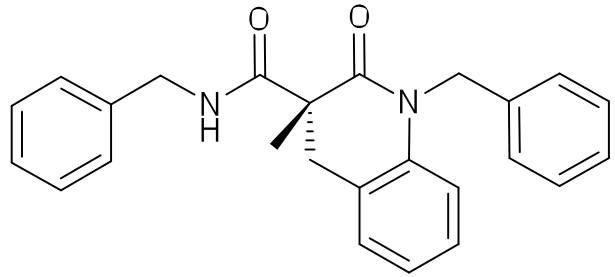

$80 \%, 56 \%$ ee

(46)

\section{Scheme 51: Intramolecular desymmetrization using $\mathrm{Cy}_{2} \mathrm{MOP}$}

Nevertheless compound $\mathbf{4 1}$ was remarkably more air-stable than MOP and showed a substantial increase in activity for the intramolecular palladium catalyzed amidation reaction with other substrates i.e. compounds 20, 31 and $\mathbf{3 5}$. Both $\mathrm{MOP}$ and $\mathrm{Cy}_{2} \mathrm{MOP}$ have an ortho-methoxy group that can act as a hemilabile coordination site with palladium, thus increasing electron density and stability of the palladium center. Replacement of the diphenylphosphino group of MOP with the 
bulkier and more basic dicyclohexylphosphino group probably slows down the rate of oxidative addition and ligand exchange but at the same time speeds up the rate of reductive elimination and thus regeneration of the active catalyst due to the massive steric bulk surrounding palladium. Therefore the acceleration in rate of cross coupling can be attributed to the fact that regeneration of the active catalyst is in fact the rate determining step in this catalytic cycle. ${ }^{19}$

Furthermore complexation of $\mathrm{Cy}_{2} \mathrm{MOP}$ with borane-THF resulted in the desired phosphineborane complex which was easily purified by column chromatography is air-stable and crystalline (scheme 52, Figure 16).

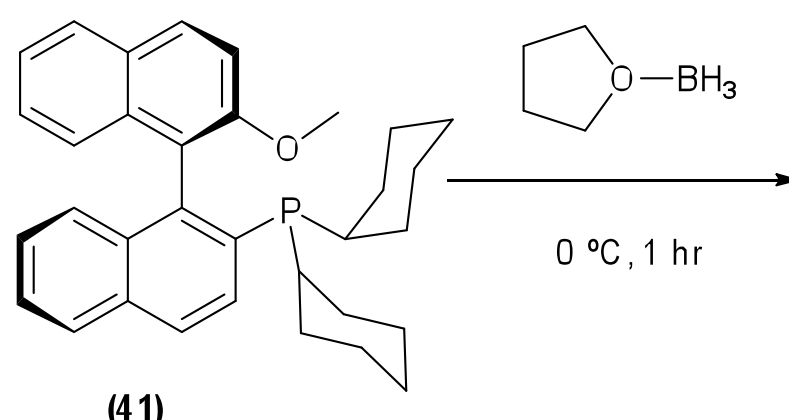

(41)

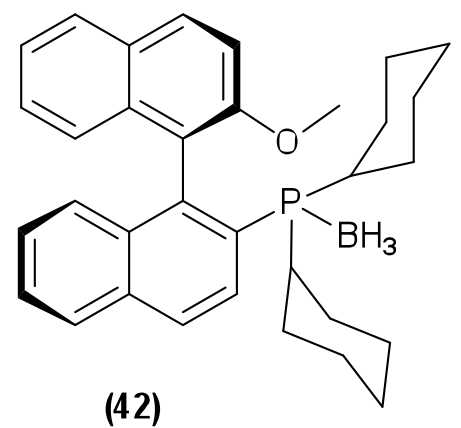

$83 \%$

Scheme 52: Synthesis of $\mathrm{Cy}_{2} \mathrm{MOP} \cdot \mathrm{BH}_{3}$ via complexation with borane-THF 


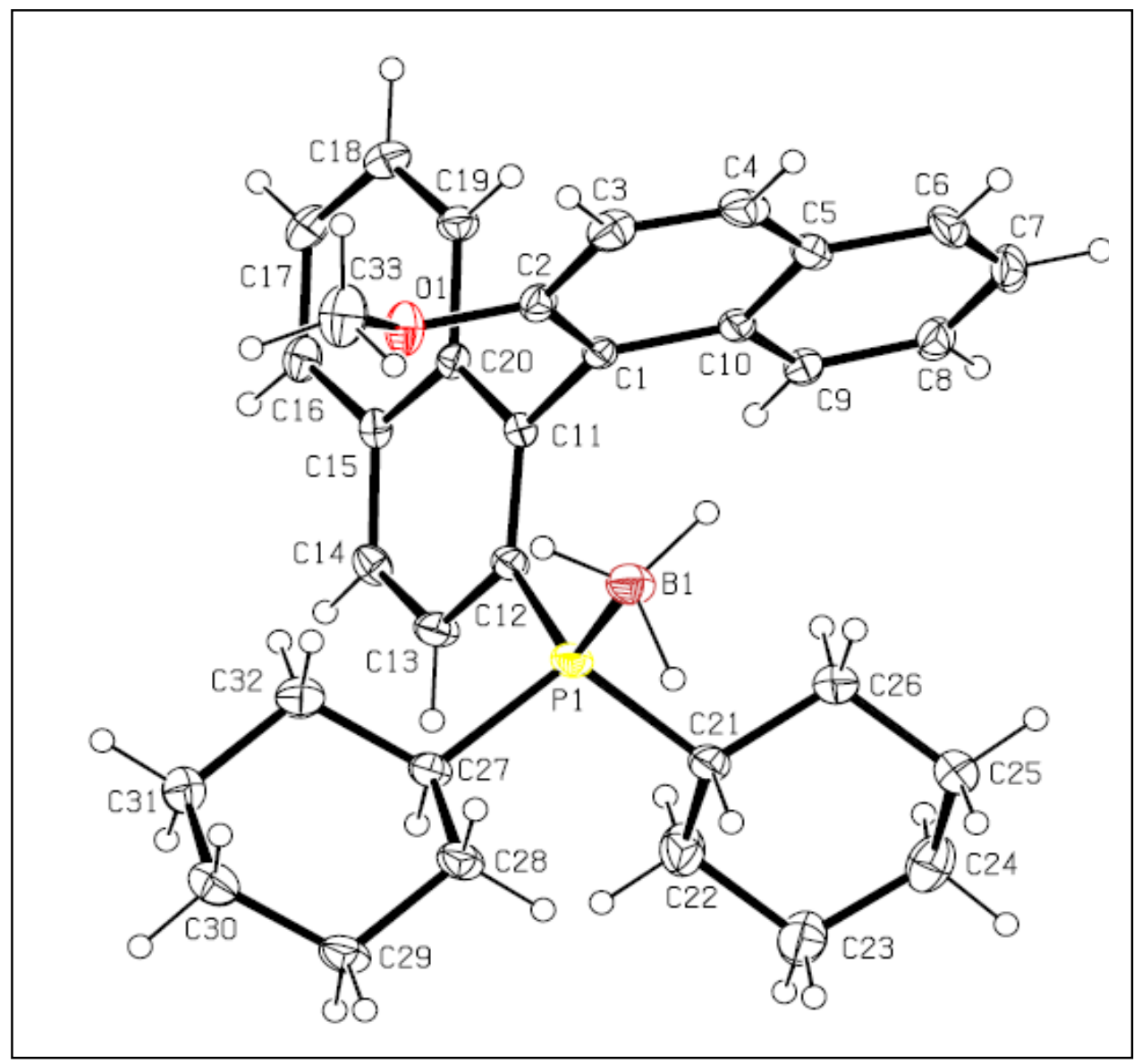

Figure 16: X-ray crystal structure of $\mathrm{Cy}_{2} \mathrm{MOP}^{\mathrm{B}} \mathrm{H}_{3}$

\subsection{Palladium Precatalyst Synthesis}

With compound 41 in hand a palladium precatalyst complex was envisioned which would incorporate an element of chirality into the precatalyst complexes synthesiszed by Buchwald et al. in $2008^{42-43}$ (Figure 17). 


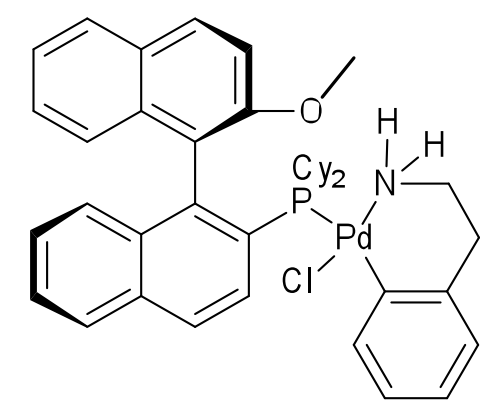

Figure 17: An axially chiral, enantiopure palladium precatalyst

\subsubsection{Palladium Precatalyst Synthesis via orthopalladated complexes}

Initially the synthetic protocol towards these precatalysts was based on a report by Vicente et al in 1997, whereby the authors treated orthopalladated complexes with tertiary phosphines to obtain the desired compound 44 (Figure 18). ${ }^{48}$

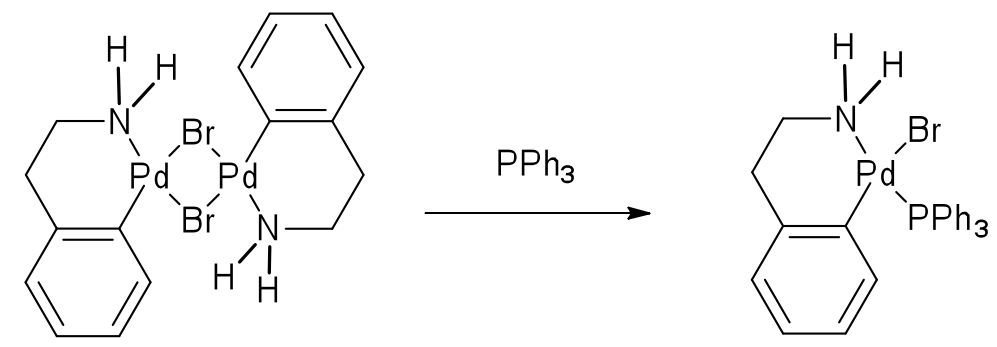

(43)

(44)

Figure 18: Reaction of tertiary phosphines with orthopalladated complexes

Synthesis of compound $\mathbf{4 3}$ was attempted by dissolving $\mathrm{Pd}(\mathrm{OAc})_{2}$ in acetonitrile followed by the addition of phenethylamine. The reaction was heated to $85{ }^{\circ} \mathrm{C}$ and left refluxing for four hours. Next the reaction mixture was filtered through a plug of $\mathrm{MgSO}_{4}$, the solvent was removed and acetone was added followed by the addition of $\mathrm{NaBr}$. The resulting suspension was heated to 85 ${ }^{\circ} \mathrm{C}$ and left stirring overnight at this temperature. After an aqueous work-up, ${ }^{1} \mathrm{H}-\mathrm{NMR}$ analysis of the crude reaction showed a complex mixture of products. Furthermore TLC of the crude material at various different solvent conditions failed to show distinct spots, but rather a large 
smear on the TLC plate (scheme 53). This reaction was repeated twice more however the result was the same.

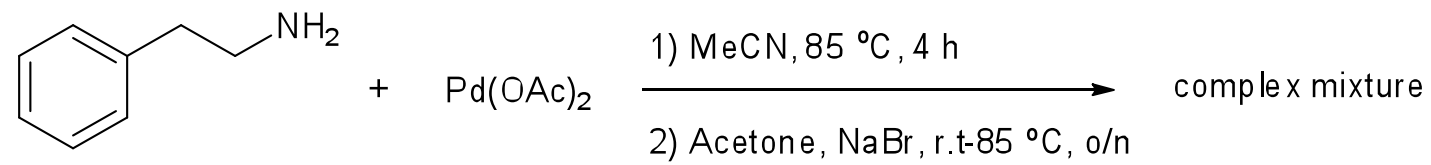

\section{Scheme 53: Attempted orthopalladation of (2-Phenylethyl)amine}

\subsubsection{Palladium Precatalyst Synthesis using Pd(II)Me $\mathrm{Me}_{2} \mathrm{TMEDA}$}

Palladium precatalyst synthesis was also attempted following Buchwald's procedure which entailed reacting the desired phosphine ligand with $\mathrm{Pd}(\mathrm{II}) \mathrm{Me}_{2}$ TMEDA (figure 16). ${ }^{42-43}$

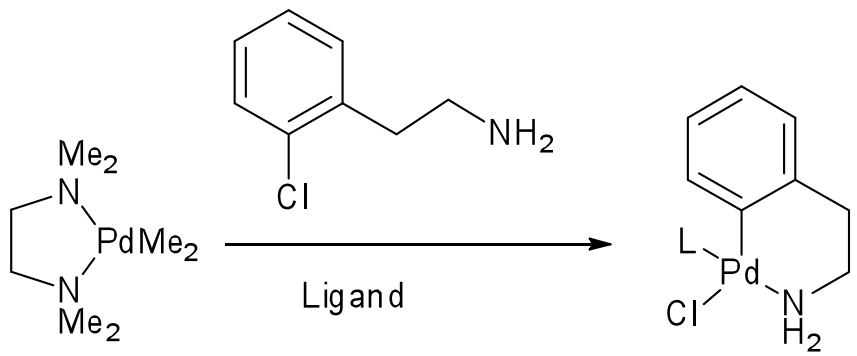

\section{Figure 19: Buchwald's Palladium precatalyst synthesis using Pd(II)Me $\mathrm{M}_{2} \mathrm{TMEDA}$}

Thus in a nitrogen glove box, $\mathrm{Pd}(\mathrm{II}) \mathrm{Me}_{2}$ TMEDA was dissolved in MTBE followed by the addition of 2-chloro(phenylethyl)amine. $\mathrm{Cy}_{2} \mathrm{MOP}$ was then added to the reaction and the mixture was heated to $55{ }^{\circ} \mathrm{C}$ outside the glove box. The reaction was left stirring at this temperature for two hours. Next the reaction mixture was cooled to room temperature, the solvent was removed under reduced pressure and the crude solid was redissolved in MTBE and precipitated out with hexanes. An off-white powder was obtained in $50 \%$ yield however this compound did not appear to be the desired precatalyst by ${ }^{1} \mathrm{H}-\mathrm{NMR}$ or ${ }^{31} \mathrm{P}-\mathrm{NMR}$. In fact there was no methyl peak corresponding to the methoxy group of $\mathrm{Cy}_{2} \mathrm{MOP}$ in the proton spectrum. Furthermore there was 
not enough signal in the alkyl region of the proton spectrum with respect to cyclohexyl groups of $\mathrm{Cy}_{2} \mathrm{MOP}$. Lastly the phosphorus signal for these precatalysts usually show up around $\delta 55-65$, however in this case the phosphorus signal was visible at $\delta 36.0$. Nevertheless a cross coupling reaction was set up to determine if this compound was able to catalyze the intramolecular cyclization reaction (scheme 54).<smiles>CC(Cc1ccccc1Br)(C(=O)NCc1ccccc1)C(=O)NCc1ccccc1</smiles>

(45)

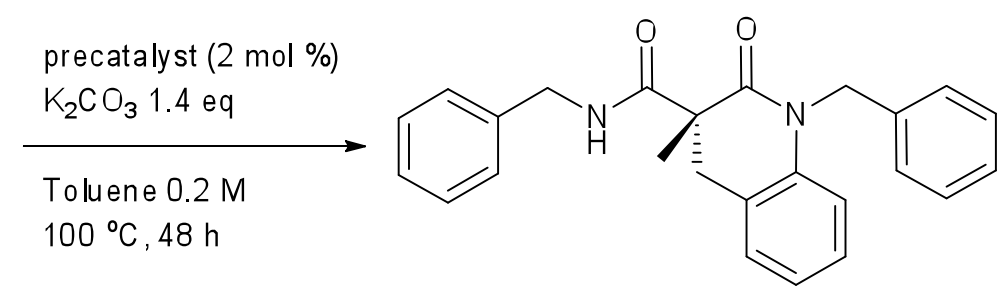

(46)

\section{Scheme 54: Cross coupling reaction using putative $\mathrm{Cy}_{2} \mathrm{MOP}$ precatalyst}

Therefore compound 45, the putative precatalyst and $\mathrm{K}_{2} \mathrm{CO}_{3}$ were added to a Schlenk flask and the flask was evacuated and backfilled with argon. Toluene was added under a stream of argon, the reaction was sealed and heated to $100{ }^{\circ} \mathrm{C}$. The reaction mixture was left stirring at $100{ }^{\circ} \mathrm{C}$ for two days. Analysis of the crude reaction by ${ }^{1} \mathrm{H}$-NMR showed a $40 \%$ conversion of compound 45 to 46 . Thus under these reaction conditions the assumed precatalyst was able to cyclize compound 45. Efforts are underway to recrystallize the presumed precatalyst in order to determine its structure.

Precatalyst synthesis was also attempted with $(R)$-MOP instead of $\mathrm{Cy}_{2} \mathrm{MOP}$ following Buchwald's procedure, ${ }^{42-43}$ i.e. in a nitrogen glove box, $\mathrm{Pd}(\mathrm{II}) \mathrm{Me}_{2}$ TMEDA was dissolved in MTBE followed by the addition of 2-chloro(phenylethyl)amine. (R)-MOP was then added to the reaction and the mixture was heated to $55^{\circ} \mathrm{C}$ outside the glove box. The reaction was left stirring at this temperature for two hours. Next the reaction mixture was cooled to room temperature, the solvent was removed under reduced pressure and the crude solid was redissolved in MTBE and 
precipitated out with hexanes. An orange powder was obtained this time and analysis of this compound by ${ }^{1} \mathrm{H}-\mathrm{NMR}$ and ${ }^{31} \mathrm{P}-\mathrm{NMR}$ revealed the formation of at least three different MOP complexes. In the proton spectrum there were three separate methyl signals corresponding to the methoxy group of $(R)$-MOP in a 1:1:0.5 ratio. Furthermore ${ }^{31}$ P-NMR showed two distinct phosphorus signals at $\delta 28.6$ and -13.8 respectively, neither of which correspond to the precatalyst or the free phosphine. Since this reaction was done on a small scale (50 mg w.r.t. $(R)-$ MOP) no attempt was made to purify the crude product. Nonetheless a cross coupling reaction was set up to determine if this crude material would be able to catalyze the cyclization of compound 45 to 46 (scheme 55).<smiles>Cc1ccccc1N(Cc1ccccc1)C(=O)[C@H](C)C(=O)NCc1ccc(I)cc1</smiles>

\section{Scheme 55: Cross coupling reaction using putative $(R)$-MOP precatalyst}

Thus compound 45, the putative ( $R$ )-MOP precatalyst and $\mathrm{K}_{2} \mathrm{CO}_{3}$ were added to a Schlenk flask and the flask was evacuated and backfilled with argon. Toluene was added under a stream of argon, the reaction was sealed and heated to $100{ }^{\circ} \mathrm{C}$. The reaction mixture was left stirring at 100 ${ }^{\circ} \mathrm{C}$ for two days. However analysis of the crude reaction by ${ }^{1} \mathrm{H}-\mathrm{NMR}$ showed $<10 \%$ conversion of compound 45 to $\mathbf{4 6}$. Thus under these reaction conditions the assumed precatalyst was not effective in the cyclization of compound $\mathbf{4 5}$.

Palladium precatalyst synthesis was attempted one last time with $\mathrm{Cy}_{2} \mathrm{MOP}$ following Buchwald's procedure. ${ }^{42-43}$ All the reaction parameters were kept constant and interestingly a 
different result was obtained. Again an off-white powder was obtained in $50 \%$ yield however ${ }^{1} \mathrm{H}-\mathrm{NMR}$ of this compound looked more encouraging than the first time this reaction was attempted. There was indeed enough signal in the aliphatic region of the proton spectrum, corresponding to the cyclohexyl groups of $\mathrm{Cy}_{2} \mathrm{MOP}$, and these signals were in the appropriate region i.e. between $\delta 1-2$, for the precatalyst complex. Oddly though there was no methyl signal for the methoxy group of $\mathrm{Cy}_{2} \mathrm{MOP}$. Also there was no phosphorus signal in the ${ }^{31} \mathrm{P}-\mathrm{NMR}$ spectrum. Nevertheless a cross coupling reaction was carried out with this compound but unlike in the first case there was no conversion of compound $\mathbf{4 5}$ to $\mathbf{4 6}$ (scheme 56).<smiles>CC(Cc1ccccc1Br)(C(=O)NCc1ccccc1)C(=O)NCc1ccccc1</smiles>

(45)<smiles>Cc1ccccc1N(Cc1ccccc1)C(=O)[C@](C)(C(=O)NCc1ccccc1)C(=O)O[Mg]</smiles>

(46)

\section{Scheme 56: Cross coupling reaction using another putative precatalyst}

This suggests that there may not be a palladium atom present which consequently does not allow the reaction to occur. Efforts are also underway to recrystallize this compound in order to determine its structure. 


\section{Experimental}

\subsection{General Considerations}

All reagents unless otherwise noted were purchased from SIGMA-ALDRICH.

(R)-MOP was purchased from STREM CHEMICAL COMPANY. ${ }^{1} \mathrm{H},{ }^{13} \mathrm{C},{ }^{11} \mathrm{~B}$, and ${ }^{31} \mathrm{P}-\mathrm{NMR}$ spectra were recorded on a $400 \mathrm{MHz}$ Bruker Avance II-400 Spectrometer (Ryerson University). High-performance liquid chromatography (HPLC) analysis was performed with a $25 \times 0.4 \mathrm{~cm}$ i.d. CHIRALCEL-OD-H column with a UV-detector.

\subsection{Towards the Synthesis of Oxindole Heterocycles}

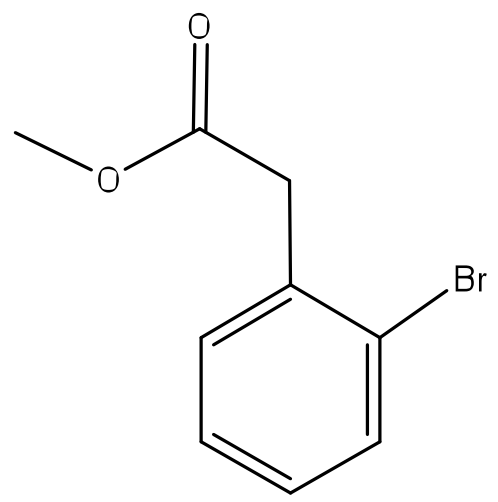

Methyl 2-(2-bromophenyl)acetate (5): 2-(2-bromophenyl)acetic acid (12.0 g, $55.8 \mathrm{mmol})$ was dissolved in methanol $(200 \mathrm{~mL})$. Several drops of $\mathrm{H}_{2} \mathrm{SO}_{4}$ were added and the mixture was heated to $85{ }^{\circ} \mathrm{C}$ and left refluxing for three hours. The reaction mixture was diluted with diethyl ether $(600 \mathrm{~mL})$ and extracted with $0.1 \mathrm{M} \mathrm{HCl}$, saturated $\mathrm{NaHCO}_{3}$, and brine. The organic phase was dried over $\mathrm{Na}_{2} \mathrm{SO}_{4}$ and evaporated under reduced pressure to afford methyl 2-(2bromophenyl)acetate, compound 5 (12.1 g, 95\%) as an opaque oil. This compound was used without further purification. $\mathrm{R}_{\mathrm{f}}=0.45\left(\mathrm{SiO}_{2}, 5 \%\right.$ EtOAc:Hexanes); ${ }^{1} \mathrm{H}-\mathrm{NMR}\left(\mathrm{CDCl}_{3}, 400\right.$ $\mathrm{MHz}): \delta 7.55\left(\mathrm{~d}, J=7.9 \mathrm{~Hz}, 1 \mathrm{H}, \mathrm{C}_{6} \mathrm{H}_{4}\right), 7.29-7.23\left(\mathrm{~m}, 2 \mathrm{H}, \mathrm{C}_{6} \mathrm{H}_{4}\right), 7.16-7.08\left(\mathrm{~m}, 1 \mathrm{H}, \mathrm{C}_{6} \mathrm{H}_{4}\right), 3.79$ 
(s, $\left.2 \mathrm{H}, \mathrm{CH}_{2}\right), 3.69$ (s, 3H, $\left.\mathrm{CH}_{3}\right) .{ }^{13} \mathrm{C}-\mathrm{NMR}\left(\mathrm{CDCl}_{3}, 400 \mathrm{MHz}\right): \delta 170.8,134.2,132.8,131.5$, $128.9,127.5,124.9,52.1,41.5$.

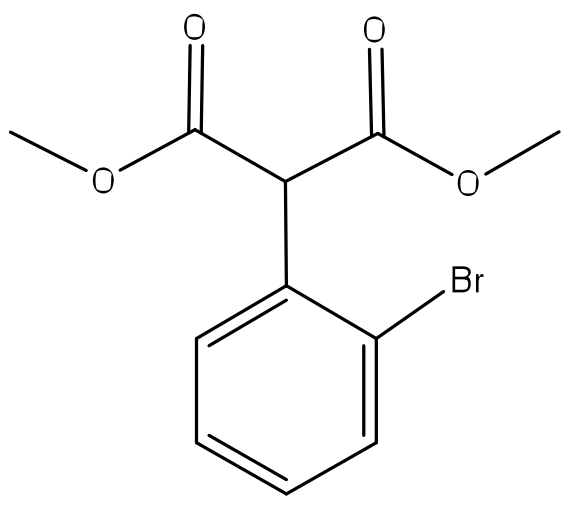

Dimethyl 2-(2-bromophenyl)malonate (6): To a solution of methyl 2-(2-bromophenyl)acetate, compound 5, $(5 \mathrm{~g}, 21.8 \mathrm{mmol})$ in dimethyl carbonate $(40 \mathrm{~mL})$ was added sodium hydride $(2.62 \mathrm{~g}$, $65.4 \mathrm{mmol})$ at $0{ }^{\circ} \mathrm{C}$. The mixture was left stirring overnight at room temperature. The reaction mixture was quenched with saturated ammonium chloride and extracted three times with ethyl acetate. The organic phase was dried over $\mathrm{Na}_{2} \mathrm{SO}_{4}$ and concentrated under reduced pressure. The crude product was purified via flash chromatography eluting with $5 \%$ EtOAc:Hexanes to afford Dimethyl 2-(2-bromophenyl)malonate compound 6 in $85 \%$ yield as a white solid. Melting point: $41-42{ }^{\circ} \mathrm{C} ; \mathrm{R}_{\mathrm{f}}=0.35\left(\mathrm{SiO}_{2}, 5 \%\right.$ EtOAc:Hexanes); ${ }^{1} \mathrm{H}-\mathrm{NMR}\left(\mathrm{CDCl}_{3}, 400 \mathrm{MHz}\right): \delta 7.59$ (dd, $J_{1}=$ $\left.8.0 \mathrm{~Hz}, J_{2}=1.3 \mathrm{~Hz}, 1 \mathrm{H}, \mathrm{C}_{6} \mathrm{H}_{4}\right), 7.47\left(\mathrm{dd}, J_{1}=7.8 \mathrm{~Hz}, J_{2}=1.7 \mathrm{~Hz}, 1 \mathrm{H}, \mathrm{C}_{6} \mathrm{H}_{4}\right), 7.33\left(\operatorname{td}, J_{1}=7.6\right.$ $\left.\mathrm{Hz}, J_{2}=1.3,1 \mathrm{H}, \mathrm{C}_{6} \mathrm{H}_{4}\right), 7.19\left(\mathrm{td}, J_{1}=7.9 \mathrm{~Hz}, J_{2}=1.7,1 \mathrm{H}, \mathrm{C}_{6} \mathrm{H}_{4}\right), 3.78\left(\mathrm{~s}, 6 \mathrm{H}, \mathrm{CH}_{3}\right) .{ }^{13} \mathrm{C}-\mathrm{NMR}$ $\left(\mathrm{CDCl}_{3}, 400 \mathrm{MHz}\right): \delta 168.1,132.9,132.7,130.3,129.8,127.8,125.0,56.8,53.0$. 


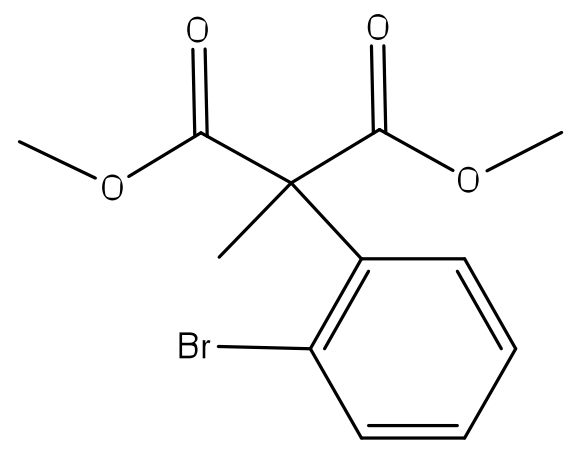

Dimethyl 2-(2-bromophenyl)-2-methylmalonate (7): Method A: A round bottom flask was charged with sodium hydride, $60 \%$ dispersion in mineral oil, (194.9 $\mathrm{mg}, 4.87 \mathrm{mmol})$. The hydride was washed twice with anhydrous hexanes $(5 \mathrm{~mL})$ and suspended in anhydrous THF $(6.7 \mathrm{~mL})$. A solution of dimethyl 2-(2-bromophenyl)malonate, compound $\mathbf{6},(1 \mathrm{~g}, 3.48 \mathrm{mmol})$ in THF $(2 \mathrm{~mL})$ was added to the rapidly stirring sodium hydride suspension at $0{ }^{\circ} \mathrm{C}$. The reaction mixture was allowed to warm to room temperature. Once gas evolution had ceased, iodomethane $(0.3 \mathrm{~mL}, 4.87 \mathrm{mmol})$ was added, the mixture was heated to $70{ }^{\circ} \mathrm{C}$ and left refluxing overnight. The reaction mixture was quenched with saturated ammonium chloride $(10 \mathrm{~mL})$ and extracted with ethyl acetate $(3 \times 20 \mathrm{~mL})$. The organic phase was dried over $\mathrm{Na}_{2} \mathrm{SO}_{4}$ and concentrated under reduced pressure. The crude product was purified via column chromatography eluting with $5 \%$ EtOAc:Hexanes to afford dimethyl 2-(2-bromophenyl)-2-methylmalonate, compound 7 (856.7 $\mathrm{mg}, 82 \%)$ as a colorless oil.

Dimethyl 2-(2-bromophenyl)-2-methylmalonate (7): Method B: A round bottom flask was charged with sodium hydride, $60 \%$ dispersion in mineral oil (1.304 g, $32.6 \mathrm{mmol})$. The hydride was washed twice with anhydrous hexanes $(10 \mathrm{~mL})$ and suspended in anhydrous THF $(43 \mathrm{~mL})$. A solution of dimethyl 2-(2-bromophenyl)malonate, compound 6, $(6.547 \mathrm{~g}, 23.3 \mathrm{mmol})$ in THF $(15.2 \mathrm{~mL})$ was added to the rapidly stirring sodium hydride suspension at $0{ }^{\circ} \mathrm{C}$. The reaction mixture was allowed to warm to room temperature, once gas evolution had ceased dimethyl 
sulfate $(3.09 \mathrm{~mL}, 32.6 \mathrm{mmol})$ was added, the reaction was heated to $70{ }^{\circ} \mathrm{C}$ and left refluxing overnight. The reaction mixture was quenched with saturated ammonium chloride and extracted three times with ethyl acetate. The organic phase was dried over $\mathrm{Na}_{2} \mathrm{SO}_{4}$ and concentrated under reduced pressure. The crude product was purified via column chromatography eluting with $5 \%$ EtOAc:Hexanes to afford dimethyl 2-(2-bromophenyl)-2-methylmalonate, compound 7 (6.663 g, $95 \%)$ as a colorless oil. $\mathrm{R}_{\mathrm{f}}=0.25\left(\mathrm{SiO}_{2}, 5 \%\right.$ EtOAc:Hexanes $) ;{ }^{1} \mathrm{H}-\mathrm{NMR}\left(\mathrm{CDCl}_{3}, 400 \mathrm{MHz}\right): \delta$ $7.60\left(\mathrm{dd}, J_{1}=7.9 \mathrm{~Hz}, J_{2}=1.3 \mathrm{~Hz}, 1 \mathrm{H}, \mathrm{C}_{6} \mathrm{H}_{4}\right), 7.29\left(\mathrm{td}, J_{1}=7.7 \mathrm{~Hz}, J_{2}=1.4,1 \mathrm{H}, \mathrm{C}_{6} \mathrm{H}_{4}\right), 7.16(\mathrm{td}$, $\left.J_{1}=7.8 \mathrm{~Hz}, J_{2}=1.6 \mathrm{~Hz}, 1 \mathrm{H}, \mathrm{C}_{6} \mathrm{H}_{4}\right), 7.11\left(\mathrm{dd}, J_{1}=7.8 \mathrm{~Hz}, J_{2}=1.6 \mathrm{~Hz}, 1 \mathrm{H}, \mathrm{C}_{6} \mathrm{H}_{4}\right), 3.77(\mathrm{~s}, 6 \mathrm{H}$, $\left.\mathrm{CH}_{3}\right), 1.91\left(\mathrm{~s}, 3 \mathrm{H}, \mathrm{CH}_{3}\right) .{ }^{13} \mathrm{C}-\mathrm{NMR}\left(\mathrm{CDCl}_{3}, 400 \mathrm{MHz}\right): \delta$ 171.0, 139.0, 134.4, 128.8, 128.6, $127.4,123.2,61.1,52.2,21.3$.

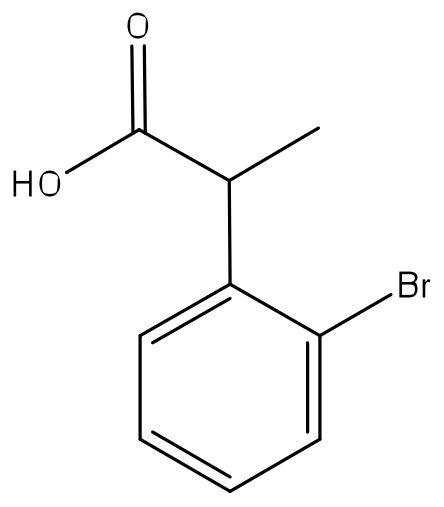

2-(2-bromophenyl)propanoic acid (8): Dimethyl 2-(2-bromophenyl)-2-methylmalonate, compound 7, $(619.3 \mathrm{mg}, 2.057 \mathrm{mmol})$ was dissolved in methanol $(2.5 \mathrm{~mL})$ followed by the addition of $4 \mathrm{M} \mathrm{NaOH}(2.5 \mathrm{~mL})$. The reaction was refluxed overnight. The reaction mixture was cooled to room temperature, diluted with water $(10 \mathrm{~mL})$ and extracted with ether $(10 \mathrm{~mL})$. The aqueous phase was acidified via slow dropwise addition of $6 \mathrm{M} \mathrm{HCl}$ and extracted with $\mathrm{CH}_{2} \mathrm{Cl}_{2}$ $(3 \times 15 \mathrm{~mL})$. The combined organic phases were dried over $\mathrm{MgSO}_{4}$, filtered and evaporated 
under reduced pressure to afford 2-(2-bromophenyl)propanoic acid, compound 8 (417.8 $\mathrm{mg}, 75$ $\%)$ as a white solid which did not require further purification. Melting point: $95-96{ }^{\circ} \mathrm{C} ;{ }^{1} \mathrm{H}-\mathrm{NMR}$ $\left(\left(\mathrm{CD}_{2}\right)_{3} \mathrm{O}, 400 \mathrm{MHz}\right): \delta 7.61\left(\mathrm{dd}, J_{1}=8.1 \mathrm{~Hz}, J_{2}=1.3 \mathrm{~Hz}, 1 \mathrm{H}, \mathrm{C}_{6} \mathrm{H}_{4}\right), 7.43-7.34\left(\mathrm{~m}, 2 \mathrm{H}, \mathrm{C}_{6} \mathrm{H}_{4}\right)$, 7.22-7.16 (m, 1H, $\left.\mathrm{C}_{6} \mathrm{H}_{4}\right), 4.21(\mathrm{q}, J=7.2 \mathrm{~Hz}, 1 \mathrm{H}, \mathrm{CH}), 1.45\left(\mathrm{~d}, J=7.2 \mathrm{~Hz}, 3 \mathrm{H}, \mathrm{CH}_{3}\right) .{ }^{13} \mathrm{C}-\mathrm{NMR}$ $\left(\left(\mathrm{CD}_{2}\right)_{3} \mathrm{O}, 400 \mathrm{MHz}\right): \delta 205.6,174.0,140.7,132.8,128.7,128.0,124.0,44.3,17.3$.

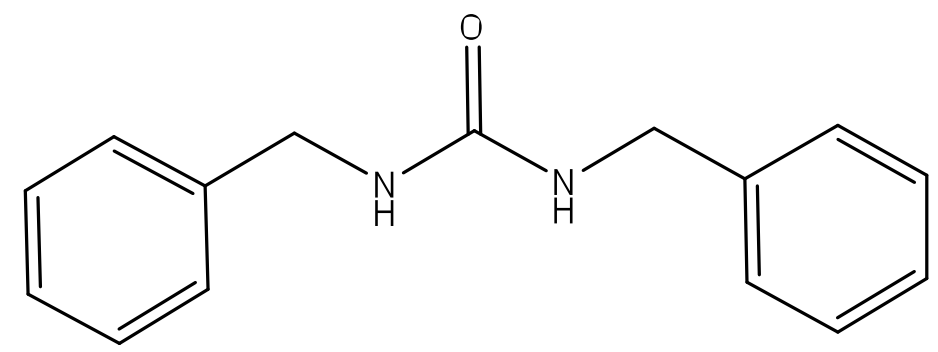

Dibenzylurea (15): Benzylamine $(5.5 \mathrm{~mL}, 50 \mathrm{mmol})$ was dissolved in $104 \mathrm{~mL}$ of dichloromethane and cooled in an ice bath. Next 1,1'-carbonyldiimidazole (4.05 g, $25 \mathrm{mmol})$ was dissolved in $125 \mathrm{~mL}$ of dichloromethane and added dropwise to the ice cold benzylamine solution. The reaction was left stirring overnight at room temperature. The reaction mixture was diluted with dichloromethane and extracted three times with $0.1 \mathrm{M} \mathrm{HCl}$. The crude product was dried over $\mathrm{MgSO}_{4}$, filtered and evaporated under reduced pressure to afford dibenzylurea, compound $15,(5.17 \mathrm{~g}, 86 \%)$ as a white solid which was used without further purification. ${ }^{1} \mathrm{H}-$ NMR $\left(\mathrm{CDCl}_{3}, 400 \mathrm{MHz}\right): \delta 7.35-7.20\left(\mathrm{~m}, 10 \mathrm{H}, \mathrm{C}_{6} \mathrm{H}_{5}\right), 4.76(\mathrm{~s}, 2 \mathrm{H}, \mathrm{NH}), 4.36\left(\mathrm{~d}, J_{1}=5.8 \mathrm{~Hz}\right.$, $\left.4 \mathrm{H}, \mathrm{CH}_{2}\right)$. 


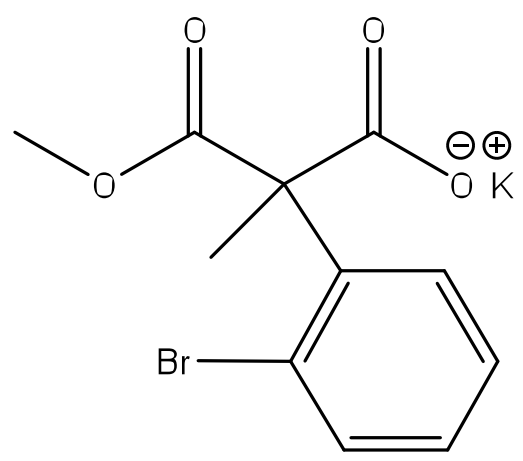

potassium 2-(2-bromophenyl)-3-methoxy-2-methyl-3-oxopropanoate (18): Dimethyl 2-(2bromophenyl)-2-methylmalonate, compound 7, (150 $\mathrm{mg}, 0.5 \mathrm{mmol})$ was dissolved in methanol $(0.8 \mathrm{~mL})$ followed by the addition of $4 \mathrm{M} \mathrm{KOH}(0.3 \mathrm{~mL})$. The reaction was left stirring overnight at room temperature. The crude reaction mixture was evaporated to dryness under reduced pressure and stored under vacuum overnight to afford compound $\mathbf{1 8}(276.4 \mathrm{mg}, 85 \%)$ as a white solid which was used without further purification. ${ }^{1} \mathrm{H}-\mathrm{NMR}\left(\mathrm{D}_{2} \mathrm{O}, 400 \mathrm{MHz}\right): \delta 7.65(\mathrm{~d}, J=8.2$ $\left.\mathrm{Hz}, 1 \mathrm{H}, \mathrm{C}_{6} \mathrm{H}_{4}\right), 7.39-7.34\left(\mathrm{~m}, 2 \mathrm{H}, \mathrm{C}_{6} \mathrm{H}_{4}\right), 7.22-7.19\left(\mathrm{~m}, 1 \mathrm{H}, \mathrm{C}_{6} \mathrm{H}_{4}\right), 3.70\left(\mathrm{~s}, 3 \mathrm{H}, \mathrm{CH}_{3}\right), 1.82(\mathrm{~s}$, $\left.3 \mathrm{H}, \mathrm{CH}_{3}\right)$. 


\subsection{Towards the Synthesis of Benzomorpholinone Heterocycles}

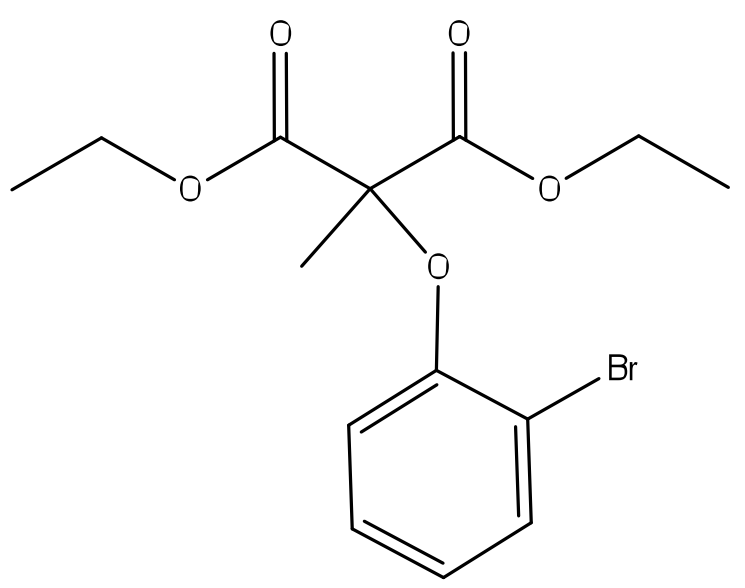

Diethyl 2-(2-bromophenoxy)-2-methylmalonate (22): Under an atmosphere of argon, 2bromophenol (1.62 mL, $15.3 \mathrm{mmol})$ was dissolved in DMF $(250 \mathrm{~mL})$ followed by the addition of $t$-BuOK (1.545 g, $13.8 \mathrm{mmol})$. The reaction mixture was stirred for 30 minutes at room temperature before the addition of diethyl 2-bromo-2-methylmalonate $(2.77 \mathrm{~mL}, 14.5 \mathrm{mmol})$ at room temperature. The reaction was left stirring for 16 hours at room temperature. The reaction was diluted with EtOAc $(500 \mathrm{~mL})$ washed with water $(5 \times 250 \mathrm{~mL})$ and $1 \mathrm{M} \mathrm{NaOH}(100 \mathrm{~mL})$. The organic layer was dried over $\mathrm{MgSO}_{4}$ and evaporated under reduced pressure to afford diethyl 2-(2-bromophenoxy)-2-methylmalonate 22 as an orange oil (3.277 g, $66 \%$ ) which was used without further purification. $\mathrm{R}_{\mathrm{f}}=0.80\left(\mathrm{SiO}_{2}, 25 \%\right.$ EtOAc:Hexanes $) ;{ }^{1} \mathrm{H}-\mathrm{NMR}\left(\mathrm{CDCl}_{3}, 400\right.$ MHz): $\delta 7.55\left(\mathrm{dd}, J_{1}=7.9 \mathrm{~Hz}, J_{2}=1.6 \mathrm{~Hz}, 1 \mathrm{H}, \mathrm{C}_{6} \mathrm{H}_{4}\right), 7.21-7.15\left(\mathrm{~m}, 1 \mathrm{H}, \mathrm{C}_{6} \mathrm{H}_{4}\right), 7.07\left(\mathrm{dd}, J_{1}=\right.$ $\left.8.2 \mathrm{~Hz}, J_{2}=1.5 \mathrm{~Hz}, 1 \mathrm{H}, \mathrm{C}_{6} \mathrm{H}_{4}\right), 6.96-6.90\left(\mathrm{~m}, 1 \mathrm{H}, \mathrm{C}_{6} \mathrm{H}_{4}\right), 4.29\left(\mathrm{q}, J=7.1 \mathrm{~Hz}, 4 \mathrm{H}, \mathrm{CH}_{2}\right), 1.73(\mathrm{~s}$, $\left.3 \mathrm{H}, \mathrm{CH}_{3}\right), 1.30-1.24\left(\mathrm{~m}, 6 \mathrm{H}, \mathrm{CH}_{3}\right) .{ }^{13} \mathrm{C}-\mathrm{NMR}\left(\mathrm{CDCl}_{3}, 400 \mathrm{MHz}\right): \delta 168.5,151.9,133.5,128.0$, $124.8,120.7,116.8,83.9,62.4,20.3,14.0$. 


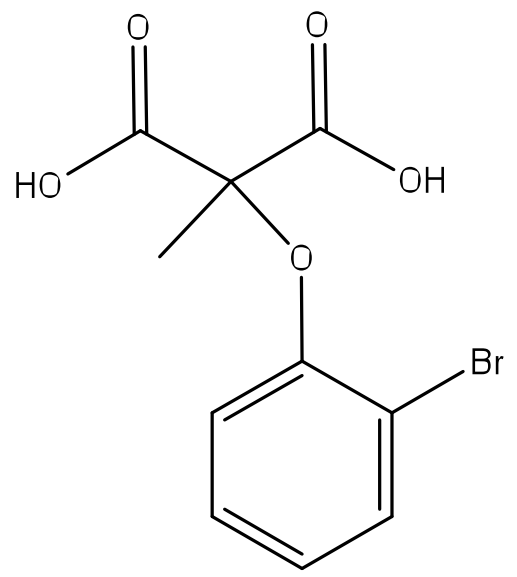

2-(2-bromophenoxy)-2-methylmalonic acid (23): Diethyl 2-(2-bromophenoxy)-2methylmalonate $22(1.000 \mathrm{~g}, 2.70 \mathrm{mmol})$ was dissolved in methanol $(8.1 \mathrm{~mL})$ followed by the addition of $4 \mathrm{M} \mathrm{NaOH}(2.70 \mathrm{~mL})$. The reaction was left stirring overnight at room temperature. The reaction mixture was diluted with water $(20 \mathrm{~mL})$ and extracted with ether $(20 \mathrm{~mL})$. The aqueous phase was acidified via slow dropwise addition of a $\mathrm{pH} 3$ phosphate buffer and extracted with $\mathrm{CH}_{2} \mathrm{Cl}_{2}(3 \times 30 \mathrm{~mL})$. The combined organic phases were dried over $\mathrm{MgSO}_{4}$, filtered and evaporated under reduced pressure to afford 2-(2-bromophenoxy)-2-methylmalonic acid 23 as an opaque solid (507.3 $\mathrm{mg}, 80 \%$ ) which was used without further purification. Melting point: $95-97{ }^{\circ} \mathrm{C} ;{ }^{1} \mathrm{H}-\mathrm{NMR}\left(\mathrm{CDCl}_{3}, 400 \mathrm{MHz}\right): \delta 7.59\left(\mathrm{dd}, J_{1}=7.9 \mathrm{~Hz}, J_{2}=1.6 \mathrm{~Hz}, 1 \mathrm{H}\right.$, $\left.\mathrm{C}_{6} \mathrm{H}_{4}\right), 7.29-7.23\left(\mathrm{~m}, 1 \mathrm{H}, \mathrm{C}_{6} \mathrm{H}_{4}\right), 7.19(\mathrm{~s}, 2 \mathrm{H}, \mathrm{OH}), 7.05-6.98\left(\mathrm{~m}, 2 \mathrm{H}, \mathrm{C}_{6} \mathrm{H}_{4}\right), 1.78\left(\mathrm{~s}, 3 \mathrm{H}, \mathrm{CH}_{3}\right)$. ${ }^{13} \mathrm{C}-\mathrm{NMR}\left(\left(\mathrm{CD}_{2}\right)_{3} \mathrm{O}, 400 \mathrm{MHz}\right): \delta 205.6,169.2,152.2,133.4,128.3,124.2,119.5,115.1,20.4$. 


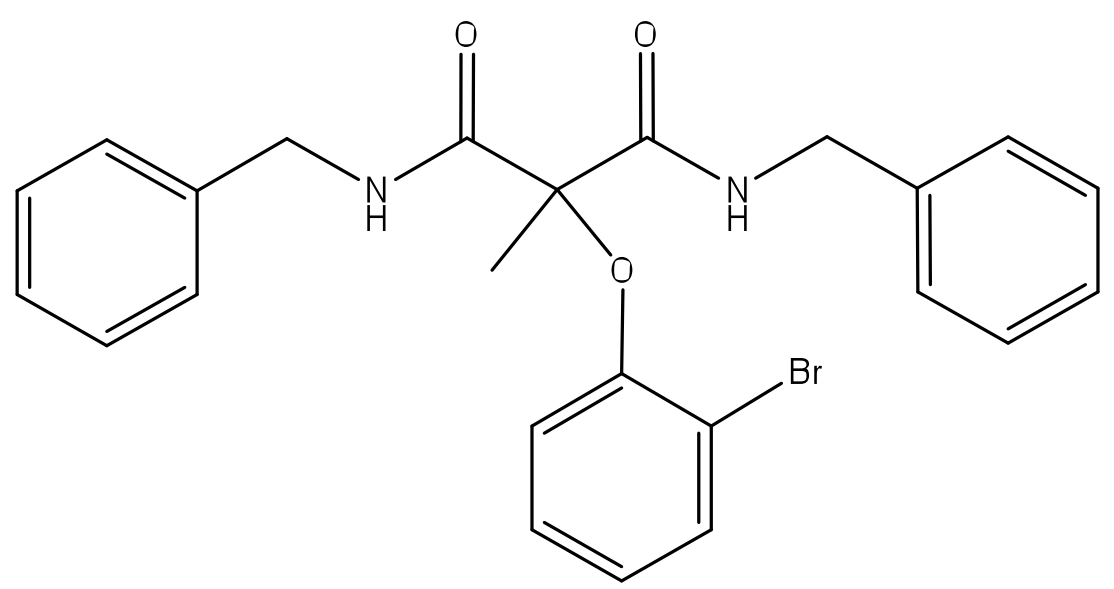

$N^{1}, N \quad{ }^{3}$-dibenzyl-2-(2-bromophenoxy)-2-methylmalonamide (20): 2-(2-bromophenoxy)-2methylmalonic acid $23(562.4 \mathrm{mg}, 1.945 \mathrm{mmol})$ was dissolved in $48.7 \mathrm{~mL}$ of dry $\mathrm{CH}_{2} \mathrm{Cl}_{2}$ and cooled to $0{ }^{\circ} \mathrm{C}$ followed by the addition of benzylamine $(0.47 \mathrm{~mL}, 4.279 \mathrm{mmol})$, Hunig's base $(0.75 \mathrm{~mL}, 4.279 \mathrm{mmol})$ and HBTU $(1.6228 \mathrm{~g}, 4.279 \mathrm{mmol})$ on ice. The reaction was left stirring at room temperature overnight. The reaction mixture was extracted with $1 \mathrm{M} \mathrm{HCl}(4 \times 10 \mathrm{~mL})$, the organic phase was dried over $\mathrm{MgSO}_{4}$, filtered and evaporated under reduced pressure. The crude product was purified via flash chromatography eluting at $40 \%$ EtOAc:Hexanes to afford $N^{1}, N^{3}$-dibenzyl-2-(2-bromophenoxy)-2-methylmalonamide, compound $\mathbf{2 0},(340.8 \mathrm{mg}, 38 \%)$ as a white solid. Melting point: $122-124{ }^{\circ} \mathrm{C} ; \mathrm{R}_{\mathrm{f}}=0.45\left(\mathrm{SiO}_{2}, 25 \%\right.$ EtOAc:Hexanes); ${ }^{1} \mathrm{H}-\mathrm{NMR}$ $\left(\mathrm{CDCl}_{3}, 400 \mathrm{MHz}\right): \delta 7.55(\mathrm{~s}, 2 \mathrm{H}, \mathrm{NH}), 7.53-7.49\left(\mathrm{~m}, 1 \mathrm{H}, \mathrm{C}_{6} \mathrm{H}_{4}\right), 7.34-7.22\left(\mathrm{~m}, 10 \mathrm{H}, \mathrm{C}_{6} \mathrm{H}_{5}\right)$, 7.18-7.12 (m, 1H, $\left.\mathrm{C}_{6} \mathrm{H}_{4}\right), 7.05-7.03\left(\mathrm{~m}, 1 \mathrm{H}, \mathrm{C}_{6} \mathrm{H}_{4}\right), 6.96-6.90\left(\mathrm{~m}, 1 \mathrm{H}, \mathrm{C}_{6} \mathrm{H}_{4}\right), 4.51(\mathrm{~d}, J=5.8,4 \mathrm{H}$, $\left.\mathrm{CH}_{2}\right), 1.78\left(\mathrm{~s}, 3 \mathrm{H}, \mathrm{CH}_{3}\right) .{ }^{13} \mathrm{C}-\mathrm{NMR}\left(\mathrm{CDCl}_{3}, 400 \mathrm{MHz}\right): \delta 169.2,150.7,137.5,133.4,128.8$, 128.4, 127.7, 127.6, 124.7, 119.7, 115.2, 84.6, 43.8, 21.5. 


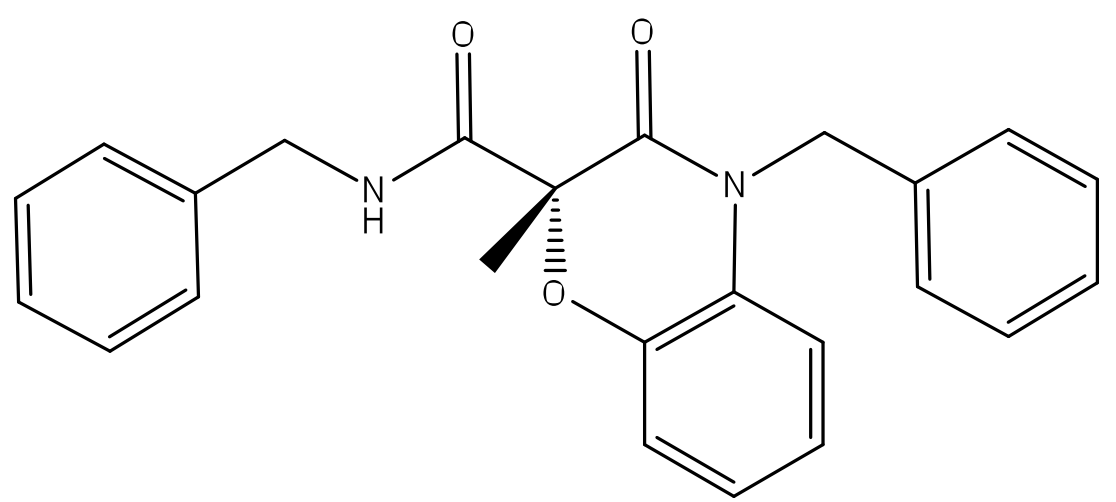

N,4-dibenzyl-2-methyl-3-oxo-3,4-dihydro-2H-benzo[b][1,4] oxazine-2-carboxamide (21):

\subsubsection{General Procedure for the Synthesis of 21}

A $10 \mathrm{~mL}$ Schlenk flask was charged with $N^{1}, N^{3}$-dibenzyl-2-(2-bromophenoxy)-2methylmalonamide (20) (50 mg, $0.107 \mathrm{mmol}), \mathrm{Cs}_{2} \mathrm{CO}_{3}(1.4 \mathrm{eq}), 5 \mathrm{~mol} \% \mathrm{Pd}(\mathrm{OAc})_{2}$ and $10 \mathrm{~mol}$ \% Ligand. The flask was evacuated and backfilled with argon a total of three times. Toluene (1.8 $\mathrm{mL}$ ) was added via syringe under a stream of argon, the reaction was sealed and left stirring at $100{ }^{\circ} \mathrm{C}$ for 48 hours. The reaction mixture was cooled to room temperature, diluted with $\mathrm{CH}_{2} \mathrm{Cl}_{2}$ $(10 \mathrm{~mL})$ and filtered through a short plug of celite. The crude product was purified via column chromatography eluting at $25 \%$ EtOAc:Hexanes to afford compound 21 as a white solid (88-99 \% yield). Melting point: $105-110{ }^{\circ} \mathrm{C} ; \mathrm{R}_{\mathrm{f}}=0.40\left(\mathrm{SiO}_{2}, 25 \%\right.$ EtOAc:Hexanes $) ;{ }^{1} \mathrm{H}-\mathrm{NMR}\left(\mathrm{CDCl}_{3}\right.$, $400 \mathrm{MHz}$ ): 7.32-7.26 (m, 4H, Ar), 7.25-7.17 (m, 4H, Ar), 7.04-6.90 (m, 5H, Ar), 6.89-6.83 (m, 1H, Ar), 6.58-6.51 (m, 1H, NH), $5.41\left(\mathrm{~d}, J=16.1 \mathrm{~Hz}, 1 \mathrm{H}, \mathrm{CH}_{2}\right), 4.92\left(\mathrm{~d}, J=16.1 \mathrm{~Hz}, 1 \mathrm{H}, \mathrm{CH}_{2}\right)$, $4.52\left(\mathrm{dd}, J_{1}=15.0 \mathrm{~Hz}, J_{2}=6.6 \mathrm{~Hz}, 1 \mathrm{H}, \mathrm{CH}_{2}\right), 4.30\left(\mathrm{dd}, J_{1}=15.0 \mathrm{~Hz}, J_{2}=5.2 \mathrm{~Hz}, 1 \mathrm{H}, \mathrm{CH}_{2}\right), 1.93$ (s, 3H, $\left.\mathrm{CH}_{3}\right) .{ }^{13} \mathrm{C}-\mathrm{NMR}\left(\mathrm{CDCl}_{3}, 400 \mathrm{MHz}\right): \delta 168.4,164.6,143.4,137.4,135.9,128.9,128.7$, $127.5,127.4,126.4,124.3,123.4,117.3,116.0,81.8,46.1,43.5,29.7,22.7,22.2$. HPLC analysis of compound 21 isolated from Ligand $=(R)$-BINAP, Base $=\mathrm{K}_{2} \mathrm{CO}_{3}$. i.e. Table 1, entry 5; (Chiaralcel OD-H column, eluting with $0.65 \mathrm{~mL} / \mathrm{min} 25 \% i$-PrOH:Hexanes), $t_{\mathrm{R}}$ minor $=17.3$ $\min ($ peak area $=1018747.76), t_{\mathrm{R}}$ major $=50.9 \min ($ peak area $=1539462.16), e e=20 \%$. HPLC 
analysis of compound 21 isolated from Ligand $=(R)$-BINAP, Base $=\mathrm{Cs}_{2} \mathrm{CO}_{3}$. i.e. Table 1, entry 7; (Chiaralcel OD-H column, eluting with $0.65 \mathrm{~mL} / \mathrm{min} 25 \% i$-PrOH:Hexanes), $t_{\mathrm{R}}$ major $=17.9$ $\min ($ peak area $=2801143.53), t_{\mathrm{R}} \operatorname{minor}=51.9 \min ($ peak area $=2193959.25), e e=12 \%$. HPLC analysis of compound $\mathbf{2 1}$ isolated from Ligand $=(R)-\mathrm{MOP}$, Base $=\mathrm{Cs}_{2} \mathrm{CO}_{3}$. i.e. Table 1, entry 8; (Chiaralcel OD-H column, eluting with $0.65 \mathrm{~mL} / \min 25 \% i$-PrOH:Hexanes), $t_{\mathrm{R}}$ minor $=17.9$ $\min ($ peak area $=1265584.01), t_{\mathrm{R}}$ major $=52.1 \mathrm{~min}($ peak area $=1370314.47), e e=3 \% . \mathrm{HPLC}$ analysis of compound 21 isolated from Ligand $=(R)-\mathrm{Cy}_{2} \mathrm{MOP}$, Base $=\mathrm{Cs}_{2} \mathrm{CO}_{3}$. i.e. Table 1, entry 6; (Chiaralcel OD-H column, eluting with $0.65 \mathrm{~mL} / \mathrm{min} 20 \% i$-PrOH:Hexanes), $t_{\mathrm{R}}$ minor $=13.7 \mathrm{~min}($ peak area $=6320578.20), t_{\mathrm{R}}$ major $=38.1 \mathrm{~min}($ peak area $=8088409.20), e e=12 \%$.

\subsection{Towards the Synthesis of Benzodiazepinone Heterocycles}

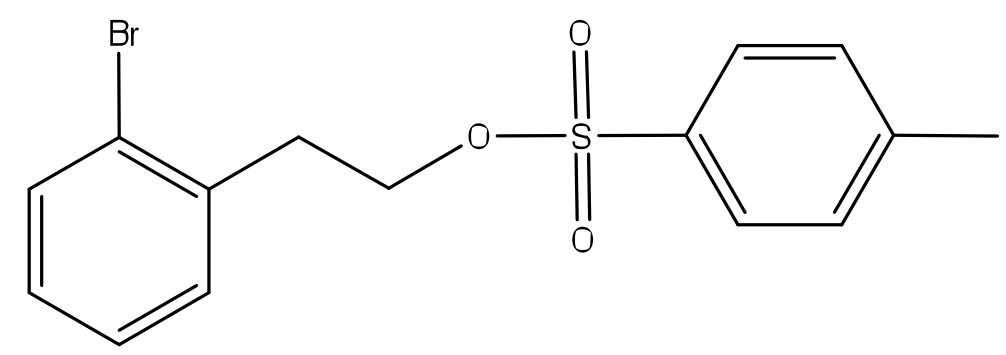

2-bromophenethyl 4-methylbenzenesulfonate (27): To a solution of 2-bromophenethyl alcohol (2.000 g, $9.95 \mathrm{mmol})$ in dry $\mathrm{CH}_{2} \mathrm{Cl}_{2}(4.1 \mathrm{~mL})$ was added triethyamine $(13.9 \mathrm{~mL}, 99.5 \mathrm{mmol})$ and DMAP (121.3 mg, $0.995 \mathrm{mmol})$ at $0{ }^{\circ} \mathrm{C}$. A solution of tosyl chloride $(2.086 \mathrm{~g}, 10.94 \mathrm{mmol})$ in dry $\mathrm{CH}_{2} \mathrm{Cl}_{2}(4.1 \mathrm{~mL})$ was slowly added to the reaction mixture at $0{ }^{\circ} \mathrm{C}$ using an addition funnel. The reaction mixture was allowed to warm to room temperature and stirred for 3 hours. The reaction was treated with aqueous $1 \mathrm{M} \mathrm{HCl}(10 \mathrm{~mL})$ and extracted with $\mathrm{CH}_{2} \mathrm{Cl}_{2}(3 \times 30 \mathrm{~mL})$ The 
organic layer was washed with $\mathrm{NaHCO}_{3}(15 \mathrm{~mL})$ and water $(15 \mathrm{~mL})$. The combined organic phases were dried over $\mathrm{MgSO}_{4}$ and concentrated under reduced pressure. Flash chromatography of the crude product eluting with $20 \%$ EtOAc:Hexanes afforded compound 27 (1.547 g, $88 \%)$ as a white solid. Melting point: $36-37{ }^{\circ} \mathrm{C} ; \mathrm{R}_{\mathrm{f}}=0.4\left(\mathrm{SiO}_{2}, 20 \%\right.$ EtOAc:Hexanes); ${ }^{1} \mathrm{H}-\mathrm{NMR}$ $\left(\mathrm{CDCl}_{3}, 400 \mathrm{MHz}\right): \delta 7.68\left(\mathrm{~d}, J=8.3 \mathrm{~Hz}, 2 \mathrm{H}, \mathrm{C}_{6} \mathrm{H}_{4}\right), 7.45\left(\mathrm{~d}, J=8.4 \mathrm{~Hz}, 1 \mathrm{H}, \mathrm{C}_{6} \mathrm{H}_{4}\right), 7.27(\mathrm{~d}, J=$ 8.1 Hz, 1H, $\left.\mathrm{C}_{6} \mathrm{H}_{4}\right), 7.24-7.15\left(\mathrm{~m}, 3 \mathrm{H}, \mathrm{C}_{6} \mathrm{H}_{4}\right), 7.11-7.05\left(\mathrm{~m}, 1 \mathrm{H}, \mathrm{C}_{6} \mathrm{H}_{4}\right), 4.24$ (t, J=6.9 Hz, 2H, $\left.\mathrm{CH}_{2}\right), 3.08\left(\mathrm{t}, J=6.9 \mathrm{~Hz}, 2 \mathrm{H}, \mathrm{CH}_{2}\right), 2.43\left(\mathrm{~s}, 3 \mathrm{H}, \mathrm{CH}_{3}\right) .{ }^{13} \mathrm{C}-\mathrm{NMR}\left(\mathrm{CDCl}_{3}, 400 \mathrm{MHz}\right): \delta 144.7$, $135.5,132.9,132.7,131.5,129.8,128.7,127.8,127.6,124.4,68.8,35.7,21.6$.

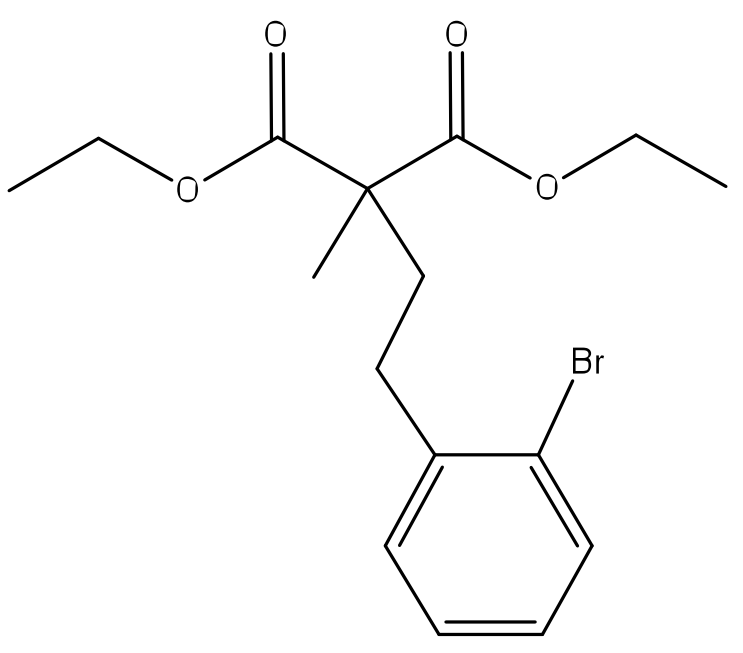

Diethyl 2-(2-bromophenethyl)-2-methylmalonate (29): A $250 \mathrm{ml}$ three-necked round bottom flask equipped with an addition funnel, reflux condenser and attachment piece to an argon line was charged with sodium hydride, $60 \%$ dispersion in mineral oil $(750 \mathrm{mg}, 18.7 \mathrm{mmol})$. The hydride was washed twice with anhydrous hexanes $(10 \mathrm{~mL})$ and suspended in anhydrous THF $(17 \mathrm{~mL})$. Diethyl methylmalonate $(2.28 \mathrm{~mL}, 13.4 \mathrm{mmol})$ was added to the rapidly stirring sodium hydride suspension at $0{ }^{\circ} \mathrm{C}$. The reaction mixture was allowed to warm to room temperature, once gas evolution had ceased a solution of compound 27, (5.212 g, $14.67 \mathrm{mmol})$ in THF (7.3 $\mathrm{mL}$ ) was added and the mixture was heated and left refluxing overnight. The reaction mixture 
was quenched with saturated ammonium chloride and extracted three times with ethyl acetate. The organic phase was dried over $\mathrm{Na}_{2} \mathrm{SO}_{4}$ and concentrated under reduced pressure. The crude product was purified via column chromatography eluting with $5 \%$ EtOAc:Hexanes to afford Diethyl 2-(2-bromophenethyl)-2-methylmalonate, compound $29(2.244 \mathrm{~g}, 47 \%)$ as a colorless oil. $\mathrm{R}_{\mathrm{f}}=0.80\left(\mathrm{SiO}_{2}, 25 \%\right.$ EtOAc:Hexanes); ${ }^{1} \mathrm{H}-\mathrm{NMR}\left(\mathrm{CDCl}_{3}, 400 \mathrm{MHz}\right): \delta 7.51$ (d, $J=7.9 \mathrm{~Hz}$, $\left.1 \mathrm{H}, \mathrm{C}_{6} \mathrm{H}_{4}\right), 7.23\left(\mathrm{~d}, J=4.2 \mathrm{~Hz}, 2 \mathrm{H}, \mathrm{C}_{6} \mathrm{H}_{4}\right), 7.09-7.01\left(\mathrm{~m}, 1 \mathrm{H}, \mathrm{C}_{6} \mathrm{H}_{4}\right), 4.24-4.10\left(\mathrm{~m}, 4 \mathrm{H}, \mathrm{CH}_{2}\right)$, 2.73-2.67 (m, 2H, $\left.\mathrm{CH}_{2}\right), 2.15-2.09\left(\mathrm{~m}, 2 \mathrm{H}, \mathrm{CH}_{2}\right), 1.53\left(\mathrm{~s}, 3 \mathrm{H}, \mathrm{CH}_{3}\right), 1.27$ (t, $J=7.1 \mathrm{~Hz}, 6 \mathrm{H}$, $\left.\mathrm{CH}_{3}\right) .{ }^{13} \mathrm{C}-\mathrm{NMR}\left(\mathrm{CDCl}_{3}, 400 \mathrm{MHz}\right): \delta 172.1,140.8,132.8,130.4,127.8,127.6,124.3,61.3$, $53.5,35.9,31.2,19.9,14.1$.

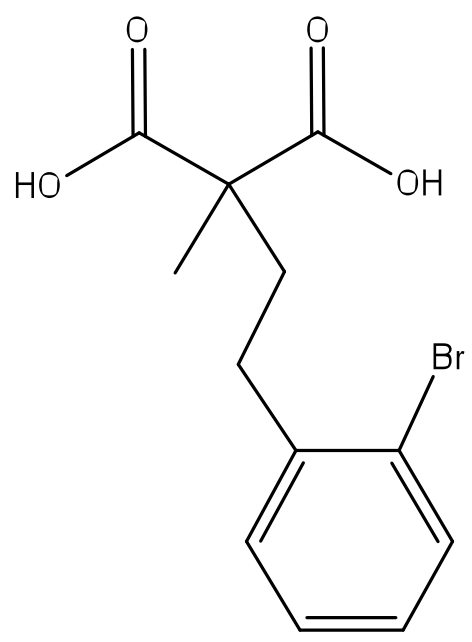

2-(2-bromophenethyl)-2-methylmalonic acid (30): Diethyl 2-(2-bromophenethyl)-2methylmalonate, compound 29, (1.006 g, $2.82 \mathrm{mmol})$ was dissolved in methanol $(8.5 \mathrm{~mL})$ followed by the addition of $4 \mathrm{M} \mathrm{NaOH}(2.8 \mathrm{~mL})$. The reaction was refluxed overnight. The reaction mixture was cooled to room temperature, diluted with water $(20 \mathrm{~mL})$ and extracted with ether $(20 \mathrm{~mL})$. The aqueous phase was acidified via slow dropwise addition of $6 \mathrm{M} \mathrm{HCl}$ and extracted with $\mathrm{CH}_{2} \mathrm{Cl}_{2}(3 \times 30 \mathrm{~mL})$. The combined organic phases were dried over $\mathrm{MgSO}_{4}$, 
filtered and evaporated under reduced pressure to afford 2-(2-bromophenethyl)-2-methylmalonic acid, compound 30 (574.6 mg, $68 \%$ ) which was used without further purification. Melting point: 161-166 ${ }^{\circ} \mathrm{C} ;{ }^{1} \mathrm{H}-\mathrm{NMR}\left(\mathrm{CDCl}_{3}, 400 \mathrm{MHz}\right): \delta 7.52\left(\mathrm{~d}, J=7.9 \mathrm{~Hz}, 1 \mathrm{H}, \mathrm{C}_{6} \mathrm{H}_{4}\right), 7.28(\mathrm{~d}, J=4.2 \mathrm{~Hz}$, $\left.2 \mathrm{H}, \mathrm{C}_{6} \mathrm{H}_{4}\right), 7.12-7.06\left(\mathrm{~m}, 1 \mathrm{H}, \mathrm{C}_{6} \mathrm{H}_{4}\right), 4.92(\mathrm{~s}, 2 \mathrm{H}, \mathrm{OH}), 2.76-2.70\left(\mathrm{~m}, 2 \mathrm{H}, \mathrm{CH}_{2}\right), 2.09-2.03(\mathrm{~m}$, $\left.2 \mathrm{H}, \mathrm{CH}_{2}\right), 1.50\left(\mathrm{~s}, 3 \mathrm{H}, \mathrm{CH}_{2}\right) \cdot{ }^{13} \mathrm{C}-\mathrm{NMR}\left(\mathrm{CDCl}_{3}, 400 \mathrm{MHz}\right): \delta 174.3,141.0,132.5,130.2,127.6$, 127.5, 123.6, 53.1, 36.0, 31.0, 19.1.

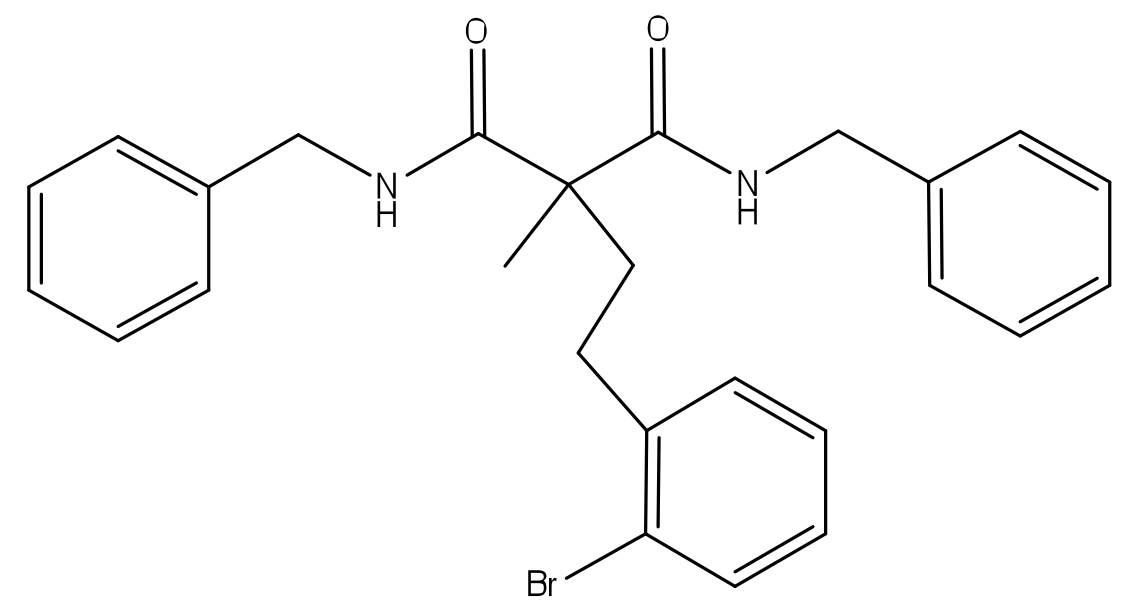

$N^{1}, N^{3}$-dibenzyl-2-(2-bromophenethyl)-2-methylmalonamide (31): 2-(2-bromophenethyl)-2methylmalonic acid, compound 30, $(529.0 \mathrm{mg}, 1.76 \mathrm{mmol})$ was dissolved in $2 \mathrm{~mL}$ of $\mathrm{SOCl}_{2}$ and stirred at $60{ }^{\circ} \mathrm{C}$ for 4 hours. The excess $\mathrm{SOCl}_{2}$ was removed by rotary evaporation under reduced pressure. The crude product was redissolved in $\mathrm{CHCl}_{3}(5 \mathrm{~mL})$ and subjected to rotary evaporation under reduced pressure. This process of redissolving the crude product in $\mathrm{CHCl}_{3}$ followed by rotary evaporation was repeated a total of three times to ensure complete removal of any remaining $\mathrm{SOCl}_{2}$. The crude product was redissolved in $\mathrm{CHCl}_{3}(10 \mathrm{~mL})$ and cooled to $0{ }^{\circ} \mathrm{C}$ followed by the addition of benzylamine $(0.42 \mathrm{~mL}, 3.87 \mathrm{mmol})$ on ice. The reaction mixture was allowed to warm to room temperature and left stirring for one hour. The reaction mixture was cooled back down to $0{ }^{\circ} \mathrm{C}$ followed by the addition of triethyamine $(0.54 \mathrm{~mL}, 3.87 \mathrm{mmol})$ on ice. 
The reaction mixture was warmed to room temperature and refluxed overnight. The reaction was cooled to room temperature and extracted with $1 \mathrm{M} \mathrm{HCl}(4 \times 10 \mathrm{~mL})$. The organic phase was dried over $\mathrm{MgSO}_{4}$, filtered and evaporated under reduced pressure. The crude product was purified via flash chromatography eluting at $40 \%$ EtOAc:Hexanes to afford $N^{1}, N^{3}$-dibenzyl-2(2-bromophenethyl)-2-methylmalonamide, compound 31 (365.5 $\mathrm{mg}, 43 \%$ ) as a white solid. Melting point: $113-115{ }^{\circ} \mathrm{C} ; \mathrm{R}_{\mathrm{f}}=0.35\left(\mathrm{SiO}_{2}, 40 \%\right.$ EtOAc:Hexanes$) ;{ }^{1} \mathrm{H}-\mathrm{NMR}\left(\mathrm{CDCl}_{3}, 400\right.$ MHz): $\delta 7.48\left(\mathrm{dd}, J_{1}=8.0 \mathrm{~Hz}, \mathrm{~J}_{2}=0.9 \mathrm{~Hz}, 1 \mathrm{H}, \mathrm{C}_{6} \mathrm{H}_{4}\right), 7.36-7.17\left(\mathrm{~m}, 12 \mathrm{H}, \mathrm{C}_{6} \mathrm{H}_{4}\right), 7.15-7.10(\mathrm{~m}$, $\left.1 \mathrm{H}, \mathrm{C}_{6} \mathrm{H}_{4}\right), 7.07-7.02\left(\mathrm{~m}, 1 \mathrm{H}, \mathrm{C}_{6} \mathrm{H}_{4}\right), 4.52-4.39\left(\mathrm{~m}, 3 \mathrm{H}, \mathrm{CH}_{2}\right), 2.71-2.65\left(\mathrm{~m}, 2 \mathrm{H}, \mathrm{CH}_{2}\right), 2.18-2.11$ (m, $\left.2 \mathrm{H}, \mathrm{CH}_{2}\right), 1.58\left(\mathrm{~s}, 3 \mathrm{H}, \mathrm{CH}_{3}\right) \cdot{ }^{13} \mathrm{C}-\mathrm{NMR}\left(\mathrm{CDCl}_{3}, 400 \mathrm{MHz}\right): \delta 172.6,140.5,137.9,132.7$, $130.6,128.8,127.9,127.7,127.6,127.5,124.2,53.1,44.0,39.2,31.8,19.8$.

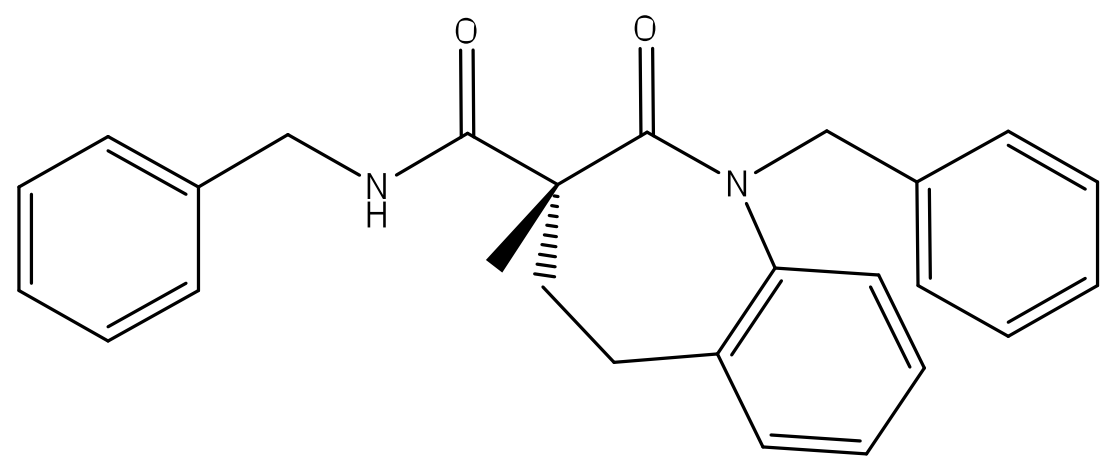

\section{N, 1-dibenzyl-3-methyl-2-oxo-2,3,4,5-tetrahydro-1H-benzo[b]azepine-3-carboxamide (32) A}

$10 \mathrm{~mL}$ Schlenk flask was charged with $N^{1}, \quad N^{3}$-dibenzyl-2-(2-bromophenethyl)-2methylmalonamide (31.4 mg, $0.065 \mathrm{mmol}), \mathrm{Cs}_{2} \mathrm{CO}_{3}(29.6 \mathrm{mg}, 0.091 \mathrm{mmol}), 5 \mathrm{~mol} \% \mathrm{Pd}(\mathrm{OAc})_{2}$ and 10 mol \% $\mathrm{Cy}_{2} \mathrm{MOP}$. The flask was evacuated and backfilled with argon a total of three times. Toluene $(1.1 \mathrm{~mL})$ was added via syringe under a stream of argon, the reaction was sealed and left stirring at $100{ }^{\circ} \mathrm{C}$ for 48 hours. The reaction mixture was cooled to room temperature, diluted with $\mathrm{CH}_{2} \mathrm{Cl}_{2}(10 \mathrm{~mL})$ and filtered through a short plug of celite. The crude product was 
purified by preparative plate TLC eluting at $30 \%$ EtOAc:Hexanes to afford compound 32 (13 $\mathrm{mg}, 50 \%)$ as an off-white solid. $\mathrm{R}_{\mathrm{f}}=0.30\left(\mathrm{SiO}_{2}, 40 \%\right.$ EtOAc:Hexanes $) ;{ }^{1} \mathrm{H}-\mathrm{NMR}\left(\mathrm{CDCl}_{3}, 400\right.$ MHz): $\delta$ 7.33-7.04 (m, 15H, Ar), 6.97 (d, $J=8.0 \mathrm{~Hz}, 1 \mathrm{H}, \mathrm{Ar}), 5.34$ (s, 1H, NH), 5.12 (d, $J=14.4$ $\left.\mathrm{Hz}, 1 \mathrm{H}, \mathrm{CH}_{2}\right), 4.86\left(\mathrm{~d}, J=14.4 \mathrm{~Hz}, 1 \mathrm{H}, \mathrm{CH}_{2}\right), 4.05\left(\mathrm{dd}, J_{1}=14.2 \mathrm{~Hz}, J_{2}=5.7 \mathrm{~Hz}, 1 \mathrm{H}, \mathrm{CH}_{2}\right)$, $3.80\left(\mathrm{dd}, J_{1}=14.3 \mathrm{~Hz}, J_{2}=4.7 \mathrm{~Hz}, 1 \mathrm{H}, \mathrm{CH}_{2}\right), 3.08-2.97\left(\mathrm{~m}, 1 \mathrm{H}, \mathrm{CH}_{2}\right), 2.59-2.51\left(\mathrm{~m}, 1 \mathrm{H}, \mathrm{CH}_{2}\right)$, 2.44-2.40 (m, 1H, $\left.\mathrm{CH}_{2}\right), 1.99-1.91\left(\mathrm{~m}, 1 \mathrm{H}, \mathrm{CH}_{2}\right), 1.41\left(\mathrm{~s}, 3 \mathrm{H}, \mathrm{CH}_{3}\right) \cdot{ }^{13} \mathrm{C}-\mathrm{NMR}\left(\mathrm{CDCl}_{3}, 400\right.$ MHz): $\delta 172.9,171.8,140.6,137.7,137.5,136.9,129.4,129.0,128.8,128.7,128.6,128.5$, 128.3, 128.1, 127.7, 127.5, 127.4, 127.2, 124.1, 29.7, 29.1, 25.9.

\subsection{Towards the Synthesis of $t$-butyl substituted Quinolinone}

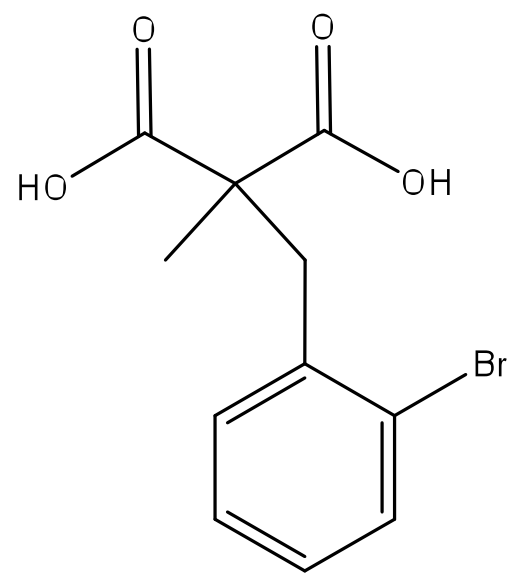

2-(2-bromobenzyl)-2-methylmalonic acid (34): Diethyl 2-(2-bromobenzyl)-2methylmalonate, ${ }^{47}$ (3.6 g, $\left.10.5 \mathrm{mmol}\right)$ was dissolved in methanol $(10.8 \mathrm{~mL})$ followed by the addition of $4 \mathrm{M} \mathrm{NaOH}(10.8 \mathrm{~mL})$. The reaction was refluxed overnight. The reaction mixture was cooled to room temperature, diluted with water $(20 \mathrm{~mL})$ and extracted with ether $(20 \mathrm{~mL})$. The aqueous phase was cooled to $0^{\circ} \mathrm{C}$ and acidified via slow dropwise addition of $6 \mathrm{M} \mathrm{HCl}$. The 
white suspension was extracted with $\mathrm{CH}_{2} \mathrm{Cl}_{2}(3 \times 30 \mathrm{~mL})$ and the combined organic phases were dried over $\mathrm{MgSO}_{4}$, filtered and evaporated under reduced pressure to afford 2-(2bromophenethyl)-2-methylmalonic acid, compound 34 (2.19 g, 73 \%) which was used without further purification. Melting point: $172-175{ }^{\circ} \mathrm{C} ;{ }^{1} \mathrm{H}-\mathrm{NMR}\left(\left(\mathrm{CD}_{2}\right)_{3} \mathrm{O}, 400 \mathrm{MHz}\right): \delta 7.60\left(\mathrm{dd}, J_{1}=\right.$ $\left.8.0 \mathrm{~Hz}, J_{2}=1.2 \mathrm{~Hz}, 1 \mathrm{H}, \mathrm{C}_{6} \mathrm{H}_{4}\right), 7.37,\left(\mathrm{dd}, J_{1}=7.7 \mathrm{~Hz}, J_{2}=1.7 \mathrm{~Hz}, 1 \mathrm{H}, \mathrm{C}_{6} \mathrm{H}_{4}\right), 7.28\left(\mathrm{td}, J_{1}=7.4\right.$ $\left.\mathrm{Hz}, J_{2}=1.3 \mathrm{~Hz}, 1 \mathrm{H}, \mathrm{C}_{6} \mathrm{H}_{4}\right), 7.16\left(\mathrm{td}, J_{1}=7.9 \mathrm{~Hz}, J_{2}=1.8 \mathrm{~Hz}, 1 \mathrm{H}, \mathrm{C}_{6} \mathrm{H}_{4}\right), 3.53\left(\mathrm{~s}, 2 \mathrm{H}, \mathrm{CH}_{2}\right), 1.34$ (s, 3H, $\left.\mathrm{CH}_{3}\right) .{ }^{13} \mathrm{C}-\mathrm{NMR}\left(\left(\mathrm{CD}_{2}\right)_{3} \mathrm{O}, 400 \mathrm{MHz}\right): 205.6,172.4,136.7,133.0,131.4,128.7,127.6$, $125.9,54.4,39.0,18.6$.

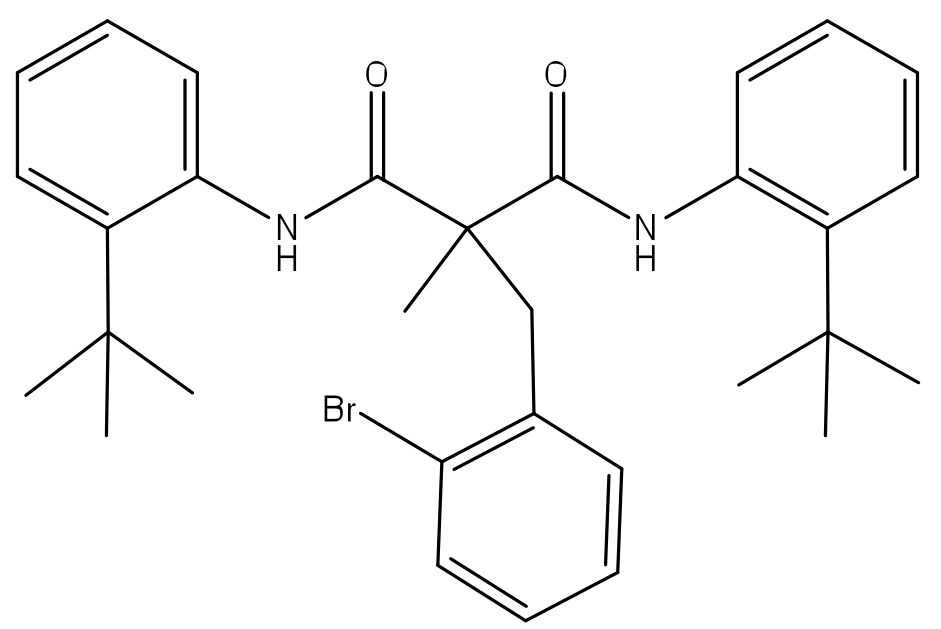

2-(2-bromobenzyl)- $N^{1}, N \quad{ }^{3}$-bis(2-(tert-butyl)phenyl)-2-methylmalonamide $\quad$ (35): $\quad$ 2-(2bromobenzyl)-2-methylmalonic acid (529.0 mg, $1.76 \mathrm{mmol})$ was dissolved in $2 \mathrm{~mL}$ of $\mathrm{SOCl}_{2}$ and stirred at $60{ }^{\circ} \mathrm{C}$ for 4 hours. The excess $\mathrm{SOCl}_{2}$ was removed by rotary evaporation under reduced pressure. The crude product was redissolved in $\mathrm{CHCl}_{3}(5 \mathrm{~mL})$ and subjected to rotary evaporation under reduced pressure. This process of redissolving the crude product in $\mathrm{CHCl}_{3}$ followed by rotary evaporation was repeated a total of three times to ensure complete removal of any remaining $\mathrm{SOCl}_{2}$. The crude product was redissolved in $\mathrm{CHCl}_{3}(10 \mathrm{~mL})$ and cooled to $0{ }^{\circ} \mathrm{C}$ followed by the addition of $t$-butylaniline $(0.42 \mathrm{~mL}, 3.87 \mathrm{mmol})$ on ice. The reaction mixture 
was allowed to warm to room temperature and left stirring for one hour. The reaction mixture was cooled back down to $0{ }^{\circ} \mathrm{C}$ followed by the addition of triethyamine $(0.54 \mathrm{~mL}, 3.87 \mathrm{mmol})$ on ice. The reaction mixture was warmed to room temperature and refluxed overnight. The reaction was cooled to room temperature and extracted with $1 \mathrm{M} \mathrm{HCl}(4 \times 10 \mathrm{~mL})$. The organic phase was dried over $\mathrm{MgSO}_{4}$, filtered and evaporated under reduced pressure. The crude product was purified via flash chromatography eluting at $40 \%$ EtOAc:Hexanes to afford $N^{1}, N^{3}$-dibenzyl-2(2-bromophenethyl)-2-methylmalonamide, compound 35 (365.5 $\mathrm{mg}, 43 \%$ ) as a white solid. Melting point: $125-130{ }^{\circ} \mathrm{C} ; \mathrm{R}_{\mathrm{f}}=0.45\left(\mathrm{SiO}_{2}, 15 \%\right.$ EtOAc:Hexanes $) ;{ }^{1} \mathrm{H}-\mathrm{NMR}\left(\mathrm{CDCl}_{3}, 400\right.$ MHz): $\delta 8.67$ (s, 2H, NH), 7.64-7.09 (m, 13H, $\left.\mathrm{C}_{6} \mathrm{H}_{4}\right), 3.80\left(\mathrm{~s}, 2 \mathrm{H}, \mathrm{CH}_{2}\right), 1.73\left(\mathrm{~s}, 3 \mathrm{H}, \mathrm{CH}_{3}\right), 1.39$ (s, $\left.18 \mathrm{H},\left(\mathrm{CH}_{3}\right)_{3}\right) .{ }^{13} \mathrm{C}-\mathrm{NMR}\left(\mathrm{CDCl}_{3}, 400 \mathrm{MHz}\right): \delta$ 170.7, 142.8, 136.2, 134.8, 133.3, 131.6, $128.8,128.0,127.8,127.0,126.4,126.1,56.3,42.9,34.4,30.5,29.7,18.4$.

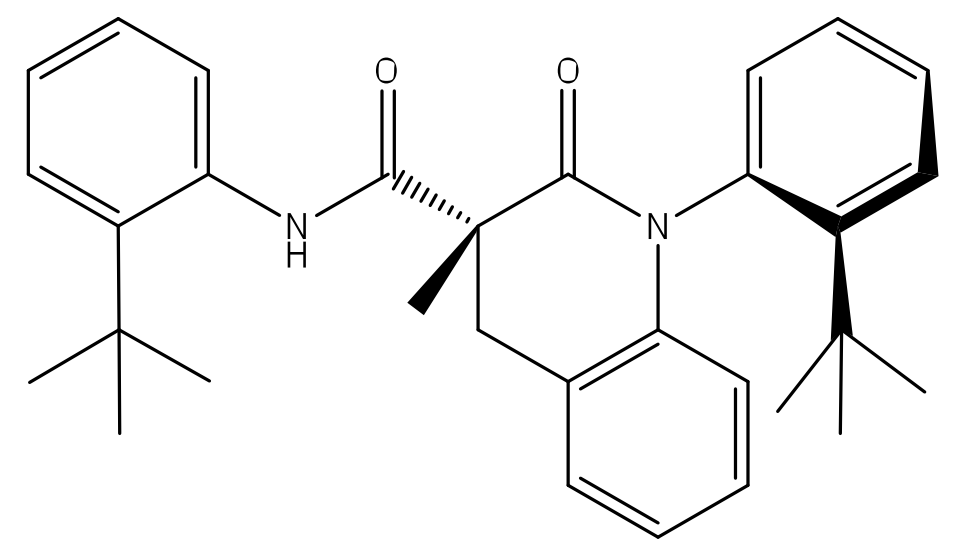

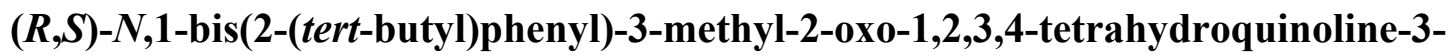

carboxamide (36): A $10 \mathrm{~mL}$ Schlenk flask was charged with 2-(2-bromobenzyl)- $N^{1}, N^{3}$-bis(2(tert-butyl)phenyl)-2-methylmalonamide, compound 35 (50 mg, $0.091 \mathrm{mmol}), \mathrm{Cs}_{2} \mathrm{CO}_{3}(17.6 \mathrm{mg}$, $0.127 \mathrm{mmol}), \mathrm{Pd}(\mathrm{OAc})_{2}(5 \mathrm{~mol} \%)$ and $\mathrm{Cy}_{2} \mathrm{MOP}(10 \mathrm{~mol} \%)$. The flask was evacuated and backfilled with argon a total of three times. Toluene $(1.5 \mathrm{~mL})$ was added via syringe under a 
stream of argon, the reaction was sealed and left stirring at $100{ }^{\circ} \mathrm{C}$ for 48 hours. The reaction mixture was cooled to room temperature, diluted with $\mathrm{CH}_{2} \mathrm{Cl}_{2}(10 \mathrm{~mL})$ and filtered through a short plug of celite. The crude product was purified via column chromatography eluting at $30 \%$ EtOAc:Hexanes to afford compound $\mathbf{3 6}$ (42.3 mg, $99 \%$ ) as a white solid. Melting point: 175-180 ${ }^{\circ} \mathrm{C} ; \mathrm{R}_{\mathrm{f}}=0.40\left(\mathrm{SiO}_{2}, 15 \%\right.$ EtOAc:Hexanes); ${ }^{1} \mathrm{H}-\mathrm{NMR}\left(\mathrm{CDCl}_{3}, 400 \mathrm{MHz}\right): \delta 8.37$ (s, 1H, NH), 7.65-7.61 (m, 1H, $\left.\mathrm{C}_{6} \mathrm{H}_{4}\right), 7.47-7.26\left(\mathrm{~m}, 5 \mathrm{H}, \mathrm{C}_{6} \mathrm{H}_{4}\right), 7.15-7.09\left(\mathrm{~m}, 2 \mathrm{H}, \mathrm{C}_{6} \mathrm{H}_{4}\right)$, 7.05-7.01 (m, $2 \mathrm{H}$, $\left.\mathrm{C}_{6} \mathrm{H}_{4}\right), 6.95\left(\mathrm{dd}, J_{1}=7.8 \mathrm{~Hz}, J_{2}=1.4 \mathrm{~Hz}, 1 \mathrm{H}, \mathrm{C}_{6} \mathrm{H}_{4}\right), 6.22-6.18\left(\mathrm{~m}, 1 \mathrm{H}, \mathrm{C}_{6} \mathrm{H}_{4}\right), 3.78(\mathrm{~d}, J=15.6$ $\left.\mathrm{Hz}, 1 \mathrm{H}, \mathrm{CH}_{2}\right), 3.08\left(\mathrm{~d}, J=15.6 \mathrm{~Hz}, 1 \mathrm{H}, \mathrm{CH}_{2}\right), 1.77\left(\mathrm{~s}, 3 \mathrm{H}, \mathrm{CH}_{3}\right), 1.35\left(\mathrm{~s}, 9 \mathrm{H},\left(\mathrm{CH}_{3}\right)_{3}\right), 1.24(\mathrm{~s}$, $\left.9 \mathrm{H},\left(\mathrm{CH}_{3}\right)_{3}\right)$ (When the ${ }^{1} \mathrm{H}-\mathrm{NMR}$ spectrum was ran in $\mathrm{C}_{6} \mathrm{D}_{6}$ there appeared to be a $13 \%$ impurity which is most likely due to debromination of the starting material). ${ }^{13} \mathrm{C}-\mathrm{NMR}\left(\mathrm{CDCl}_{3}, 400\right.$ MHz): $\delta 173.3,168.3,147.4,142.3,140.7,135.9,135.2,132.2,129.4,129.0,128.9,127.5$, $127.2,127.0,126.6,126.5,125.9,124.0,123.9,116.6,50.7,35.7,35.2,34.7,34.5,31.60,31.55$, $31.4,30.54,30.50,25.3,24.1,20.7$ (There are extra signals in the aliphatic region of the ${ }^{13} \mathrm{C}$ NMR spectrum which might correspond to the debrominated starting material, however there is not enough evidence at this time to distinguish between the peaks corresponding to compound $\mathbf{3 6}$ and the peaks corresponding to compound 37). HPLC (Chiaralcel OD-H column, eluting with $0.65 \mathrm{~mL} / \mathrm{min} 2 \% i$-PrOH:Hexanes), $t_{\mathrm{R}}$ minor $=10.9 \min ($ peak area $=1088767.27), t_{\mathrm{R}}$ major $=$ $12.9 \min ($ peak area $=16418111.55), e e=88 \%$ 


\subsection{Synthesis of $\mathrm{Cy}_{2} \mathrm{MOP}$ and $\mathrm{Cy}_{2} \mathrm{MOP} \cdot \mathrm{BH}_{3}$}

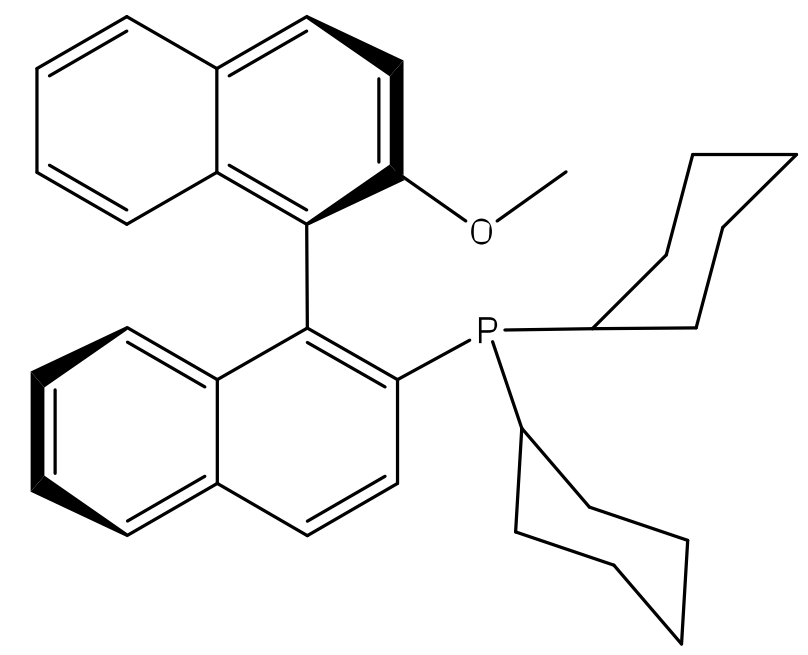

(R)-2(Dicyclohexylphosphino)-2'-methoxy-1,1'-binaphthyl) (41): A $10 \mathrm{~mL}$ Schlenk flask was charged with (R)-2'-methoxy-[1,1'-binaphthalen]-2-yl trifluoromethanesulfonate ${ }^{46}(150 \mathrm{mg}$, $0.347 \mathrm{mmol})$, dicyclohexylphosphonium tetrafluoroborate ${ }^{46}(99.2 \mathrm{mg}, 0.347 \mathrm{mmol}), \mathrm{Pd}(\mathrm{OAc})_{2}(5$ mol \%) and 1,1'-(bisdiisopropyl) phosphino ferrocene (6 mol \%). The flask was evacuated and backfilled with argon a total of three times. DMSO $(2.0 \mathrm{~mL})$ and $N, N$ '-diisopropylethylamine $(0.6 \mathrm{~mL})$ were added via syringe under a stream of argon. The reaction was sealed and left stirring at $120{ }^{\circ} \mathrm{C}$ for 48 hours. The reaction mixture was cooled to room temperature, diluted with EtOAc $(40 \mathrm{~mL})$ and washed with water $(5 \times 20 \mathrm{~mL})$. The organic phase was dried over $\mathrm{MgSO}_{4}$, filtered and evaporated under reduced pressure. The crude product was purified via flash chromatography eluting at $3 \%$ EtOAc:Hexanes to afford (R)-2(Dicyclohexylphosphino)-2'methoxy-1,1'-binaphthyl) (133 mg, $80 \%$ ) as a white solid. Melting point: $180-182{ }^{\circ} \mathrm{C} ; \mathrm{R}_{\mathrm{f}}=0.50$ $\left(\mathrm{SiO}_{2}, 5 \%\right.$ EtOAc:Hexanes); ${ }^{1} \mathrm{H}-\mathrm{NMR}\left(\mathrm{CDCl}_{3}, 400 \mathrm{MHz}\right): \delta 8.0\left(\mathrm{~d}, J=9.0 \mathrm{~Hz}, 1 \mathrm{H}, \mathrm{C}_{10} \mathrm{H}_{6}\right)$, 7.92-7.87 (m, $\left.1 \mathrm{H}, \mathrm{C}_{10} \mathrm{H}_{6}\right), 7.84\left(\mathrm{~d}, J=8.1 \mathrm{~Hz}, 1 \mathrm{H}, \mathrm{C}_{10} \mathrm{H}_{6}\right), 7.78\left(\mathrm{dd}, J_{1}=8.5 \mathrm{~Hz}, J_{2}=1.3 \mathrm{~Hz}, 1 \mathrm{H}\right.$, 
$\left.\mathrm{C}_{10} \mathrm{H}_{6}\right), 7.46-7.40\left(\mathrm{~m}, 1 \mathrm{H}, \mathrm{C}_{10} \mathrm{H}_{6}\right), 7.39\left(\mathrm{~d}, J=9.0 \mathrm{~Hz}, 1 \mathrm{H}, \mathrm{C}_{10} \mathrm{H}_{6}\right), 7.29-7.23\left(\mathrm{~m}, 1 \mathrm{H}, \mathrm{C}_{10} \mathrm{H}_{6}\right)$, 7.23-7.11 (m, $\left.3 \mathrm{H}, \mathrm{C}_{10} \mathrm{H}_{6}\right), 6.91\left(\mathrm{~d}, J=8.6 \mathrm{~Hz}, 1 \mathrm{H}, \mathrm{C}_{10} \mathrm{H}_{6}\right), 3.75\left(\mathrm{~s}, 3 \mathrm{H}, \mathrm{CH}_{3}\right), 1.87-1.46(\mathrm{~m}, 12 \mathrm{H}$, $\left.\mathrm{C}_{6} \mathrm{H}_{11}\right), 1.29-0.86\left(\mathrm{~m}, 11 \mathrm{H}, \mathrm{C}_{6} \mathrm{H}_{11}\right) .{ }^{13} \mathrm{C}-\mathrm{NMR}\left(\mathrm{CDCl}_{3}, 400 \mathrm{MHz}\right): \delta 154.37,154.36,143.56$, $143.25,135.20,135.02,134.30,134.28,133.56,133.33,133.26,129.61,129.22,129.19,128.52$, $127.88,127.82,126.97,126.95,126.72,126.26,126.18,125.99,125.80,123.19,122.56,122.48$ $112.27,60.43,55.51,35.44,35.29,34.54,34.40,30.68,30.59,30.50,30.43,30.01,29.97,29.90$, $29.87,27.67,27.65,27.59,27.53,27.39,27.31,27.20,26.58,26.40$ (observed complexity results from C-P coupling). ${ }^{31} \mathrm{P}-\mathrm{NMR}\left(\mathrm{CDCl}_{3}, 400 \mathrm{MHz}\right): \delta$-8.90. HPLC (Chiaralcel OD-H column, eluting with $0.65 \mathrm{~mL} / \mathrm{min} 2 \% i$-PrOH:Hexanes), $t_{\mathrm{R}}$ major $=5.6 \mathrm{~min}($ peak area $=7053734.00)$, $t_{\mathrm{R}} \operatorname{minor}=7.5 \mathrm{~min}($ peak area $=401749.73), t_{\mathrm{R}} \operatorname{minor}=10.9 \min ($ peak area $=916931.01)$. 


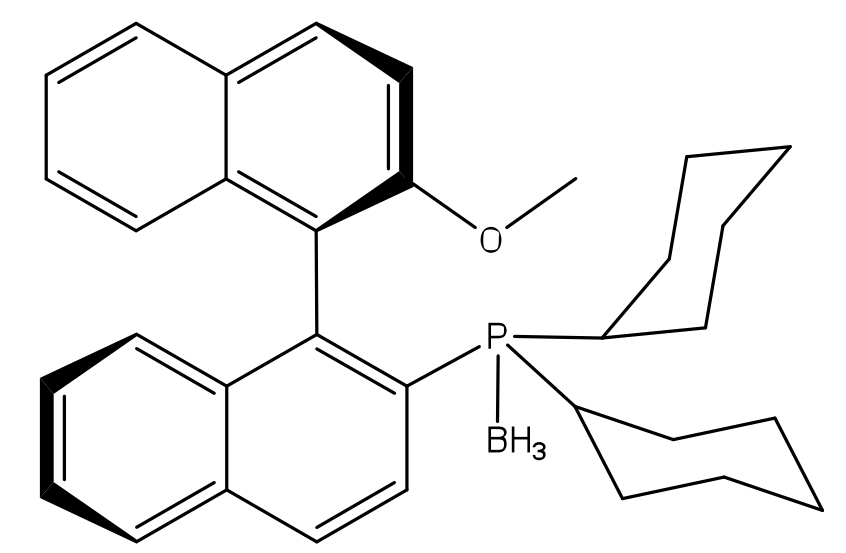

(R)-2(Dicyclohexylphosphino)-2'-methoxy-1,1'-binaphthyl) borane complex (42): A $10 \mathrm{~mL}$

Schlenk flask was charged with (R)-2(Dicyclohexylphosphino)-2'-methoxy-1,1'-binaphthyl), compound 41 (304.6 mg, $0.634 \mathrm{mmol})$ followed by addition of THF $(0.6 \mathrm{~mL})$ and cooled to $0{ }^{\circ} \mathrm{C}$. A $1 \mathrm{M}$ solution of borane THF complex $(0.76 \mathrm{~mL}, 0.76 \mathrm{mmol})$ was added to the rapidly stirring mixture at $0{ }^{\circ} \mathrm{C}$. The reaction mixture was stirred on ice for 30 minutes, diluted with EtOAc (10 $\mathrm{mL})$ and extracted with water $(50 \mathrm{~mL})$. The organic phase was dried over $\mathrm{MgSO}_{4}$, filtered and evaporated under reduced pressure. The crude product was purified via flash chromatography eluting with $3 \%$ EtOAc:Hexanes to afford (R)-2(Dicyclohexylphosphino)-2'-methoxy-1,1'binaphthyl) borane complex $(228.5 \mathrm{mg}, 73 \%)$ as a white crystalline material. Melting point: 255-260 ${ }^{\circ} \mathrm{C} ; \mathrm{R}_{\mathrm{f}}=0.40\left(\mathrm{SiO}_{2}, 5 \%\right.$ EtOAc:Hexanes $) ;{ }^{1} \mathrm{H}-\mathrm{NMR}\left(\mathrm{CDCl}_{3}, 400 \mathrm{MHz}\right): \delta 8.10-7.80$ $\left(\mathrm{m}, 5 \mathrm{H}, \mathrm{C}_{6} \mathrm{H}_{10}\right), 7.54-7.49\left(\mathrm{~m}, 1 \mathrm{H}, \mathrm{C}_{6} \mathrm{H}_{10}\right), 7.42\left(\mathrm{~d}, J=9.1 \mathrm{~Hz}, 1 \mathrm{H}, \mathrm{C}_{10} \mathrm{H}_{6}\right), 7.33-7.28(\mathrm{~m}, 1 \mathrm{H}$, $\left.\mathrm{C}_{10} \mathrm{H}_{6}\right), 7.26-7.21\left(\mathrm{~m}, 1 \mathrm{H}, \mathrm{C}_{10} \mathrm{H}_{6}\right), 7.17-7.12\left(\mathrm{~m}, 2 \mathrm{H}, \mathrm{C}_{10} \mathrm{H}_{6}\right), 6.82\left(\mathrm{~d}, J=8.5 \mathrm{~Hz}, 1 \mathrm{H}, \mathrm{C}_{10} \mathrm{H}_{6}\right)$, $3.77\left(\mathrm{~s}, 3 \mathrm{H}, \mathrm{CH}_{3}\right), 2.1-0.4\left(\mathrm{~m}, 26 \mathrm{H}, \mathrm{C}_{6} \mathrm{H}_{11}\right) .{ }^{13} \mathrm{C}-\mathrm{NMR}\left(\mathrm{CDCl}_{3}, 400 \mathrm{MHz}\right): \delta 155.13,142.37$, $134.98,134.18,134.17,133.67,130.45,129.89,129.81,128.84,127.94,127.80,127.48,127.31$, $127.22,127.10,126.84,126.63,126.13,125.87,125.63,125.43,123.40,120.35,120.32,55.78$, $34.61,34.29,34.09,33.77,28.22,27.65,27.48,27.21,27.10,27.01,26.89,26.87,26.48,26.37$, 25.93, 25.92, 25.80, 25.79, 21.05, 14.20 (observed complexity results from C-P coupling). 


\section{Conclusion}

A non commercially available ligand, (R)-2(Dicyclohexylphosphino)-2'-methoxy-1,1'binaphthyl), (R)-Cy ${ }_{2} \mathrm{MOP}$, has been synthesized in good yield, $80 \%$, and proved to be very effective in the palladium catalyzed intramolecular desymmetrization of di-nitrogen malonamides. The efficiency of this ligand can be attributed to the increased steric bulk provided by the dicyclohexylphosphino group, which speeds up the rate of reductive elimination thus increasing the rate at which the active catalyst is regenerated. Additionally an enantio- and diastereoselective Buchwald-Hartwig reaction has been developed through the desymmetrization of 2-(2-bromobenzyl)- $N^{1}, N \quad{ }^{3}$-bis(2-(tert-butyl)phenyl)-2-methylmalonamide using palladium/Cy $2 \mathrm{MOP}$ as the catalyst system to produce $\left(3 R, S_{\mathrm{a}}\right)-N, 1-$ bis(2-(tert-butyl)phenyl)-3methyl-2-oxo-1,2,3,4-tetrahydroquinoline-3-carboxamide in excellent yield, with high enantioand diastereoselectivity $(99 \%, 88 \% e e)$. The absolute configuration of the formed diastereomer was determined by x-ray crystallography. This is the first example in which an enantio- and diastereoselective Buchwald-Hartwig reaction takes place in a single step from the preferential $\mathrm{N}$-arylation of prochiral di-nitrogen malonamides. Application of the palladium $/ \mathrm{Cy}_{2} \mathrm{MOP}$ catalyst system in the intramolecular desymmetrization reaction also resulted in the formation of six membered ring benzomorpholinone heterocycles in excellent yield (88-99\%) however the $e e$ `s of the products were quite low $(3-20 \%$ ee). A seven membered ring benzodiazepineone heterocycle was also synthesized using palladium/ $\mathrm{Cy}_{2} \mathrm{MOP}$ and the product was isolated in $50 \%$

yield. Furthermore several synthetic routes towards the synthesis of five membered ring oxindoles were explored but none of them were successful. Lastly the synthesis of a precatalyst was attempted using $\mathrm{Cy}_{2} \mathrm{MOP}$ and $\mathrm{Pd}(\mathrm{II}) \mathrm{Me}_{2}$ TMEDA however the isolated product does not appear to be the desired precatalyst. 
5 Appendix:

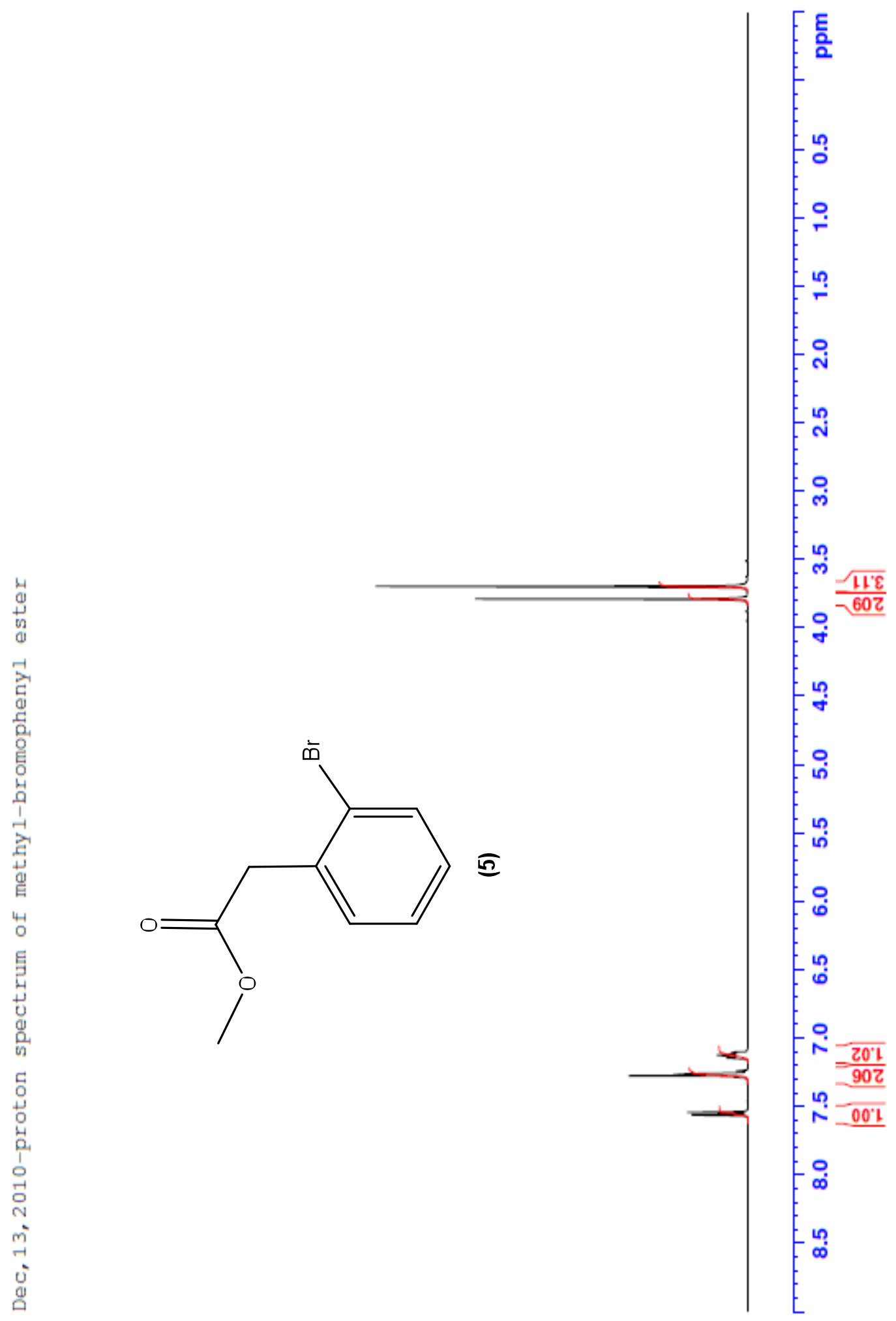




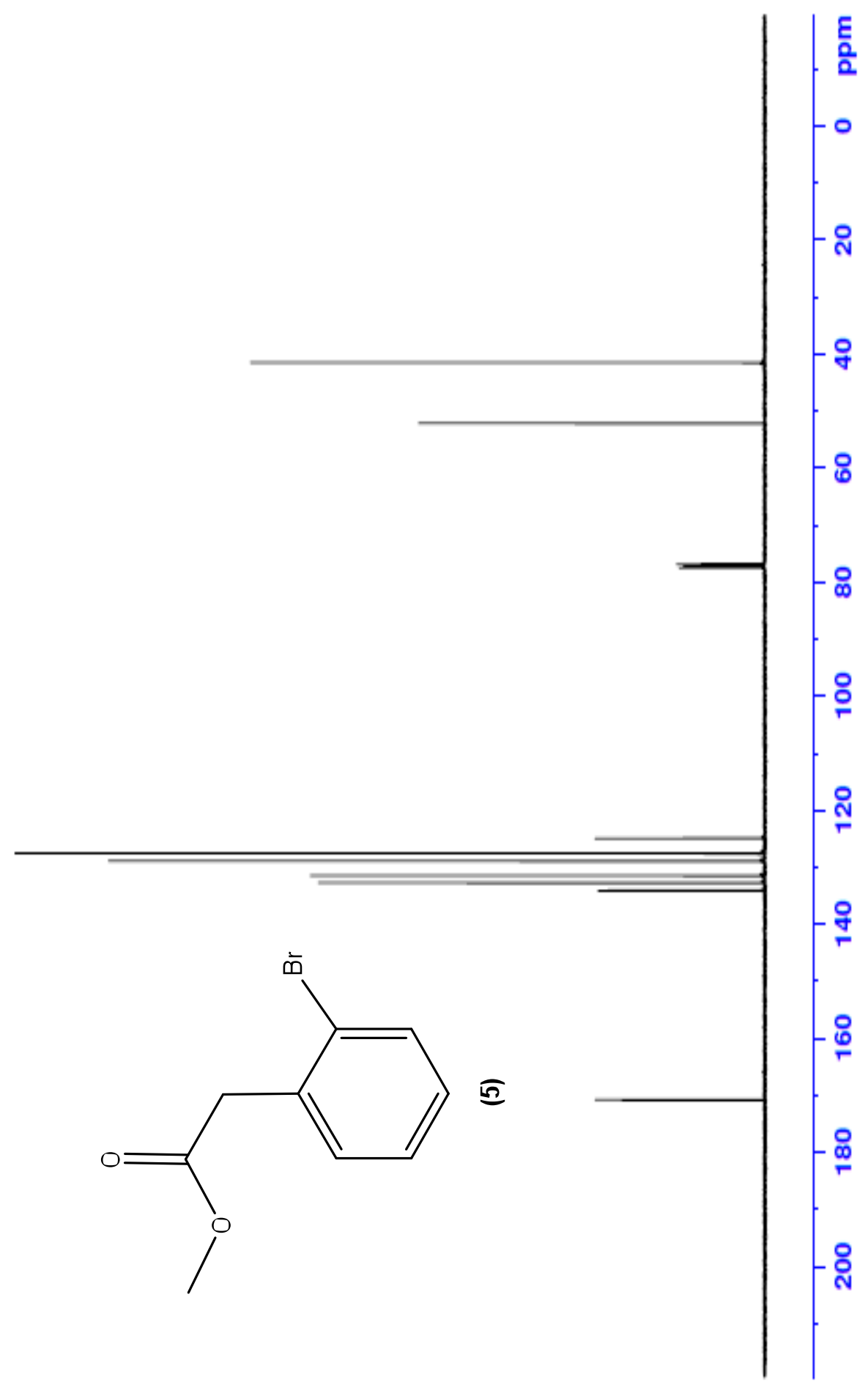




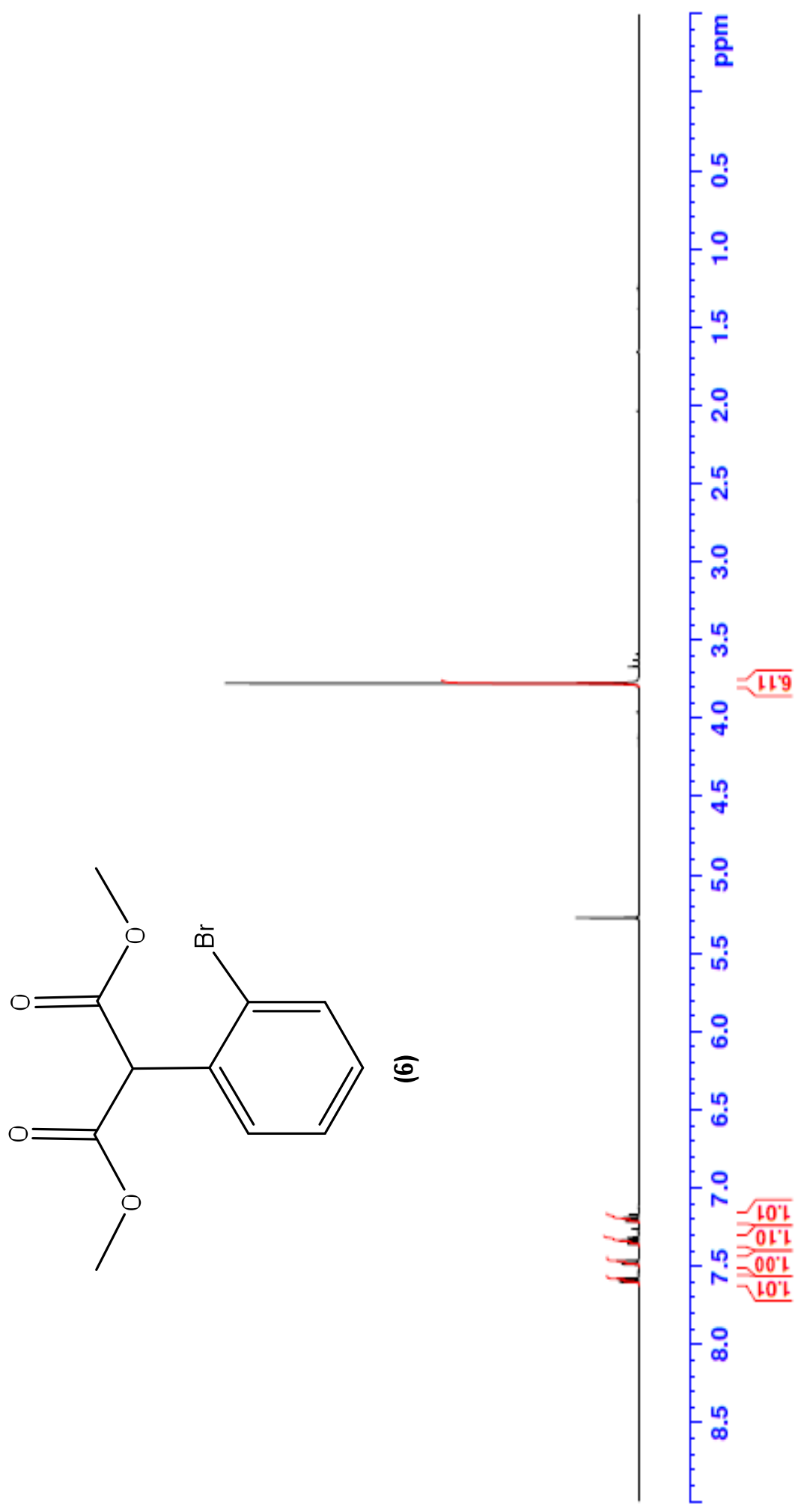



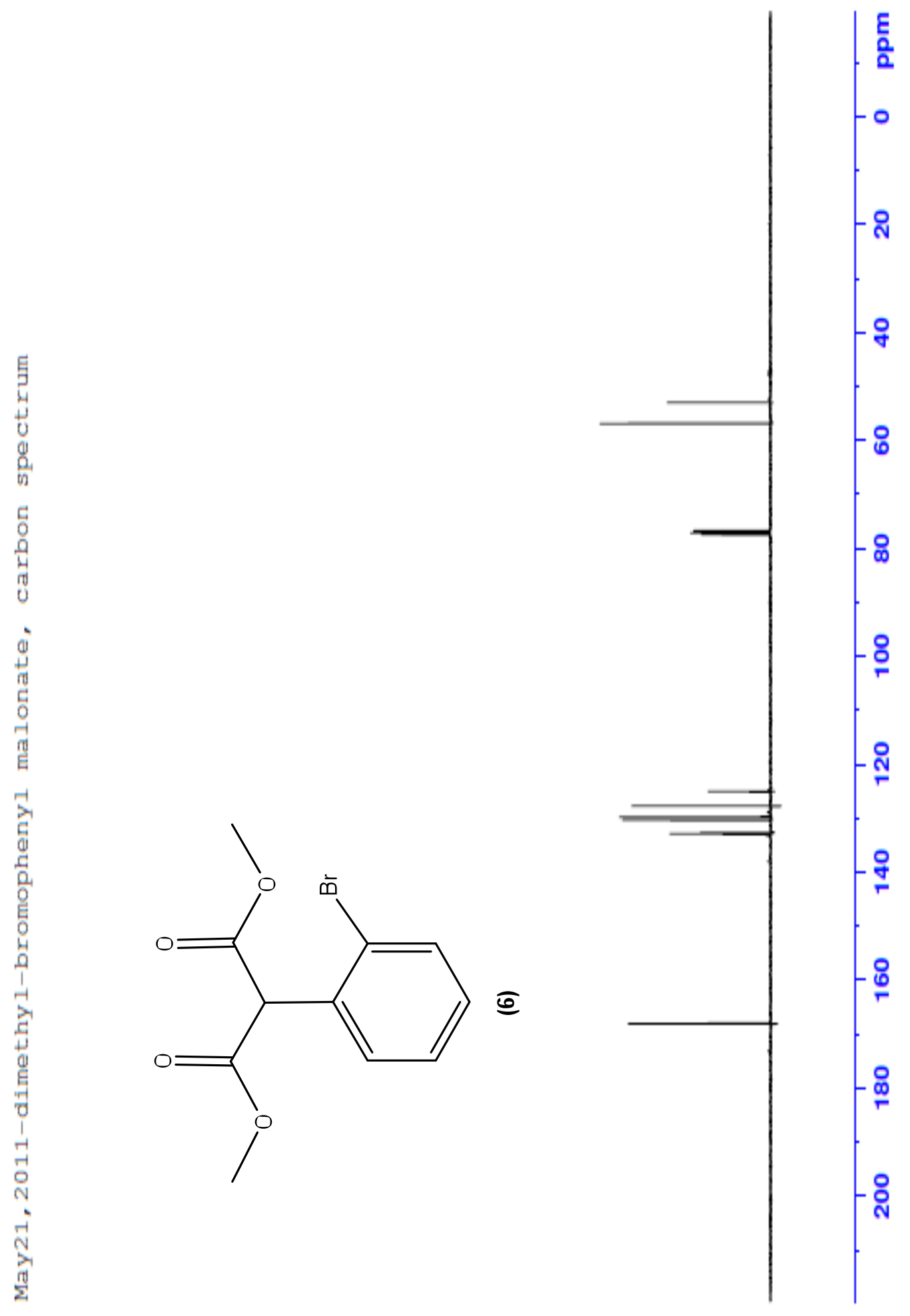


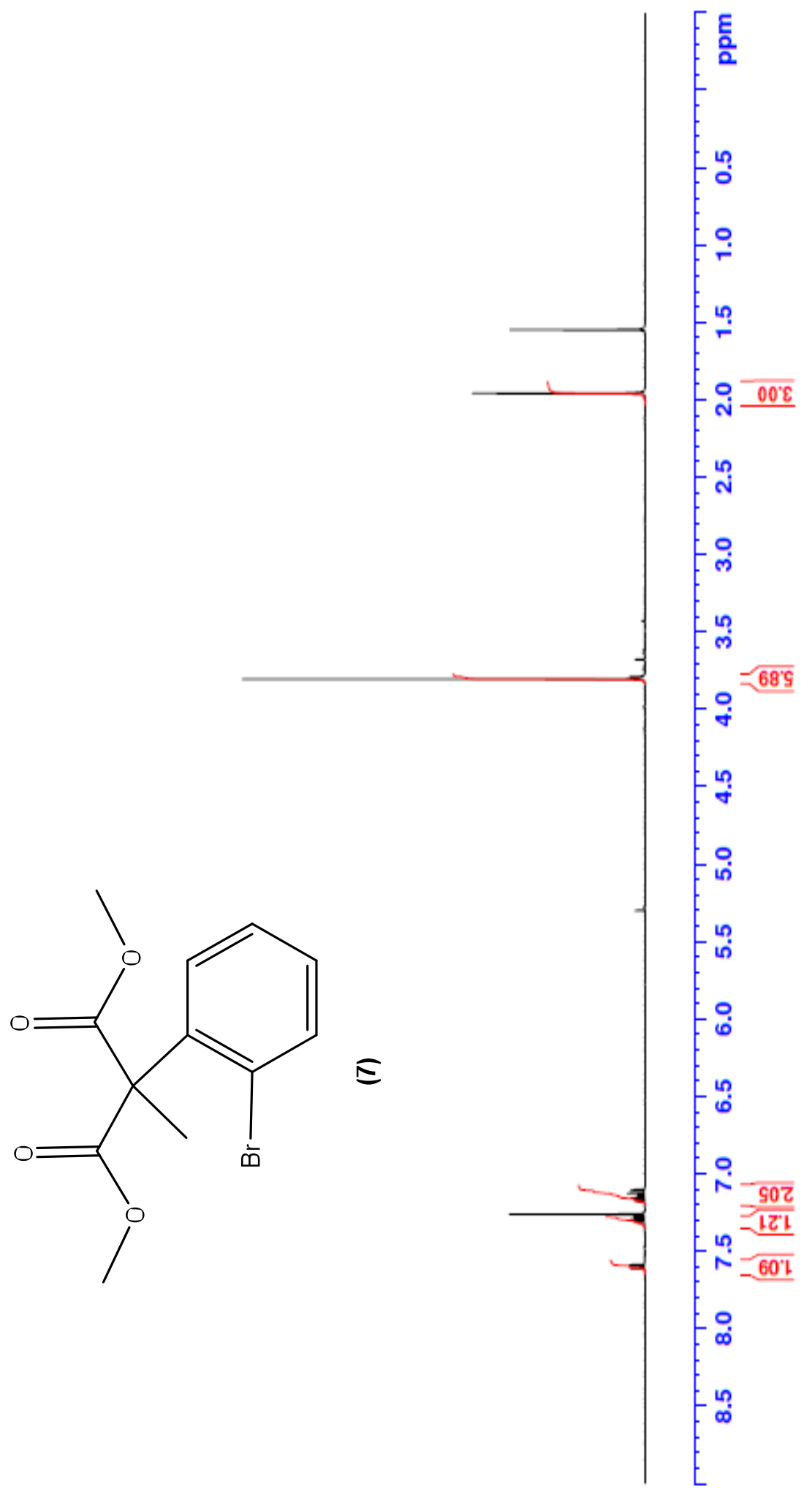




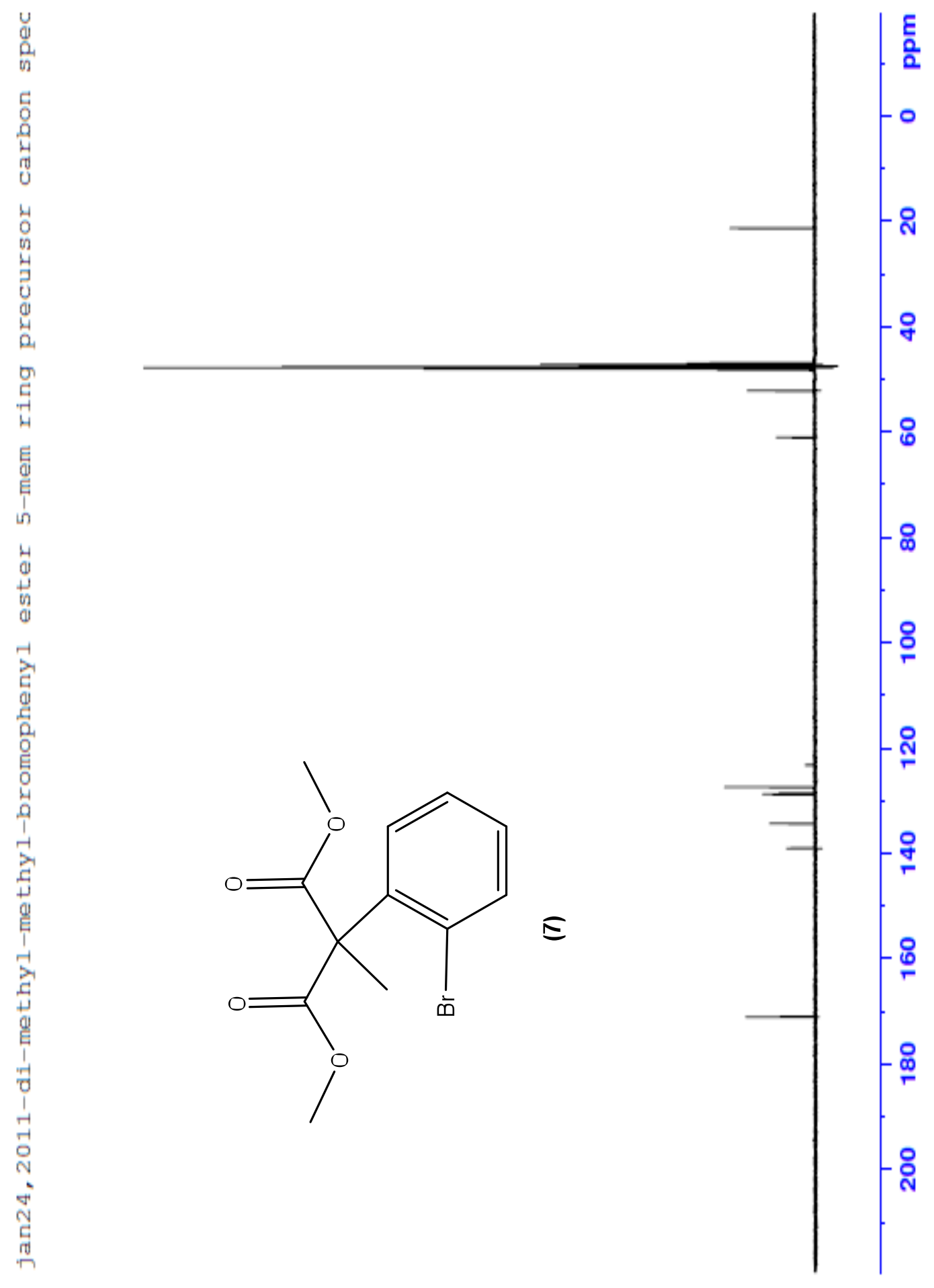




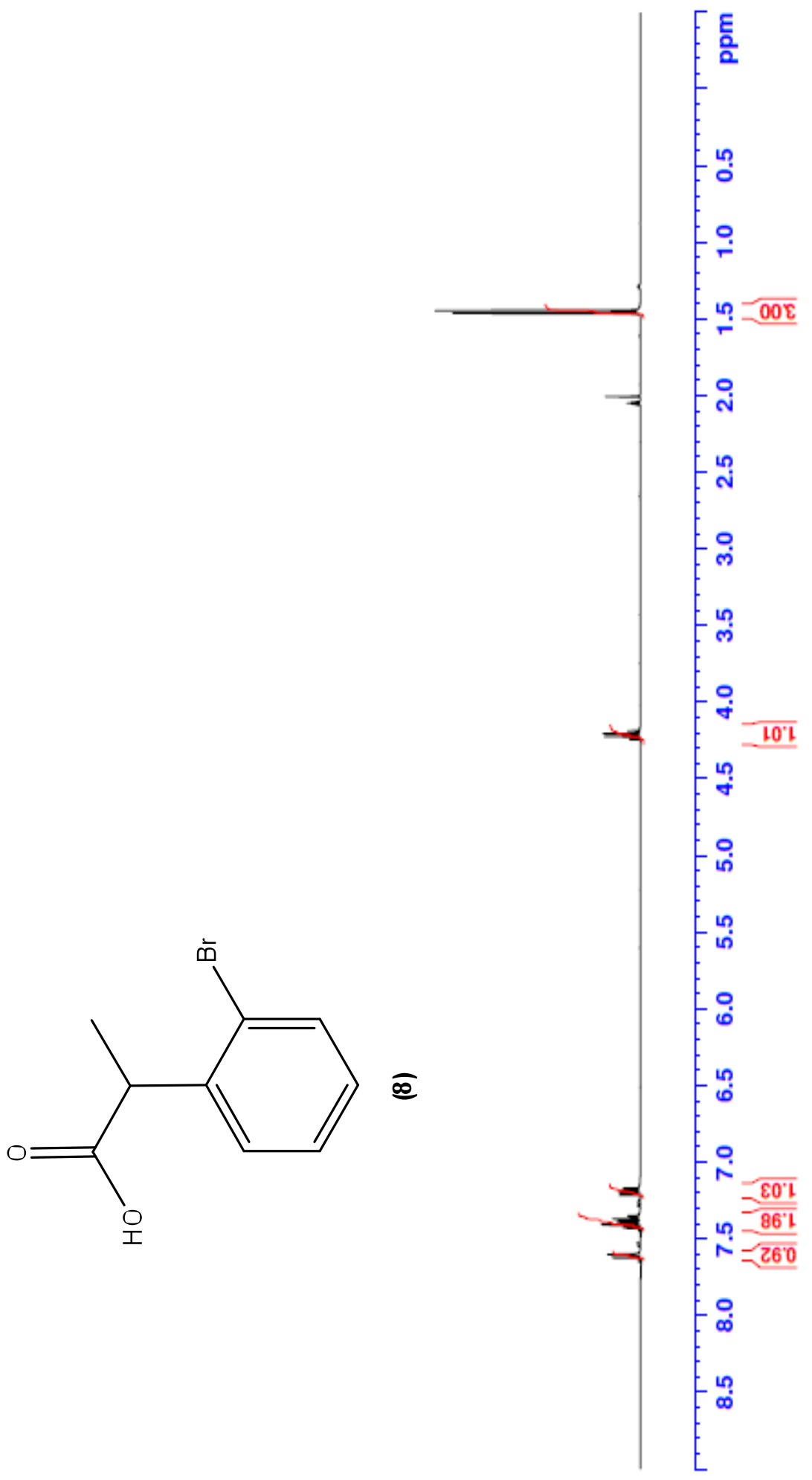




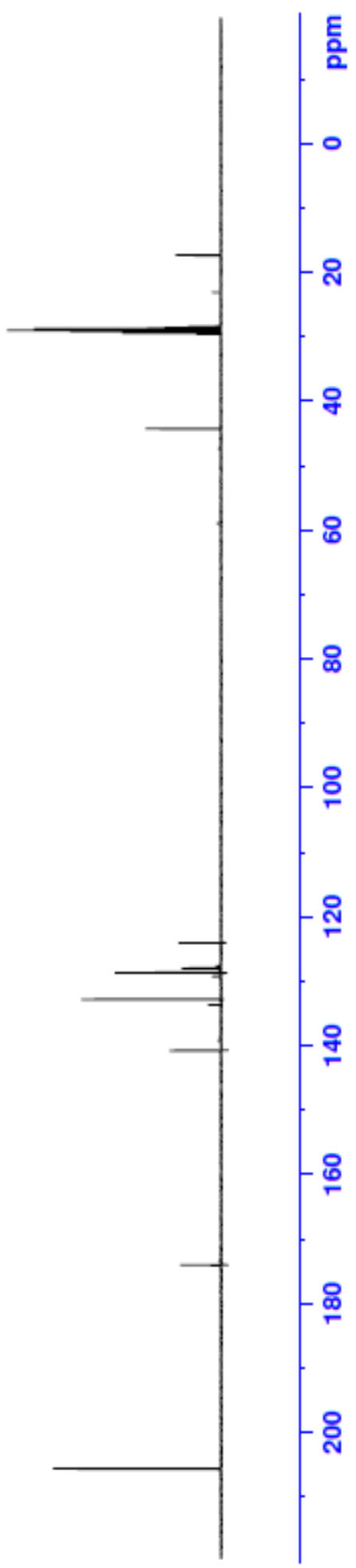




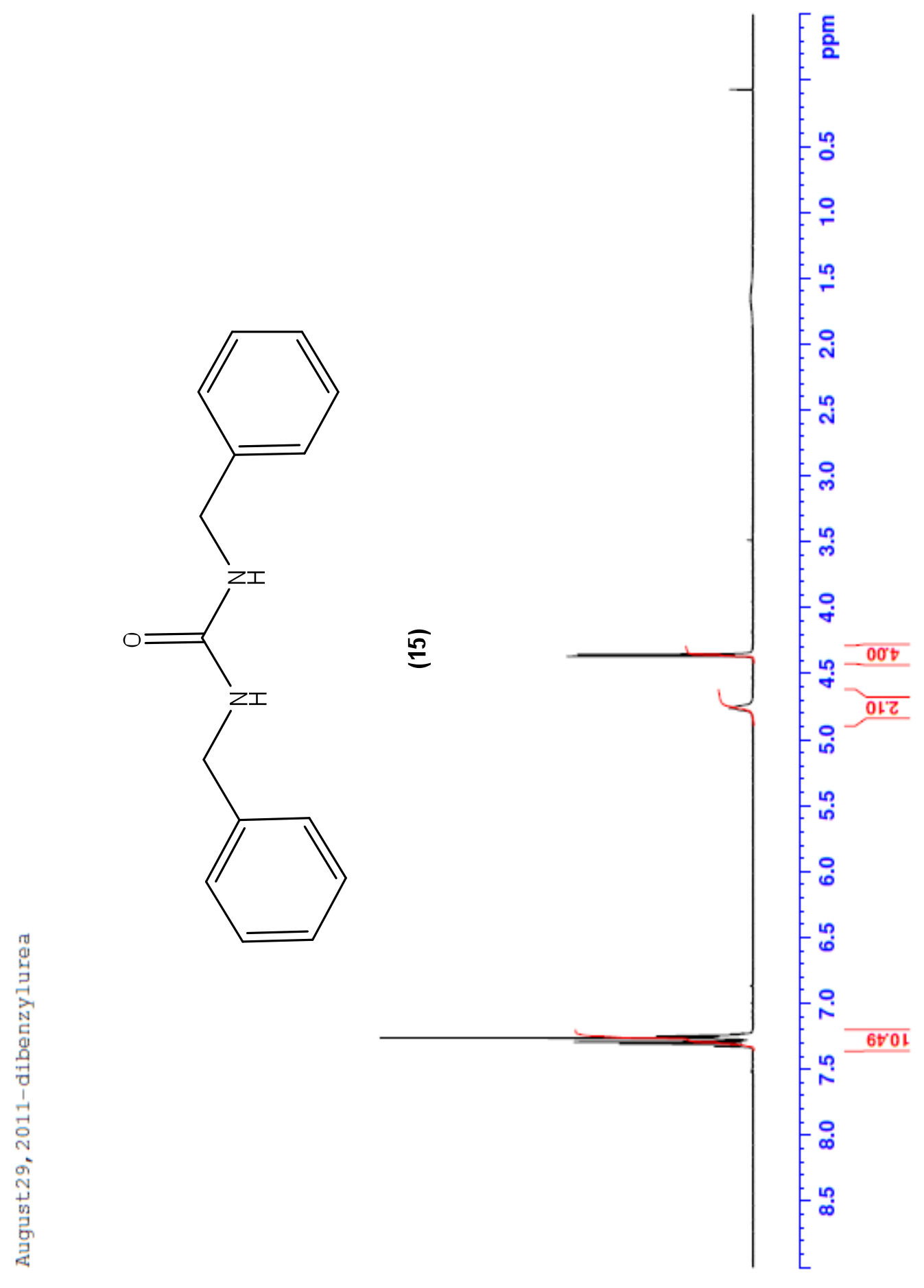




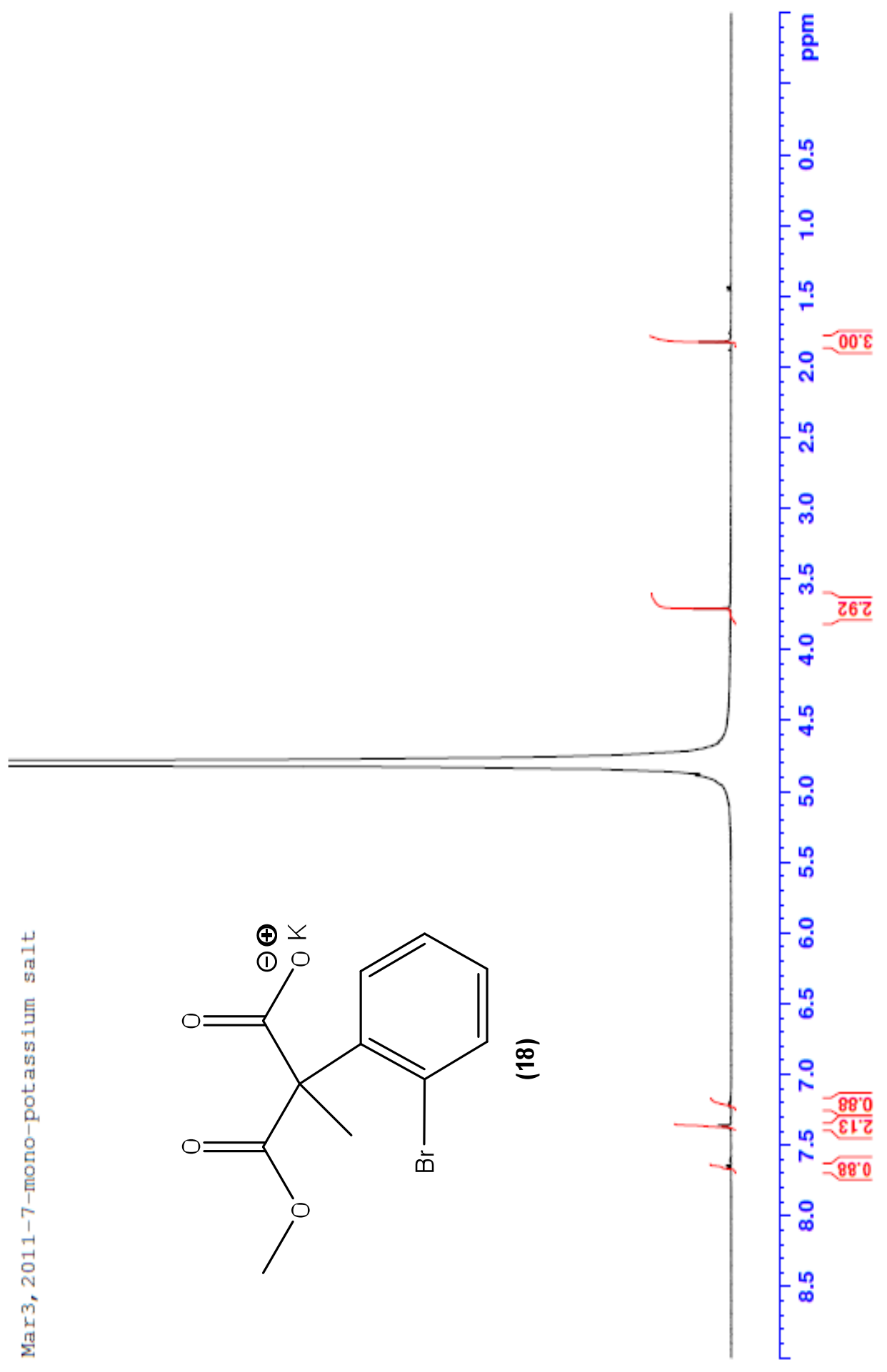




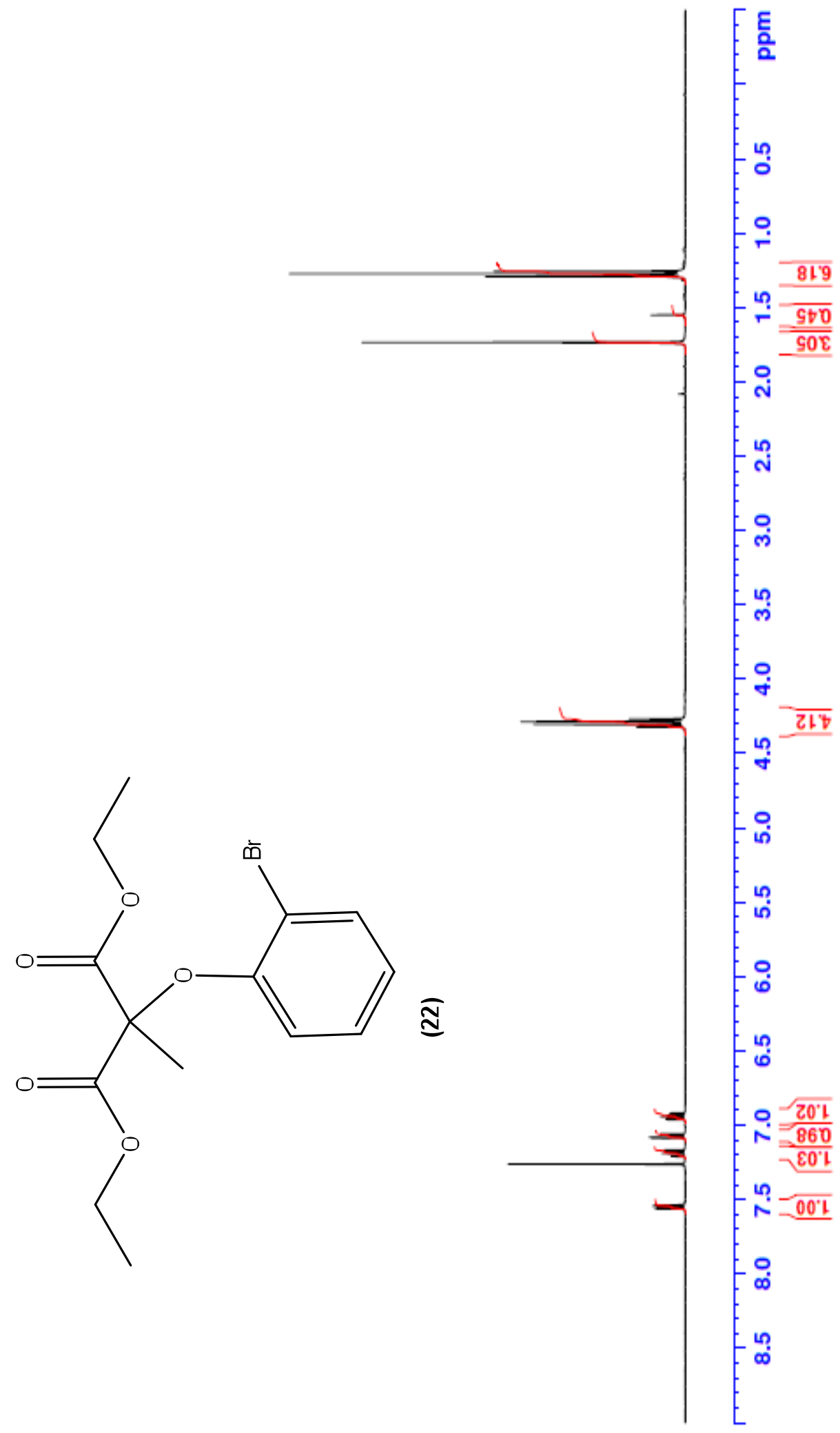




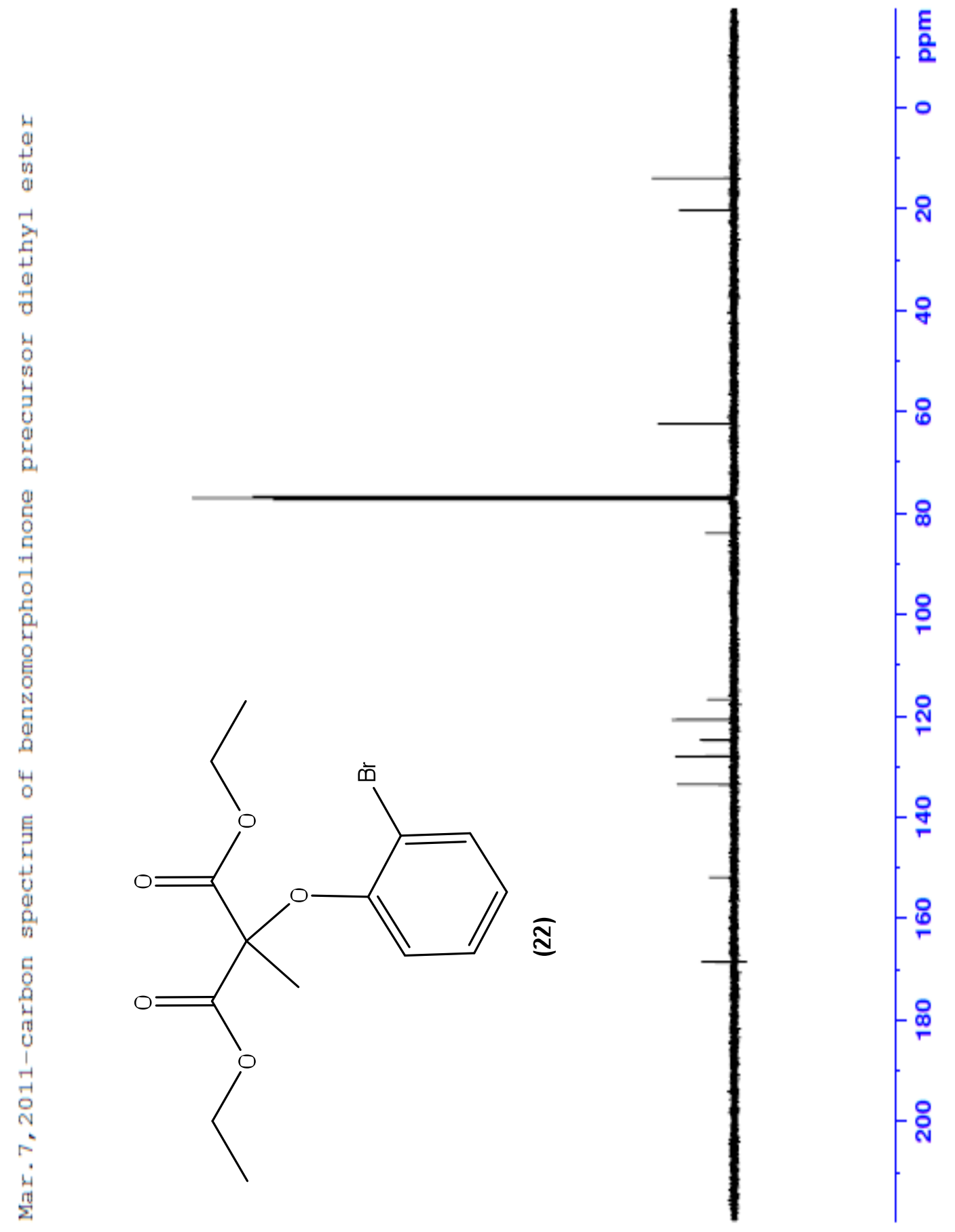




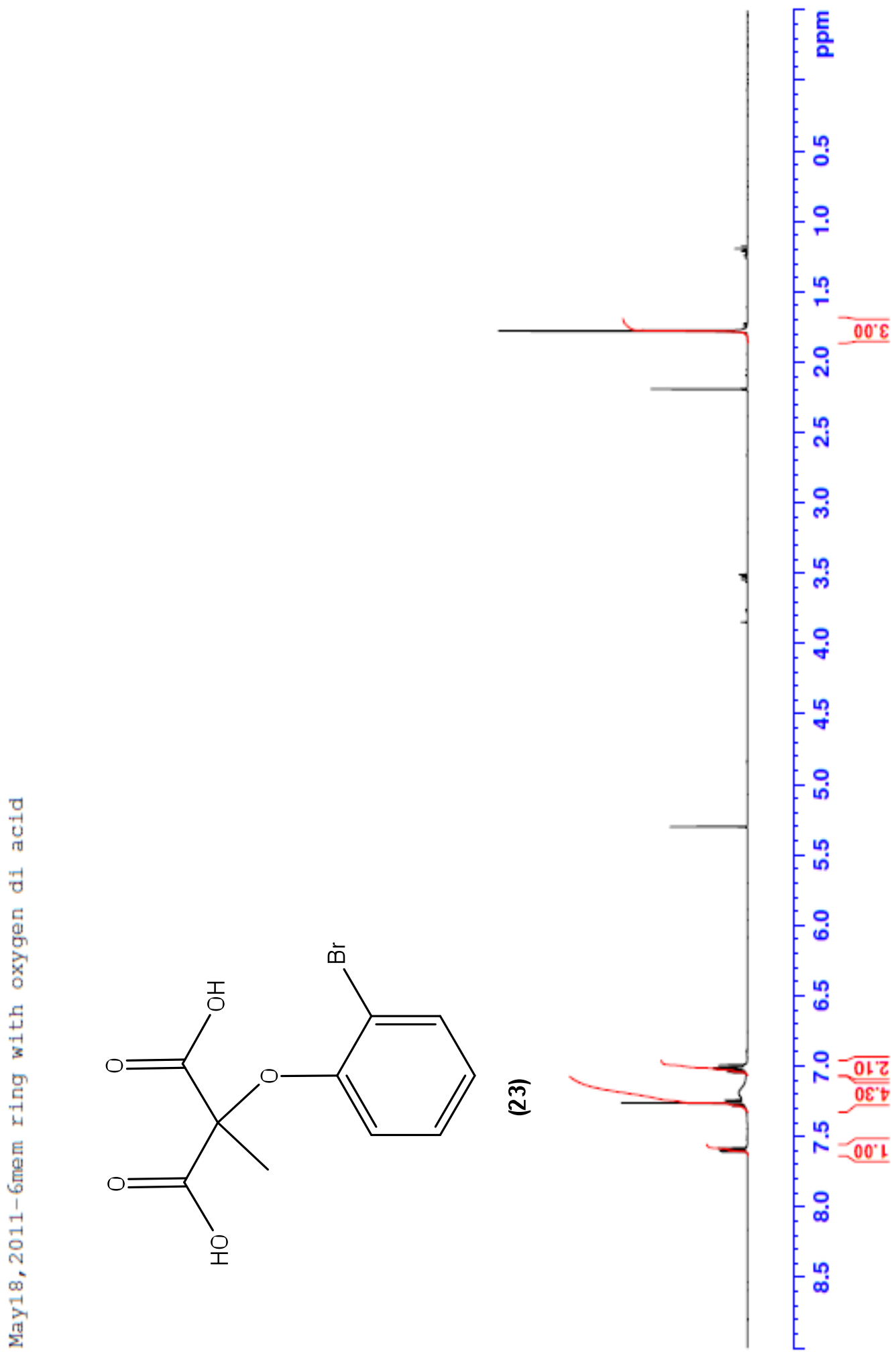



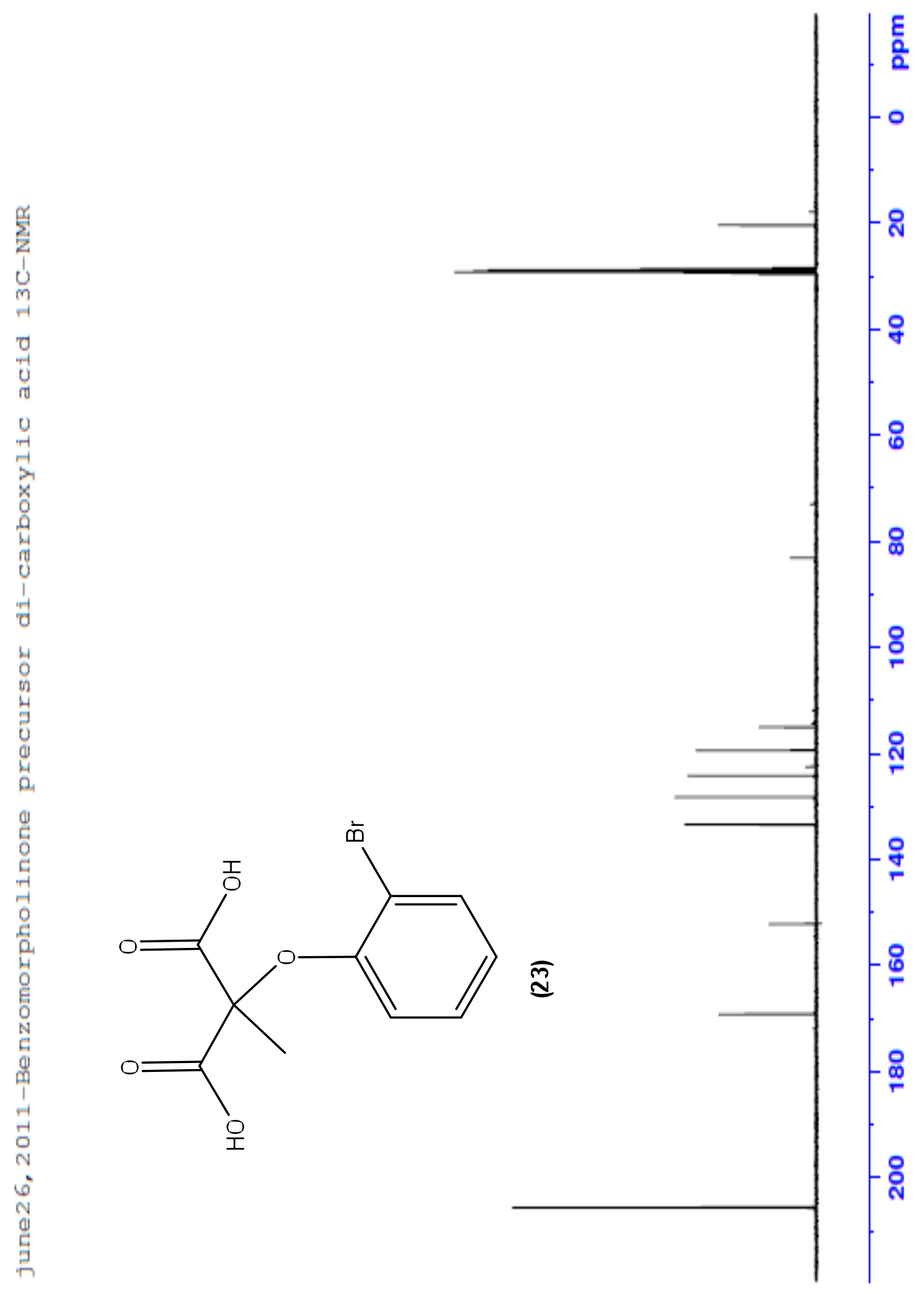


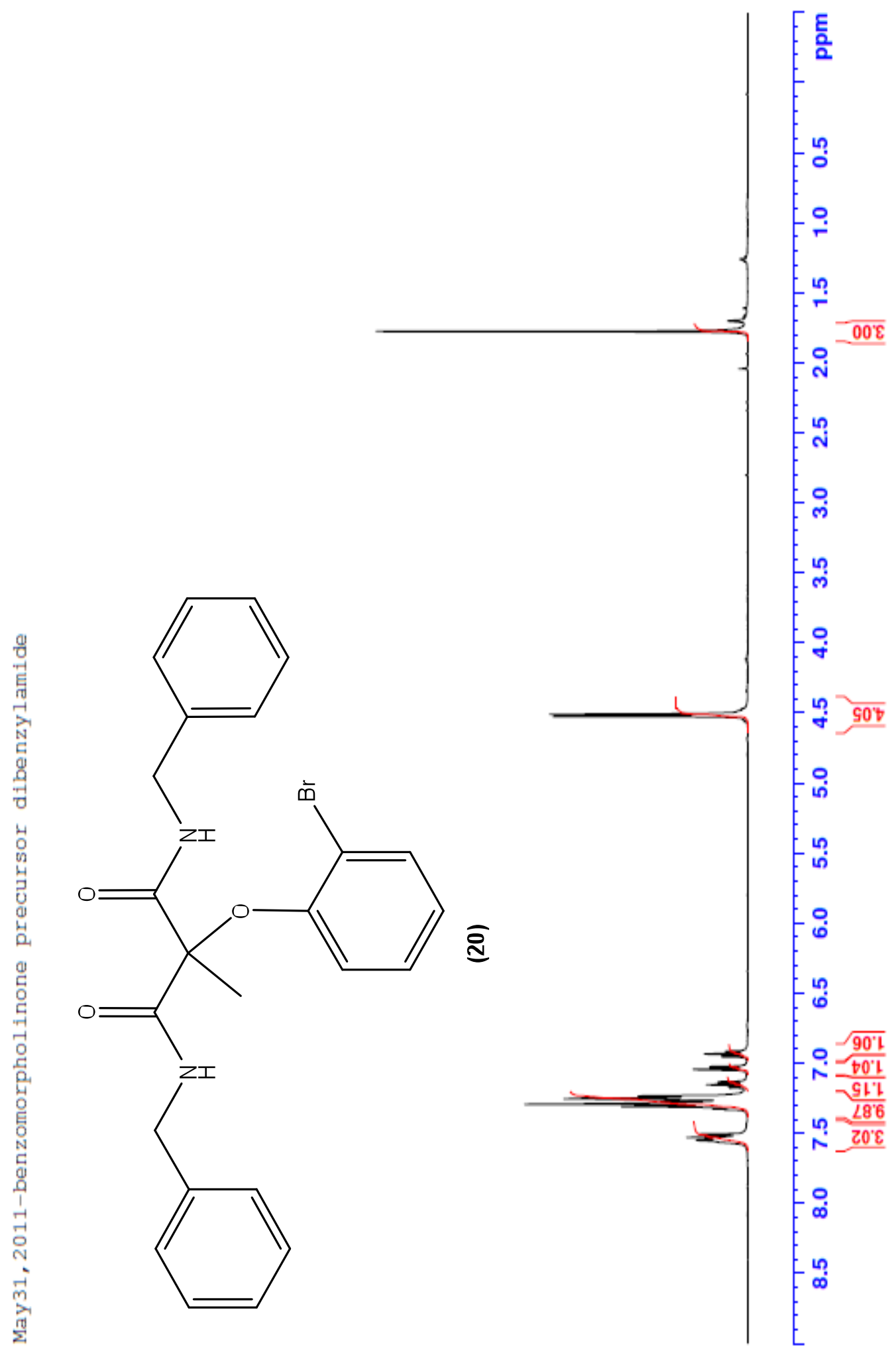




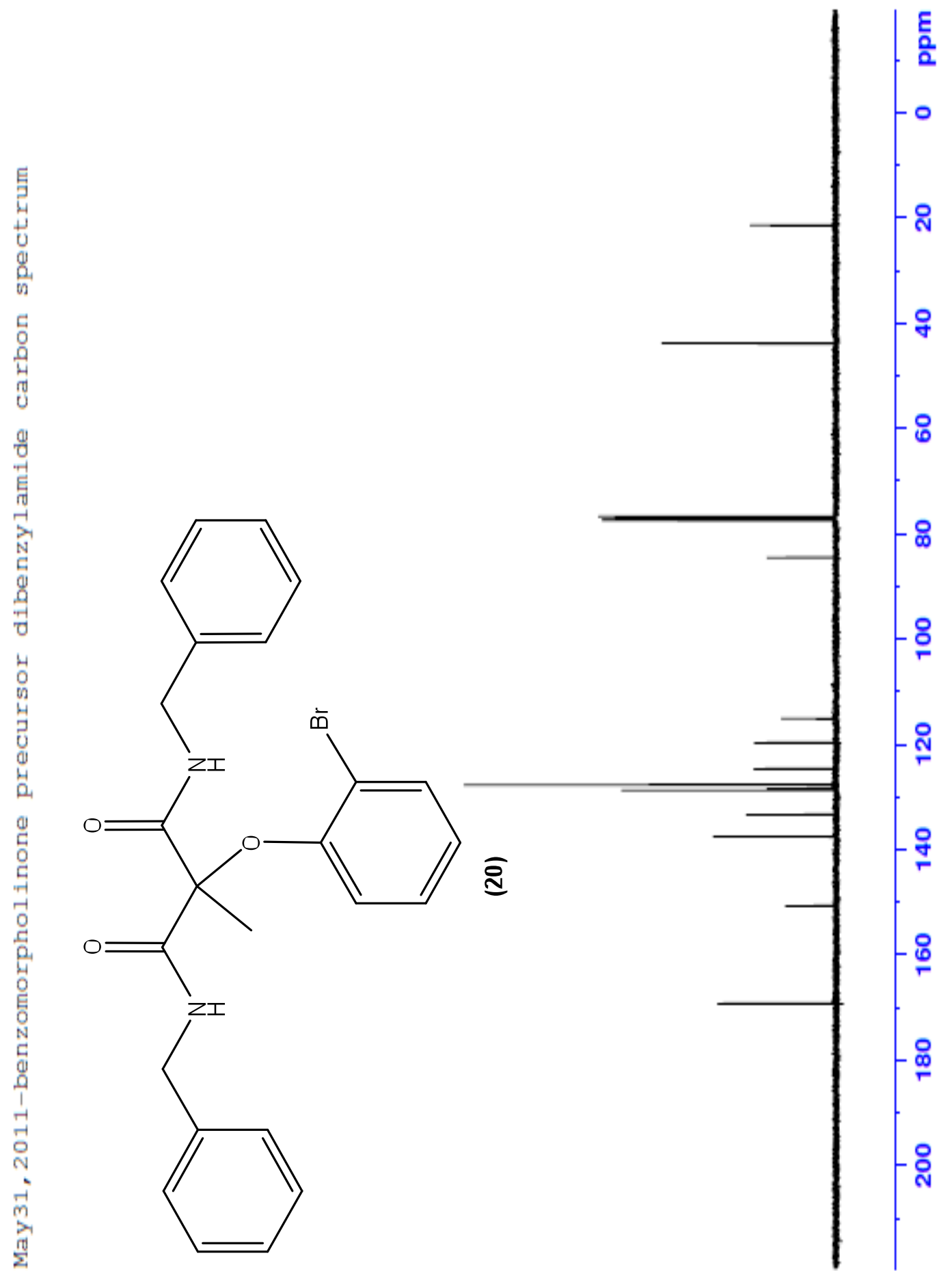



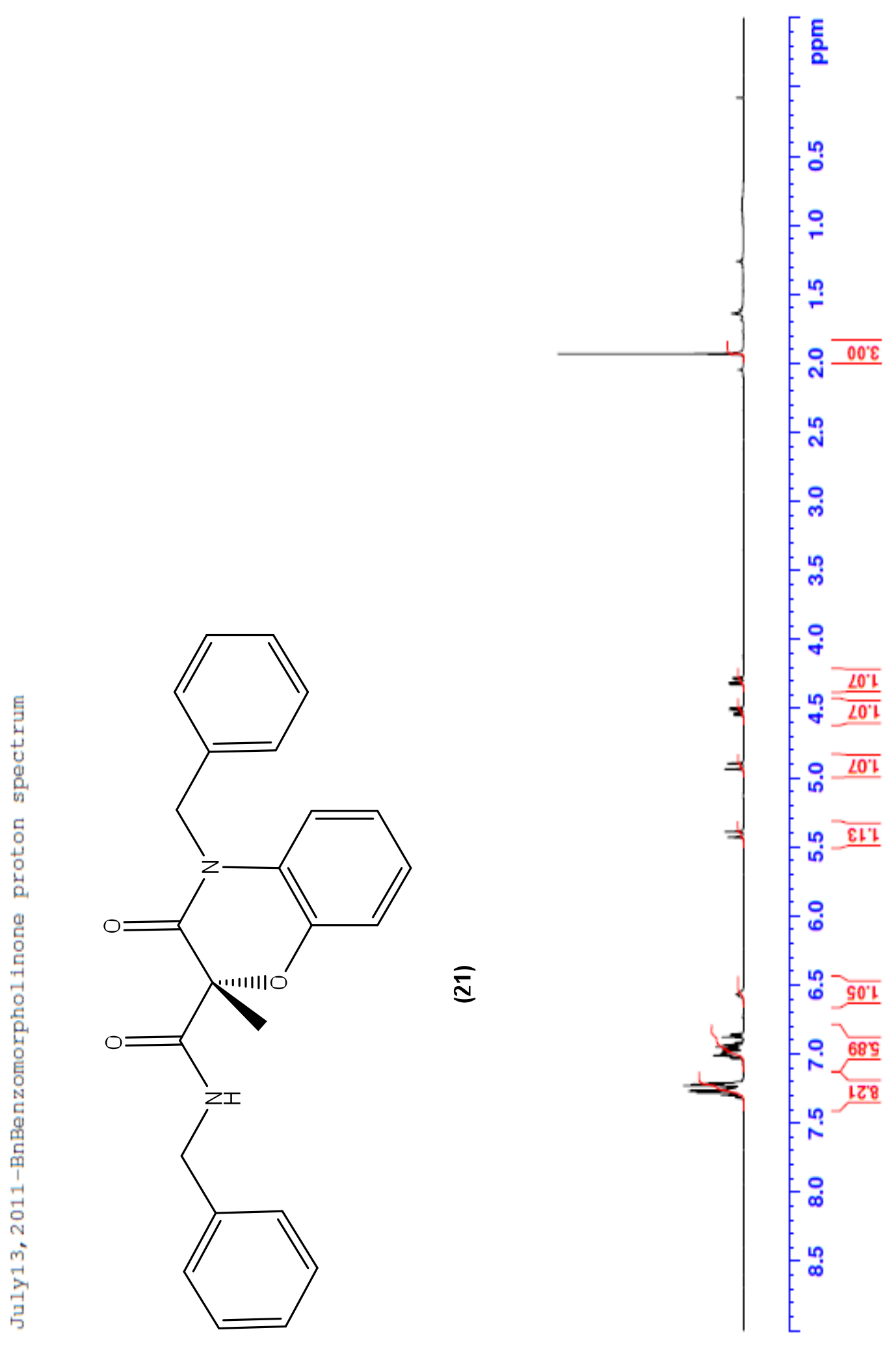


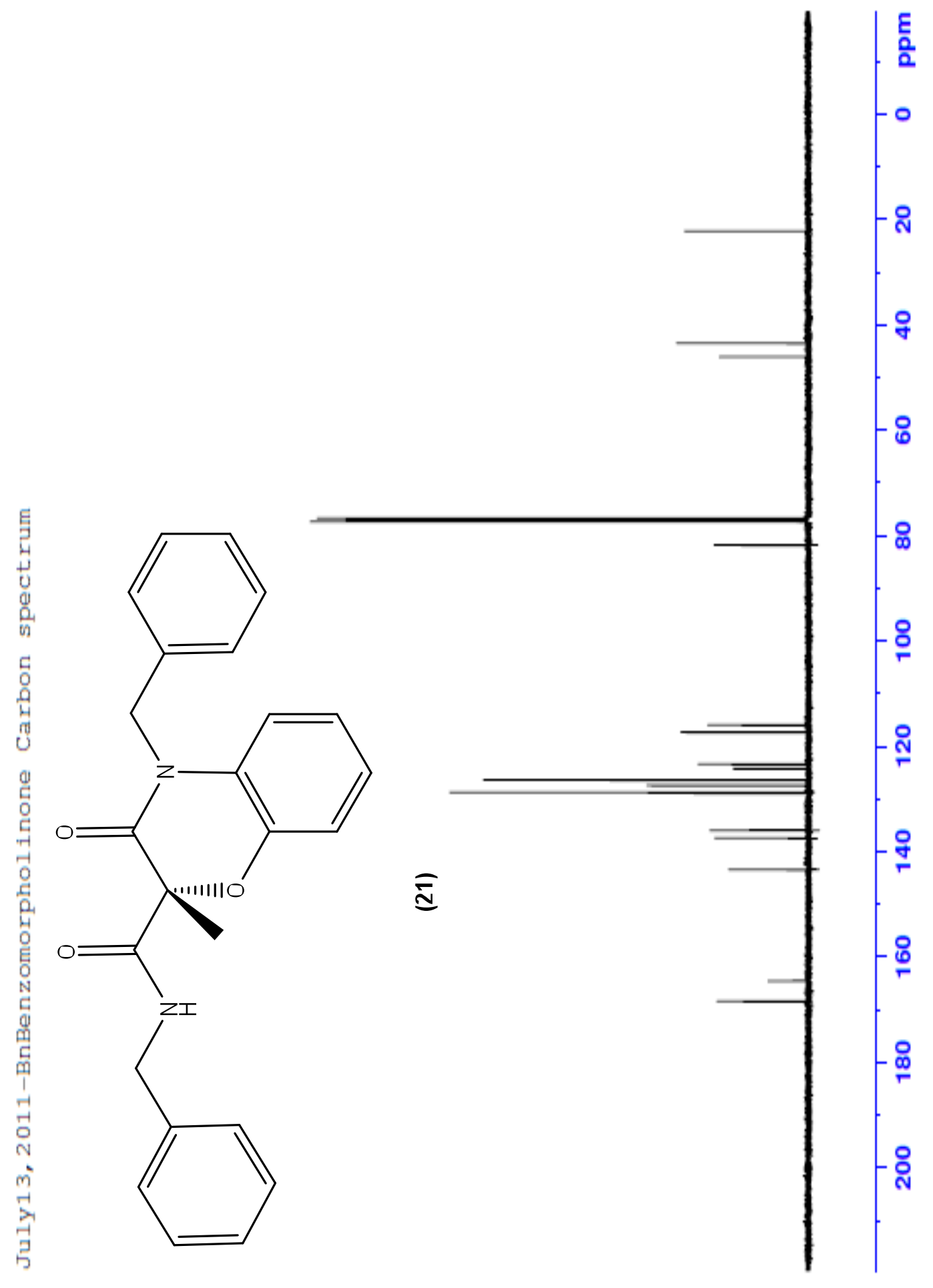




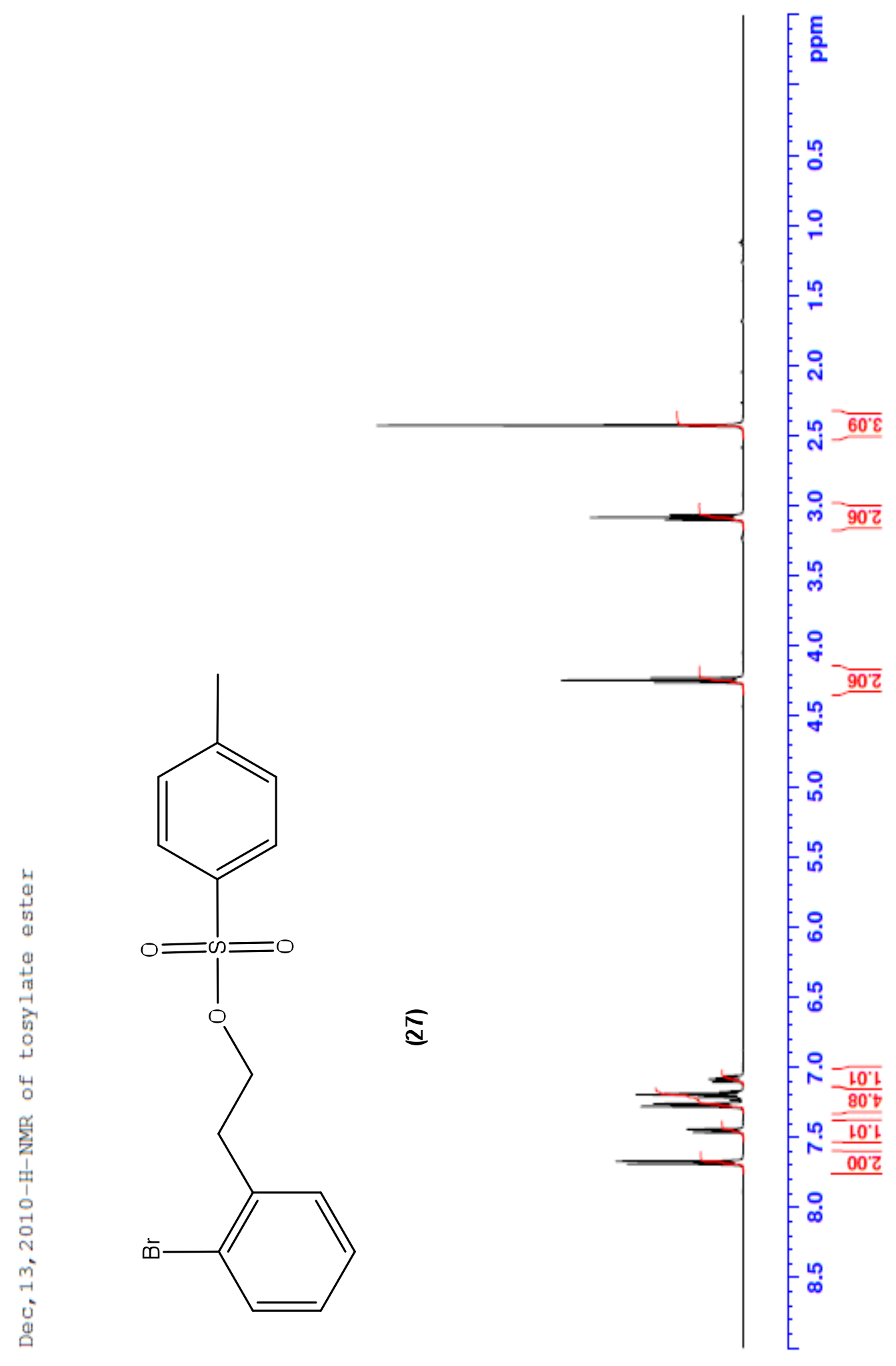



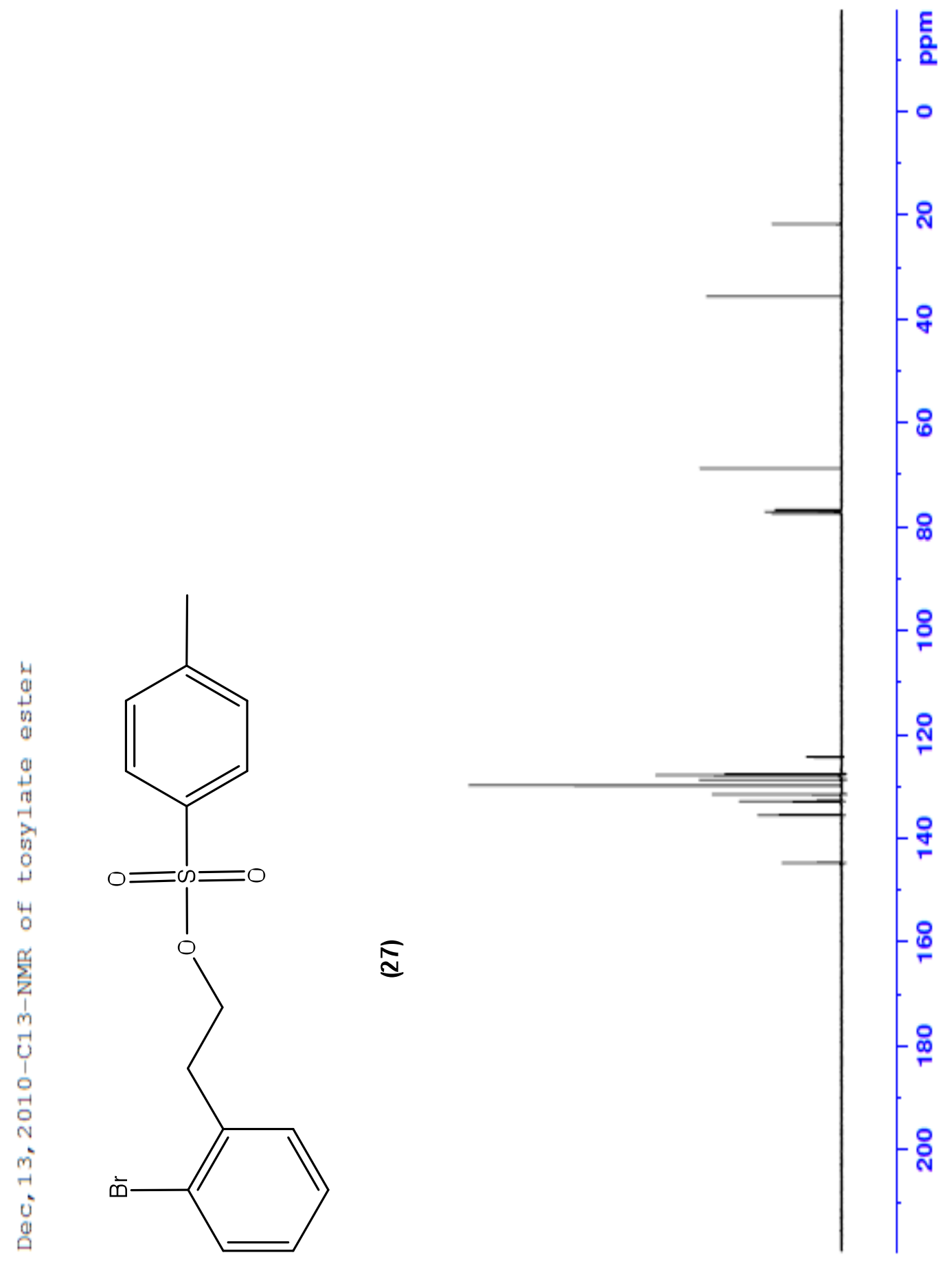


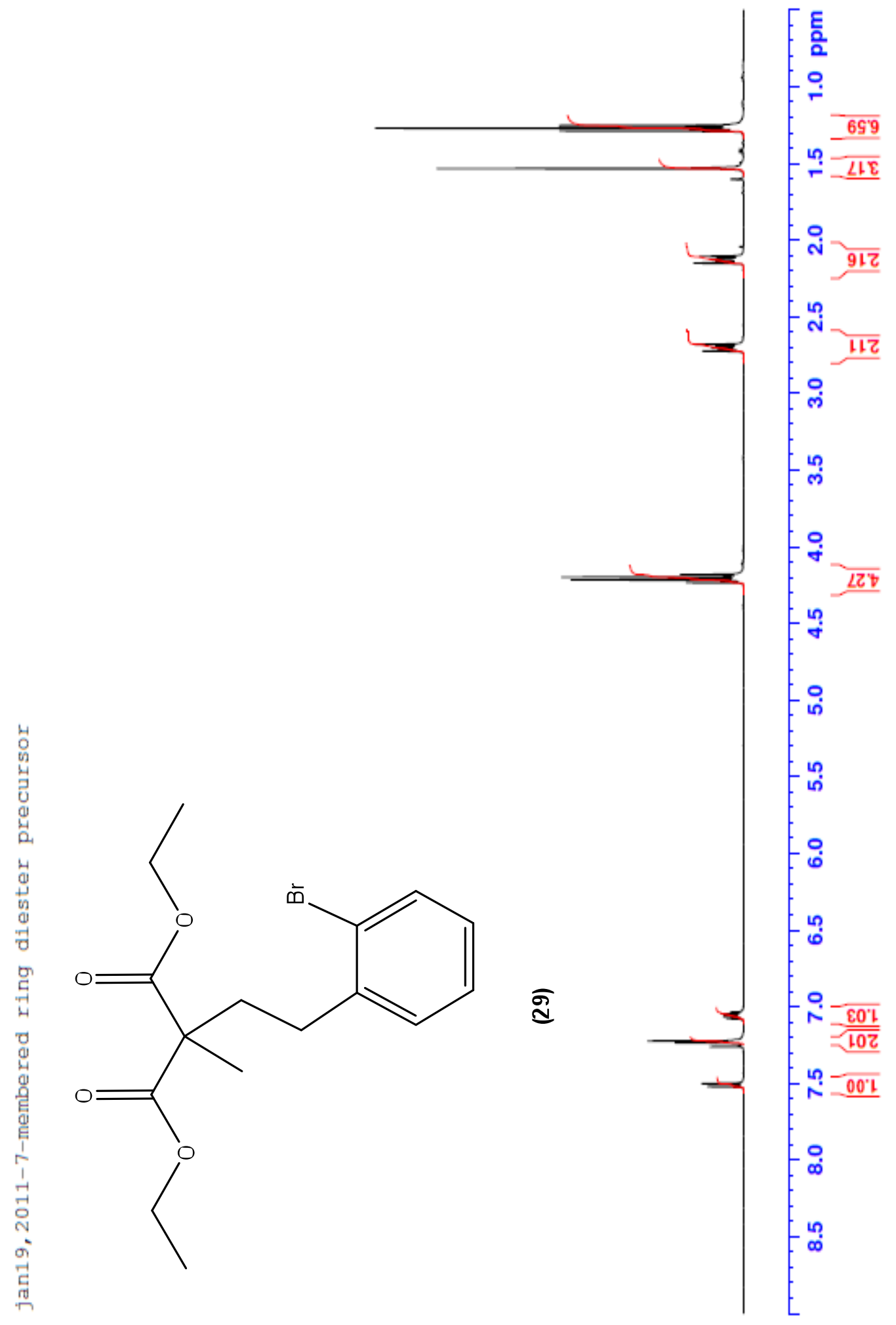




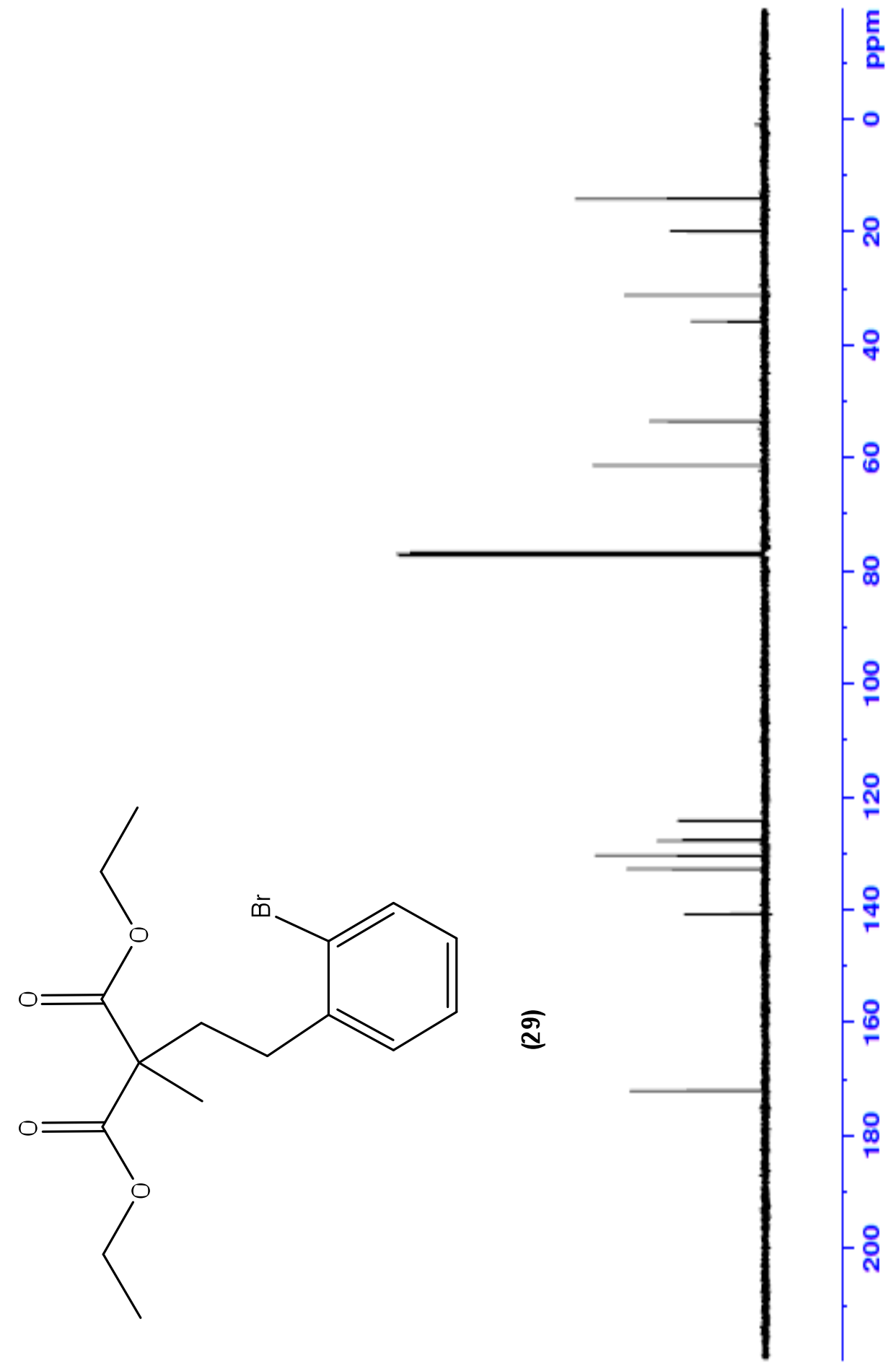




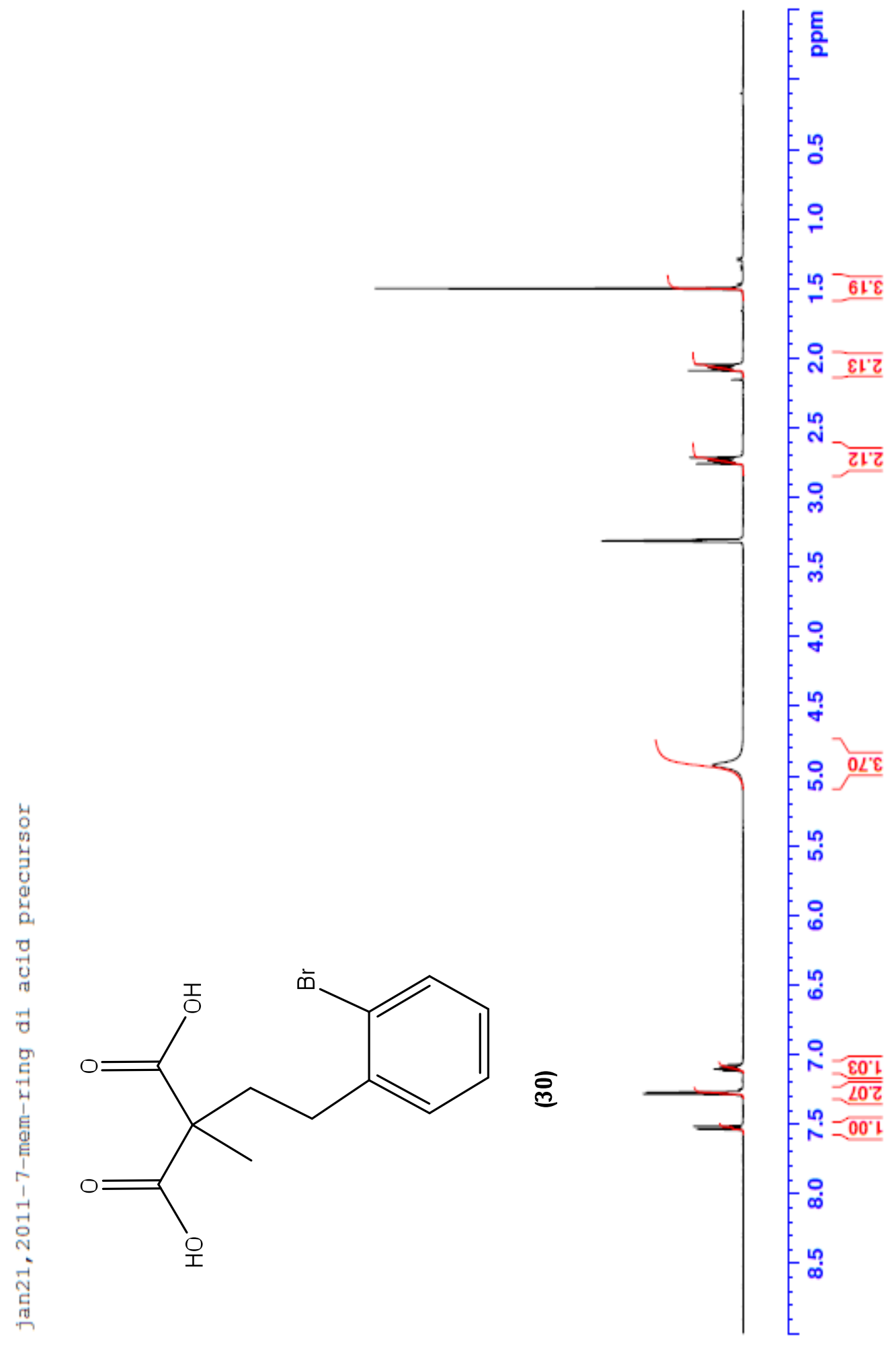




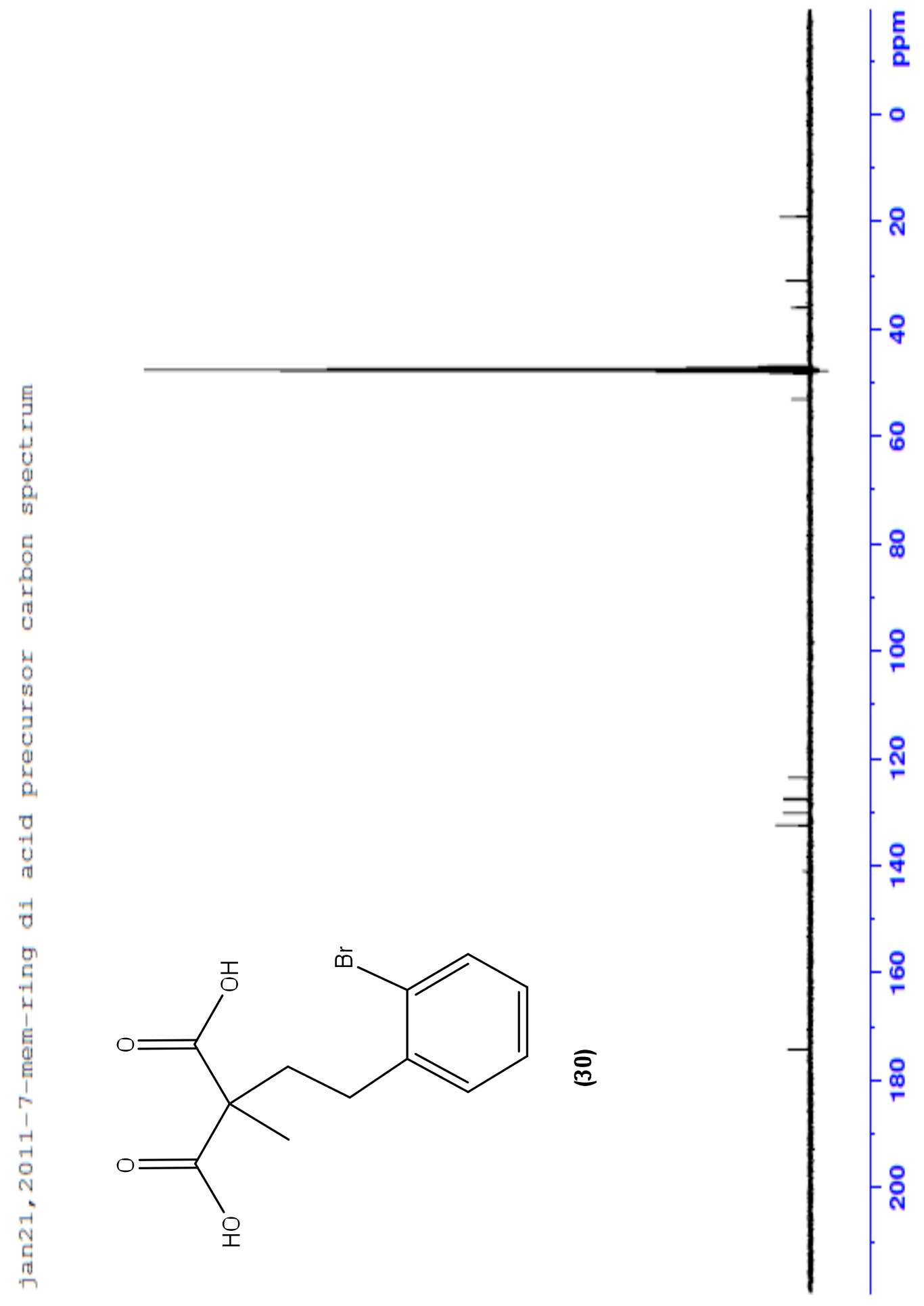




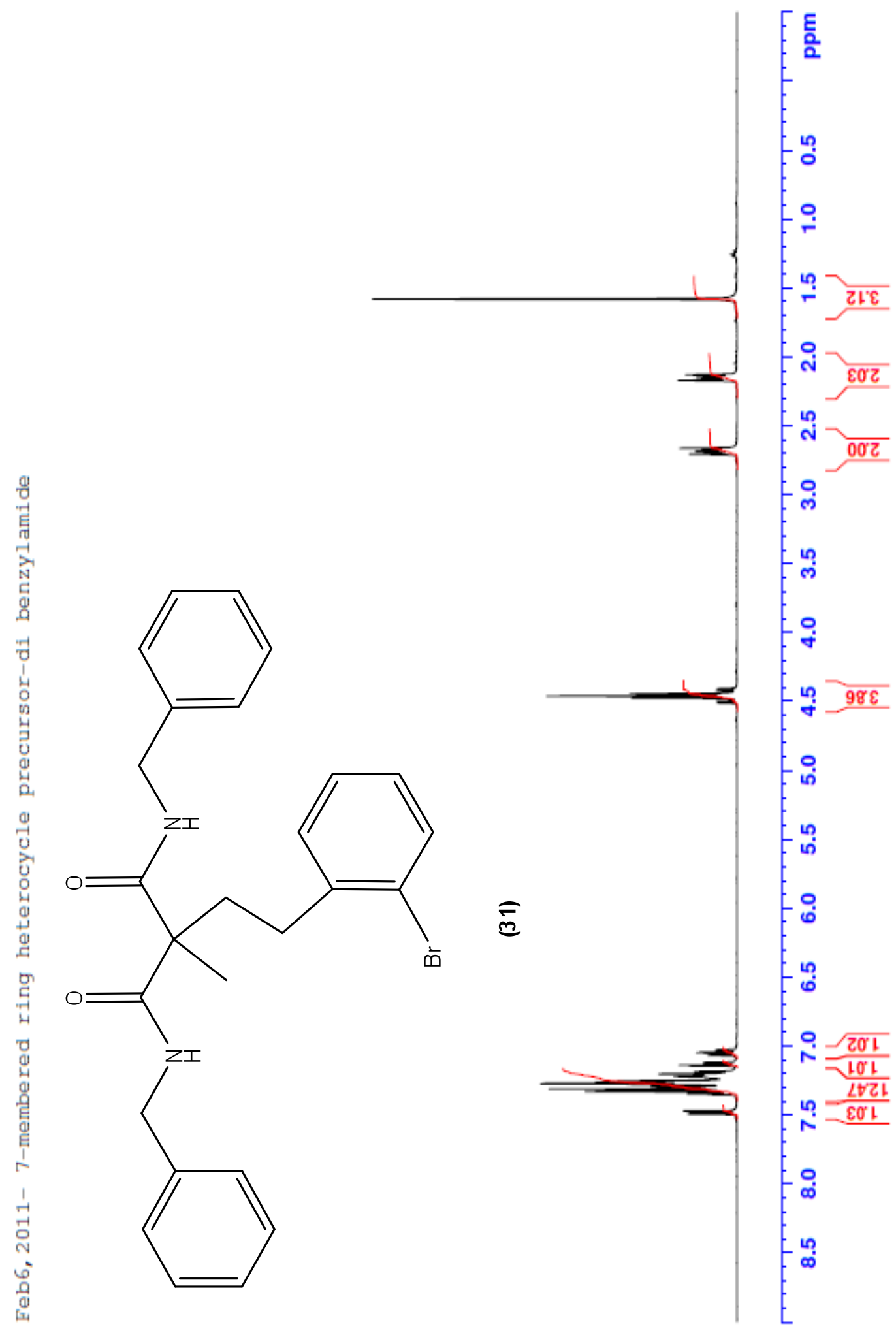




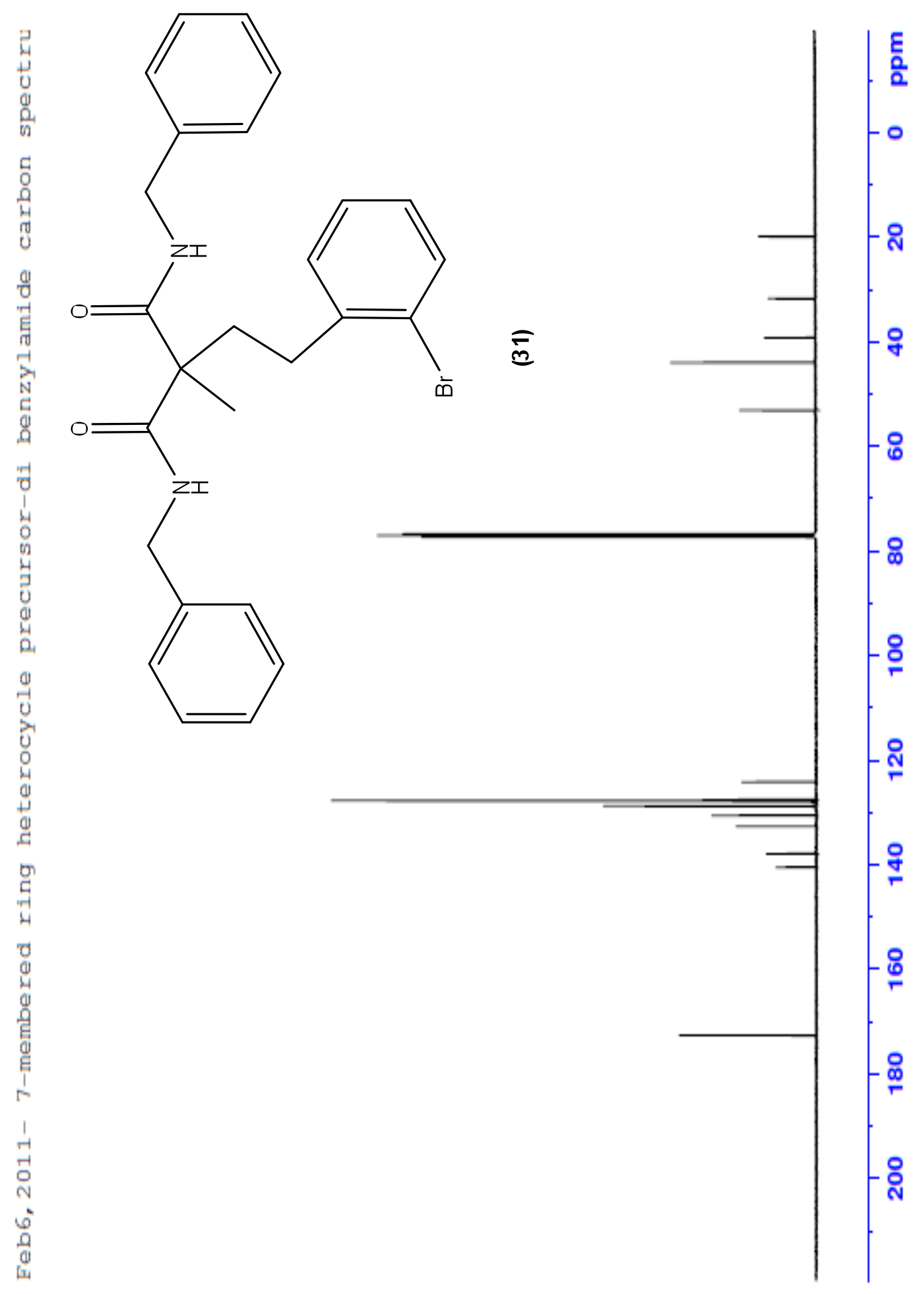




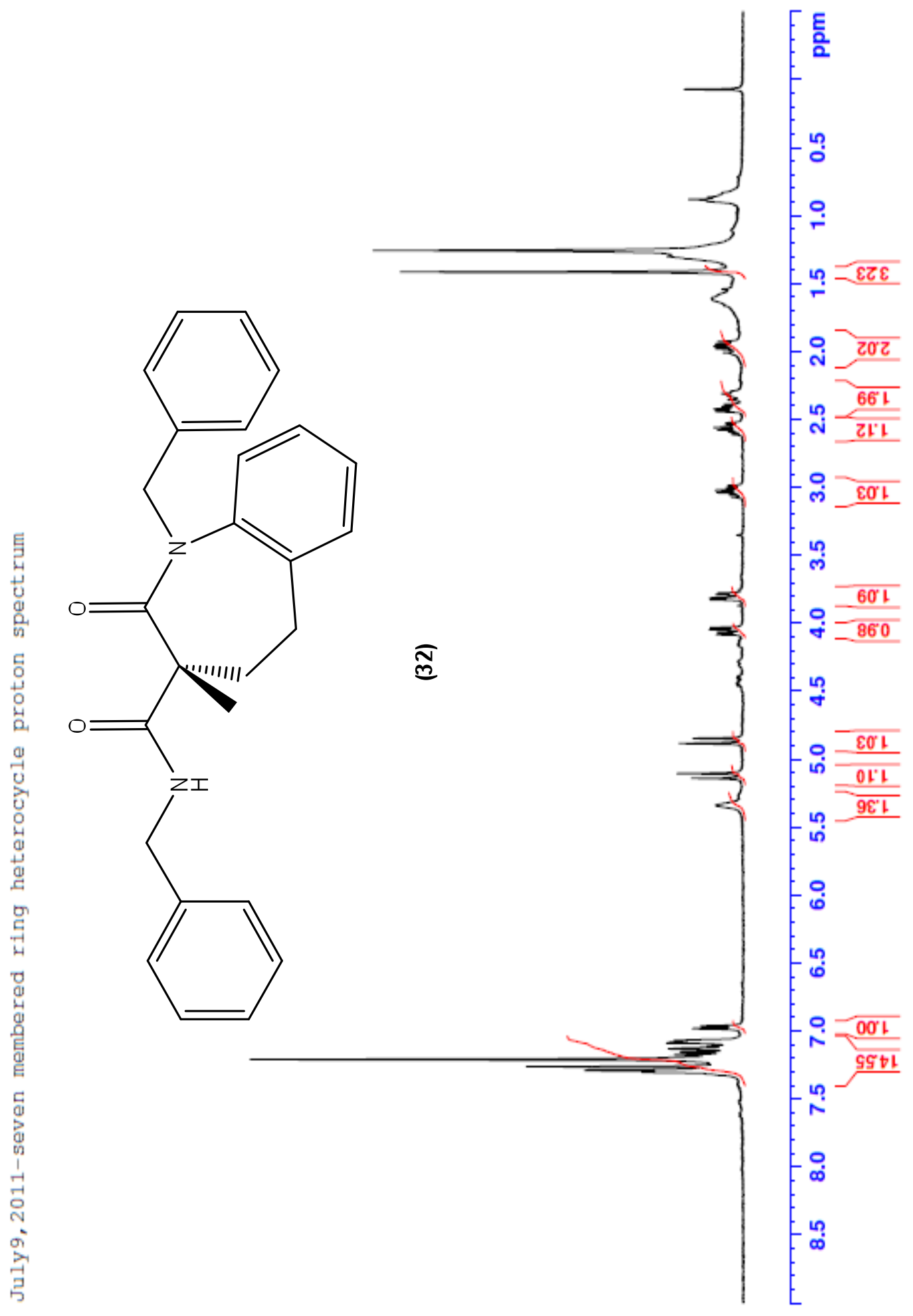




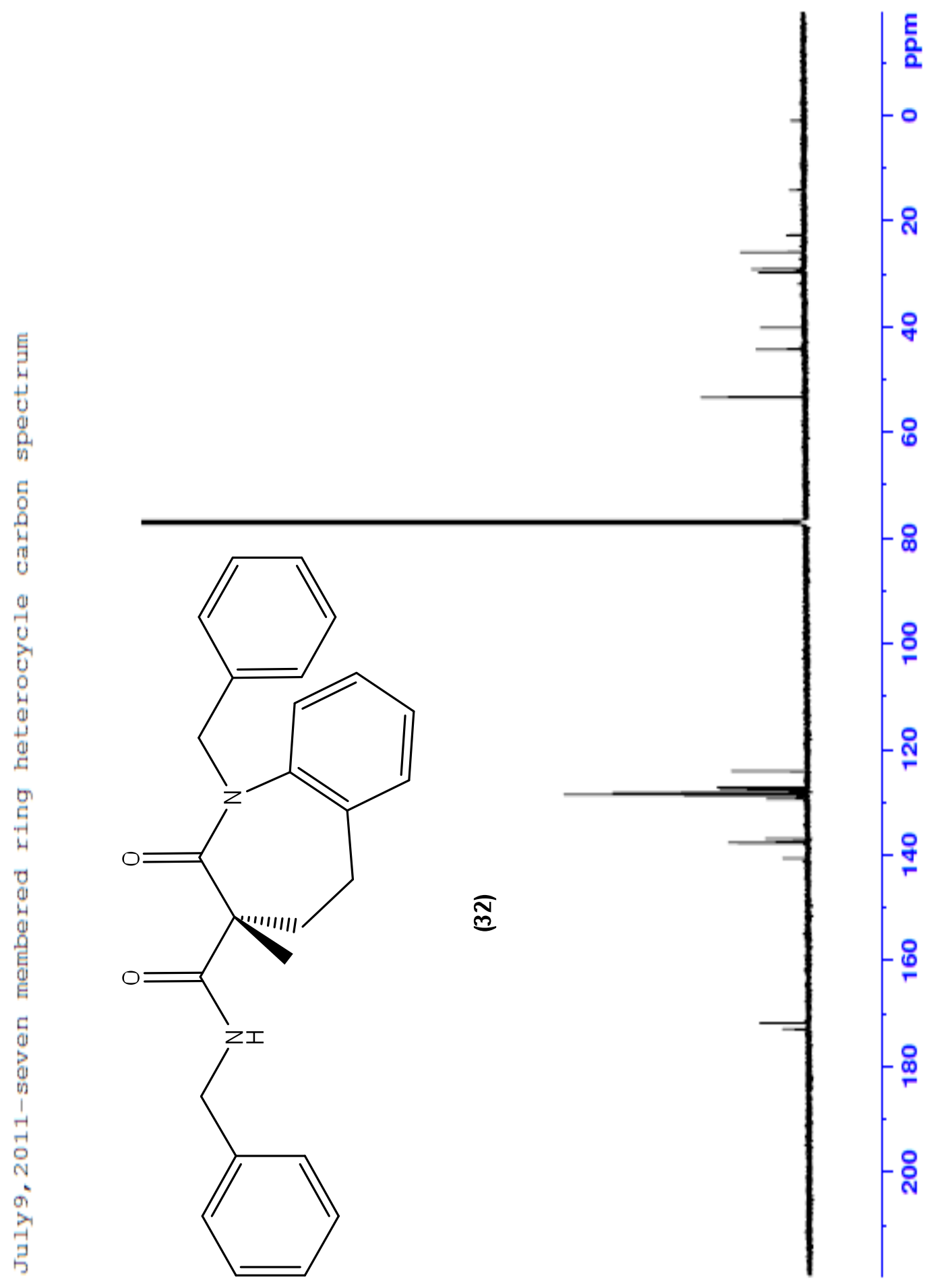




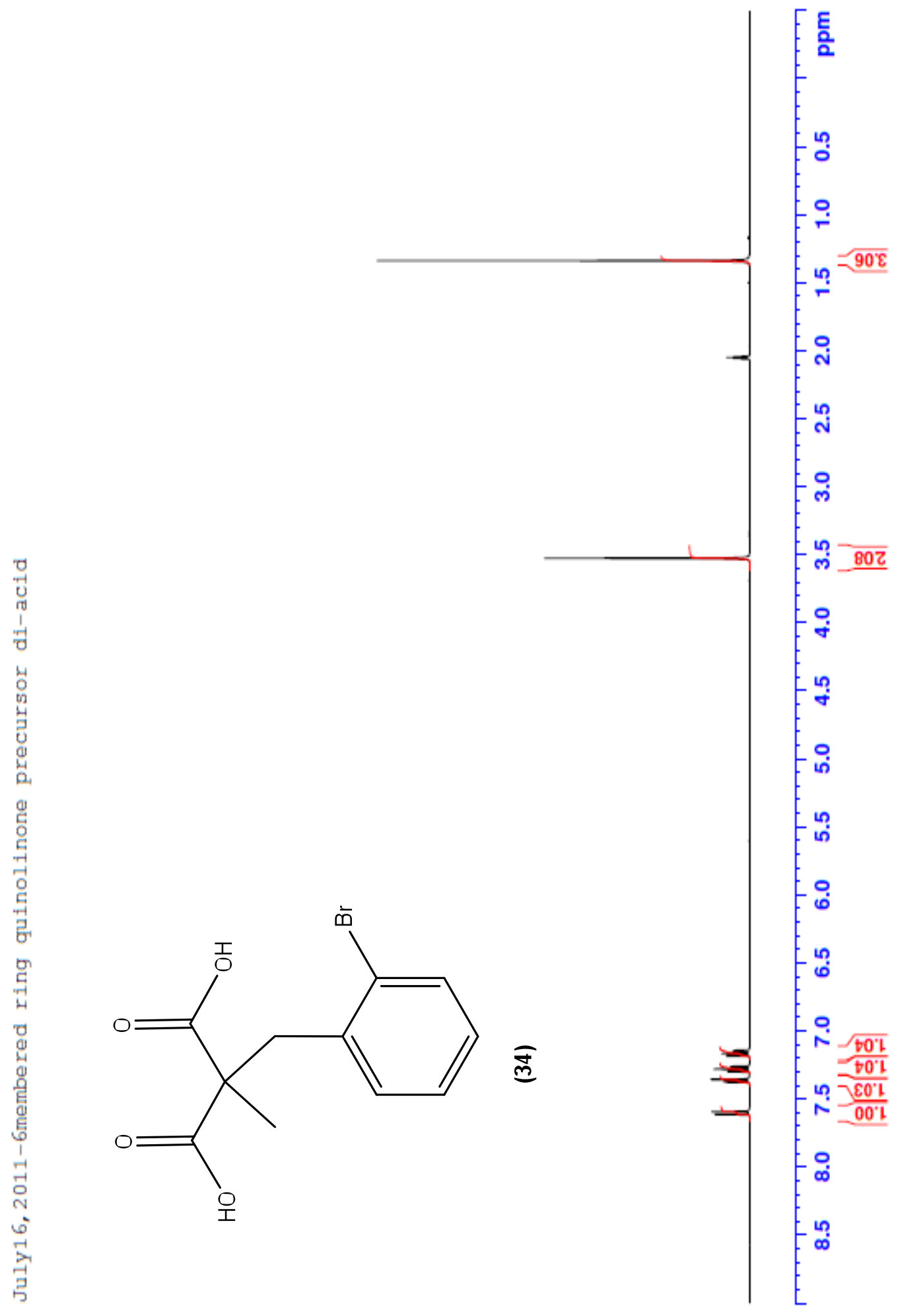




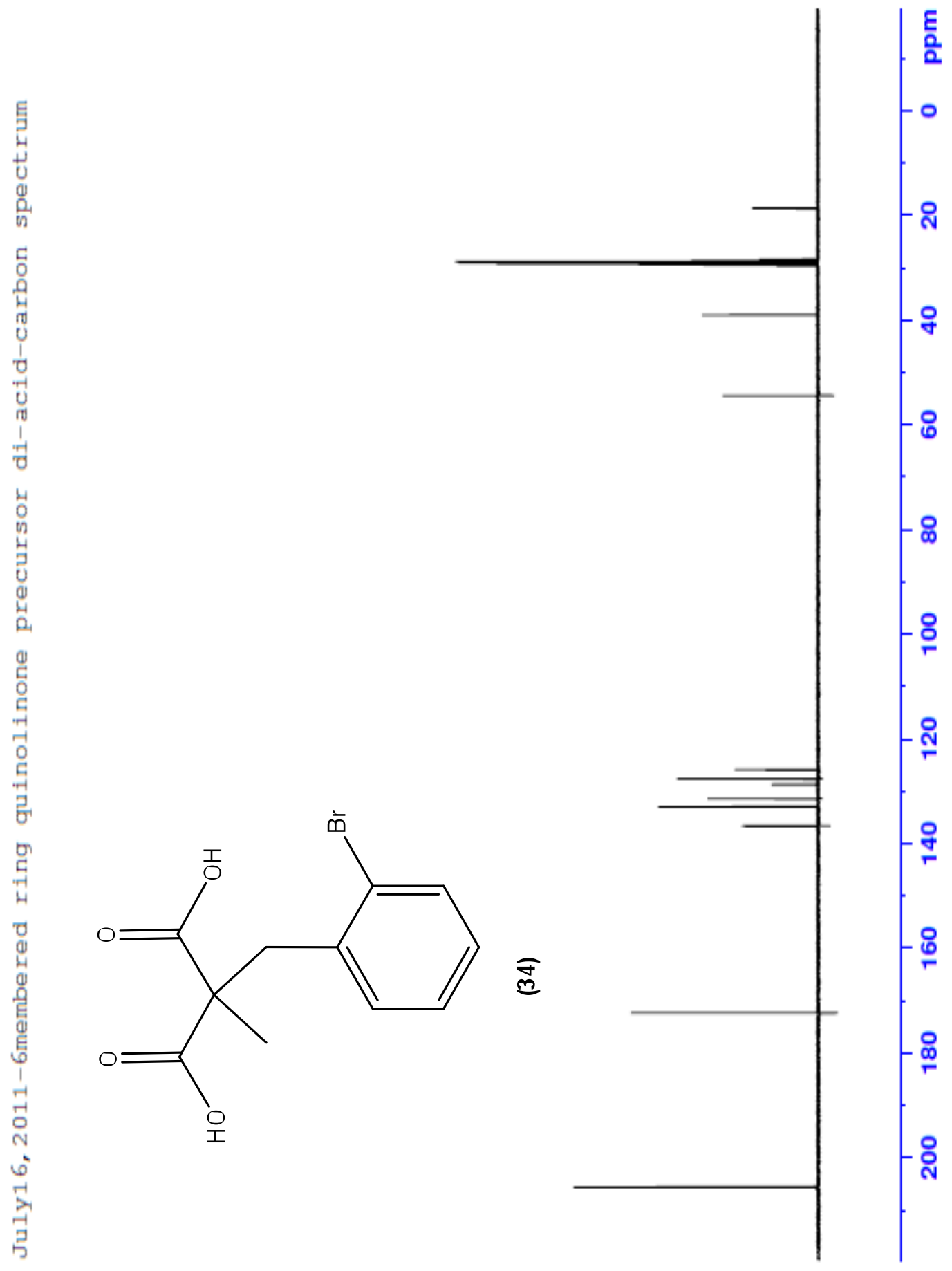




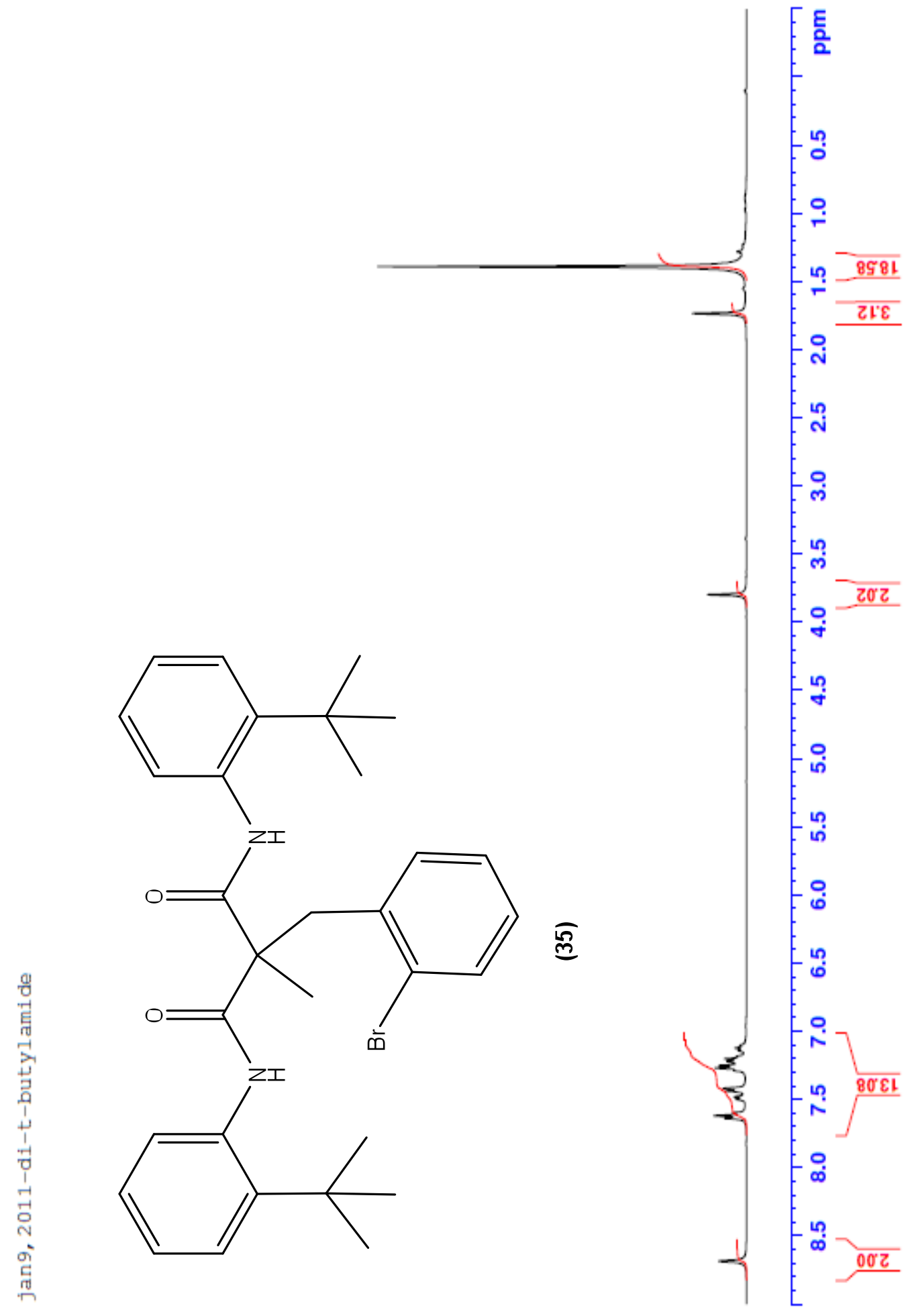




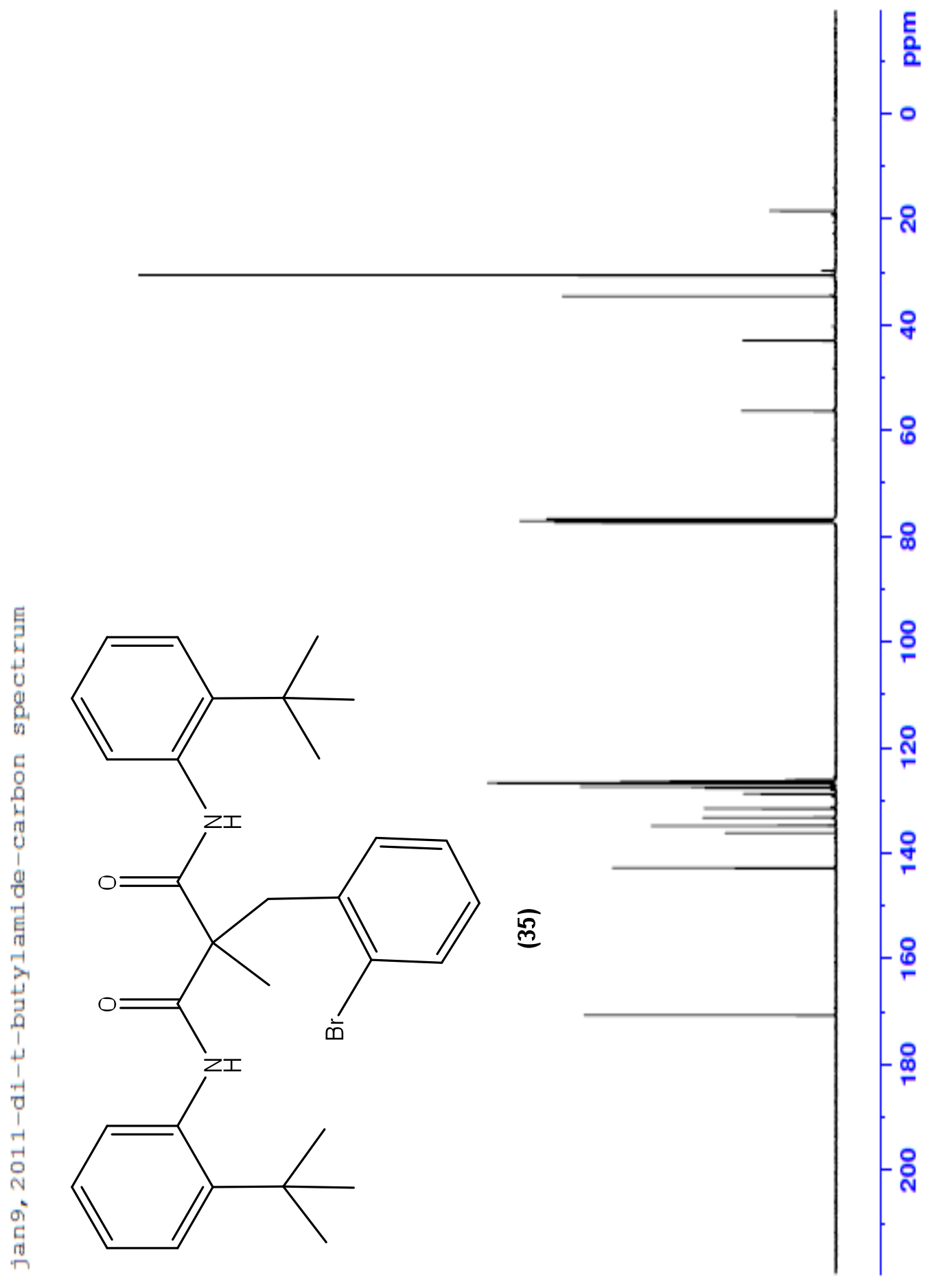




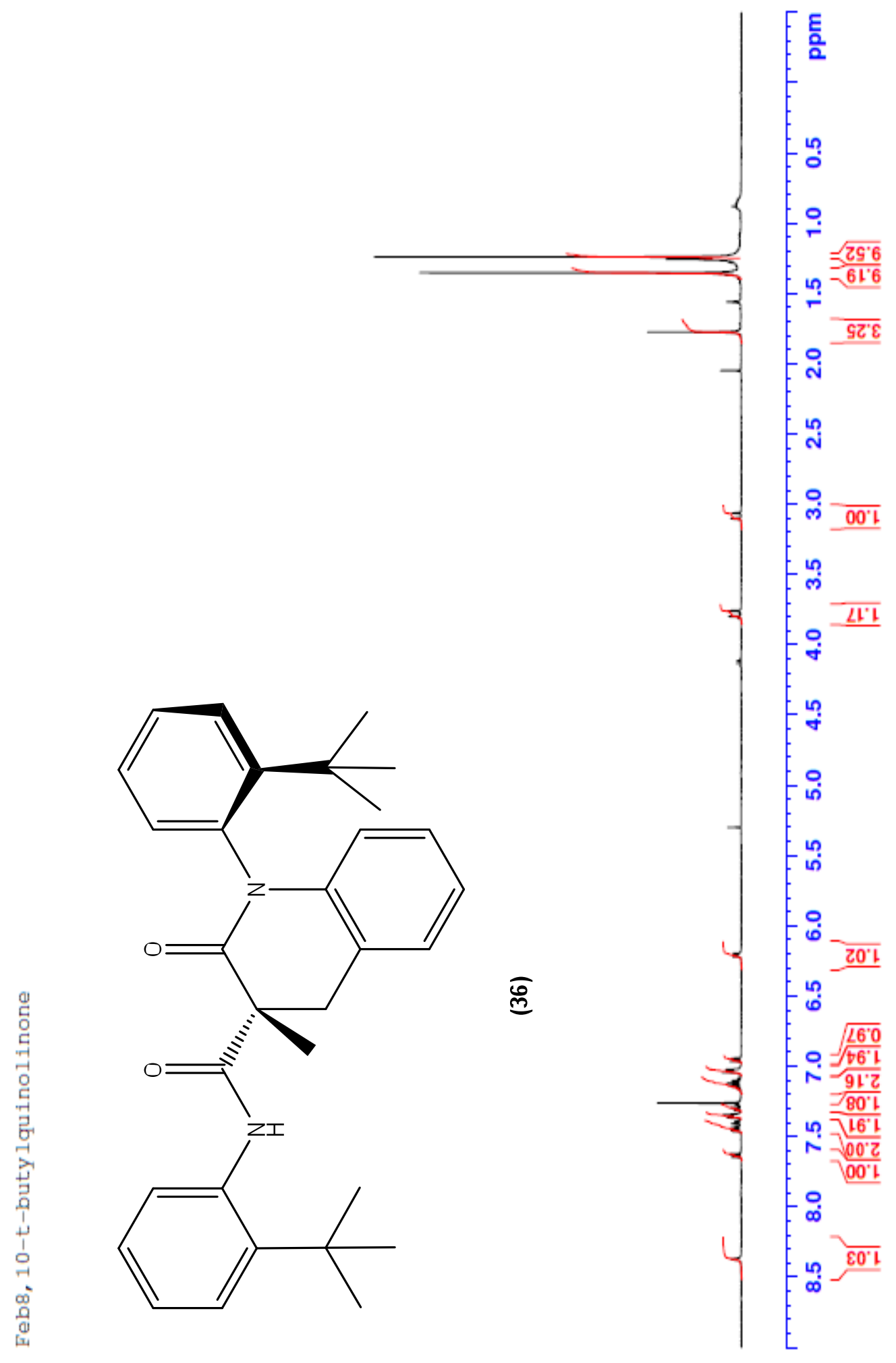




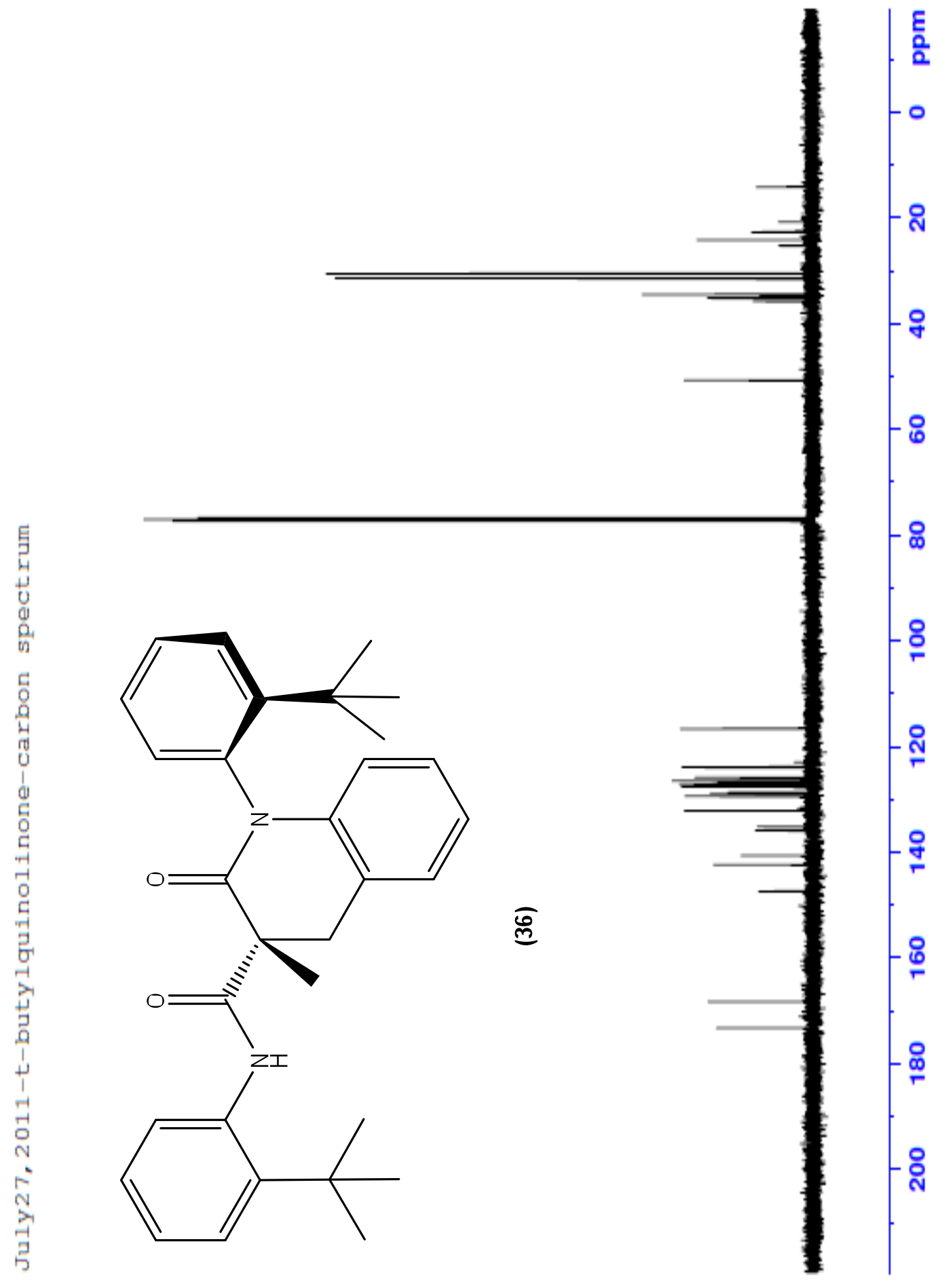




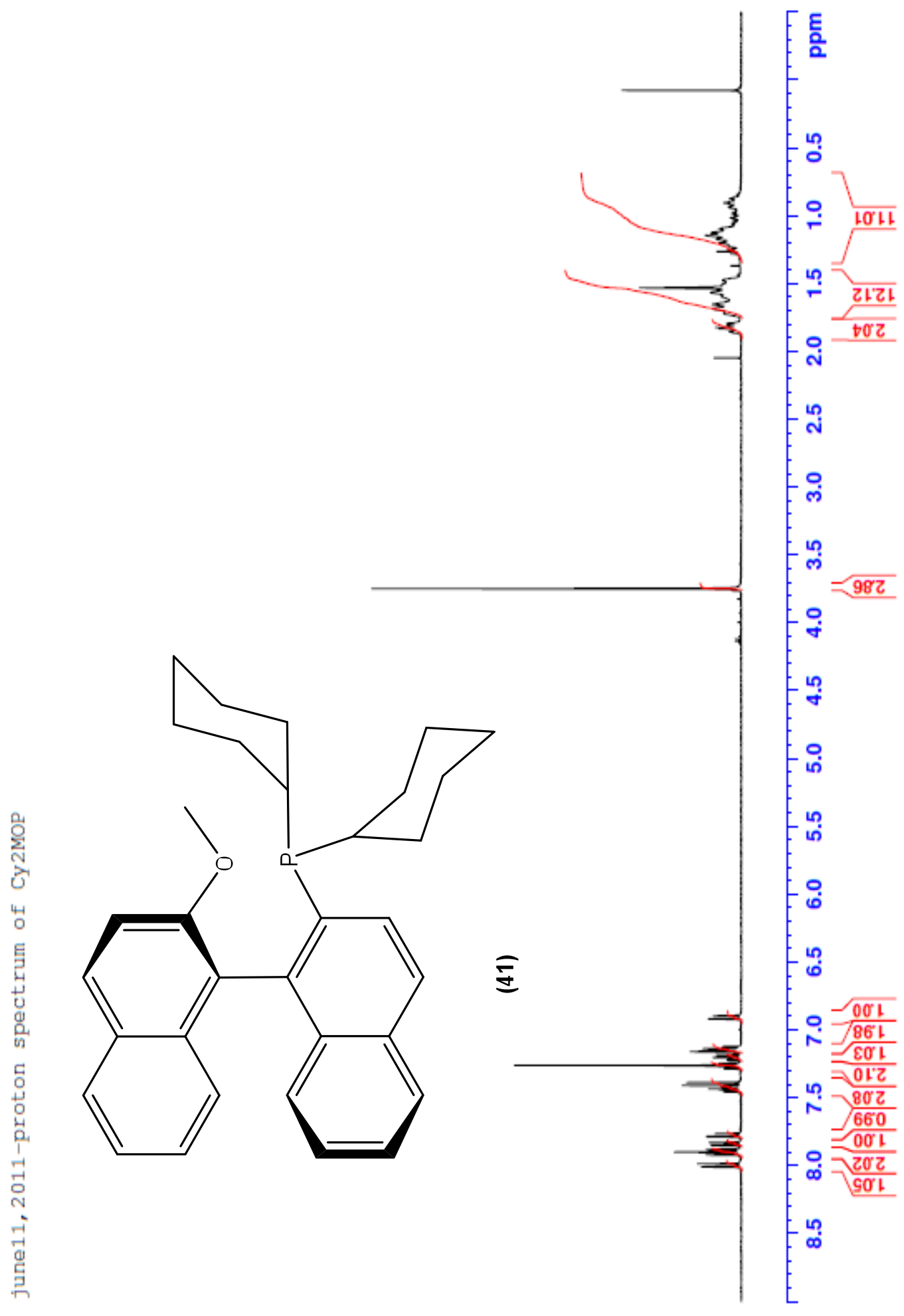




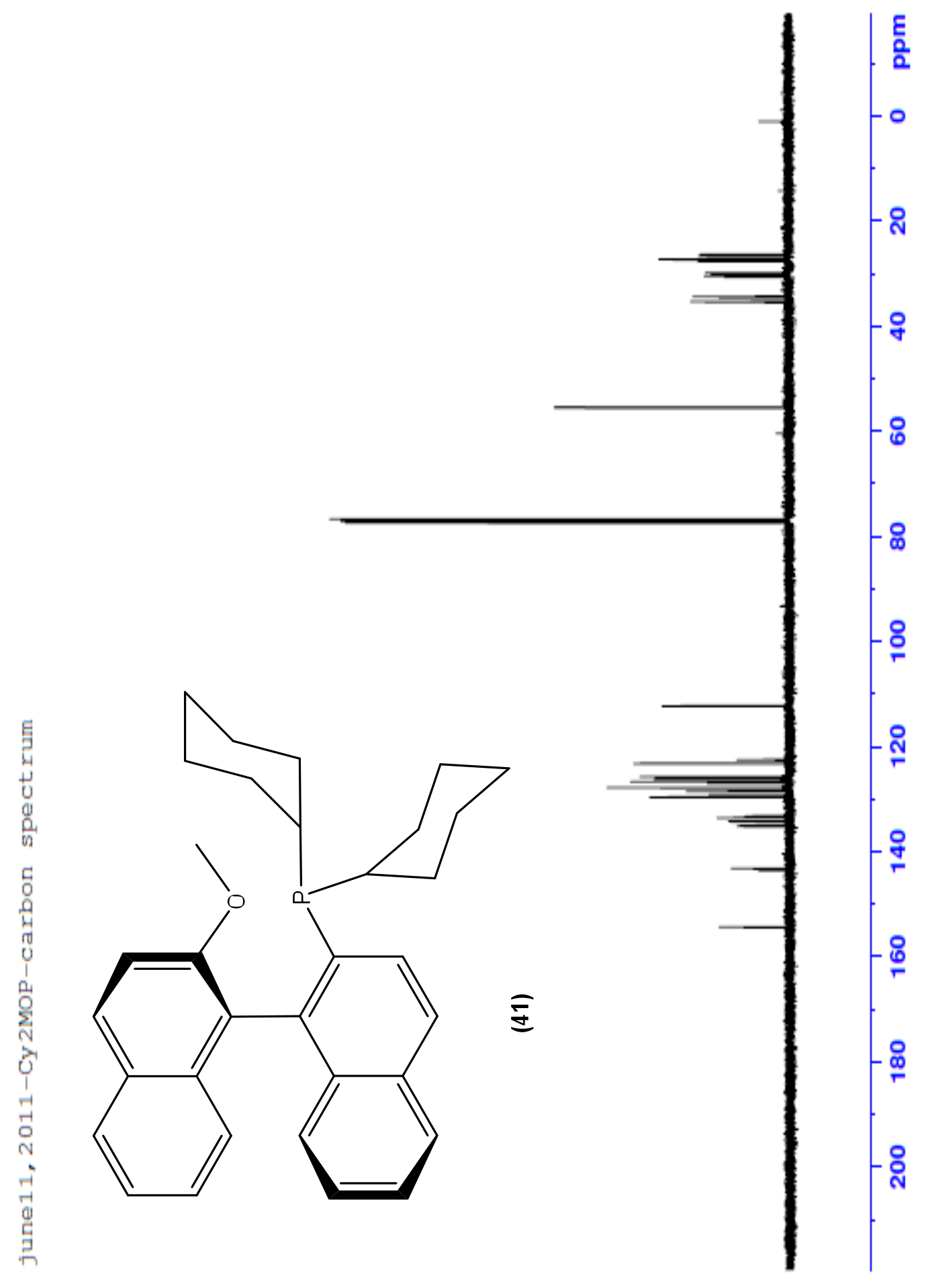




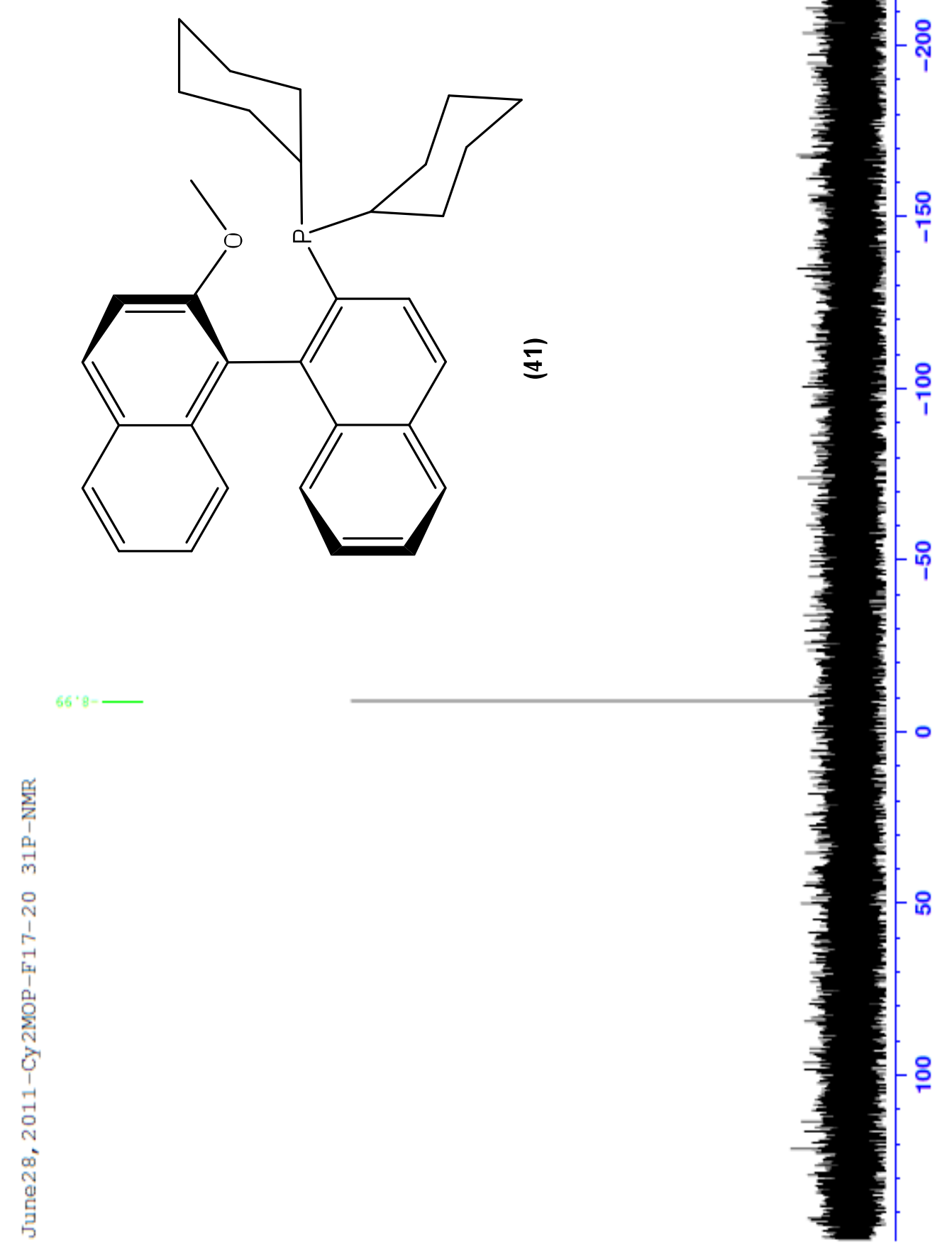




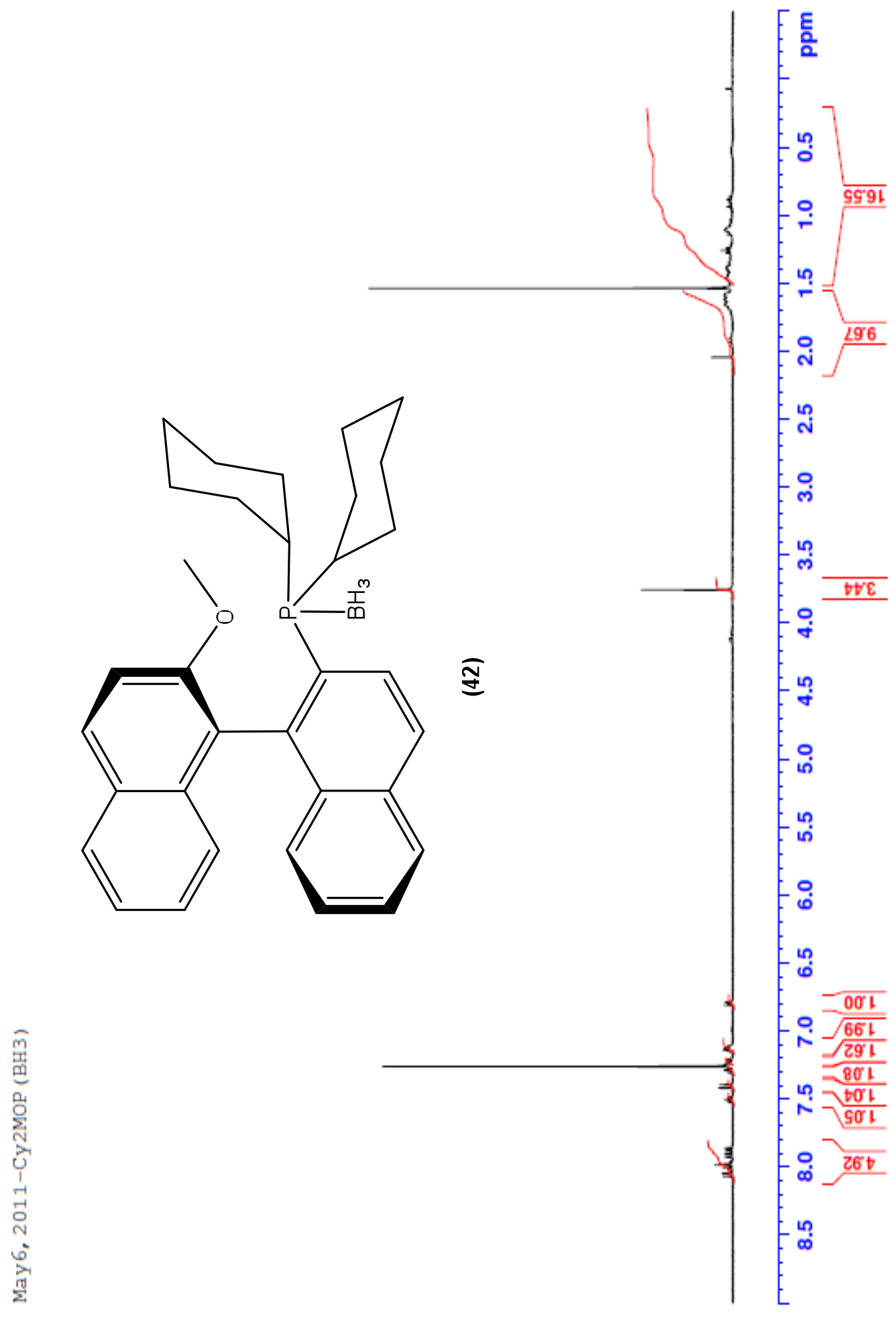




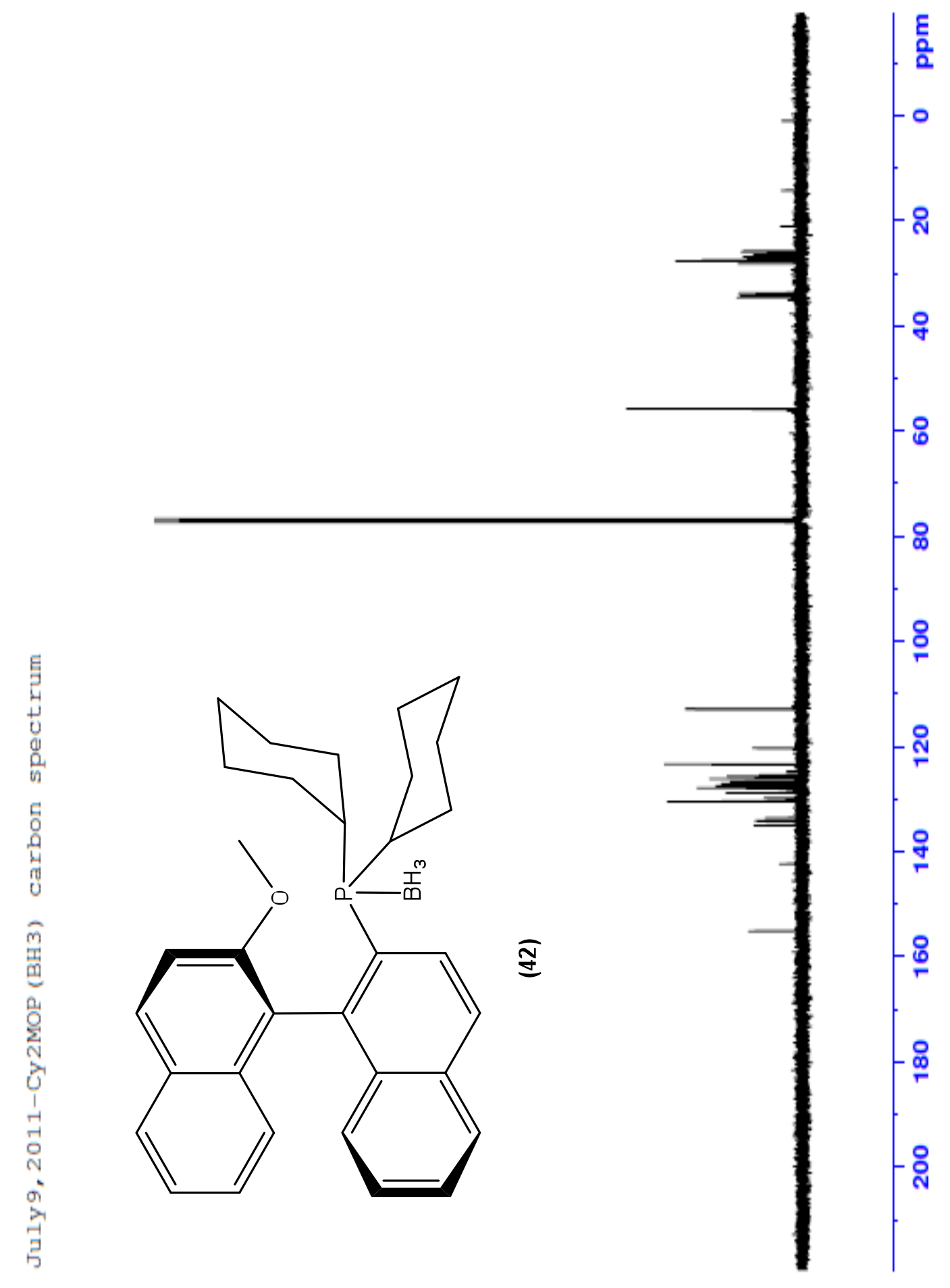




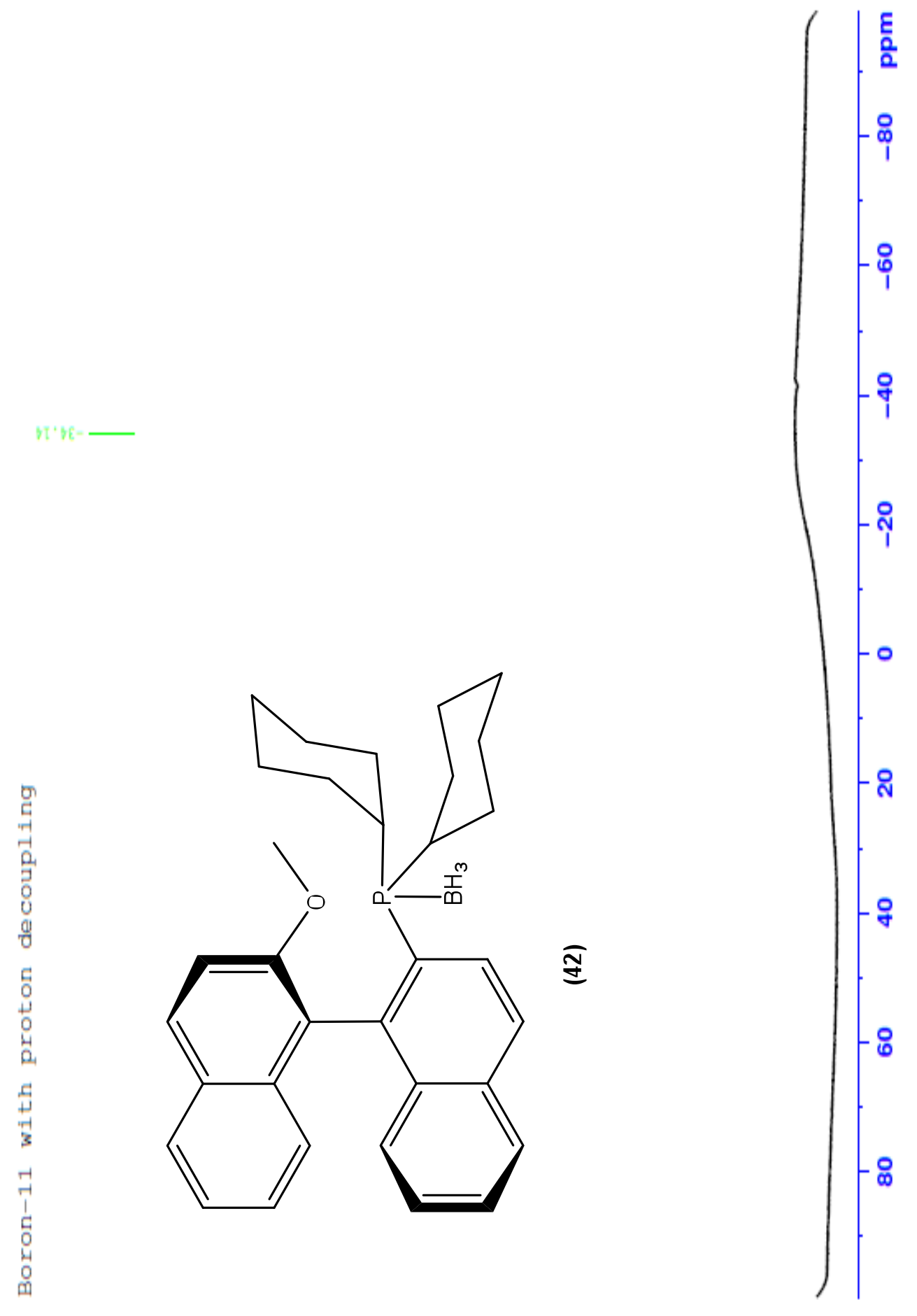



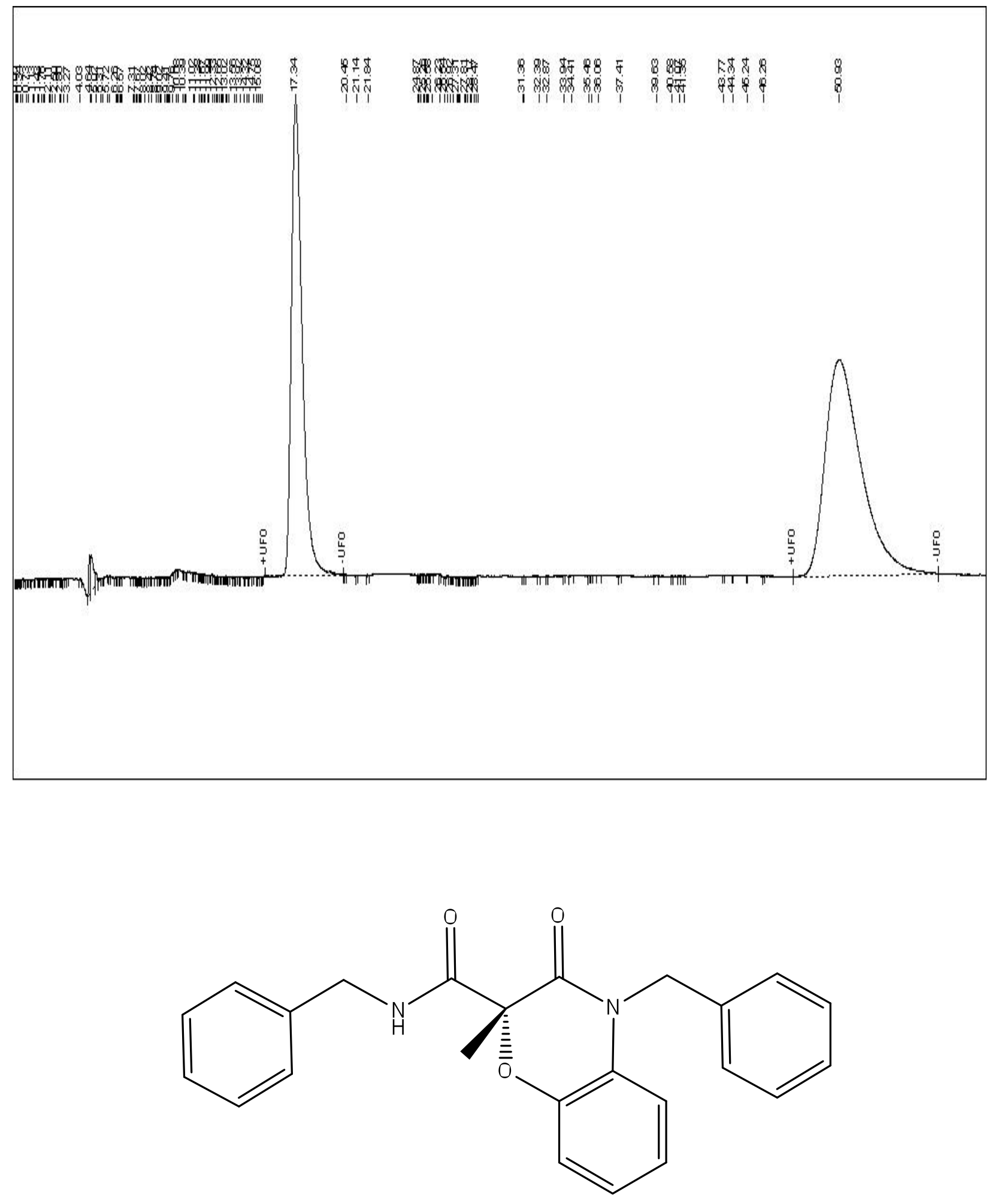

(21)

Isolate d from Ligand $=(R)$-BINAP, Base $=\mathrm{K}_{2} \mathrm{CO}_{3}$

i.e. Table 1 , entry 5 


\begin{tabular}{|c|c|c|c|}
\hline $\begin{array}{l}\text { Software Version } \\
\text { Operator } \\
\text { Sample Number } \\
\text { AutoSampler } \\
\text { Instrument Name } \\
\text { Instrument Serial \# } \\
\text { Delay Time } \\
\text { Sampling Rate } \\
\text { Sample Volume } \\
\text { Sample Amount } \\
\text { Data Acquisition Time }\end{array}$ & $\begin{array}{ll}: & 6.3 .1 .0504 \\
: \text { manager } \\
: 001 \\
\vdots \text { SER200 } \\
\vdots \text { HPLC } \\
\vdots \text { None } \\
: 0.00 \mathrm{~min} \\
: 2.5000 \mathrm{pts} / \mathrm{s} \\
\vdots 1.000000 \mathrm{ul} \\
\vdots 1.0000 \\
: 7 / 27 / 20111: 51: 46 \mathrm{PM}\end{array}$ & $\begin{array}{l}\text { Date } \\
\text { Sample Name } \\
\text { Study } \\
\text { Rack/Vial } \\
\text { Channel } \\
\text { A/D mV Range } \\
\text { End Time } \\
\\
\text { Area Reject } \\
\text { Dilution Factor } \\
\text { Cycle }\end{array}$ & $\begin{array}{l}: 7 / 27 / 20116: 34: 45 \text { PM } \\
\vdots \text { benzomorpholinone (R-BINAP, K2CO3) } \\
\vdots 1 / 1 \\
\vdots \\
\vdots 1000 \\
: 59.99 \mathrm{~min} \\
\vdots \\
\vdots 1.0000000 \\
: 1\end{array}$ \\
\hline \multicolumn{4}{|c|}{ 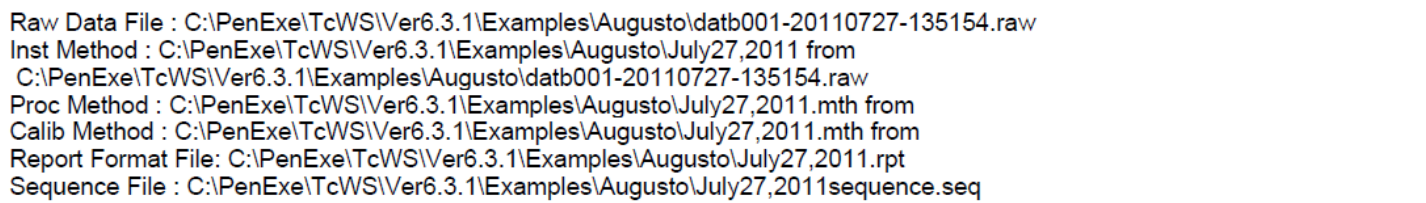 } \\
\hline
\end{tabular}

\begin{tabular}{|c|c|c|c|c|c|c|c|}
\hline $\begin{array}{c}\text { Peak } \\
\#\end{array}$ & $\begin{array}{l}\text { Time } \\
\text { [min] }\end{array}$ & $\begin{array}{l}\text { Area } \\
{[\mu \mathrm{V} \cdot \mathrm{s}]}\end{array}$ & $\begin{array}{c}\text { Height } \\
{[\mu \mathrm{V}]}\end{array}$ & $\begin{array}{c}\text { Area } \\
{[\%]}\end{array}$ & $\begin{array}{c}\text { Norm. Area } \\
{[\%]}\end{array}$ & $B L$ & $\begin{array}{l}\text { rea/Height } \\
\text { [s] }\end{array}$ \\
\hline - & 0.001 & 0.00 & 0.00 & 0.00 & 0.00 & & \\
\hline 1 & 0.049 & 222.00 & 67.03 & 0.01 & 0.01 & $\mathrm{BB}$ & 3.3118 \\
\hline 2 & 0.152 & 100.12 & 69.85 & 0.00 & 0.00 & BV & 1.4333 \\
\hline 3 & 0.204 & 201.88 & 69.05 & 0.01 & 0.01 & VB & 2.9235 \\
\hline 4 & 0.338 & 259.00 & 67.86 & 0.01 & 0.01 & $\mathrm{BB}$ & 3.8166 \\
\hline 5 & 0.507 & 199.00 & 43.72 & 0.01 & 0.01 & $\mathrm{BB}$ & 4.5515 \\
\hline 6 & 0.727 & 228.00 & 30.17 & 0.01 & 0.01 & $\mathrm{BB}$ & 7.5569 \\
\hline 7 & 0.858 & 145.20 & 37.59 & 0.01 & 0.01 & $\mathrm{BB}$ & 3.8623 \\
\hline 8 & 1.131 & 413.60 & 59.78 & 0.02 & 0.02 & $\mathrm{BB}$ & 6.9181 \\
\hline 9 & 1.195 & 62.80 & 39.43 & 0.00 & 0.00 & $\mathrm{BB}$ & 1.5926 \\
\hline 10 & 1.430 & 144.80 & 60.22 & 0.01 & 0.01 & $\mathrm{BB}$ & 2.4046 \\
\hline 11 & 1.497 & 190.60 & 74.28 & 0.01 & 0.01 & BV & 2.5660 \\
\hline 12 & 1.650 & 767.95 & 78.38 & 0.03 & 0.03 & VV & 9.7973 \\
\hline 13 & 1.762 & 150.65 & 71.48 & 0.01 & 0.01 & VB & 2.1075 \\
\hline 14 & 1.850 & 192.60 & 58.20 & 0.01 & 0.01 & $\mathrm{BB}$ & 3.3092 \\
\hline 15 & 2.109 & 73.00 & 37.48 & 0.00 & 0.00 & $\mathrm{BB}$ & 1.9477 \\
\hline 16 & 2.202 & 54.00 & 42.38 & 0.00 & 0.00 & $\mathrm{BB}$ & 1.2741 \\
\hline 17 & 2.280 & 94.00 & 33.55 & 0.00 & 0.00 & $\mathrm{BB}$ & 2.8014 \\
\hline 18 & 2.503 & 290.80 & 64.96 & 0.01 & 0.01 & $\mathrm{BB}$ & 4.4769 \\
\hline 19 & 2.804 & 128.40 & 56.32 & 0.00 & 0.00 & $\mathrm{BB}$ & 2.2796 \\
\hline 20 & 2.865 & 92.00 & 46.14 & 0.00 & 0.00 & $\mathrm{BB}$ & 1.9939 \\
\hline 21 & 3.020 & 196.00 & 55.68 & 0.01 & 0.01 & $\mathrm{BB}$ & 3.5201 \\
\hline 22 & 3.269 & 112.80 & 24.25 & 0.00 & 0.00 & $\mathrm{BB}$ & 4.6512 \\
\hline 23 & 4.033 & 349.60 & 67.23 & 0.01 & 0.01 & $\mathrm{BB}$ & 5.2003 \\
\hline 24 & 4.641 & 12495.91 & 1805.36 & 0.48 & 0.48 & BV & 6.9216 \\
\hline 25 & 4.734 & 21362.67 & 1705.21 & 0.81 & 0.81 & VV & 12.5279 \\
\hline 26 & 5.017 & 4221.87 & 592.35 & 0.16 & 0.16 & VV & 7.1273 \\
\hline 27 & 5.309 & 1047.95 & 56.90 & 0.04 & 0.04 & VB & 18.4184 \\
\hline 28 & 5.451 & 47.77 & 29.18 & 0.00 & 0.00 & BV & 1.6370 \\
\hline 29 & 5.719 & 515.83 & 38.52 & 0.02 & 0.02 & VB & 13.3911 \\
\hline 30 & 5.875 & 209.20 & 42.70 & 0.01 & 0.01 & BB & 4.8991 \\
\hline 31 & 6.259 & 458.01 & 79.12 & 0.02 & 0.02 & BV & 5.7891 \\
\hline 32 & 6.306 & 194.29 & 87.73 & 0.01 & 0.01 & V V & 2.2146 \\
\hline 33 & 6.365 & 491.46 & 101.91 & 0.02 & 0.02 & VV & 4.8227 \\
\hline 34 & 6.477 & 334.31 & 87.50 & 0.01 & 0.01 & VV & 3.8209 \\
\hline 35 & 6.566 & 271.53 & 80.12 & 0.01 & 0.01 & VB & 3.3892 \\
\hline 36 & 6.627 & 39.60 & 32.61 & 0.00 & 0.00 & $\mathrm{BB}$ & 1.2142 \\
\hline 37 & 7.309 & 685.60 & 86.14 & 0.03 & 0.03 & $\mathrm{BB}$ & 7.9594 \\
\hline 38 & 7.395 & 245.00 & 64.36 & 0.01 & 0.01 & BB & 3.8066 \\
\hline 39 & 7.496 & 116.00 & 69.70 & 0.00 & 0.00 & $\mathrm{BB}$ & 1.6643 \\
\hline 40 & 7.575 & 66.20 & 44.19 & 0.00 & 0.00 & $\mathrm{BB}$ & 1.4980 \\
\hline 41 & 7.668 & 115.98 & 67.11 & 0.00 & 0.00 & BV & 1.7281 \\
\hline 42 & 7.726 & 171.22 & 57.47 & 0.01 & 0.01 & VB & 2.9791 \\
\hline 43 & 7.798 & 178.60 & 65.23 & 0.01 & 0.01 & BB & 2.7381 \\
\hline 44 & 8.019 & 113.20 & 44.79 & 0.00 & 0.00 & $\mathrm{BB}$ & 2.5272 \\
\hline 45 & 8.273 & 253.60 & 40.50 & 0.01 & 0.01 & $\mathrm{BB}$ & 6.2612 \\
\hline
\end{tabular}


7/27/2011 6:34:45 PM Result:

\begin{tabular}{|c|c|c|c|c|c|c|c|}
\hline $\begin{array}{l}\text { Peak } \\
\#\end{array}$ & $\begin{array}{l}\text { Time } \\
\text { [min] }\end{array}$ & $\begin{array}{c}\text { Area } \\
{[\mu \mathrm{V} \cdot \mathrm{s}]}\end{array}$ & $\begin{array}{l}\text { Height } \\
{[\mu \mathrm{V}]}\end{array}$ & $\begin{array}{l}\text { Area } \\
{[\%]}\end{array}$ & $\begin{array}{c}\text { Norm. Area } \\
{[\%]}\end{array}$ & BL & $\begin{array}{c}\text { Area/Height } \\
{[\mathrm{s}]}\end{array}$ \\
\hline 46 & 8.416 & 140.80 & 37.22 & 0.01 & 0.01 & BB & 3.7831 \\
\hline 47 & 8.737 & 3 & 54 & 0.01 & 0.01 & $\mathrm{BB}$ & 7.1344 \\
\hline 48 & 8.865 & 285.40 & 50.65 & 0.01 & 0.01 & $\mathrm{BB}$ & 5.6351 \\
\hline 49 & 8.961 & 114.80 & 46.17 & 0.00 & 0.00 & $\mathrm{BB}$ & 2.4862 \\
\hline 50 & 9.023 & 130.80 & 42.04 & 0.00 & 0.00 & $\mathrm{BB}$ & 3.1111 \\
\hline 51 & 9.241 & 92.80 & 45.84 & 0.00 & 0.00 & $\mathrm{BB}$ & 2.0246 \\
\hline 52 & 9.408 & 103.92 & 52.52 & 0.00 & 0.00 & BV & 1.9787 \\
\hline 53 & 9.458 & 91.17 & 52.40 & 0.00 & 0.00 & VV & 1.7400 \\
\hline 54 & 9.533 & 102.91 & 41.92 & 0.00 & 0.00 & VB & 2.4549 \\
\hline 55 & 9.582 & 66.80 & 37.26 & 0.00 & 0.00 & $\mathrm{BB}$ & 1.7929 \\
\hline 56 & 9.763 & 403.00 & 61.22 & 0.02 & 0.02 & BB & 6.5826 \\
\hline 57 & 9.998 & 392.12 & 61.14 & 0.01 & 0.01 & BV & 6.4130 \\
\hline 58 & 10.084 & 136.68 & 48.90 & 0.01 & 0.01 & VB & 2.7952 \\
\hline 59 & 10.395 & 44.00 & 24.10 & 0.00 & 0.00 & $\mathrm{BB}$ & 1.8258 \\
\hline 60 & 10.523 & 200.04 & 57.86 & 0.01 & 0.01 & BV & 3.4575 \\
\hline 61 & 10.592 & 165.96 & 58.54 & 0.01 & 0.01 & VB & 2.8349 \\
\hline 62 & 11.016 & 158.63 & 52.46 & 0.01 & 0.01 & BV & 3.0239 \\
\hline 63 & 11.087 & 233.97 & 66.06 & 0.01 & 0.01 & VB & 3.5417 \\
\hline 64 & 11.378 & 124.20 & 47.10 & 0.00 & 0.00 & BB & 2.6371 \\
\hline 65 & 11.507 & 182.40 & 63.06 & 0.01 & 0.01 & BB & 2.8923 \\
\hline 66 & 11.556 & 143.40 & 62.36 & 0.01 & 0.01 & $\mathrm{BB}$ & 2.2995 \\
\hline 67 & 11.669 & 124.20 & 66.23 & 0.00 & 0.00 & BB & 1.8753 \\
\hline 68 & 11.754 & 201.20 & 60.07 & 0.01 & 0.01 & $\mathrm{BB}$ & 3.3495 \\
\hline 69 & 11.897 & 210.00 & 63.23 & 0.01 & 0.01 & $\mathrm{BB}$ & 3.3210 \\
\hline 70 & 11.988 & 154.00 & 41.47 & 0.01 & 0.01 & $\mathrm{BB}$ & 3.7134 \\
\hline 71 & 12.205 & 539.20 & 136.12 & 0.02 & 0.02 & $\mathrm{BB}$ & 3.9613 \\
\hline 72 & 12.332 & 254.80 & 44.24 & 0.01 & 0.01 & $\mathrm{BB}$ & 5.7601 \\
\hline 73 & 12.438 & 63.20 & 49.87 & 0.00 & 0.00 & $\mathrm{BB}$ & 1.2673 \\
\hline 74 & 12.531 & 179.60 & 60.31 & 0.01 & 0.01 & $\mathrm{BB}$ & 2.9778 \\
\hline 75 & 12.651 & 127.00 & 43.51 & 0.00 & 0.00 & $\mathrm{BB}$ & 2.9188 \\
\hline 76 & 12.751 & 62.00 & 51.02 & 0.00 & 0.00 & BB & 1.2152 \\
\hline 77 & 12.832 & 124.31 & 37.56 & 0.00 & 0.00 & BV & 3.3091 \\
\hline 78 & 12.890 & 146.09 & 45.61 & 0.01 & 0.01 & VB & 3.2030 \\
\hline 79 & 13.019 & 134.40 & 61.13 & 0.01 & 0.01 & $\mathrm{BB}$ & 2.1986 \\
\hline 80 & 13.077 & 109.20 & 46.13 & 0.00 & 0.00 & BB & 2.3670 \\
\hline 81 & 13.205 & 14 & 52. & 0.01 & 0.01 & $\mathrm{BB}$ & 2.7 \\
\hline 82 & 13.556 & 216.40 & 57.09 & 0.01 & 0.01 & $\mathrm{BB}$ & 3.7903 \\
\hline 83 & 13.675 & 133.60 & 36.92 & 0.01 & 0.01 & $\mathrm{BB}$ & 3. \\
\hline 84 & 13.922 & 117.60 & 47.55 & 0.00 & 0.00 & $\mathrm{BB}$ & 2.4730 \\
\hline 85 & 14.175 & 117.20 & 37.29 & 0.00 & 0.00 & $\mathrm{BB}$ & 3.1432 \\
\hline 86 & 14.318 & 180.00 & 31.57 & 0.01 & 0.01 & $\mathrm{BB}$ & 5.7008 \\
\hline 87 & 14.436 & 97.60 & 62.95 & 0.00 & 0.00 & BB & 1.5505 \\
\hline 88 & 14.751 & 210.40 & 20.97 & 0.01 & 0.01 & $\mathrm{BB}$ & 10.0351 \\
\hline 89 & 14.951 & 267.41 & 72.36 & 0.01 & 0.01 & BV & 3.6957 \\
\hline 90 & 15.079 & & & 0. & & V & \\
\hline 91 & 15.166 & 237.60 & 73.34 & 0.01 & 0.01 & VB & 3.2397 \\
\hline 92 & 15.309 & 141.60 & 57.88 & 0.01 & 0.01 & $\mathrm{BB}$ & 2. \\
\hline 93 & 17.340 & 1018747.76 & 21870.50 & 38.83 & 38.83 & MM & 46.5809 \\
\hline 94 & 20.451 & 14080 & 3912 & 0.01 & 0.01 & BB & 90 \\
\hline 95 & 21.136 & 60.00 & 25.28 & 0.00 & 0.00 & BB & 2.3736 \\
\hline 96 & 21.842 & 42980 & 53. & 0.02 & 0.02 & BB & \\
\hline 97 & 24.874 & 151.61 & 54.06 & 0.01 & 0.01 & BV & 2.8046 \\
\hline 98 & 24.925 & 13 & 68. & & & VB & \\
\hline & & & 56. & 0.0 & & B) & \\
\hline 100 & 25.051 & 164.46 & 49. & 0.01 & 0.01 & VE & 3.3 \\
\hline & & & 52. & 0.0 & & BV & \\
\hline 102 & 25.340 & 321. & 74. & 0.01 & 0.01 & $\mathrm{~V}$ & 4.3 \\
\hline 103 & & 106.29 & 59 & 0.0 & 0.00 & VE & \\
\hline 104 & 25.501 & 281.83 & 67. & 0.01 & 0.01 & BV & 4.1611 \\
\hline 105 & 25.576 & 57.37 & 46. & 0.00 & 0.00 & VB & 1.2453 \\
\hline 106 & 25.765 & 244.40 & 56.02 & 0.01 & 0.01 & BB & 4.3627 \\
\hline 107 & 26.231 & 289.20 & 69.52 & 0.01 & 0.01 & $\mathrm{BE}$ & 4.1602 \\
\hline 108 & 26.542 & 312.80 & 61.86 & 0.01 & 0.01 & $\mathrm{BB}$ & 5.0564 \\
\hline 109 & 26.741 & 348.80 & 46.00 & 0.01 & 0.01 & BB & 7.5828 \\
\hline 11 & 26.922 & 59.60 & 39. & 0.00 & 0.00 & $\mathrm{BE}$ & 1.5142 \\
\hline 111 & 27.066 & 71.20 & 35.62 & 0.00 & 0.00 & $\mathrm{BE}$ & 1.9989 \\
\hline 11 & 27.31 & 242.40 & 51.3 & 0.01 & 0.01 & B & 4.7172 \\
\hline 11 & 27.394 & 107.50 & 67.8 & 0.00 & 0.00 & BV & 1.5836 \\
\hline 114 & 27.436 & 202.14 & 72.29 & 0.01 & 0.01 & WV & 2.7964 \\
\hline
\end{tabular}


7/27/2011 6:34:45 PM Result:

\begin{tabular}{|c|c|c|c|c|c|c|c|}
\hline $\begin{array}{l}\text { eak } \\
\#\end{array}$ & $\begin{array}{l}\text { Time } \\
\text { [min] }\end{array}$ & $\begin{array}{c}\text { Area } \\
{[\mu \mathrm{V} \cdot \mathrm{s}]}\end{array}$ & $\begin{array}{l}\text { Height } \\
{[\mu \mathrm{V}]}\end{array}$ & $\begin{array}{l}\text { Area } \\
{[\%]}\end{array}$ & $\begin{array}{c}\text { Norm. Area } \\
{[\%]}\end{array}$ & $\mathrm{BL}$ & $\begin{array}{c}\text { Area/Height } \\
{[\mathrm{s}]}\end{array}$ \\
\hline $\begin{array}{l}115 \\
116 \\
117 \\
118 \\
119 \\
120 \\
121 \\
122 \\
123 \\
124 \\
125 \\
126 \\
127 \\
128 \\
129 \\
130 \\
131 \\
132 \\
133 \\
134 \\
135 \\
136 \\
137 \\
138 \\
139 \\
140 \\
141 \\
142\end{array}$ & $\begin{array}{l}27.500 \\
27.805 \\
27.847 \\
27.991 \\
28.170 \\
28.223 \\
28.409 \\
28.475 \\
28.593 \\
31.363 \\
31.467 \\
32.391 \\
32.874 \\
33.941 \\
34.411 \\
35.458 \\
35.651 \\
36.057 \\
37.413 \\
39.628 \\
40.583 \\
41.067 \\
41.349 \\
43.766 \\
44.338 \\
45.243 \\
46.255 \\
50.927\end{array}$ & $\begin{array}{r}513.97 \\
147.60 \\
50.00 \\
130.40 \\
148.40 \\
74.60 \\
262.40 \\
139.97 \\
215.23 \\
124.45 \\
192.35 \\
255.60 \\
124.20 \\
81.20 \\
351.60 \\
107.60 \\
77.20 \\
281.40 \\
219.60 \\
389.60 \\
116.40 \\
172.80 \\
71.00 \\
88.00 \\
84.00 \\
47.00 \\
70.00 \\
539462.16\end{array}$ & $\begin{array}{r}60.82 \\
58.10 \\
43.79 \\
42.18 \\
66.43 \\
46.29 \\
70.72 \\
64.21 \\
32.07 \\
30.13 \\
40.03 \\
38.49 \\
28.06 \\
19.79 \\
30.30 \\
22.83 \\
29.61 \\
31.77 \\
28.15 \\
35.16 \\
29.23 \\
26.57 \\
25.60 \\
27.84 \\
38.41 \\
24.24 \\
27.80 \\
9973.42\end{array}$ & $\begin{array}{l}0.02 \\
0.01 \\
0.00 \\
0.00 \\
0.01 \\
0.00 \\
0.01 \\
0.01 \\
0.01 \\
0.00 \\
0.01 \\
0.01 \\
0.00 \\
0.00 \\
0.01 \\
0.00 \\
0.00 \\
0.01 \\
0.01 \\
0.01 \\
0.00 \\
0.01 \\
0.00 \\
0.00 \\
0.00 \\
0.00 \\
0.00 \\
58.68\end{array}$ & $\begin{array}{l}0.02 \\
0.01 \\
0.00 \\
0.00 \\
0.01 \\
0.00 \\
0.01 \\
0.01 \\
0.01 \\
0.00 \\
0.01 \\
0.01 \\
0.00 \\
0.00 \\
0.01 \\
0.00 \\
0.00 \\
0.01 \\
0.01 \\
0.01 \\
0.00 \\
0.01 \\
0.00 \\
0.00 \\
0.00 \\
0.00 \\
0.00 \\
58.68\end{array}$ & $\begin{array}{l}\text { VB } \\
B B \\
B B \\
B B \\
B B \\
B B \\
B B \\
B V \\
\text { VB } \\
B V \\
\text { VB } \\
B B \\
B B \\
B B \\
B B \\
B B \\
B B \\
B B \\
B B \\
B B \\
B B \\
B B \\
B B \\
B B \\
B B \\
B B \\
B B \\
M M\end{array}$ & $\begin{array}{r}8.4505 \\
2.5405 \\
1.1418 \\
3.0915 \\
2.2339 \\
1.6116 \\
3.7106 \\
2.1797 \\
6.7118 \\
4.1304 \\
4.8049 \\
6.6399 \\
4.4262 \\
4.1025 \\
11.6056 \\
4.7132 \\
2.6072 \\
8.8563 \\
7.7997 \\
11.0818 \\
3.9815 \\
6.5025 \\
2.7735 \\
3.1607 \\
2.1871 \\
1.9393 \\
2.5182 \\
154.3565\end{array}$ \\
\hline & & & & & & & \\
\hline
\end{tabular}

Missing Component Report Component Expected Retention (Calibration File)

$\begin{array}{ll}\text { July27,2011BnBenzomorpholinone } & 0.001\end{array}$ 

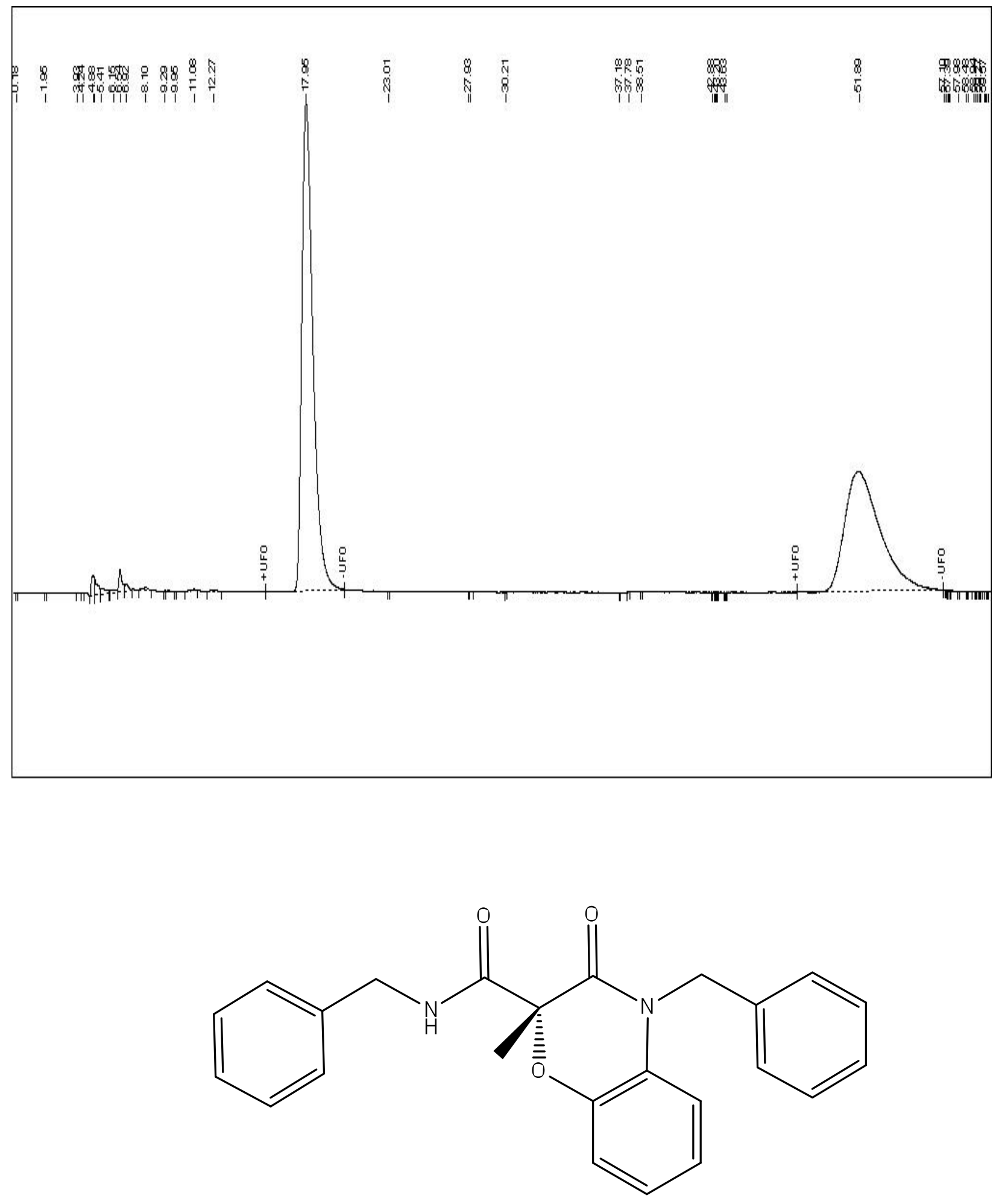

(21)

I solated from Ligand $=(R)$-BINAP, Base $=\mathrm{Cs}_{2} \mathrm{CO}_{3}$

i.e. Table 1 , entry 7 
Page 1 of 2

\begin{tabular}{|c|c|c|c|}
\hline $\begin{array}{l}\text { Software Version } \\
\text { Operator } \\
\text { Sample Number } \\
\text { AutoSampler } \\
\text { Instrument Name } \\
\text { Instrument Serial \# } \\
\text { Delay Time } \\
\text { Sampling Rate } \\
\text { Sample Volume } \\
\text { Sample Amount } \\
\text { Data Acquisition Time }\end{array}$ & $\begin{array}{ll}: & 6.3 .1 .0504 \\
: & \text { manager } \\
: & 003 \\
: & \text { SER200 } \\
: & \text { HPLC } \\
: & \text { None } \\
: & 0.00 \mathrm{~min} \\
: & 2.5000 \mathrm{pts} / \mathrm{s} \\
: & 1.000000 \mathrm{ul} \\
: & 1.0000 \\
: & 7 / 27 / 20113: 53: 39 \mathrm{PM}\end{array}$ & $\begin{array}{l}\text { Date } \\
\text { Sample Name } \\
\text { Study } \\
\text { Rack/Vial } \\
\text { Channel } \\
\text { A/D mV Range } \\
\text { End Time } \\
\\
\text { Area Reject } \\
\text { Dilution Factor } \\
\text { Cycle }\end{array}$ & $\begin{array}{ll}: & 7 / 27 / 20116: 47: 52 \text { PM } \\
: & \text { benzomorpholinone (R-BINAP, CS2CO3) } \\
: & 1 / 3 \\
: & B \\
: & 1000 \\
: & 59.99 \mathrm{~min} \\
: & 0.000000 \\
: & 1.00 \\
: & 1\end{array}$ \\
\hline \multicolumn{4}{|c|}{ 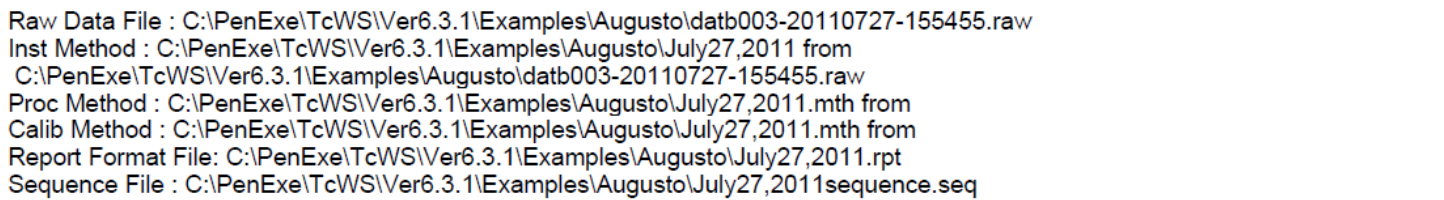 } \\
\hline
\end{tabular}

\section{DEFAULT REPORT}

\begin{tabular}{|c|c|c|c|c|c|c|c|}
\hline $\begin{array}{c}\text { Peak } \\
\#\end{array}$ & $\begin{array}{l}\text { Time } \\
\text { [min] }\end{array}$ & $\begin{array}{c}\text { Area } \\
{[\mu \mathrm{V} \cdot \mathrm{s}]}\end{array}$ & $\begin{array}{l}\text { Height } \\
{[\mu \mathrm{V}]}\end{array}$ & $\begin{array}{c}\text { Area } \\
{[\%]}\end{array}$ & $\begin{array}{c}\text { Norm. Area } \\
{[\%]}\end{array}$ & BL & $\begin{array}{c}\text { Area/Height } \\
\text { [s] }\end{array}$ \\
\hline - & 0.001 & 0.00 & 0.00 & 0.00 & 0.00 & & \\
\hline 1 & 0.176 & 63.60 & 19.60 & 0.00 & 0.00 & BB & 3.2455 \\
\hline 2 & 1.947 & 67.20 & 23.37 & 0.00 & 0.00 & $\mathrm{BB}$ & 2.8752 \\
\hline 3 & 3.926 & 342.40 & 39.79 & 0.01 & 0.01 & BB & 8.6060 \\
\hline 4 & 4.244 & 166.80 & 26.24 & 0.00 & 0.00 & $\mathrm{BB}$ & 6.3565 \\
\hline 5 & 4.877 & 25329.68 & 2461.43 & 0.49 & 0.49 & BV & 10.2906 \\
\hline 6 & 4.965 & 30691.44 & 2242.80 & 0.60 & 0.60 & W & 13.6844 \\
\hline 7 & 5.406 & 16688.53 & 764.12 & 0.32 & 0.32 & W & 21.8401 \\
\hline 8 & 6.146 & 8024.44 & 328.39 & 0.16 & 0.16 & W & 24.4357 \\
\hline 9 & 6.535 & 34517.16 & 2609.76 & 0.67 & 0.67 & W & 13.2262 \\
\hline 10 & 6.917 & 11482.24 & 811.22 & 0.22 & 0.22 & VB & 14.1542 \\
\hline 11 & 8.103 & 6595.60 & 318.80 & 0.13 & 0.13 & & 20.6887 \\
\hline 12 & 9.294 & 135.60 & 29.03 & 0.00 & 0.00 & $\mathrm{BB}$ & 4.6703 \\
\hline 13 & 9.945 & 93.80 & 27.07 & 0.00 & 0.00 & $\mathrm{BB}$ & 3.4655 \\
\hline 14 & 11.078 & 3608.80 & 173.35 & 0.07 & 0.07 & BB & 20.8180 \\
\hline 15 & 12.270 & 6557.20 & 264.06 & 0.13 & 0.13 & BB & 24.8319 \\
\hline 16 & 17.947 & 2801143.53 & 59207.34 & 54.44 & 54.44 & $\mathrm{MM}$ & 47.3107 \\
\hline 17 & 23.006 & 99.00 & 28.36 & 0.00 & 0.00 & BB & 3.4910 \\
\hline 18 & 27.935 & 103.60 & 44.40 & 0.00 & 0.00 & BB & 2.3332 \\
\hline 19 & 28.046 & 269.80 & 35.93 & 0.01 & 0.01 & $B B$ & 7.5100 \\
\hline 20 & 30.214 & 103.60 & 25.35 & 0.00 & 0.00 & & 4.0861 \\
\hline 21 & 37.185 & 102.80 & 29. & 0.00 & 0.00 & & 3.5175 \\
\hline 22 & 37.777 & 396.60 & 45.89 & 0.01 & 0.01 & BB & 8.6426 \\
\hline 23 & 38.513 & 120.40 & 28.93 & 0.00 & 0.00 & & 4.1611 \\
\hline 24 & 42.877 & 117.20 & 48.10 & 0.00 & 0.00 & & 364 \\
\hline 25 & 43.001 & 194.80 & 48. & 0.00 & 0.00 & & 904 \\
\hline 26 & 43.044 & 54.80 & 35.75 & 0.00 & 0.00 & & 1.5330 \\
\hline 27 & 43.137 & 105.46 & 47. & 0.00 & 0.00 & B & 2.2004 \\
\hline 28 & 43.202 & & 42 & 0. & 0. & VB & 1.6630 \\
\hline 29 & 43.627 & 101.20 & 51. & 0.00 & 0.00 & $B$ & 1.9717 \\
\hline 30 & 43.766 & 40.40 & 29. & 0.00 & 0.00 & $\mathrm{BB}$ & 1.3751 \\
\hline 31 & 51.887 & 3959.25 & 4573.34 & 42.64 & 42.64 & $\mathrm{MM}$ & 150.5461 \\
\hline 32 & 57.101 & 240.00 & 51.02 & 0. & 0.00 & B & 4.7042 \\
\hline 33 & 57.201 & 95 & 6 & 0. & 0. & $B$ & 1.4700 \\
\hline 34 & 57.250 & 97.26 & 63 & 0. & 0. & B & 372 \\
\hline 35 & 57.314 & 299.74 & & 0. & & $\mathrm{~V}$ & 13 \\
\hline 36 & 57.393 & 242.29 & 77 & 0. & 0. & B & 43 \\
\hline 37 & 57.469 & 166.91 & 45. & 0. & 0. & $\mathrm{~V}$ & 44 \\
\hline 38 & 57.984 & 169.60 & 5 & 0. & 0. & B & 515 \\
\hline 39 & 58.478 & & & 0. & 0. & B & 32 \\
\hline 40 & 58.585 & 177.60 & 37 & 0. & 0. & B & 4.7810 \\
\hline 41 & 58.938 & 367.20 & 8 & 0. & & B & 170 \\
\hline 42 & 59.028 & 184.85 & 83 & 0.0 & 0. & B & 2.2086 \\
\hline 43 & 59.074 & 133.55 & 74. & 0.0 & & VB & 1.7972 \\
\hline 44 & 59.16 & & & 0. & & B) & 359 \\
\hline 45 & 59.272 & 254.02 & 78.86 & 0.00 & 0.00 & W & 3.2211 \\
\hline
\end{tabular}




\begin{tabular}{|c|c|c|c|c|c|c|c|}
\hline $\begin{array}{c}\text { Peak } \\
\#\end{array}$ & $\begin{array}{l}\text { Time } \\
\text { [min] }\end{array}$ & $\begin{array}{c}\text { Area } \\
{[\mu \mathrm{V} \cdot \mathrm{s}]}\end{array}$ & $\begin{array}{l}\text { Height } \\
{[\mu \mathrm{V}]}\end{array}$ & $\begin{array}{c}\text { Area } \\
{[\%]}\end{array}$ & $\begin{array}{c}\text { Norm. Area } \\
{[\%]}\end{array}$ & $\mathrm{BL}$ & $\begin{array}{l}\text { Area/Height } \\
{[\mathrm{s}]}\end{array}$ \\
\hline \multirow[t]{2}{*}{$\begin{array}{l}49 \\
50\end{array}$} & $\begin{array}{l}59.331 \\
59.572 \\
59.624 \\
59.722 \\
59.799\end{array}$ & $\begin{array}{r}79.16 \\
258.40 \\
165.20 \\
71.40 \\
42.00\end{array}$ & $\begin{array}{l}52.09 \\
45.40 \\
45.62 \\
38.06 \\
33.43\end{array}$ & $\begin{array}{l}0.00 \\
0.01 \\
0.00 \\
0.00 \\
0.00\end{array}$ & $\begin{array}{l}0.00 \\
0.01 \\
0.00 \\
0.00 \\
0.00\end{array}$ & $\begin{array}{l}\text { VB } \\
B B \\
B B \\
B B \\
B B\end{array}$ & $\begin{array}{l}1.5195 \\
5.6916 \\
3.6213 \\
1.8761 \\
1.2565\end{array}$ \\
\hline & & & 3 & 100.00 & 100.00 & & \\
\hline
\end{tabular}

Missing Component Report Component

Expected Retention (Calibration File)

July27,2011BnBenzomorpholinone

0.001 

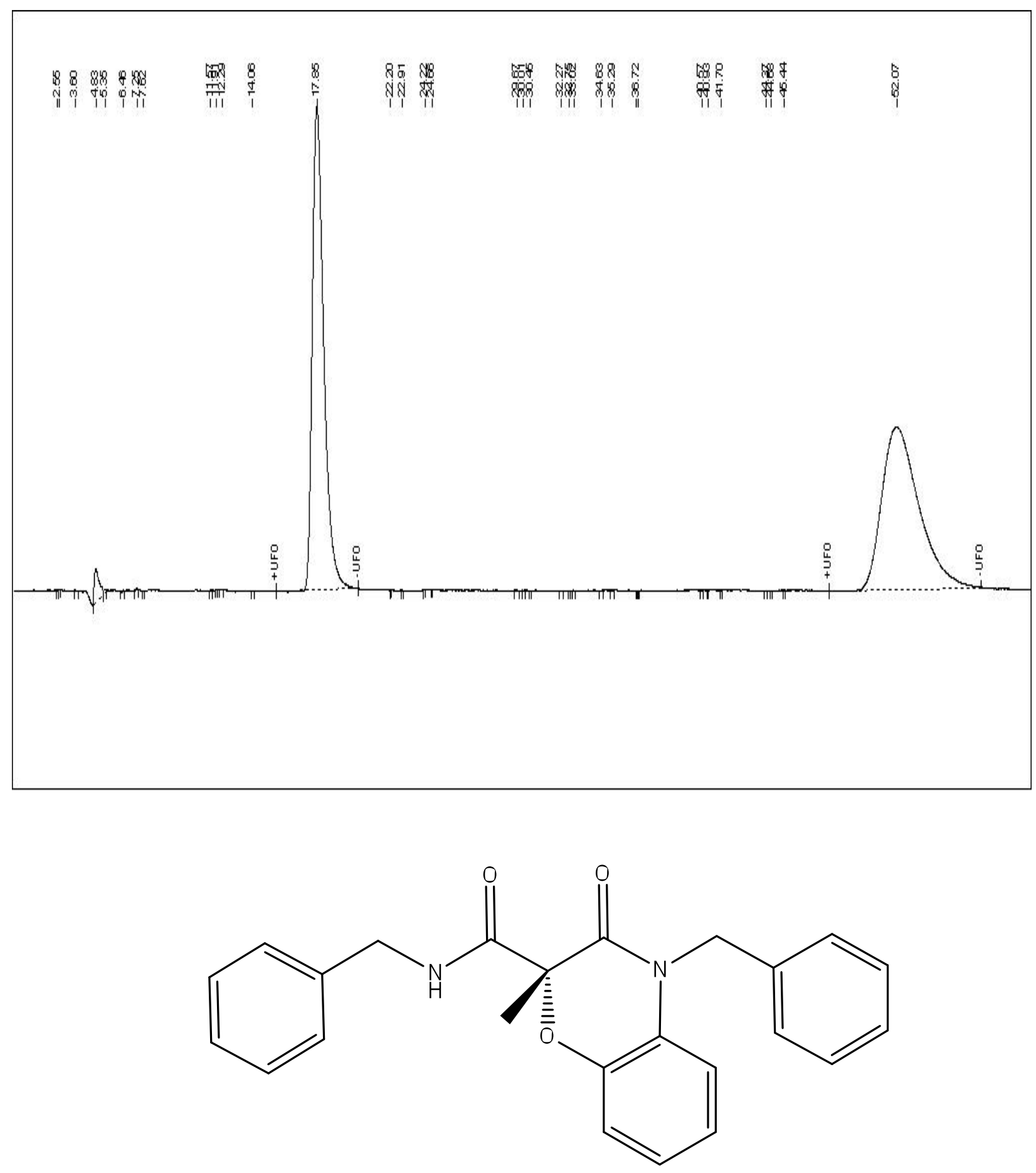

(21)

I solated from Ligand $=(R)$ - MOP, Base $=\mathrm{Cs}_{2} \mathrm{CO}_{3}$ i.e. Table 1 , entry 8 


\begin{tabular}{|c|c|c|c|}
\hline $\begin{array}{l}\text { Software Version } \\
\text { Operator } \\
\text { Sample Number } \\
\text { AutoSampler } \\
\text { Instrument Name } \\
\text { Instrument Serial \# } \\
\text { Delay Time } \\
\text { Sampling Rate } \\
\text { Sample Volume } \\
\text { Sample Amount } \\
\text { Data Acquisition Time }\end{array}$ & $\begin{array}{ll}: & 6.3 .1 .0504 \\
: & \text { manager } \\
: & 002 \\
: & \text { SER200 } \\
: & \text { HPLC } \\
: & \text { None } \\
: & 0.00 \mathrm{~min} \\
: & 2.5000 \mathrm{pts} / \mathrm{s} \\
: & 1.000000 \mathrm{ul} \\
: & 1.0000 \\
: & 7 / 27 / 20112: 52: 42 \mathrm{PM}\end{array}$ & $\begin{array}{l}\text { Date } \\
\text { Sample Name } \\
\text { Study } \\
\text { Rack/Vial } \\
\text { Channel } \\
\text { A/D mV Range } \\
\text { End Time } \\
\\
\text { Area Reject } \\
\text { Dilution Factor } \\
\text { Cycle }\end{array}$ & $\begin{array}{l}: 7 / 27 / 20116: 41: 30 \text { PM } \\
: \text { benzomorpholinone (R-MOP, CS2CO3) } \\
: 1 / 2 \\
\text { B } \\
1000 \\
: 59.99 \text { min } \\
\\
0.000000 \\
1.00 \\
: 1\end{array}$ \\
\hline \multicolumn{4}{|c|}{ 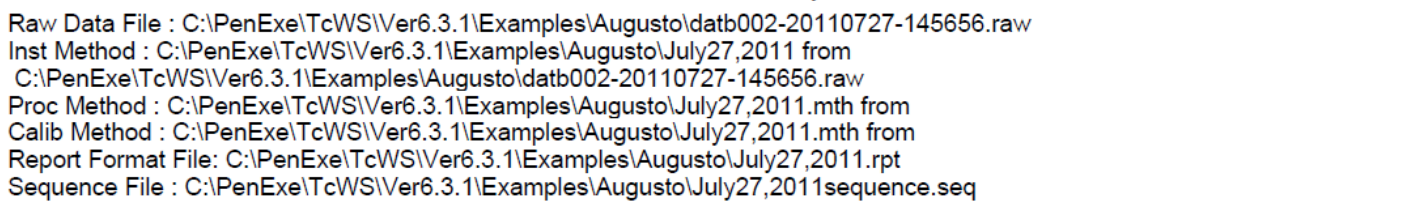 } \\
\hline
\end{tabular}

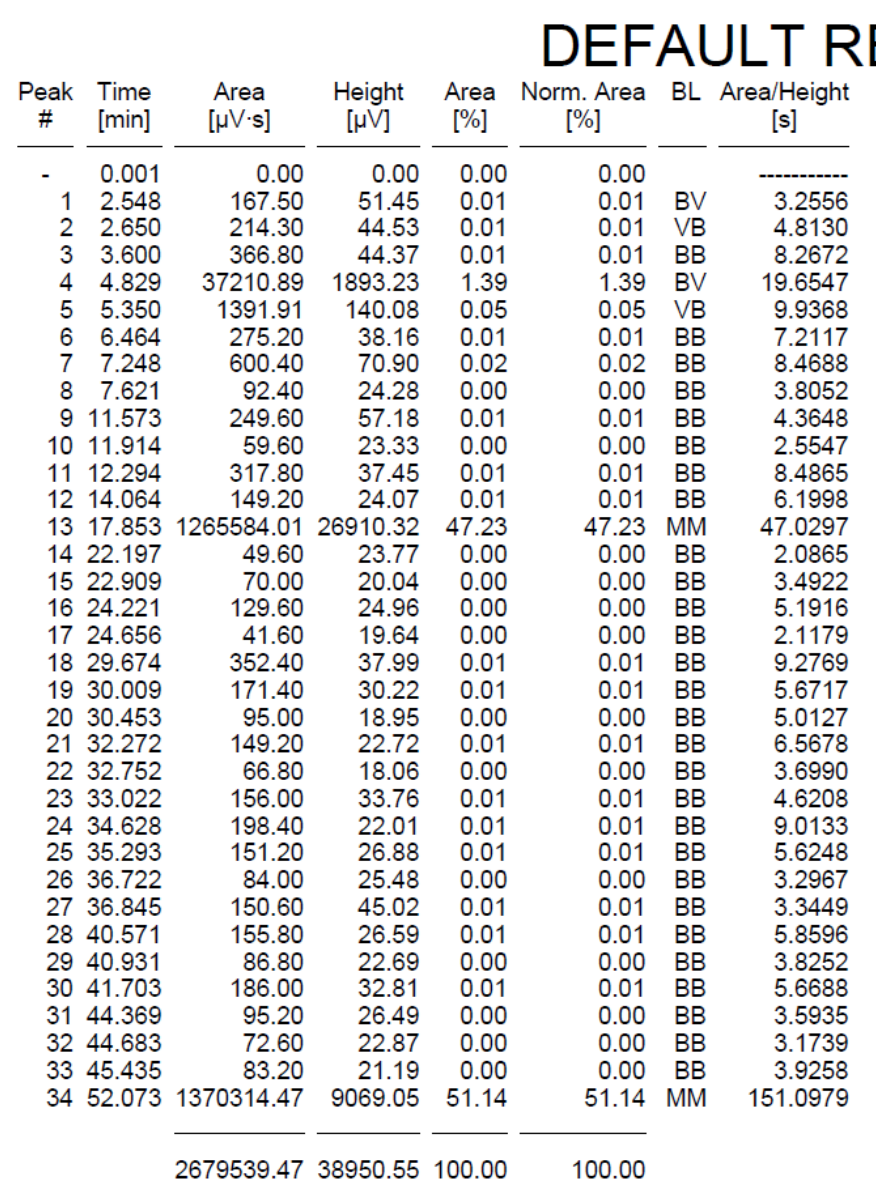

Missing Component Report Component Expected Retention (Calibration File)

July27,2011BnBenzomorpholinone

0.001 

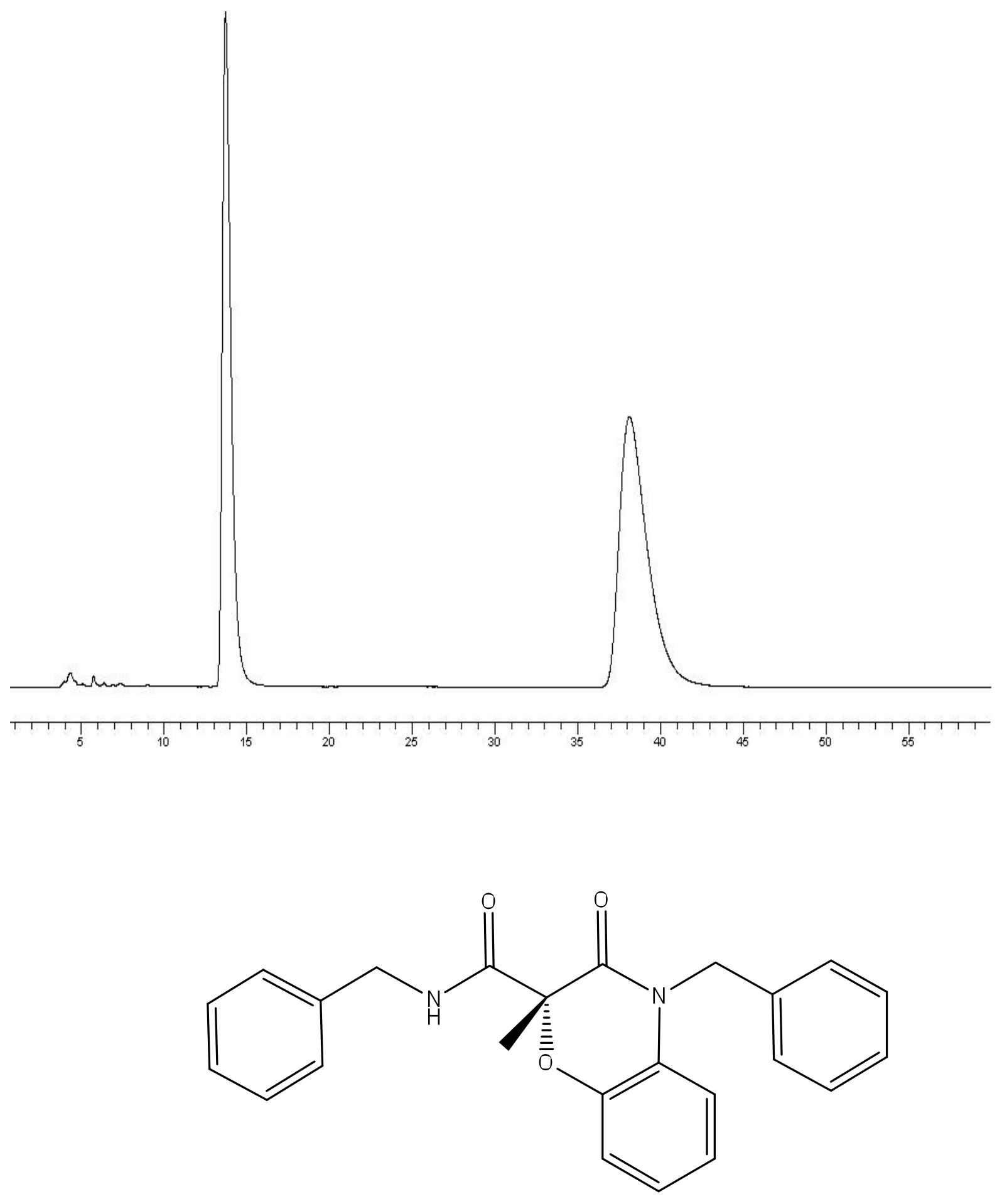

(21)

Isolated from Ligand $=(R)-\mathrm{Cy}_{2} \mathrm{MOP}$, Base $=\mathrm{Cs}_{2} \mathrm{CO}_{3}$

i.e. Table 1 , entry 6 


\begin{tabular}{|c|c|c|c|}
\hline $\begin{array}{l}\text { Software Version } \\
\text { Operator } \\
\text { Sample Number } \\
\text { AutoSampler } \\
\text { Instrument Name } \\
\text { Instrument Serial \# } \\
\text { Delay Time } \\
\text { Sampling Rate } \\
\text { Sample Volume } \\
\text { Sample Amount } \\
\text { Data Acquisition Time }\end{array}$ & $\begin{array}{ll}: & 6.3 .1 .0504 \\
: & \text { manager } \\
: & 001 \\
: & \text { SER200 } \\
: & \text { HPLC } \\
: & \text { None } \\
: & 0.00 \mathrm{~min} \\
: & 2.5000 \mathrm{pts} / \mathrm{s} \\
: & 1.000000 \mathrm{ul} \\
: & 1.0000 \\
: & 7 / 12 / 20117: 53: 48 \mathrm{PM}\end{array}$ & $\begin{array}{l}\text { Date } \\
\text { Sample Name } \\
\text { Study } \\
\text { Rack/Vial } \\
\text { Channel } \\
\text { A/D mV Range } \\
\text { End Time } \\
\\
\text { Area Reject } \\
\text { Dilution Factor } \\
\text { Cycle }\end{array}$ & $\begin{array}{l}: 7 / 13 / 201110: 18: 02 \text { AM } \\
: \text { Benzomorpholine cyclized with Cy2MOP } \\
: \\
: 1 / 1 \\
: \text { B } \\
: 1000 \\
: 59.99 \mathrm{~min} \\
: 0.000000 \\
: 1.00 \\
: 1\end{array}$ \\
\hline \multicolumn{4}{|c|}{ 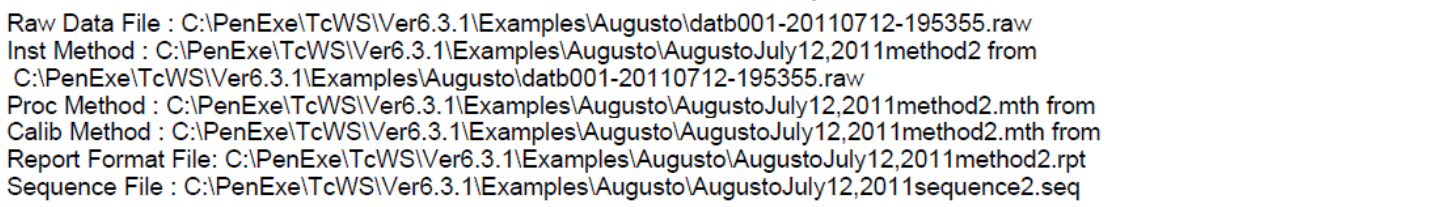 } \\
\hline
\end{tabular}

\begin{tabular}{|c|c|c|c|c|c|c|c|}
\hline $\begin{array}{l}\text { Peak } \\
\#\end{array}$ & $\begin{array}{l}\text { Time } \\
\text { [min] }\end{array}$ & $\begin{array}{l}\text { Area } \\
{[\mu \vee \cdot s]}\end{array}$ & $\begin{array}{l}\text { Height } \\
{[\mu \mathrm{V}]}\end{array}$ & $\begin{array}{c}\text { Area } \\
{[\%]}\end{array}$ & $\begin{array}{c}\text { Norm. Area } \\
{[\%]}\end{array}$ & $B L$ & $\begin{array}{c}\text { ea/Heic } \\
\text { [s] }\end{array}$ \\
\hline - & 0.001 & 0.00 & 0.00 & 0.00 & 0.00 & & \\
\hline 1 & 0.804 & 197.20 & 42.13 & 0.00 & 0.00 & BB & 4.681 \\
\hline 2 & 2.354 & 447.20 & 27.85 & 0.00 & 0.00 & BB & 16.055 \\
\hline 3 & 3.967 & 18539.91 & 1363.57 & 0.13 & 0.13 & BV & 13.596 \\
\hline 4 & 4.348 & 90556.09 & 3530.02 & 0.62 & 0.62 & VE & 25.653 \\
\hline 5 & 5.045 & 6774.40 & 483.23 & 0.05 & 0.05 & EB & $14.01 \mathrm{~s}$ \\
\hline 6 & 5.480 & 586.95 & 79.51 & 0.00 & 0.00 & BV & 7.382 \\
\hline 7 & 5.728 & 30779.28 & 2667.53 & 0.21 & 0.21 & VV & 11.538 \\
\hline 8 & 6.361 & 9588.17 & 834.44 & 0.07 & 0.07 & VB & 11.490 \\
\hline 9 & 6.882 & 3799.73 & 312.34 & 0.03 & 0.03 & BV & 12.165 \\
\hline 10 & 7.327 & 12267.87 & 704.51 & 0.08 & 0.08 & VB & 17.413 \\
\hline 11 & 8.069 & 203.40 & 40.69 & 0.00 & 0.00 & BB & 4.999 \\
\hline 12 & 8.386 & 715.49 & 54.32 & 0.00 & 0.00 & BV & 13.172 \\
\hline 13 & 9.011 & 5246.51 & 259.88 & 0.04 & 0.04 & VB & 20.187 \\
\hline 14 & 9.547 & 254.80 & 32.08 & 0.00 & 0.00 & BB & 7.942 \\
\hline 15 & 10.239 & 155.20 & 31.99 & 0.00 & 0.00 & BB & 4.85 \\
\hline 16 & 11.402 & 168.20 & 28.35 & 0.00 & 0.00 & BB & 5.932 \\
\hline 17 & 13.712 & 6320578.20 & 174285.10 & 43.31 & 43.31 & BB & 36.265 \\
\hline 18 & 19.357 & 291.20 & 29.00 & 0.00 & 0.00 & BB & 10.040 \\
\hline 19 & 20.436 & 135.20 & 37.42 & 0.00 & 0.00 & BB & 3.612 \\
\hline 20 & 21.234 & 106.00 & 23.18 & 0.00 & 0.00 & BB & 4.571 \\
\hline 21 & 24.227 & 262.40 & 34.20 & 0.00 & 0.00 & BB & 7.672 \\
\hline 22 & 26.002 & 90.80 & 33.40 & 0.00 & 0.00 & BB & 2.718 \\
\hline 23 & 26.423 & 96.40 & 31.19 & 0.00 & 0.00 & $\mathrm{~B}$ & 3.090 \\
\hline 24 & 26.674 & 132.40 & 29.99 & 0.00 & 0.00 & $\mathrm{~B}$ & 4.414 \\
\hline 25 & 27.255 & 212.40 & 44.26 & 0.00 & 0.00 & $\mathrm{~B}$ & 4.798 \\
\hline 26 & 28.896 & 130.00 & 26.77 & 0.00 & 0.00 & $\mathrm{~B}$ & 4.855 \\
\hline 27 & 30.947 & 40.00 & 28.04 & 0.00 & 0.00 & $\mathrm{~B}$ & 1.426 \\
\hline 28 & 31.461 & 101.20 & 32.88 & 0.00 & 0.00 & $\mathrm{~B}$ & 3.077 \\
\hline 29 & 32.804 & 75.60 & 28.61 & 0.00 & 0.00 & B & 2.642 \\
\hline 30 & 33.098 & 68.40 & 42.94 & 0.00 & 0.00 & $\mathrm{~B}$ & 1. \\
\hline 31 & 33.363 & 66.40 & 24.61 & 0.00 & 0.00 & $\mathrm{~B}$ & 2. \\
\hline 32 & 33.840 & 88.00 & 29.11 & 0.00 & 0.00 & B & 3. \\
\hline 33 & 35.183 & 441.60 & 51.86 & 0.00 & 0.00 & $\mathrm{~B}$ & 8. \\
\hline 34 & 35.390 & 122.80 & 60.79 & 0.00 & 0.00 & B & 2. \\
\hline 35 & 36.226 & 73.20 & 47.99 & 0.00 & 0.00 & $\mathrm{~B}$ & 1. \\
\hline 36 & 38.123 & 8088409.20 & 69567.81 & 55.42 & 55.42 & $\mathrm{~B}$ & 116.266 \\
\hline 37 & 44.101 & 69.40 & 42.64 & 0.00 & 0.00 & B & 1.627 \\
\hline 38 & 47.298 & 66.40 & 28.74 & 0.00 & 0.00 & $\mathrm{~B}$ & \\
\hline 39 & 47.357 & 92.80 & 35.23 & 0.0 & 0.00 & $\mathrm{~B}$ & \\
\hline 40 & 48.469 & 52.40 & 28.48 & 0.00 & 0.00 & $\mathrm{~B}$ & 1.8 \\
\hline 41 & 49.027 & 240.60 & 23.48 & 0.00 & 0.00 & $B$ & 10.2 \\
\hline 42 & 49.883 & 59.00 & 33.90 & 0.00 & 0.00 & $\mathrm{~B}$ & 1.74 \\
\hline 43 & 50.975 & 193.60 & 52.90 & 0.00 & 0.00 & & 3. \\
\hline 44 & 51.441 & 92.80 & 35.68 & 0.00 & 0.00 & $\mathrm{~B}$ & 2.600 \\
\hline 45 & 51.585 & 119.20 & 34.03 & 0.00 & 0.00 & B & 3.503 \\
\hline
\end{tabular}


Page 2 of 2

7/13/2011 10:18:02 AM Result:

\begin{tabular}{|c|c|c|c|c|c|c|c|}
\hline $\begin{array}{l}\text { Peak } \\
\#\end{array}$ & $\begin{array}{l}\text { Time } \\
\text { [min] }\end{array}$ & $\begin{array}{c}\text { Area } \\
{[\mu \mathrm{V} \cdot \mathrm{s}]}\end{array}$ & $\begin{array}{l}\text { Height } \\
{[\mu \mathrm{V}]}\end{array}$ & $\begin{array}{c}\text { Area } \\
{[\%]}\end{array}$ & $\begin{array}{c}\text { Norm. Area } \\
{[\%]}\end{array}$ & $\mathrm{BL}$ & $\begin{array}{c}\text { Area/Height } \\
{[\mathrm{s}]}\end{array}$ \\
\hline \multirow{13}{*}{5} & 52.348 & 76.00 & 54.28 & 0.00 & 0.00 & BB & 1.4000 \\
\hline & 53.384 & 97.40 & 20.38 & 0.00 & 0.00 & $\mathrm{BB}$ & 4.7794 \\
\hline & 53.735 & 126.80 & 32.06 & 0.00 & 0.00 & BB & 3.9552 \\
\hline & 54.143 & 351.40 & 36.95 & 0.00 & 0.00 & BB & 9.5105 \\
\hline & 54.606 & 89.60 & 13.48 & 0.00 & 0.00 & $\mathrm{BB}$ & 6.6464 \\
\hline & 54.840 & 104.80 & 29.33 & 0.00 & 0.00 & $\mathrm{BB}$ & 3.5729 \\
\hline & 55.043 & 148.20 & 49.13 & 0.00 & 0.00 & $\mathrm{BB}$ & 3.0163 \\
\hline & 56.336 & 176.80 & 38.57 & 0.00 & 0.00 & $\mathrm{BB}$ & 4.5840 \\
\hline & 57.221 & 77.60 & 26.99 & 0.00 & 0.00 & $\mathrm{BB}$ & 2.8747 \\
\hline & 58.622 & 160.60 & 33.67 & 0.00 & 0.00 & BB & 4.7693 \\
\hline & 59.235 & 143.80 & 40.14 & 0.00 & 0.00 & BB & 3.5824 \\
\hline & 59.488 & 72.40 & 33.92 & 0.00 & 0.00 & BB & 2.1346 \\
\hline & & 1340 & 05.58 & 000 & .00 & & \\
\hline
\end{tabular}

Missing Component Report Component

Expected Retention (Calibration File)

Benzomorpholine cyclized with Cy2MOP

0.001 

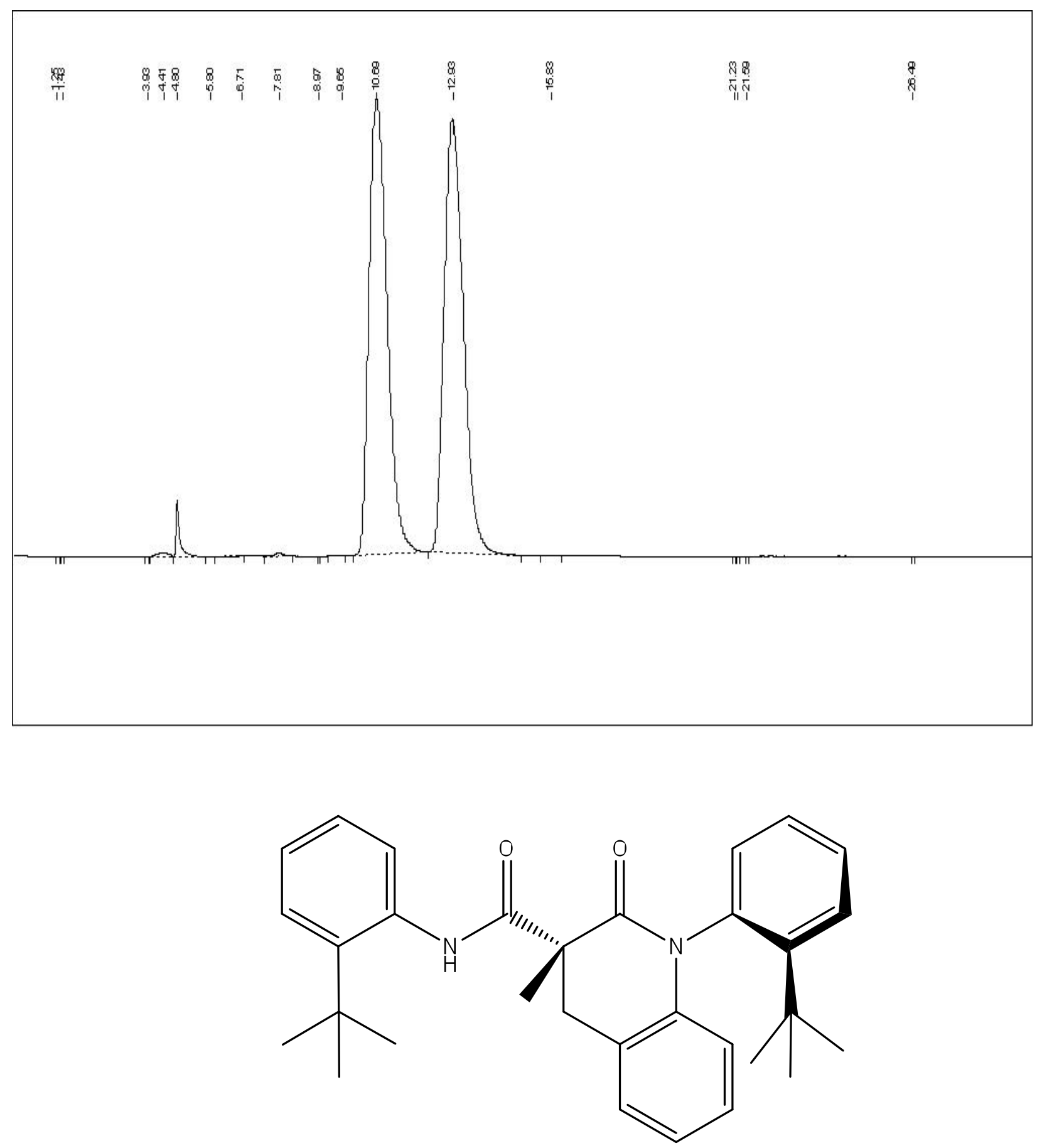

(36)

Isolated from Ligand $=\mathrm{S}$ - Phos precatalyst, Base $=\mathrm{Cs}_{2} \mathrm{CO}_{3}$ i.e. Table 3, entry 7 


\begin{tabular}{llll}
\hline Software Version & $: 6.3 .1 .0504$ & Date & $: 8 / 13 / 20115: 16: 39$ PM \\
Operator & $:$ manager & Sample Name & $:$ t-butylquin(racemic) \\
Sample Number & $:$ O02 & Study & $:$ \\
AutoSampler & $:$ SER200 & Rack/Vial & $: 1 / 2$ \\
Instrument Name & $:$ HPLC & Channel & $:$ B \\
Instrument Serial \# & $:$ None & A/D mV Range : 1000 \\
Delay Time & $: 0.00 \mathrm{~min}$ & End Time & $: 29.99 \mathrm{~min}$ \\
Sampling Rate & $: 2.5000 \mathrm{pts} / \mathrm{s}$ & & \\
Sample Volume & $: 1.000000 \mathrm{ul}$ & & \\
Sample Amount & $: 1.0000$ & Area Reject $: 0.00000$ \\
Data Acquisition Time & $: 8 / 12 / 20118: 18: 31 \mathrm{PM}$ & Dilution Factor : 1.00
\end{tabular}

Raw Data File : C:IPenExelTcWSIVer6.3.1\Examples\Augustoldatb002-20110812-202246.raw

Inst Method : C:IPenExelTcWSIVer6.3.1\Examples\Augusto\August12,2011 from

C:IPenExelTcWSIVer6.3.1\Examples\Augustoldatb002-20110812-202246.raw

Proc Method : C:IPenExelTcWSIVer6.3.11Examples\AugustolAugust12,2011.mth from

Calib Method : C:IPenExelTcWSIVer6.3.1 Examples\AugustolAugust12,2011.mth from

Report Format File: C:IPenExelTcWSIVer6.3.1\Examples\AugustolAugust12,2011.rpt

Sequence File : C:IPenExelTcWSIVer6.3.11Examples\Augusto\August12,2011 sequence.seq

\begin{tabular}{|c|c|c|c|c|c|c|c|}
\hline $\begin{array}{l}\text { Peak } \\
\text { \# }\end{array}$ & $\begin{array}{l}\text { Time } \\
\text { [min] }\end{array}$ & $\begin{array}{c}\text { Area } \\
{[\mu \mathrm{V} \cdot \mathrm{s}]}\end{array}$ & $\begin{array}{l}\text { Height } \\
{[\mu \mathrm{V}]}\end{array}$ & $\begin{array}{c}\text { Area } \\
{[\%]}\end{array}$ & $\begin{array}{c}\text { Norm. Area } \\
{[\%]}\end{array}$ & $\mathrm{BL}$ & $\begin{array}{c}\text { Area/Height } \\
\text { [s] }\end{array}$ \\
\hline- & 0.001 & 0.00 & 0.00 & 0.00 & 0.00 & & \\
\hline 1 & 1.254 & 187.60 & 40.59 & 0.00 & 0.00 & $\mathrm{BB}$ & 4.6213 \\
\hline 2 & 1.429 & 100.80 & 40.54 & 0.00 & 0.00 & $\mathrm{BB}$ & 2.4862 \\
\hline 3 & 3.930 & 156.37 & 45.76 & 0.00 & 0.00 & BV & 3.4174 \\
\hline 4 & 4.409 & 44638.43 & 1775.95 & 0.26 & 0.26 & VB & 25.1350 \\
\hline 5 & 4.801 & 215075.00 & 28148.16 & 1.24 & 1.24 & BB & 7.6408 \\
\hline 6 & 5.796 & 2587.34 & 260.06 & 0.01 & 0.01 & BV & 9.9490 \\
\hline 7 & 6.705 & 2108.66 & 38.58 & 0.01 & 0.01 & VB & 54.6547 \\
\hline 8 & 7.807 & 29351.20 & 1541.83 & 0.17 & 0.17 & $\mathrm{BB}$ & 19.0367 \\
\hline 9 & 8.968 & 59.80 & 33.12 & 0.00 & 0.00 & $\mathrm{BB}$ & 1.8058 \\
\hline 10 & 9.652 & 1963.80 & 86.45 & 0.01 & 0.01 & $\mathrm{BB}$ & 22.7168 \\
\hline 11 & 10.689 & 8512436.20 & 228357.08 & 48.91 & 48.91 & $\mathrm{BB}$ & 37.2769 \\
\hline 12 & 12.932 & 8591907.80 & 217996.93 & 49.37 & 49.37 & $\mathrm{BB}$ & 39.4130 \\
\hline 13 & 15.832 & 3424.80 & 203.26 & 0.02 & 0.02 & $\mathrm{BB}$ & 16.8493 \\
\hline 14 & 21.228 & 85.60 & 27.84 & 0.00 & 0.00 & $\mathrm{BB}$ & 3.0752 \\
\hline 15 & 21.321 & 72.80 & 26.68 & 0.00 & 0.00 & $\mathrm{BB}$ & 2.7286 \\
\hline 16 & 21.594 & 75.60 & 30.27 & 0.00 & 0.00 & $\mathrm{BB}$ & 2.4972 \\
\hline \multirow[t]{2}{*}{17} & 26.491 & 74.40 & 23.55 & 0.00 & 0.00 & BB & 3.1594 \\
\hline & & 0 & & & 10 & & \\
\hline
\end{tabular}

Missing Component Report

Component Expected Retention (Calibration File)

t-butylquin

0.001 

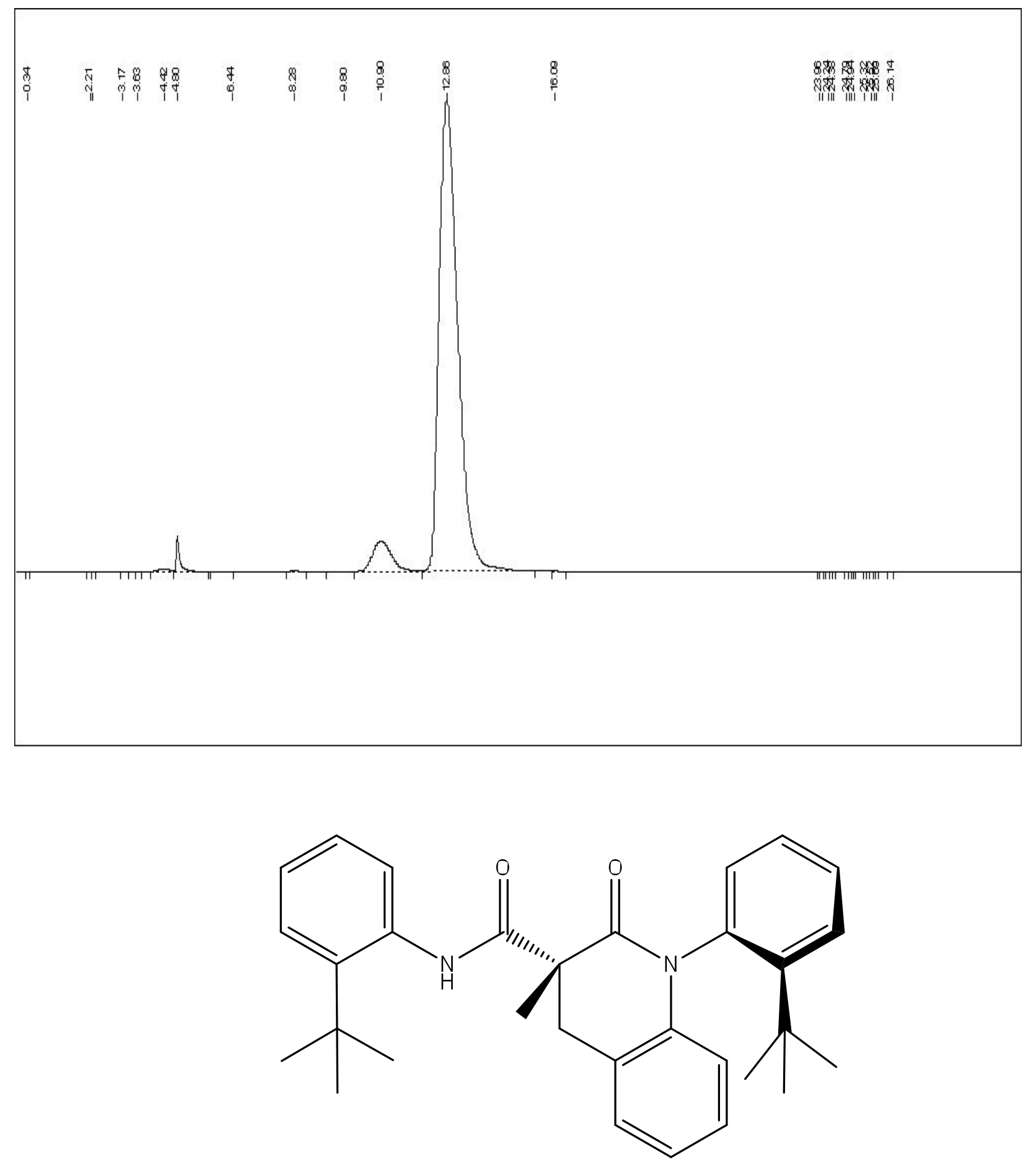

(36)

Isolate d from Ligand $=(R)-\mathrm{Cy}_{2} \mathrm{MOP}$, Base $=\mathrm{Cs}_{2} \mathrm{CO}_{3}$

i.e. Table 3 , entry 5 


\begin{tabular}{|c|c|c|c|}
\hline $\begin{array}{l}\text { Software Version } \\
\text { Operator } \\
\text { Sample Number } \\
\text { AutoSampler } \\
\text { Instrument Name } \\
\text { Instrument Serial \# } \\
\text { Delay Time } \\
\text { Sampling Rate } \\
\text { Sample Volume } \\
\text { Sample Amount } \\
\text { Data Acquisition Time }\end{array}$ & $\begin{array}{ll}: & 6.3 .1 .0504 \\
: & \text { manager } \\
: & 001 \\
: & \text { SER200 } \\
: & \text { HPLC } \\
: & \text { None } \\
: & 0.00 \mathrm{~min} \\
: & 2.5000 \mathrm{pts} / \mathrm{s} \\
: & 1.000000 \mathrm{ul} \\
: & 1.0000 \\
: & 8 / 12 / 20115: 41: 37 \mathrm{PM}\end{array}$ & $\begin{array}{l}\text { Date } \\
\text { Sample Name } \\
\text { Study } \\
\text { Rack/Vial } \\
\text { Channel } \\
\text { A/D mV Range } \\
\text { End Time } \\
\\
\text { Area Reject } \\
\text { Dilution Factor } \\
\text { Cycle }\end{array}$ & $\begin{array}{ll}: & 8 / 13 / 20115: 31: 48 \text { PM } \\
: & t-b u t y l q u i n(C y 2 M O P, C s 2 C O 3) \\
\vdots & 1 / 1 \\
\vdots & B \\
: & 1000 \\
: & 29.99 \mathrm{~min} \\
& \\
: & 0.000000 \\
: & 1.00 \\
: & 1\end{array}$ \\
\hline \multicolumn{4}{|c|}{ 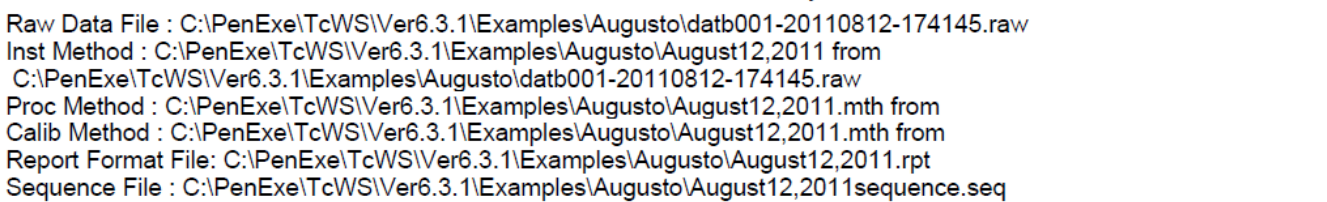 } \\
\hline
\end{tabular}

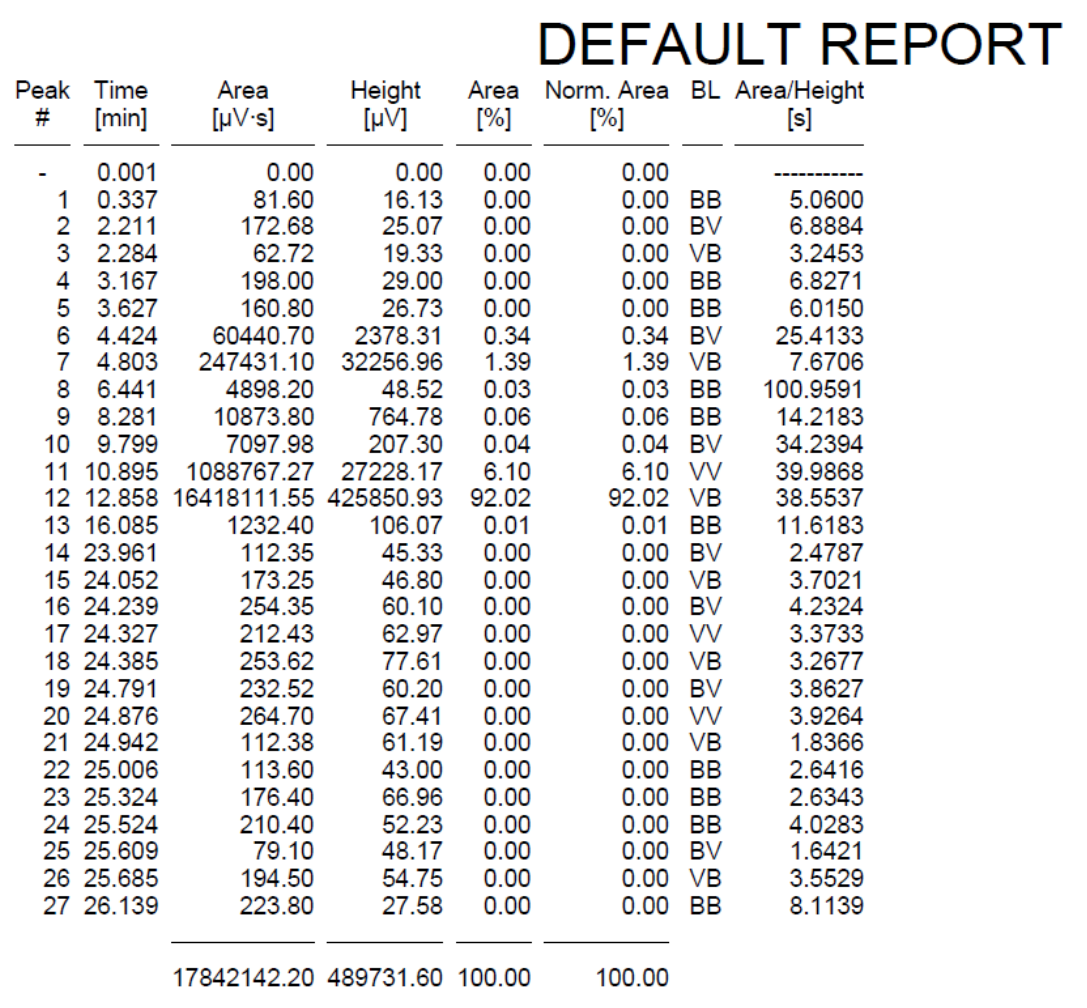

Missing Component Report

Component Expected Retention (Calibration File)

t-butylquin

0.001 

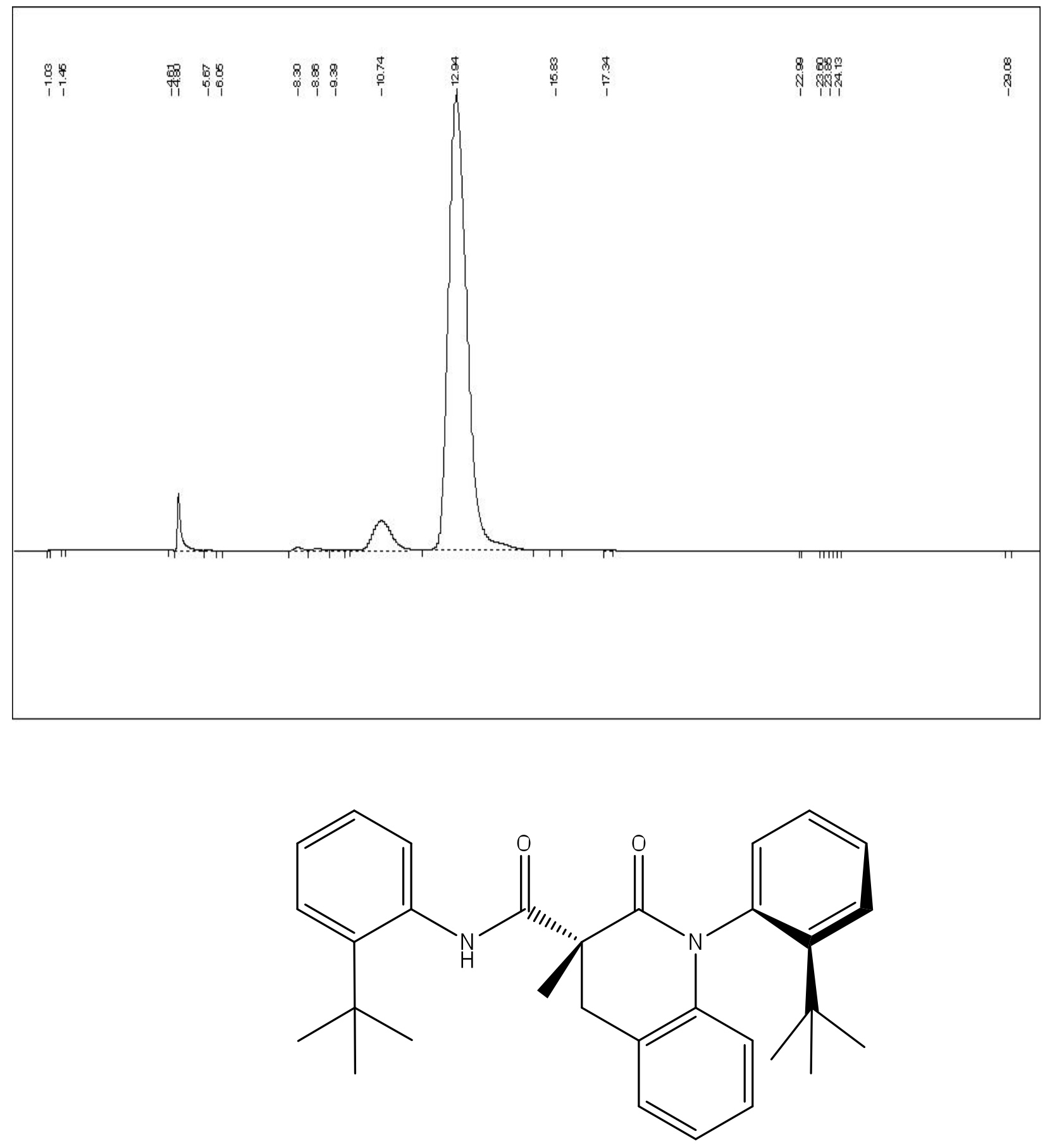

(36)

I solated from Ligand $=(R)-\mathrm{Cy}_{2} \mathrm{MOP}$, Base $=\mathrm{K}_{2} \mathrm{CO}_{3}$

i.e. Table 3 , entry 4 


\begin{tabular}{ll}
\hline Software Version & $:$ 6.3.1.0504 \\
Operator & $:$ manager \\
Sample Number & $:$ O03 \\
AutoSampler & $:$ SER200 \\
Instrument Name & $:$ HPLC \\
Instrument Serial \# & $:$ None \\
Delay Time & $: 0.00 \mathrm{~min}$ \\
Sampling Rate & $: 2.5000 \mathrm{pts} / \mathrm{s}$ \\
Sample Volume & $: 1.000000 \mathrm{ul}$ \\
Sample Amount & $: 1.0000$ \\
Data Acquisition Time & $: 8 / 12 / 20118: 49: 27 \mathrm{PM}$
\end{tabular}

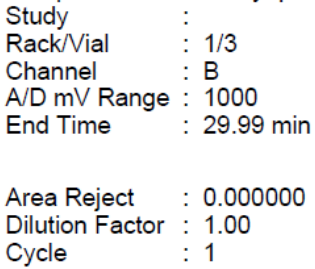

Raw Data File : C:IPenExelTcWSIVer6.3.1\Examples\Augustoldatb003-20110812-205341.raw

Inst Method: C:IPenExelTcWSIVer6.3.1\Examples\AugustolAugust12,2011 from

C:IPenExelTcWSIVer6.3.1 Examples\Augustoldatb003-20110812-205341.raw

Proc Method : C:IPenExelTcWSIVer6.3.11Examples\AugustolAugust12,2011.mth from

Calib Method : C:IPenExelTcWSIVer6.3.1\Examples\AugustolAugust12,2011.mth from

Report Format File: C:IPenExelTcWSIVer6.3.1\Examples\AugustolAugust12,2011.rpt

Sequence File : C:IPenExelTcWSIVer6.3.1\Examples\AugustolAugust12,2011sequence.seq

\begin{tabular}{|c|c|c|c|c|c|c|c|}
\hline $\begin{array}{l}\text { Peak } \\
\#\end{array}$ & $\begin{array}{l}\text { Time } \\
\text { [min] }\end{array}$ & $\begin{array}{l}\text { Area } \\
{[\mu \mathrm{V} \cdot \mathrm{s}]}\end{array}$ & $\begin{array}{l}\text { Height } \\
{[\mu \mathrm{V}]}\end{array}$ & $\begin{array}{c}\text { Area } \\
{[\%]}\end{array}$ & $\begin{array}{c}\text { Norm. Area } \\
{[\%]}\end{array}$ & $B L$ & $\begin{array}{c}\text { Area/Height } \\
\text { [s] }\end{array}$ \\
\hline- & 0.001 & 0.00 & 0.00 & 0.00 & 0.00 & \multirow{19}{*}{$\begin{array}{l}\text { BB } \\
\text { BB } \\
B B \\
B V \\
\text { VB } \\
\text { BB } \\
B V \\
V V \\
V V \\
V V \\
V B \\
\text { BB } \\
\text { BB } \\
\text { BB } \\
\text { BB } \\
\text { BB } \\
\text { BB } \\
\text { BB }\end{array}$} & \\
\hline 1 & 1.031 & 90.80 & 20.73 & 0.00 & 0.00 & & 4.3796 \\
\hline 2 & 1.451 & 106.20 & 23.28 & 0.00 & 0.00 & & 4 \\
\hline 3 & 4.611 & 2858.80 & 464.81 & 0.03 & 0.03 & & 6.1504 \\
\hline 4 & 4.801 & 224033.89 & 27910.44 & 2.47 & 2.47 & & 8.0269 \\
\hline 5 & 5.667 & 10127.11 & 898.39 & 0.11 & 0.11 & & 11.2726 \\
\hline 6 & 6.051 & 389.60 & 44.32 & 0.00 & 0.00 & & 8.7910 \\
\hline 7 & 8.300 & 25095.55 & 1526.28 & 0.28 & 0.28 & & 16.4423 \\
\hline 8 & 8.859 & 20069.76 & 873.27 & 0.22 & 0.22 & & 22.9824 \\
\hline 9 & 9.385 & 5131.81 & 282.06 & 0.06 & 0.06 & & 18.1943 \\
\hline 10 & 10.744 & 550555.19 & 14226.16 & 6.08 & 6.08 & & 38.7002 \\
\hline 11 & 12.941 & 8221688.74 & 219752.36 & 90.73 & 90.73 & & 37.4134 \\
\hline 12 & 15.826 & 1280.00 & 128.40 & 0.01 & 0.01 & & 9.969 \\
\hline 13 & 17.337 & 226.80 & 30.88 & 0.00 & 0.00 & & 7.343 \\
\hline 14 & 22.994 & 48.60 & 32.94 & 0.00 & 0.00 & & 1.475 \\
\hline 15 & 23.598 & 109.60 & 33.06 & 0.00 & 0.00 & & 3.315 \\
\hline 16 & 23.853 & 108.40 & 27.88 & 0.00 & 0.00 & & 3.8875 \\
\hline 17 & 24.133 & 78.80 & 29.57 & 0.00 & 0.00 & & 2.6653 \\
\hline 18 & 29. & 201.60 & 27.37 & 0.00 & 0.00 & & 7.3647 \\
\hline & & 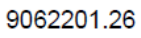 & & 列 & 100.00 & & \\
\hline
\end{tabular}

Missing Component Report

Component Expected Retention (Calibration File)

t-butylquin

0.001 

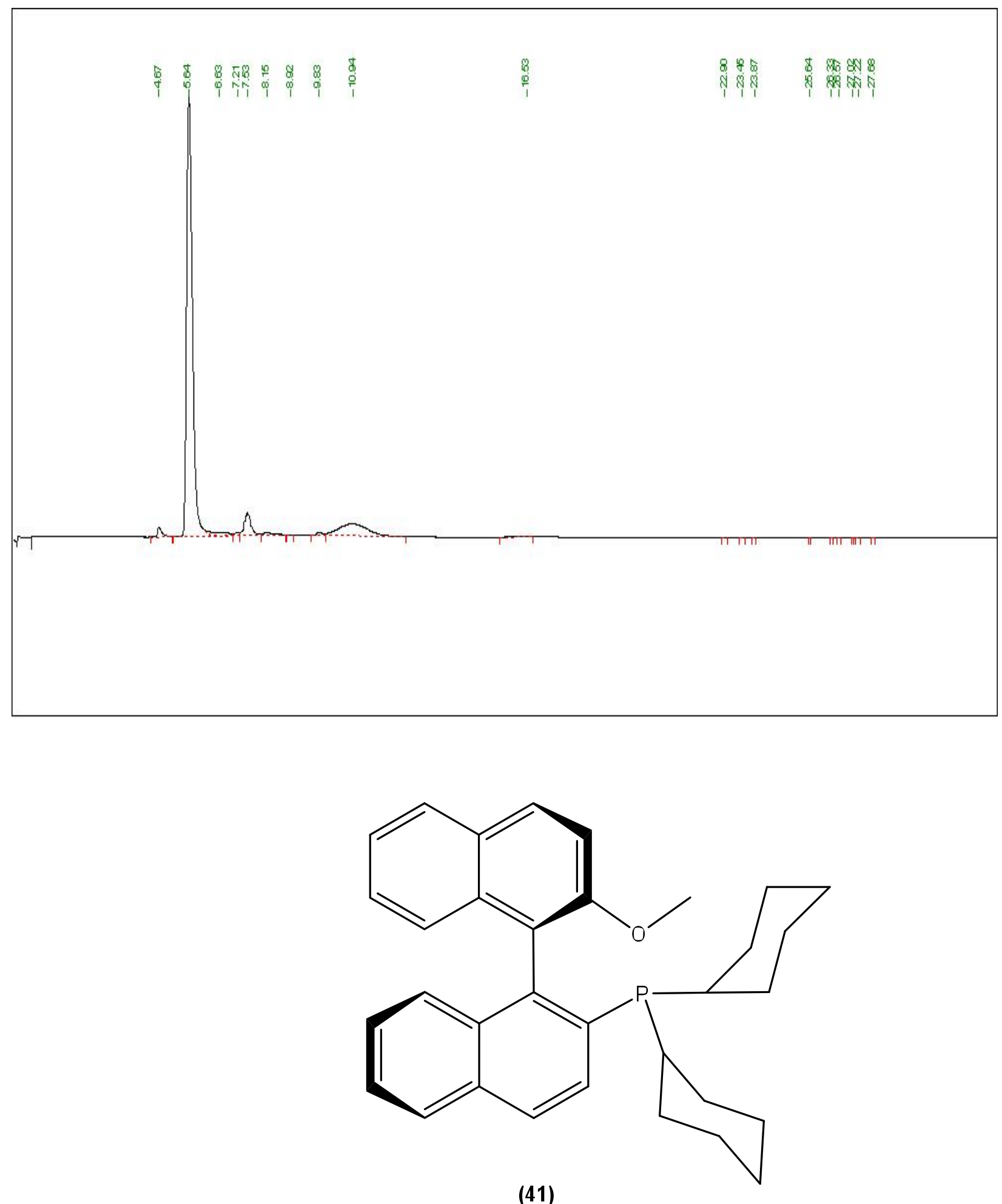

Isolated from Ligand = dippf, Base $=$ Hunig's base 


\begin{tabular}{ll}
\hline Software Version & $:$ 6.3.1.0504 \\
Operator & $:$ manager \\
Sample Number & $:$ O01 \\
AutoSampler & $:$ SER200 \\
Instrument Name & $:$ HPLC \\
Instrument Serial \# & $:$ None \\
Delay Time & $: 0.00 \mathrm{~min}$ \\
Sampling Rate & $: 2.5000 \mathrm{pts} / \mathrm{s}$ \\
Sample Volume & $: 1.000000 \mathrm{ul}$ \\
Sample Amount & $: 1.0000$ \\
Data Acquisition Time & $: 8 / 13 / 20115: 41: 52 \mathrm{PM}$
\end{tabular}

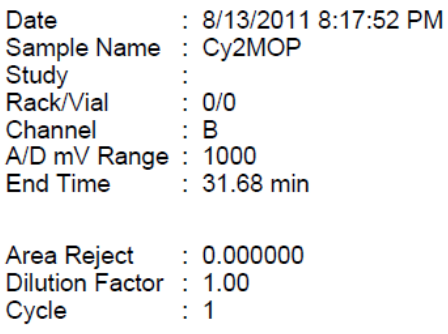

Raw Data File : C:IPenExelTcWSIVer6.3.1\Examples\Augustoldatb001-20110813-174152.raw <Incomplete> Inst Method: C:IPenExelTcWSIVer6.3.11Examples\AugustolCy2MOPmethod.mth from C:IPenExelTcWSIVer6.3.1\Examples\Augustoldatb001-20110813-174152.raw

Proc Method : C:IPenExelTcWSIVer6.3.1 Examples\AugustolCy2MOPmethod. $m$ th from Calib Method: C:IPenExelTcWSIVer6.3.11Examples\AugustolCy2MOPmethod.mth from Report Format File: C:IPenExelTcWSIVer6.3.1\Examples IIdefault.rpt

Sequence File : C:IPenExelTcWSIVer6.3.1\Examples\AugustolCy2MOPsequence.seq

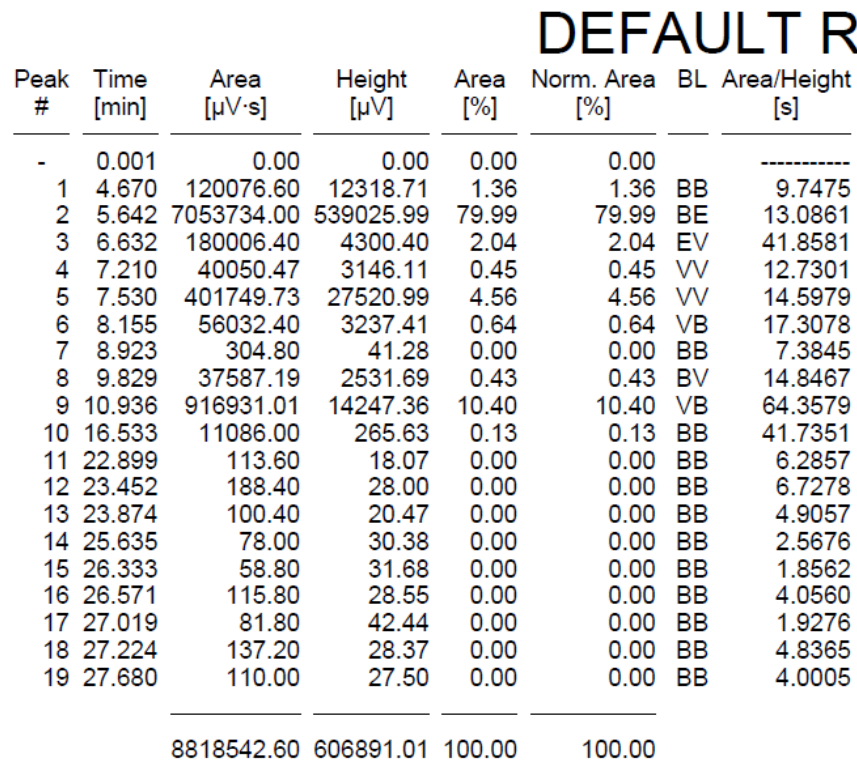

Missing Component Report

Component Expected Retention (Calibration File)

Cy2MOP 0.001 


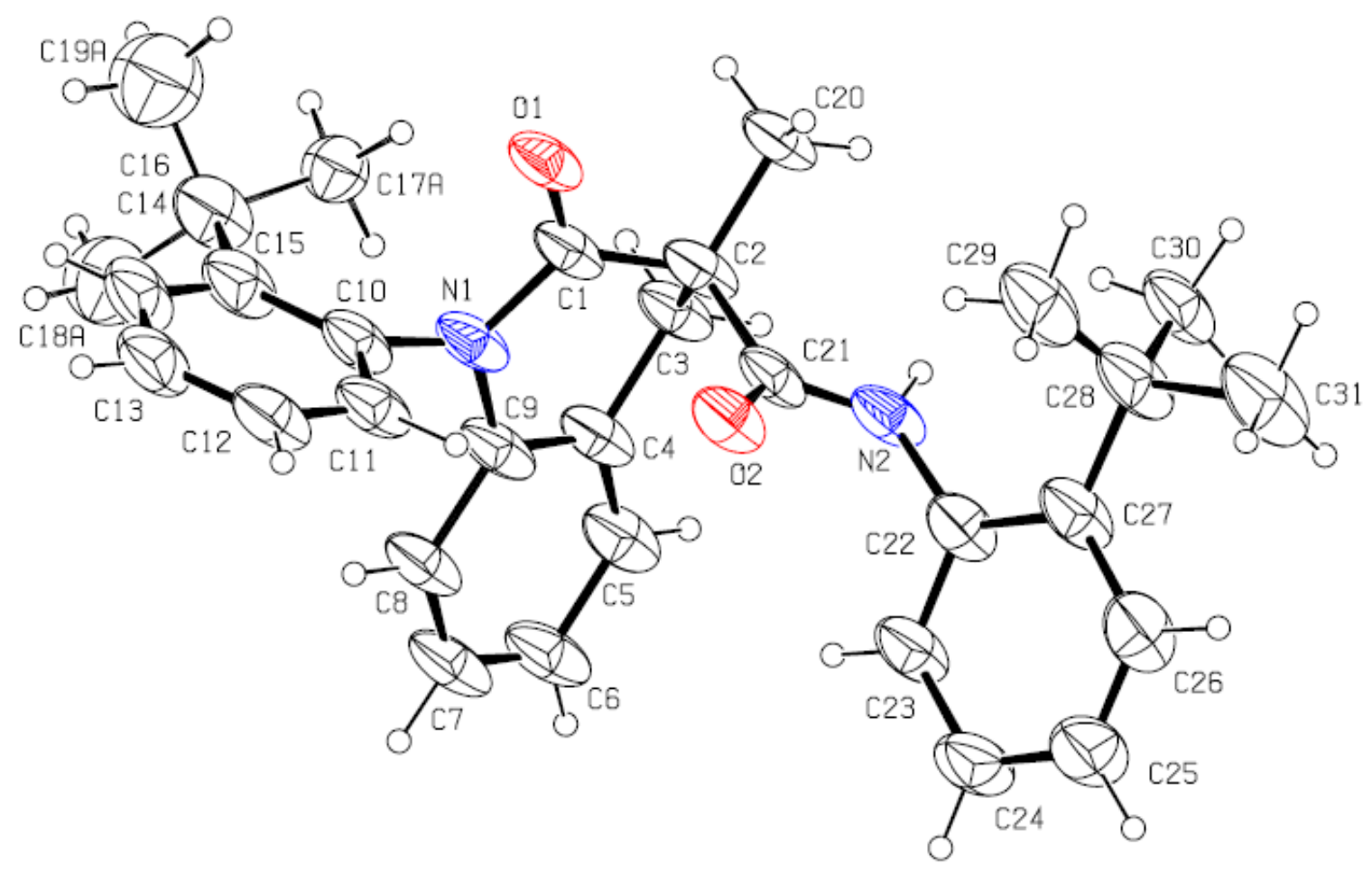


Table 1.Crystal data and structure refinement for k11200.

Identification code

Empirical formula

Formula weight

Temperature

Wavelength

Crystal system

Space group

Unit cell dimensions

Volume

Z

Density (calculated)

Absorption coefficient

$\mathrm{F}(000)$

Crystal size

Theta range for data collection

Index ranges

Reflections collected

Independent reflections

Completeness to theta $=69.75^{\circ}$

Absorption correction

Max. and min. transmission

Refinement method

Data / restraints / parameters

Goodness-of-fit on $\mathrm{F}^{2}$

Final $\mathrm{R}$ indices [I $>2 \operatorname{sigma}(\mathrm{I})]$

$\mathrm{R}$ indices (all data)

Absolute structure parameter

Largest diff. peak and hole loug16

$\mathrm{C} 32 \mathrm{H} 37 \mathrm{Cl} 3 \mathrm{~N} 2 \mathrm{O} 2$

587.99

$150 \mathrm{~K}$

\section{$1.54178 \AA$}

Trigonal

P31

$$
\begin{array}{ll}
\mathrm{a}=12.8503(6) \AA & \alpha=90^{\circ} . \\
\mathrm{b}=12.8503(6) \AA & \beta=90^{\circ} . \\
\mathrm{c}=16.9258(10) \AA & \gamma=120^{\circ} .
\end{array}
$$

2420.5(2) $\AA^{3}$

3

$1.210 \mathrm{Mg} / \mathrm{m}^{3}$

$2.798 \mathrm{~mm}^{-1}$

930

$0.16 \times 0.11 \times 0.11 \mathrm{~mm}^{3}$

3.97 to $69.75^{\circ}$.

$-15<=\mathrm{h}<=15,-15<=\mathrm{k}<=15,-20<=\mathrm{l}<=20$

31931

$5979[\mathrm{R}(\mathrm{int})=0.057]$

$99.2 \%$

Semi-empirical from equivalents

0.7351 and 0.5293

Full-matrix least-squares on $\mathrm{F}^{2}$

5979 / 16 / 361

1.040

$\mathrm{R} 1=0.0706, \mathrm{wR} 2=0.2033$

$\mathrm{R} 1=0.0799, \mathrm{wR} 2=0.2143$

$0.04(2)$

0.476 and -0.248 e. $\AA^{-3}$ 
Table 2. Atomic coordinates $\left(\times 10^{4}\right)$ and equivalent isotropic displacement parameters $\left(\AA^{2} \times 10^{3}\right)$ for $\mathrm{k} 11200$. $\mathrm{U}(\mathrm{eq})$ is defined as one third of the trace of the orthogonalized $\mathrm{U}^{\mathrm{ij}}$ tensor.

\begin{tabular}{|c|c|c|c|c|}
\hline & $\mathrm{x}$ & $\mathrm{y}$ & $\mathrm{z}$ & $\mathrm{U}(\mathrm{eq})$ \\
\hline$C(1)$ & $4554(3)$ & 7559(3) & $131(4)$ & $81(1)$ \\
\hline$C(2)$ & $3928(3)$ & $7123(3)$ & $924(4)$ & $85(1)$ \\
\hline$C(3)$ & $4605(3)$ & $8115(3)$ & $1539(4)$ & $85(1)$ \\
\hline$C(4)$ & $5881(3)$ & $8382(3)$ & $1584(3)$ & $82(1)$ \\
\hline$C(5)$ & $6502(4)$ & $8597(4)$ & $2288(4)$ & $90(2)$ \\
\hline$C(6)$ & $7682(4)$ & $8816(4)$ & $2304(4)$ & $100(2)$ \\
\hline$C(7)$ & $8216(4)$ & $8833(4)$ & $1604(4)$ & $98(2)$ \\
\hline$C(8)$ & $7630(3)$ & $8627(4)$ & $893(4)$ & $88(2)$ \\
\hline$C(9)$ & $6440(3)$ & $8379(3)$ & $869(4)$ & $84(1)$ \\
\hline$C(10)$ & 6413(3) & $8405(3)$ & $-590(4)$ & $84(1)$ \\
\hline $\mathrm{C}(11)$ & $6485(4)$ & 7415(4) & $-871(4)$ & $87(2)$ \\
\hline$C(12)$ & $7057(4)$ & $7480(5)$ & $-1570(4)$ & $98(2)$ \\
\hline$C(13)$ & $7544(4)$ & $8525(5)$ & $-1991(4)$ & $104(2)$ \\
\hline$C(14)$ & $7454(4)$ & 9501(5) & $-1712(5)$ & $106(2)$ \\
\hline$C(15)$ & $6894(4)$ & 9476(4) & $-1001(4)$ & $101(2)$ \\
\hline$C(16)$ & $6876(5)$ & 10623(4) & $-712(5)$ & $122(2)$ \\
\hline$C(17 A)$ & $5952(9)$ & $10436(9)$ & $-62(6)$ & $82(3)$ \\
\hline $\mathrm{C}(18 \mathrm{~A})$ & $8106(13)$ & $11597(16)$ & $-617(13)$ & $142(6)$ \\
\hline$C(19 A)$ & $6390(20)$ & $11030(20)$ & $-1371(11)$ & $159(7)$ \\
\hline$C(17 B)$ & $7574(16)$ & $11613(14)$ & $-1333(9)$ & $126(5)$ \\
\hline$C(18 B)$ & $7890(10)$ & 11294(11) & $-84(7)$ & $91(3)$ \\
\hline $\mathrm{C}(19 \mathrm{~B})$ & $5650(12)$ & $10378(15)$ & $-590(10)$ & $121(5)$ \\
\hline$C(20)$ & 2611(3) & $6825(4)$ & $847(4)$ & $88(1)$ \\
\hline $\mathrm{C}(21)$ & $3964(3)$ & $5965(3)$ & $1114(3)$ & $77(1)$ \\
\hline$C(22)$ & $3647(4)$ & 4521(4) & $2167(4)$ & $89(2)$ \\
\hline $\mathrm{C}(23)$ & $4784(4)$ & $4826(4)$ & 2443(4) & $97(2)$ \\
\hline$C(24)$ & $5002(5)$ & $3982(5)$ & 2793(4) & $109(2)$ \\
\hline$C(25)$ & $4039(5)$ & $2817(5)$ & $2854(5)$ & $117(2)$ \\
\hline$C(26)$ & 2921(5) & $2508(4)$ & $2590(5)$ & $110(2)$ \\
\hline$C(27)$ & $2682(4)$ & $3358(4)$ & $2229(4)$ & $98(2)$ \\
\hline$C(28)$ & $1408(4)$ & 2954(4) & $1916(6)$ & $111(2)$ \\
\hline
\end{tabular}




\begin{tabular}{lrrrr}
$\mathrm{C}(29)$ & $1424(5)$ & $3182(6)$ & $1052(5)$ & $113(2)$ \\
$\mathrm{C}(30)$ & $897(4)$ & $3621(4)$ & $2415(5)$ & $105(2)$ \\
$\mathrm{C}(31)$ & $527(6)$ & $1608(5)$ & $2093(7)$ & $152(4)$ \\
$\mathrm{C}(32)$ & $4818(4)$ & $3448(4)$ & $192(4)$ & $87(1)$ \\
$\mathrm{Cl}(1)$ & $3584(1)$ & $2012(1)$ & $179(1)$ & $118(1)$ \\
$\mathrm{Cl}(2)$ & $5331(2)$ & $3917(2)$ & $-766(1)$ & $115(1)$ \\
$\mathrm{Cl}(3)$ & $5971(2)$ & $3506(2)$ & $775(1)$ & $133(1)$ \\
$\mathrm{N}(1)$ & $5800(3)$ & $8191(3)$ & $154(3)$ & $81(1)$ \\
$\mathrm{N}(2)$ & $3542(3)$ & $5497(3)$ & $1836(3)$ & $86(1)$ \\
$\mathrm{O}(1)$ & $4029(2)$ & $7388(2)$ & $-490(3)$ & $89(1)$ \\
$\mathrm{O}(2)$ & $4335(2)$ & $5525(2)$ & $647(2)$ & $87(1)$ \\
\hline
\end{tabular}


Table 3. Bond lengths $[\AA]$ and angles $\left[{ }^{\circ}\right]$ for $\mathrm{k} 11200$.

\begin{tabular}{|c|c|}
\hline $\mathrm{C}(1)-\mathrm{O}(1)$ & $1.209(7)$ \\
\hline $\mathrm{C}(1)-\mathrm{N}(1)$ & $1.387(5)$ \\
\hline$C(1)-C(2)$ & $1.520(8)$ \\
\hline$C(2)-C(3)$ & $1.536(6)$ \\
\hline$C(2)-C(20)$ & $1.543(5)$ \\
\hline$C(2)-C(21)$ & $1.545(6)$ \\
\hline$C(3)-C(4)$ & $1.500(5)$ \\
\hline $\mathrm{C}(3)-\mathrm{H}(3 \mathrm{a})$ & 0.9900 \\
\hline $\mathrm{C}(3)-\mathrm{H}(3 \mathrm{~b})$ & 0.9900 \\
\hline$C(4)-C(5)$ & $1.383(8)$ \\
\hline$C(4)-C(9)$ & $1.409(8)$ \\
\hline$C(5)-C(6)$ & $1.397(6)$ \\
\hline $\mathrm{C}(5)-\mathrm{H}(5)$ & 0.9500 \\
\hline$C(6)-C(7)$ & $1.365(9)$ \\
\hline $\mathrm{C}(6)-\mathrm{H}(6)$ & 0.9500 \\
\hline $\mathrm{C}(7)-\mathrm{C}(8)$ & $1.372(9)$ \\
\hline $\mathrm{C}(7)-\mathrm{H}(7)$ & 0.9500 \\
\hline $\mathrm{C}(8)-\mathrm{C}(9)$ & $1.397(5)$ \\
\hline $\mathrm{C}(8)-\mathrm{H}(8)$ & 0.9500 \\
\hline $\mathrm{C}(9)-\mathrm{N}(1)$ & $1.414(7)$ \\
\hline$C(10)-C(15)$ & $1.382(7)$ \\
\hline$C(10)-C(11)$ & $1.403(6)$ \\
\hline $\mathrm{C}(10)-\mathrm{N}(1)$ & $1.437(7)$ \\
\hline $\mathrm{C}(11)-\mathrm{C}(12)$ & $1.373(8)$ \\
\hline $\mathrm{C}(11)-\mathrm{H}(11)$ & 0.9500 \\
\hline$C(12)-C(13)$ & $1.366(9)$ \\
\hline $\mathrm{C}(12)-\mathrm{H}(12)$ & 0.9500 \\
\hline$C(13)-C(14)$ & $1.398(9)$ \\
\hline $\mathrm{C}(13)-\mathrm{H}(13)$ & 0.9500 \\
\hline$C(14)-C(15)$ & $1.394(10)$ \\
\hline $\mathrm{C}(14)-\mathrm{H}(14)$ & 0.9500 \\
\hline$C(15)-C(16)$ & $1.564(7)$ \\
\hline $\mathrm{C}(16)-\mathrm{C}(18 \mathrm{a})$ & $1.453(13)$ \\
\hline$C(16)-C(19 b)$ & $1.459(12)$ \\
\hline
\end{tabular}




\begin{tabular}{|c|c|}
\hline$C(16)-C(19 a)$ & $1.497(14)$ \\
\hline$C(16)-C(17 b)$ & $1.545(12)$ \\
\hline$C(16)-C(17 a)$ & $1.548(10)$ \\
\hline$C(16)-C(18 b)$ & $1.565(11)$ \\
\hline $\mathrm{C}(17 \mathrm{a})-\mathrm{H}(17 \mathrm{a})$ & 0.9800 \\
\hline $\mathrm{C}(17 \mathrm{a})-\mathrm{H}(17 \mathrm{~b})$ & 0.9800 \\
\hline $\mathrm{C}(17 \mathrm{a})-\mathrm{H}(17 \mathrm{c})$ & 0.9800 \\
\hline $\mathrm{C}(18 \mathrm{a})-\mathrm{H}(18 \mathrm{a})$ & 0.9800 \\
\hline $\mathrm{C}(18 \mathrm{a})-\mathrm{H}(18 \mathrm{~b})$ & 0.9800 \\
\hline $\mathrm{C}(18 \mathrm{a})-\mathrm{H}(18 \mathrm{c})$ & 0.9800 \\
\hline $\mathrm{C}(19 \mathrm{a})-\mathrm{H}(19 \mathrm{a})$ & 0.9800 \\
\hline $\mathrm{C}(19 \mathrm{a})-\mathrm{H}(19 \mathrm{~b})$ & 0.9800 \\
\hline $\mathrm{C}(19 \mathrm{a})-\mathrm{H}(19 \mathrm{c})$ & 0.9800 \\
\hline $\mathrm{C}(17 \mathrm{~b})-\mathrm{H}(17 \mathrm{~d})$ & 0.9800 \\
\hline $\mathrm{C}(17 \mathrm{~b})-\mathrm{H}(17 \mathrm{e})$ & 0.9800 \\
\hline $\mathrm{C}(17 \mathrm{~b})-\mathrm{H}(17 \mathrm{f})$ & 0.9800 \\
\hline $\mathrm{C}(18 \mathrm{~b})-\mathrm{H}(18 \mathrm{~d})$ & 0.9800 \\
\hline $\mathrm{C}(18 \mathrm{~b})-\mathrm{H}(18 \mathrm{e})$ & 0.9800 \\
\hline $\mathrm{C}(18 \mathrm{~b})-\mathrm{H}(18 \mathrm{f})$ & 0.9800 \\
\hline $\mathrm{C}(19 \mathrm{~b})-\mathrm{H}(19 \mathrm{~d})$ & 0.9800 \\
\hline $\mathrm{C}(19 \mathrm{~b})-\mathrm{H}(19 \mathrm{e})$ & 0.9800 \\
\hline $\mathrm{C}(19 b)-\mathrm{H}(19 f)$ & 0.9800 \\
\hline $\mathrm{C}(20)-\mathrm{H}(20 \mathrm{a})$ & 0.9800 \\
\hline $\mathrm{C}(20)-\mathrm{H}(20 \mathrm{~b})$ & 0.9800 \\
\hline $\mathrm{C}(20)-\mathrm{H}(20 \mathrm{c})$ & 0.9800 \\
\hline $\mathrm{C}(21)-\mathrm{O}(2)$ & $1.202(6)$ \\
\hline $\mathrm{C}(21)-\mathrm{N}(2)$ & $1.350(7)$ \\
\hline$C(22)-C(27)$ & $1.389(6)$ \\
\hline$C(22)-C(23)$ & $1.390(7)$ \\
\hline $\mathrm{C}(22)-\mathrm{N}(2)$ & $1.440(6)$ \\
\hline$C(23)-C(24)$ & $1.382(8)$ \\
\hline $\mathrm{C}(23)-\mathrm{H}(23)$ & 0.9500 \\
\hline$C(24)-C(25)$ & $1.389(8)$ \\
\hline $\mathrm{C}(24)-\mathrm{H}(24)$ & 0.9500 \\
\hline$C(25)-C(26)$ & $1.360(9)$ \\
\hline $\mathrm{C}(25)-\mathrm{H}(25)$ & 0.9500 \\
\hline
\end{tabular}




\begin{tabular}{|c|c|}
\hline$C(26)-C(27)$ & $1.414(8)$ \\
\hline $\mathrm{C}(26)-\mathrm{H}(26)$ & 0.9500 \\
\hline $\mathrm{C}(27)-\mathrm{C}(28)$ & $1.543(8)$ \\
\hline $\mathrm{C}(28)-\mathrm{C}(29)$ & $1.490(11)$ \\
\hline $\mathrm{C}(28)-\mathrm{C}(31)$ & $1.551(7)$ \\
\hline $\mathrm{C}(28)-\mathrm{C}(30)$ & $1.563(9)$ \\
\hline $\mathrm{C}(29)-\mathrm{H}(29 \mathrm{a})$ & 0.9800 \\
\hline $\mathrm{C}(29)-\mathrm{H}(29 b)$ & 0.9800 \\
\hline $\mathrm{C}(29)-\mathrm{H}(29 \mathrm{c})$ & 0.9800 \\
\hline $\mathrm{C}(30)-\mathrm{H}(30 \mathrm{a})$ & 0.9800 \\
\hline $\mathrm{C}(30)-\mathrm{H}(30 \mathrm{~b})$ & 0.9800 \\
\hline $\mathrm{C}(30)-\mathrm{H}(30 \mathrm{c})$ & 0.9800 \\
\hline $\mathrm{C}(31)-\mathrm{H}(31 \mathrm{a})$ & 0.9800 \\
\hline $\mathrm{C}(31)-\mathrm{H}(31 \mathrm{~b})$ & 0.9800 \\
\hline $\mathrm{C}(31)-\mathrm{H}(31 \mathrm{c})$ & 0.9800 \\
\hline $\mathrm{C}(32)-\mathrm{Cl}(1)$ & $1.730(5)$ \\
\hline $\mathrm{C}(32)-\mathrm{Cl}(2)$ & $1.740(6)$ \\
\hline $\mathrm{C}(32)-\mathrm{Cl}(3)$ & $1.751(6)$ \\
\hline $\mathrm{C}(32)-\mathrm{H}(32)$ & 1.0000 \\
\hline $\mathrm{N}(2)-\mathrm{H}(2)$ & 0.8800 \\
\hline $\mathrm{O}(1)-\mathrm{C}(1)-\mathrm{N}(1)$ & $120.5(5)$ \\
\hline $\mathrm{O}(1)-\mathrm{C}(1)-\mathrm{C}(2)$ & $123.8(3)$ \\
\hline $\mathrm{N}(1)-\mathrm{C}(1)-\mathrm{C}(2)$ & $115.8(5)$ \\
\hline$C(1)-C(2)-C(3)$ & $108.5(4)$ \\
\hline$C(1)-C(2)-C(20)$ & $109.3(5)$ \\
\hline$C(3)-C(2)-C(20)$ & $111.1(4)$ \\
\hline $\mathrm{C}(1)-\mathrm{C}(2)-\mathrm{C}(21)$ & $105.9(3)$ \\
\hline$C(3)-C(2)-C(21)$ & $112.3(4)$ \\
\hline$C(20)-C(2)-C(21)$ & $109.6(3)$ \\
\hline$C(4)-C(3)-C(2)$ & $109.0(3)$ \\
\hline $\mathrm{C}(4)-\mathrm{C}(3)-\mathrm{H}(3 \mathrm{~A})$ & 109.9 \\
\hline $\mathrm{C}(2)-\mathrm{C}(3)-\mathrm{H}(3 \mathrm{~A})$ & 109.9 \\
\hline $\mathrm{C}(4)-\mathrm{C}(3)-\mathrm{H}(3 \mathrm{~B})$ & 109.9 \\
\hline $\mathrm{C}(2)-\mathrm{C}(3)-\mathrm{H}(3 \mathrm{~B})$ & 109.9 \\
\hline $\mathrm{H}(3 \mathrm{~A})-\mathrm{C}(3)-\mathrm{H}(3 \mathrm{~B})$ & 108.3 \\
\hline
\end{tabular}




\begin{tabular}{|c|c|}
\hline$C(5)-C(4)-C(9)$ & $119.8(4)$ \\
\hline$C(5)-C(4)-C(3)$ & $123.0(5)$ \\
\hline$C(9)-C(4)-C(3)$ & $117.2(4)$ \\
\hline$C(4)-C(5)-C(6)$ & $121.1(6)$ \\
\hline $\mathrm{C}(4)-\mathrm{C}(5)-\mathrm{H}(5)$ & 119.4 \\
\hline $\mathrm{C}(6)-\mathrm{C}(5)-\mathrm{H}(5)$ & 119.4 \\
\hline$C(7)-C(6)-C(5)$ & $118.2(6)$ \\
\hline $\mathrm{C}(7)-\mathrm{C}(6)-\mathrm{H}(6)$ & 120.9 \\
\hline $\mathrm{C}(5)-\mathrm{C}(6)-\mathrm{H}(6)$ & 120.9 \\
\hline$C(6)-C(7)-C(8)$ & $122.4(4)$ \\
\hline $\mathrm{C}(6)-\mathrm{C}(7)-\mathrm{H}(7)$ & 118.8 \\
\hline $\mathrm{C}(8)-\mathrm{C}(7)-\mathrm{H}(7)$ & 118.8 \\
\hline$C(7)-C(8)-C(9)$ & $120.1(5)$ \\
\hline $\mathrm{C}(7)-\mathrm{C}(8)-\mathrm{H}(8)$ & 119.9 \\
\hline $\mathrm{C}(9)-\mathrm{C}(8)-\mathrm{H}(8)$ & 119.9 \\
\hline$C(8)-C(9)-C(4)$ & $118.4(5)$ \\
\hline $\mathrm{C}(8)-\mathrm{C}(9)-\mathrm{N}(1)$ & $122.7(5)$ \\
\hline $\mathrm{C}(4)-\mathrm{C}(9)-\mathrm{N}(1)$ & $118.8(3)$ \\
\hline$C(15)-C(10)-C(11)$ & $122.1(5)$ \\
\hline $\mathrm{C}(15)-\mathrm{C}(10)-\mathrm{N}(1)$ & $124.2(4)$ \\
\hline $\mathrm{C}(11)-\mathrm{C}(10)-\mathrm{N}(1)$ & $113.7(4)$ \\
\hline $\mathrm{C}(12)-\mathrm{C}(11)-\mathrm{C}(10)$ & $120.9(5)$ \\
\hline $\mathrm{C}(12)-\mathrm{C}(11)-\mathrm{H}(11)$ & 119.6 \\
\hline $\mathrm{C}(10)-\mathrm{C}(11)-\mathrm{H}(11)$ & 119.6 \\
\hline $\mathrm{C}(13)-\mathrm{C}(12)-\mathrm{C}(11)$ & $118.5(5)$ \\
\hline $\mathrm{C}(13)-\mathrm{C}(12)-\mathrm{H}(12)$ & 120.7 \\
\hline $\mathrm{C}(11)-\mathrm{C}(12)-\mathrm{H}(12)$ & 120.7 \\
\hline $\mathrm{C}(12)-\mathrm{C}(13)-\mathrm{C}(14)$ & $120.2(6)$ \\
\hline $\mathrm{C}(12)-\mathrm{C}(13)-\mathrm{H}(13)$ & 119.9 \\
\hline $\mathrm{C}(14)-\mathrm{C}(13)-\mathrm{H}(13)$ & 119.9 \\
\hline $\mathrm{C}(15)-\mathrm{C}(14)-\mathrm{C}(13)$ & $123.0(6)$ \\
\hline $\mathrm{C}(15)-\mathrm{C}(14)-\mathrm{H}(14)$ & 118.5 \\
\hline $\mathrm{C}(13)-\mathrm{C}(14)-\mathrm{H}(14)$ & 118.5 \\
\hline $\mathrm{C}(10)-\mathrm{C}(15)-\mathrm{C}(14)$ & $115.3(5)$ \\
\hline $\mathrm{C}(10)-\mathrm{C}(15)-\mathrm{C}(16)$ & $124.8(6)$ \\
\hline$C(14)-C(15)-C(16)$ & $119.9(5)$ \\
\hline
\end{tabular}




\begin{tabular}{|c|c|}
\hline$C(18 A)-C(16)-C(19 A)$ & $104.3(12)$ \\
\hline$C(19 B)-C(16)-C(17 B)$ & $113.2(10)$ \\
\hline$C(18 A)-C(16)-C(17 A)$ & $118.3(10)$ \\
\hline$C(19 A)-C(16)-C(17 A)$ & $99.2(10)$ \\
\hline $\mathrm{C}(18 \mathrm{~A})-\mathrm{C}(16)-\mathrm{C}(15)$ & $108.9(9)$ \\
\hline C(19B)-C(16)-C(15) & $111.4(7)$ \\
\hline$C(19 A)-C(16)-C(15)$ & $107.6(10)$ \\
\hline $\mathrm{C}(17 \mathrm{~B})-\mathrm{C}(16)-\mathrm{C}(15)$ & $106.6(8)$ \\
\hline $\mathrm{C}(17 \mathrm{~A})-\mathrm{C}(16)-\mathrm{C}(15)$ & $116.7(6)$ \\
\hline$C(19 B)-C(16)-C(18 B)$ & $122.3(9)$ \\
\hline $\mathrm{C}(17 \mathrm{~B})-\mathrm{C}(16)-\mathrm{C}(18 \mathrm{~B})$ & $91.6(8)$ \\
\hline$C(15)-C(16)-C(18 B)$ & $109.4(6)$ \\
\hline $\mathrm{C}(16)-\mathrm{C}(17 \mathrm{~A})-\mathrm{H}(17 \mathrm{~A})$ & 109.5 \\
\hline $\mathrm{C}(16)-\mathrm{C}(17 \mathrm{~A})-\mathrm{H}(17 \mathrm{~B})$ & 109.5 \\
\hline $\mathrm{C}(16)-\mathrm{C}(17 \mathrm{~A})-\mathrm{H}(17 \mathrm{C})$ & 109.5 \\
\hline $\mathrm{C}(16)-\mathrm{C}(18 \mathrm{~A})-\mathrm{H}(18 \mathrm{~A})$ & 109.5 \\
\hline $\mathrm{C}(16)-\mathrm{C}(18 \mathrm{~A})-\mathrm{H}(18 \mathrm{~B})$ & 109.5 \\
\hline $\mathrm{C}(16)-\mathrm{C}(18 \mathrm{~A})-\mathrm{H}(18 \mathrm{C})$ & 109.5 \\
\hline $\mathrm{C}(16)-\mathrm{C}(19 \mathrm{~A})-\mathrm{H}(19 \mathrm{~A})$ & 109.5 \\
\hline $\mathrm{C}(16)-\mathrm{C}(19 \mathrm{~A})-\mathrm{H}(19 \mathrm{~B})$ & 109.5 \\
\hline $\mathrm{C}(16)-\mathrm{C}(19 \mathrm{~A})-\mathrm{H}(19 \mathrm{C})$ & 109.5 \\
\hline $\mathrm{C}(16)-\mathrm{C}(17 \mathrm{~B})-\mathrm{H}(17 \mathrm{D})$ & 109.5 \\
\hline$C(16)-C(17 B)-H(17 E)$ & 109.5 \\
\hline $\mathrm{H}(17 \mathrm{D})-\mathrm{C}(17 \mathrm{~B})-\mathrm{H}(17 \mathrm{E})$ & 109.5 \\
\hline $\mathrm{C}(16)-\mathrm{C}(17 \mathrm{~B})-\mathrm{H}(17 \mathrm{~F})$ & 109.5 \\
\hline H(17D)-C(17B)-H(17F) & 109.5 \\
\hline $\mathrm{H}(17 \mathrm{E})-\mathrm{C}(17 \mathrm{~B})-\mathrm{H}(17 \mathrm{~F})$ & 109.5 \\
\hline $\mathrm{C}(16)-\mathrm{C}(18 \mathrm{~B})-\mathrm{H}(18 \mathrm{D})$ & 109.5 \\
\hline $\mathrm{C}(16)-\mathrm{C}(18 \mathrm{~B})-\mathrm{H}(18 \mathrm{E})$ & 109.5 \\
\hline $\mathrm{H}(18 \mathrm{D})-\mathrm{C}(18 \mathrm{~B})-\mathrm{H}(18 \mathrm{E})$ & 109.5 \\
\hline $\mathrm{C}(16)-\mathrm{C}(18 \mathrm{~B})-\mathrm{H}(18 \mathrm{~F})$ & 109.5 \\
\hline $\mathrm{H}(18 \mathrm{D})-\mathrm{C}(18 \mathrm{~B})-\mathrm{H}(18 \mathrm{~F})$ & 109.5 \\
\hline $\mathrm{H}(18 \mathrm{E})-\mathrm{C}(18 \mathrm{~B})-\mathrm{H}(18 \mathrm{~F})$ & 109.5 \\
\hline$C(16)-C(19 B)-H(19 D)$ & 109.5 \\
\hline$C(16)-C(19 B)-H(19 E)$ & 109.5 \\
\hline H(19D)-C(19B)-H(19E) & 109.5 \\
\hline
\end{tabular}




\begin{tabular}{|c|c|}
\hline$C(16)-C(19 B)-H(19 F)$ & 109.5 \\
\hline $\mathrm{H}(19 \mathrm{D})-\mathrm{C}(19 \mathrm{~B})-\mathrm{H}(19 \mathrm{~F})$ & 109.5 \\
\hline $\mathrm{H}(19 \mathrm{E})-\mathrm{C}(19 \mathrm{~B})-\mathrm{H}(19 \mathrm{~F})$ & 109.5 \\
\hline$C(2)-C(20)-H(20 A)$ & 109.5 \\
\hline$C(2)-C(20)-H(20 B)$ & 109.5 \\
\hline $\mathrm{H}(20 \mathrm{~A})-\mathrm{C}(20)-\mathrm{H}(20 \mathrm{~B})$ & 109.5 \\
\hline$C(2)-C(20)-H(20 C)$ & 109.5 \\
\hline $\mathrm{H}(20 \mathrm{~A})-\mathrm{C}(20)-\mathrm{H}(20 \mathrm{C})$ & 109.5 \\
\hline $\mathrm{H}(20 \mathrm{~B})-\mathrm{C}(20)-\mathrm{H}(20 \mathrm{C})$ & 109.5 \\
\hline $\mathrm{O}(2)-\mathrm{C}(21)-\mathrm{N}(2)$ & $123.5(4)$ \\
\hline $\mathrm{O}(2)-\mathrm{C}(21)-\mathrm{C}(2)$ & $121.8(5)$ \\
\hline $\mathrm{N}(2)-\mathrm{C}(21)-\mathrm{C}(2)$ & $114.8(4)$ \\
\hline $\mathrm{C}(27)-\mathrm{C}(22)-\mathrm{C}(23)$ & $121.7(4)$ \\
\hline $\mathrm{C}(27)-\mathrm{C}(22)-\mathrm{N}(2)$ & $122.9(4)$ \\
\hline $\mathrm{C}(23)-\mathrm{C}(22)-\mathrm{N}(2)$ & $115.3(4)$ \\
\hline $\mathrm{C}(24)-\mathrm{C}(23)-\mathrm{C}(22)$ & 121.3(4) \\
\hline $\mathrm{C}(24)-\mathrm{C}(23)-\mathrm{H}(23)$ & 119.4 \\
\hline $\mathrm{C}(22)-\mathrm{C}(23)-\mathrm{H}(23)$ & 119.4 \\
\hline$C(23)-C(24)-C(25)$ & $117.2(5)$ \\
\hline $\mathrm{C}(23)-\mathrm{C}(24)-\mathrm{H}(24)$ & 121.4 \\
\hline $\mathrm{C}(25)-\mathrm{C}(24)-\mathrm{H}(24)$ & 121.4 \\
\hline$C(26)-C(25)-C(24)$ & $122.1(5)$ \\
\hline $\mathrm{C}(26)-\mathrm{C}(25)-\mathrm{H}(25)$ & 118.9 \\
\hline $\mathrm{C}(24)-\mathrm{C}(25)-\mathrm{H}(25)$ & 118.9 \\
\hline$C(25)-C(26)-C(27)$ & $121.5(5)$ \\
\hline $\mathrm{C}(25)-\mathrm{C}(26)-\mathrm{H}(26)$ & 119.3 \\
\hline $\mathrm{C}(27)-\mathrm{C}(26)-\mathrm{H}(26)$ & 119.3 \\
\hline $\mathrm{C}(22)-\mathrm{C}(27)-\mathrm{C}(26)$ & $116.2(5)$ \\
\hline $\mathrm{C}(22)-\mathrm{C}(27)-\mathrm{C}(28)$ & $124.3(5)$ \\
\hline$C(26)-C(27)-C(28)$ & $119.5(4)$ \\
\hline $\mathrm{C}(29)-\mathrm{C}(28)-\mathrm{C}(27)$ & $111.3(5)$ \\
\hline $\mathrm{C}(29)-\mathrm{C}(28)-\mathrm{C}(31)$ & $109.9(7)$ \\
\hline $\mathrm{C}(27)-\mathrm{C}(28)-\mathrm{C}(31)$ & $111.7(6)$ \\
\hline $\mathrm{C}(29)-\mathrm{C}(28)-\mathrm{C}(30)$ & $113.0(6)$ \\
\hline $\mathrm{C}(27)-\mathrm{C}(28)-\mathrm{C}(30)$ & $107.2(5)$ \\
\hline$C(31)-C(28)-C(30)$ & $103.5(5)$ \\
\hline
\end{tabular}




$\begin{array}{ll}\text { C(28)-C(29)-H(29A) } & 109.5 \\ \text { C(28)-C(29)-H(29B) } & 109.5 \\ \text { H(29A)-C(29)-H(29B) } & 109.5 \\ \text { C(28)-C(29)-H(29C) } & 109.5 \\ \text { H(29A)-C(29)-H(29C) } & 109.5 \\ \text { H(29B)-C(29)-H(29C) } & 109.5 \\ \text { C(28)-C(30)-H(30A) } & 109.5 \\ \text { C(28)-C(30)-H(30B) } & 109.5 \\ \text { H(30A)-C(30)-H(30B) } & 109.5 \\ \text { C(28)-C(30)-H(30C) } & 109.5 \\ \text { H(30A)-C(30)-H(30C) } & 109.5 \\ \text { H(30B)-C(30)-H(30C) } & 109.5 \\ \text { C(28)-C(31)-H(31A) } & 109.5 \\ \text { C(28)-C(31)-H(31B) } & 109.5 \\ \text { H(31A)-C(31)-H(31B) } & 109.5 \\ \text { C(28)-C(31)-H(31C) } & 109.5 \\ \text { H(31A)-C(31)-H(31C) } & 109.5 \\ \text { H(31B)-C(31)-H(31C) } & 109.5 \\ \text { CL1-C(32)-CL2 } & 110.2(3) \\ \text { CL1-C(32)-CL3 } & 111.0(3) \\ \text { CL2-C(32)-CL3 } & 110.1(3) \\ \text { CL1-C(32)-H(32) } & 108.5 \\ \text { CL2-C(32)-H(32) } & 108.5 \\ \text { CL3-C(32)-H(32) } & 108.5 \\ \text { C(1)-N(1)-C(9) } & 121.8(5) \\ \text { C(1)-N(1)-C(10) } & 116.7(4) \\ \text { C(9)-N(1)-C(10) } & 120.0(3) \\ \text { C(21)-N(2)-C(22) } & 123.3(4) \\ \text { C(21)-N(2)-H(2) } & 118.4 \\ \text { C(22)-N(2)-H(2) } & 118.4 \\ & \end{array}$

Symmetry transformations used to generate equivalent atoms: 
Table 4. Anisotropic displacement parameters $\left(\AA^{2} \times 10^{3}\right)$ for k11200. The anisotropic displacement factor exponent takes the form: $-2 \pi^{2}\left[h^{2} a^{* 2} U^{11}+\ldots+2 h k a^{*} b^{*} U^{12}\right]$

\begin{tabular}{|c|c|c|c|c|c|c|}
\hline & $\mathrm{U}^{11}$ & $\mathrm{U}^{22}$ & $\mathrm{U}^{33}$ & $\mathrm{U}^{23}$ & $\mathrm{U}^{13}$ & $\mathrm{U}^{12}$ \\
\hline $\mathrm{C}(1)$ & $34(2)$ & $30(2)$ & $175(4)$ & $-9(2)$ & $-5(2)$ & $15(1)$ \\
\hline $\mathrm{C}(2)$ & $37(2)$ & $43(2)$ & $175(5)$ & $-20(2)$ & $-9(2)$ & $21(2)$ \\
\hline$C(3)$ & $38(2)$ & $37(2)$ & $179(5)$ & $-18(2)$ & $-12(2)$ & $17(1)$ \\
\hline$C(4)$ & $39(2)$ & $35(2)$ & $171(4)$ & $-20(2)$ & $-9(2)$ & $18(1)$ \\
\hline$C(5)$ & $52(2)$ & $47(2)$ & $168(5)$ & $-28(2)$ & $-10(3)$ & $21(2)$ \\
\hline$C(6)$ & $46(2)$ & $66(3)$ & $183(5)$ & $-38(3)$ & $-27(3)$ & $25(2)$ \\
\hline$C(7)$ & $39(2)$ & $62(2)$ & $189(5)$ & $-37(3)$ & $-16(3)$ & $23(2)$ \\
\hline $\mathrm{C}(8)$ & $38(2)$ & $52(2)$ & $173(5)$ & $-24(2)$ & $-8(2)$ & $21(2)$ \\
\hline $\mathrm{C}(9)$ & $35(2)$ & $36(2)$ & $176(5)$ & $-24(2)$ & $-13(2)$ & $13(1)$ \\
\hline $\mathrm{C}(10)$ & $38(2)$ & $40(2)$ & $167(4)$ & $-13(2)$ & $-4(2)$ & $14(1)$ \\
\hline $\mathrm{C}(11)$ & $42(2)$ & $47(2)$ & $170(5)$ & $-18(2)$ & $-12(2)$ & $20(2)$ \\
\hline $\mathrm{C}(12)$ & $48(2)$ & $75(3)$ & $169(5)$ & $-20(3)$ & $-9(3)$ & $29(2)$ \\
\hline $\mathrm{C}(13)$ & $48(2)$ & $88(4)$ & $156(5)$ & $-5(3)$ & $-6(3)$ & $19(2)$ \\
\hline$C(14)$ & $49(2)$ & $61(3)$ & $184(6)$ & $5(3)$ & $5(3)$ & $10(2)$ \\
\hline$C(15)$ & $50(2)$ & $46(2)$ & $192(6)$ & $-6(3)$ & $-6(3)$ & $13(2)$ \\
\hline$C(16)$ & $69(3)$ & $37(2)$ & $250(8)$ & $8(3)$ & $-1(4)$ & $20(2)$ \\
\hline $\mathrm{C}(20)$ & $36(2)$ & $57(2)$ & $172(5)$ & $-13(2)$ & $-6(2)$ & $23(2)$ \\
\hline $\mathrm{C}(21)$ & $30(2)$ & $40(2)$ & $153(4)$ & $-14(2)$ & $-1(2)$ & $11(1)$ \\
\hline $\mathrm{C}(22)$ & $56(2)$ & $42(2)$ & $171(5)$ & $-5(2)$ & $11(2)$ & $26(2)$ \\
\hline $\mathrm{C}(23)$ & $50(2)$ & $54(2)$ & $187(5)$ & $-5(3)$ & $4(3)$ & $27(2)$ \\
\hline $\mathrm{C}(24)$ & $68(3)$ & $81(3)$ & $194(6)$ & $6(3)$ & $3(3)$ & $50(3)$ \\
\hline$C(25)$ & $84(3)$ & $69(3)$ & $209(7)$ & $16(4)$ & $10(4)$ & $47(3)$ \\
\hline$C(26)$ & $84(3)$ & $50(2)$ & $195(6)$ & $6(3)$ & $27(4)$ & $34(2)$ \\
\hline$C(27)$ & $52(2)$ & $45(2)$ & $190(5)$ & $-13(3)$ & $7(3)$ & $20(2)$ \\
\hline $\mathrm{C}(28)$ & $45(2)$ & $42(2)$ & $224(8)$ & $-17(3)$ & $-1(3)$ & $7(2)$ \\
\hline$C(29)$ & $58(3)$ & $83(3)$ & $167(6)$ & $-32(4)$ & $-8(3)$ & $12(2)$ \\
\hline $\mathrm{C}(30)$ & $44(2)$ & $59(2)$ & $198(6)$ & $-4(3)$ & $11(3)$ & $16(2)$ \\
\hline $\mathrm{C}(31)$ & $72(3)$ & $44(2)$ & $314(12)$ & $-16(4)$ & $12(5)$ & $10(2)$ \\
\hline$C(32)$ & $69(3)$ & $57(2)$ & $142(4)$ & $-9(2)$ & $9(3)$ & $36(2)$ \\
\hline $\mathrm{Cl}(1)$ & $84(1)$ & $57(1)$ & $198(2)$ & $9(1)$ & $6(1)$ & $25(1)$ \\
\hline $\mathrm{Cl}(2)$ & $106(1)$ & $96(1)$ & $145(1)$ & $16(1)$ & $17(1)$ & $51(1)$ \\
\hline
\end{tabular}




\begin{tabular}{lcccccc}
$\mathrm{Cl}(3)$ & $108(1)$ & $168(2)$ & $147(1)$ & $-31(1)$ & $-28(1)$ & $86(1)$ \\
$\mathrm{N}(1)$ & $37(2)$ & $38(1)$ & $165(3)$ & $-18(2)$ & $-10(2)$ & $17(1)$ \\
$\mathrm{N}(2)$ & $41(2)$ & $42(2)$ & $175(4)$ & $-18(2)$ & $-6(2)$ & $22(1)$ \\
$\mathrm{O}(1)$ & $40(1)$ & $47(1)$ & $175(3)$ & $-9(2)$ & $-13(2)$ & $18(1)$ \\
$\mathrm{O}(2)$ & $54(1)$ & $42(1)$ & $167(3)$ & $-14(2)$ & $1(2)$ & $25(1)$ \\
\hline
\end{tabular}


Table 5. Hydrogen coordinates ( $\left.\times 10^{4}\right)$ and isotropic displacement parameters $\left(\AA^{2} \times 10^{3}\right)$ for k11200.

\begin{tabular}{|c|c|c|c|c|}
\hline & $\mathrm{x}$ & $\mathrm{y}$ & $\mathrm{z}$ & $\mathrm{U}(\mathrm{eq})$ \\
\hline $\mathrm{H}(3 \mathrm{~A})$ & 4586 & 8849 & 1387 & 102 \\
\hline $\mathrm{H}(3 \mathrm{~B})$ & 4215 & 7848 & 2062 & 102 \\
\hline $\mathrm{H}(5)$ & 6120 & 8595 & 2769 & 108 \\
\hline $\mathrm{H}(6)$ & 8101 & 8950 & 2790 & 119 \\
\hline $\mathrm{H}(7)$ & 9022 & 8993 & 1608 & 118 \\
\hline $\mathrm{H}(8)$ & 8034 & 8653 & 417 & 106 \\
\hline $\mathrm{H}(11)$ & 6133 & 6691 & -574 & 105 \\
\hline $\mathrm{H}(12)$ & 7112 & 6812 & -1756 & 117 \\
\hline $\mathrm{H}(13)$ & 7945 & 8589 & -2476 & 125 \\
\hline $\mathrm{H}(14)$ & 7791 & 10214 & -2020 & 127 \\
\hline $\mathrm{H}(17 \mathrm{~A})$ & 6254 & 10355 & 453 & 122 \\
\hline $\mathrm{H}(17 \mathrm{~B})$ & 5187 & 9707 & -175 & 122 \\
\hline $\mathrm{H}(17 \mathrm{C})$ & 5829 & 11130 & -50 & 122 \\
\hline $\mathrm{H}(18 \mathrm{~A})$ & 8112 & 12359 & -562 & 213 \\
\hline $\mathrm{H}(18 \mathrm{~B})$ & 8578 & 11633 & -1081 & 213 \\
\hline $\mathrm{H}(18 \mathrm{C})$ & 8456 & 11455 & -143 & 213 \\
\hline $\mathrm{H}(19 \mathrm{~A})$ & 6377 & 11758 & -1209 & 238 \\
\hline $\mathrm{H}(19 \mathrm{~B})$ & 5568 & 10395 & -1495 & 238 \\
\hline $\mathrm{H}(19 \mathrm{C})$ & 6897 & 11205 & -1839 & 238 \\
\hline $\mathrm{H}(17 \mathrm{D})$ & 7621 & 12363 & -1162 & 189 \\
\hline $\mathrm{H}(17 \mathrm{E})$ & 7156 & 11366 & -1842 & 189 \\
\hline $\mathrm{H}(17 \mathrm{~F})$ & 8387 & 11736 & -1390 & 189 \\
\hline $\mathrm{H}(18 \mathrm{D})$ & 8647 & 11386 & -285 & 137 \\
\hline $\mathrm{H}(18 \mathrm{E})$ & 7671 & 10828 & 407 & 137 \\
\hline $\mathrm{H}(18 \mathrm{~F})$ & 7988 & 12089 & 19 & 137 \\
\hline H(19D) & 5606 & 11100 & -713 & 181 \\
\hline $\mathrm{H}(19 \mathrm{E})$ & 5418 & 10150 & -38 & 181 \\
\hline $\mathrm{H}(19 \mathrm{~F})$ & 5102 & 9720 & -937 & 181 \\
\hline $\mathrm{H}(20 \mathrm{~A})$ & 2588 & 7515 & 620 & 133 \\
\hline $\mathrm{H}(20 \mathrm{~B})$ & 2234 & 6644 & 1370 & 133 \\
\hline
\end{tabular}




\begin{tabular}{lrrrr}
$\mathrm{H}(20 \mathrm{C})$ & 2173 & 6125 & 501 & 133 \\
$\mathrm{H}(23)$ & 5424 & 5630 & 2389 & 116 \\
$\mathrm{H}(24)$ & 5777 & 4189 & 2984 & 131 \\
$\mathrm{H}(25)$ & 4166 & 2218 & 3088 & 140 \\
$\mathrm{H}(26)$ & 2287 & 1702 & 2650 & 132 \\
$\mathrm{H}(29 \mathrm{~A})$ & 2024 & 4020 & 939 & 169 \\
$\mathrm{H}(29 B)$ & 629 & 3029 & 885 & 169 \\
$\mathrm{H}(29 \mathrm{C})$ & 1627 & 2647 & 763 & 169 \\
$\mathrm{H}(30 \mathrm{~A})$ & 1325 & 4476 & 2279 & 157 \\
$\mathrm{H}(30 B)$ & 1005 & 3526 & 2979 & 157 \\
$\mathrm{H}(30 \mathrm{C})$ & 39 & 3277 & 2302 & 157 \\
$\mathrm{H}(31 \mathrm{~A})$ & -293 & 1411 & 1958 & 228 \\
$\mathrm{H}(31 \mathrm{~B})$ & 566 & 1452 & 2656 & 228 \\
$\mathrm{H}(31 \mathrm{C})$ & 751 & 1110 & 1778 & 228 \\
$\mathrm{H}(32)$ & 4568 & 4005 & 423 & 105 \\
$\mathrm{H}(2)$ & 3185 & 5803 & 2119 & 103 \\
\hline
\end{tabular}




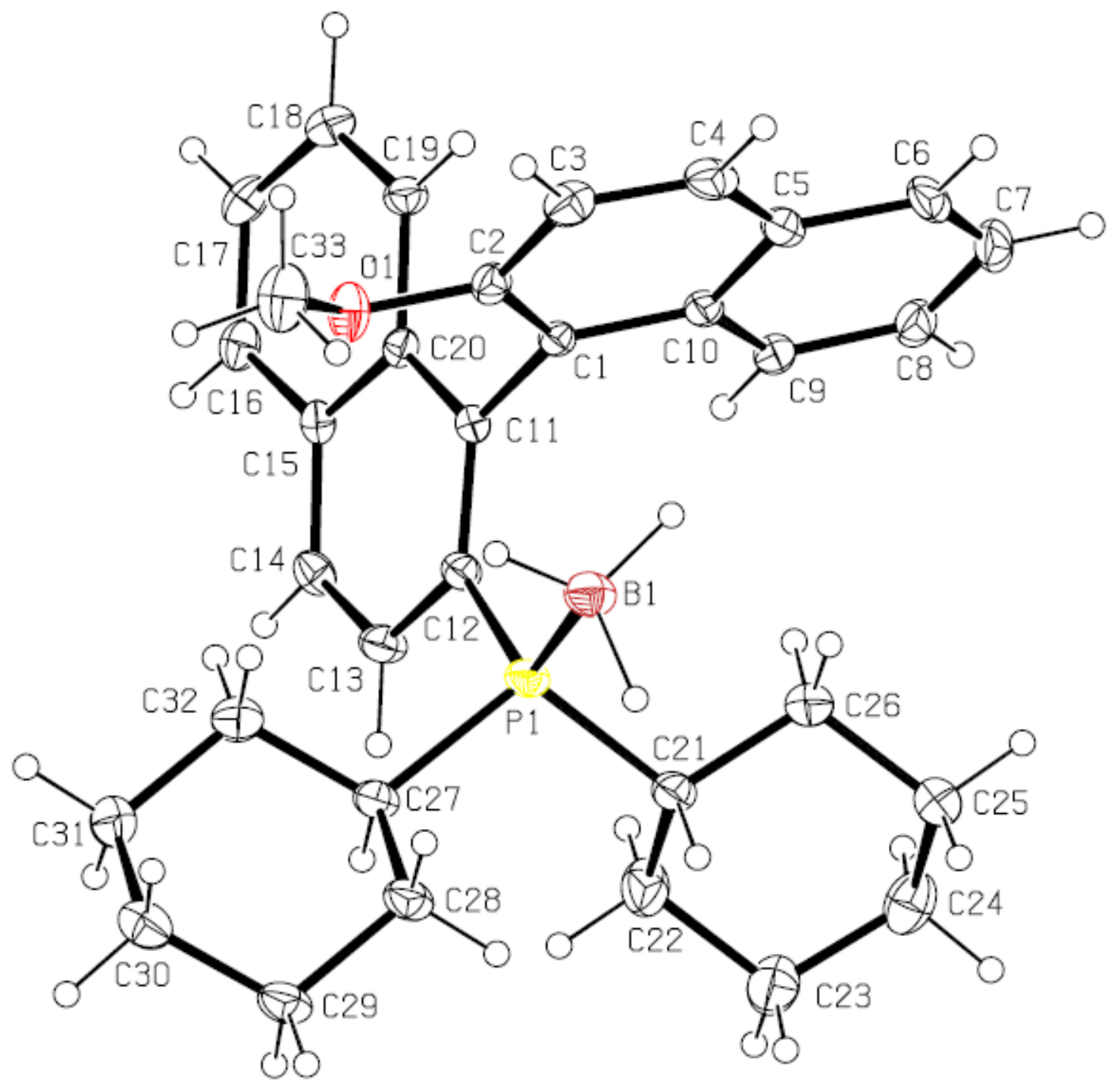


Table 1.Crystal data and structure refinement for k11125a.

Identification code

Empirical formula

Formula weight

Temperature

Wavelength

Crystal system

Space group

Unit cell dimensions

Volume

Z

Density (calculated)

Absorption coefficient

$\mathrm{F}(000)$

Crystal size

Theta range for data collection

Index ranges

Reflections collected

Independent reflections

Completeness to theta $=27.48^{\circ}$

Absorption correction

Max. and min. transmission

Refinement method

Data / restraints / parameters

Goodness-of-fit on $\mathrm{F}^{2}$

Final $\mathrm{R}$ indices $[\mathrm{I}>2 \operatorname{sigma}(\mathrm{I})]$

$\mathrm{R}$ indices (all data)

Absolute structure parameter

Largest diff. peak and hole k11125a

C33 H40 B O P

494.43

150(1) K

$0.71073 \AA$

Orthorhombic

P 212121

$\mathrm{a}=8.0421(4) \AA$

$\alpha=90^{\circ}$.

$\mathrm{b}=17.1348(2) \AA$

$\beta=90^{\circ}$.

$\mathrm{c}=19.9983(6) \AA$

$\gamma=90^{\circ}$.
2755.76(16) $\AA^{3}$

4

$1.192 \mathrm{Mg} / \mathrm{m}^{3}$

$0.124 \mathrm{~mm}^{-1}$

1064

$0.30 \times 0.28 \times 0.06 \mathrm{~mm}^{3}$

2.59 to $27.48^{\circ}$.

$-10<=\mathrm{h}<=9,-22<=\mathrm{k}<=19,-25<=\mathrm{l}<=24$

24491

$6306[\mathrm{R}(\mathrm{int})=0.0764]$

$99.7 \%$

Semi-empirical from equivalents

1.005 and 0.742

Full-matrix least-squares on $\mathrm{F}^{2}$

$6306 / 0$ / 338

1.029

$\mathrm{R} 1=0.0502, \mathrm{wR} 2=0.1076$

$\mathrm{R} 1=0.0898, \mathrm{wR} 2=0.1245$

$-0.14(10)$

0.233 and -0.450 e. $\AA^{-3}$ 
Table 2. Atomic coordinates $\left(\mathrm{x} 10^{4}\right)$ and equivalent isotropic displacement parameters $\left(\AA^{2} \times 10^{3}\right)$ for k11125a. $U(e q)$ is defined as one third of the trace of the orthogonalized $U^{i j}$ tensor.

\begin{tabular}{|c|c|c|c|c|}
\hline & $\mathrm{x}$ & $\mathrm{y}$ & $\mathrm{z}$ & $\mathrm{U}(\mathrm{eq})$ \\
\hline $\mathrm{P}(1)$ & $8027(1)$ & $10158(1)$ & 8301(1) & $28(1)$ \\
\hline $\mathrm{O}(1)$ & $9747(2)$ & 9304(1) & 9969(1) & $37(1)$ \\
\hline$C(1)$ & $7419(3)$ & $10095(1)$ & 9907(1) & $21(1)$ \\
\hline$C(2)$ & $9014(3)$ & 9993(1) & 10143(1) & $26(1)$ \\
\hline$C(3)$ & $9773(3)$ & 10571(1) & $10538(1)$ & $35(1)$ \\
\hline$C(4)$ & 8919(4) & $11234(2)$ & $10695(1)$ & $37(1)$ \\
\hline$C(5)$ & $7267(3)$ & $11356(1)$ & 10494(1) & $31(1)$ \\
\hline$C(6)$ & $6338(4)$ & $12030(1)$ & $10666(1)$ & $40(1)$ \\
\hline$C(7)$ & $4718(4)$ & $12116(2)$ & $10470(1)$ & $44(1)$ \\
\hline $\mathrm{C}(8)$ & $3951(3)$ & $11535(1)$ & $10086(1)$ & $37(1)$ \\
\hline$C(9)$ & $4814(3)$ & 10881(1) & $9900(1)$ & $29(1)$ \\
\hline$C(10)$ & $6492(3)$ & $10770(1)$ & 10091(1) & $25(1)$ \\
\hline$C(11)$ & $6642(3)$ & $9478(1)$ & $9485(1)$ & $22(1)$ \\
\hline$C(12)$ & $6729(3)$ & $9480(1)$ & $8790(1)$ & $26(1)$ \\
\hline$C(13)$ & $5877(3)$ & 8881(1) & $8428(1)$ & $31(1)$ \\
\hline$C(14)$ & $5048(3)$ & $8293(1)$ & $8745(1)$ & $29(1)$ \\
\hline$C(15)$ & $5009(3)$ & $8250(1)$ & $9454(1)$ & $25(1)$ \\
\hline$C(16)$ & $4259(3)$ & $7618(1)$ & $9795(1)$ & $31(1)$ \\
\hline$C(17)$ & $4236(3)$ & $7597(1)$ & $10478(1)$ & $36(1)$ \\
\hline$C(18)$ & 4951(3) & $8205(1)$ & $10850(1)$ & $33(1)$ \\
\hline$C(19)$ & $5707(3)$ & 8821(1) & $10540(1)$ & $27(1)$ \\
\hline$C(20)$ & $5778(3)$ & $8860(1)$ & $9826(1)$ & $22(1)$ \\
\hline$C(21)$ & $6645(3)$ & $10798(1)$ & 7812(1) & $31(1)$ \\
\hline$C(22)$ & $5358(4)$ & $10415(2)$ & $7357(2)$ & $46(1)$ \\
\hline$C(23)$ & 4463(4) & $11035(2)$ & 6934(2) & $51(1)$ \\
\hline $\mathrm{C}(24)$ & $3644(4)$ & $11652(2)$ & $7362(2)$ & $48(1)$ \\
\hline $\mathrm{C}(25)$ & 4879(4) & $12017(2)$ & 7839(1) & $45(1)$ \\
\hline$C(26)$ & $5788(4)$ & $11399(2)$ & $8259(1)$ & $45(1)$ \\
\hline $\mathrm{C}(27)$ & $9031(3)$ & $9503(1)$ & $7688(1)$ & $29(1)$ \\
\hline $\mathrm{C}(28)$ & 10207(3) & $9956(1)$ & $7223(1)$ & $35(1)$ \\
\hline C(29) & $10976(3)$ & 9413(1) & 6701(1) & $37(1)$ \\
\hline
\end{tabular}




$\begin{array}{lrrrr}\mathrm{C}(30) & 11900(3) & 8740(2) & 7029(1) & 41(1) \\ \mathrm{C}(31) & 10758(4) & 8293(2) & 7506(1) & 42(1) \\ \mathrm{C}(32) & 9973(4) & 8836(2) & 8024(1) & 39(1) \\ \mathrm{C}(33) & 11503(3) & 9250(2) & 10013(2) & 49(1) \\ \mathrm{B}(1) & 9696(4) & 10818(2) & 8709(2) & 37(1)\end{array}$


Table 3. Bond lengths $[\AA]$ and angles $\left[{ }^{\circ}\right]$ for k11125a.

\begin{tabular}{|c|c|}
\hline $\mathrm{P}(1)-\mathrm{C}(12)$ & $1.842(2)$ \\
\hline $\mathrm{P}(1)-\mathrm{C}(21)$ & $1.843(3)$ \\
\hline $\mathrm{P}(1)-\mathrm{C}(27)$ & $1.848(2)$ \\
\hline $\mathrm{P}(1)-\mathrm{B}(1)$ & $1.935(3)$ \\
\hline $\mathrm{O}(1)-\mathrm{C}(2)$ & $1.364(3)$ \\
\hline $\mathrm{O}(1)-\mathrm{C}(33)$ & $1.419(3)$ \\
\hline $\mathrm{C}(1)-\mathrm{C}(2)$ & $1.377(3)$ \\
\hline $\mathrm{C}(1)-\mathrm{C}(10)$ & $1.424(3)$ \\
\hline $\mathrm{C}(1)-\mathrm{C}(11)$ & 1.491(3) \\
\hline $\mathrm{C}(2)-\mathrm{C}(3)$ & $1.407(3)$ \\
\hline $\mathrm{C}(3)-\mathrm{C}(4)$ & $1.363(4)$ \\
\hline $\mathrm{C}(3)-\mathrm{H}(3 \mathrm{~A})$ & 0.9500 \\
\hline$C(4)-C(5)$ & $1.404(4)$ \\
\hline $\mathrm{C}(4)-\mathrm{H}(4 \mathrm{~A})$ & 0.9500 \\
\hline$C(5)-C(6)$ & $1.417(3)$ \\
\hline$C(5)-C(10)$ & $1.430(3)$ \\
\hline $\mathrm{C}(6)-\mathrm{C}(7)$ & $1.368(4)$ \\
\hline $\mathrm{C}(6)-\mathrm{H}(6 \mathrm{~A})$ & 0.9500 \\
\hline $\mathrm{C}(7)-\mathrm{C}(8)$ & $1.400(4)$ \\
\hline $\mathrm{C}(7)-\mathrm{H}(7 \mathrm{~A})$ & 0.9500 \\
\hline $\mathrm{C}(8)-\mathrm{C}(9)$ & $1.370(3)$ \\
\hline $\mathrm{C}(8)-\mathrm{H}(8 \mathrm{~A})$ & 0.9500 \\
\hline $\mathrm{C}(9)-\mathrm{C}(10)$ & $1.416(3)$ \\
\hline $\mathrm{C}(9)-\mathrm{H}(9 \mathrm{~A})$ & 0.9500 \\
\hline $\mathrm{C}(11)-\mathrm{C}(12)$ & $1.392(3)$ \\
\hline$C(11)-C(20)$ & $1.439(3)$ \\
\hline$C(12)-C(13)$ & $1.431(3)$ \\
\hline$C(13)-C(14)$ & $1.364(3)$ \\
\hline $\mathrm{C}(13)-\mathrm{H}(13 \mathrm{~A})$ & 0.9500 \\
\hline$C(14)-C(15)$ & $1.420(3)$ \\
\hline $\mathrm{C}(14)-\mathrm{H}(14 \mathrm{~A})$ & 0.9500 \\
\hline$C(15)-C(16)$ & $1.415(3)$ \\
\hline$C(15)-C(20)$ & $1.424(3)$ \\
\hline$C(16)-C(17)$ & $1.367(3)$ \\
\hline
\end{tabular}




\begin{tabular}{|c|c|}
\hline $\mathrm{C}(16)-\mathrm{H}(16 \mathrm{~A})$ & 0.9500 \\
\hline $\mathrm{C}(17)-\mathrm{C}(18)$ & $1.405(3)$ \\
\hline $\mathrm{C}(17)-\mathrm{H}(17 \mathrm{~A})$ & 0.9500 \\
\hline$C(18)-C(19)$ & $1.367(3)$ \\
\hline $\mathrm{C}(18)-\mathrm{H}(18 \mathrm{~A})$ & 0.9500 \\
\hline$C(19)-C(20)$ & $1.430(3)$ \\
\hline C(19)-H(19A) & 0.9500 \\
\hline$C(21)-C(22)$ & $1.526(4)$ \\
\hline$C(21)-C(26)$ & $1.528(3)$ \\
\hline $\mathrm{C}(21)-\mathrm{H}(21 \mathrm{~A})$ & 1.0000 \\
\hline$C(22)-C(23)$ & $1.536(4)$ \\
\hline $\mathrm{C}(22)-\mathrm{H}(22 \mathrm{~A})$ & 0.9900 \\
\hline $\mathrm{C}(22)-\mathrm{H}(22 \mathrm{~B})$ & 0.9900 \\
\hline$C(23)-C(24)$ & $1.510(4)$ \\
\hline $\mathrm{C}(23)-\mathrm{H}(23 \mathrm{~A})$ & 0.9900 \\
\hline $\mathrm{C}(23)-\mathrm{H}(23 \mathrm{~B})$ & 0.9900 \\
\hline$C(24)-C(25)$ & $1.514(4)$ \\
\hline $\mathrm{C}(24)-\mathrm{H}(24 \mathrm{~A})$ & 0.9900 \\
\hline $\mathrm{C}(24)-\mathrm{H}(24 \mathrm{~B})$ & 0.9900 \\
\hline$C(25)-C(26)$ & $1.536(4)$ \\
\hline $\mathrm{C}(25)-\mathrm{H}(25 \mathrm{~A})$ & 0.9900 \\
\hline $\mathrm{C}(25)-\mathrm{H}(25 \mathrm{~B})$ & 0.9900 \\
\hline $\mathrm{C}(26)-\mathrm{H}(26 \mathrm{~A})$ & 0.9900 \\
\hline $\mathrm{C}(26)-\mathrm{H}(26 \mathrm{~B})$ & 0.9900 \\
\hline$C(27)-C(32)$ & $1.527(3)$ \\
\hline$C(27)-C(28)$ & $1.537(3)$ \\
\hline $\mathrm{C}(27)-\mathrm{H}(27 \mathrm{~A})$ & 1.0000 \\
\hline $\mathrm{C}(28)-\mathrm{C}(29)$ & $1.529(3)$ \\
\hline $\mathrm{C}(28)-\mathrm{H}(28 \mathrm{~A})$ & 0.9900 \\
\hline $\mathrm{C}(28)-\mathrm{H}(28 \mathrm{~B})$ & 0.9900 \\
\hline$C(29)-C(30)$ & $1.520(4)$ \\
\hline C(29)-H(29A) & 0.9900 \\
\hline C(29)-H(29B) & 0.9900 \\
\hline $\mathrm{C}(30)-\mathrm{C}(31)$ & $1.530(4)$ \\
\hline $\mathrm{C}(30)-\mathrm{H}(30 \mathrm{~A})$ & 0.9900 \\
\hline C(30)-H(30B) & 0.9900 \\
\hline
\end{tabular}




\begin{tabular}{|c|c|}
\hline $\mathrm{C}(31)-\mathrm{C}(32)$ & $1.529(3)$ \\
\hline $\mathrm{C}(31)-\mathrm{H}(31 \mathrm{~A})$ & 0.9900 \\
\hline $\mathrm{C}(31)-\mathrm{H}(31 \mathrm{~B})$ & 0.9900 \\
\hline $\mathrm{C}(32)-\mathrm{H}(32 \mathrm{~A})$ & 0.9900 \\
\hline $\mathrm{C}(32)-\mathrm{H}(32 \mathrm{~B})$ & 0.9900 \\
\hline $\mathrm{C}(33)-\mathrm{H}(33 \mathrm{~A})$ & 0.9800 \\
\hline $\mathrm{C}(33)-\mathrm{H}(33 \mathrm{~B})$ & 0.9800 \\
\hline $\mathrm{C}(33)-\mathrm{H}(33 \mathrm{C})$ & 0.9800 \\
\hline $\mathrm{B}(1)-\mathrm{H}(1)$ & $1.09(3)$ \\
\hline $\mathrm{B}(1)-\mathrm{H}(2)$ & $1.09(3)$ \\
\hline $\mathrm{B}(1)-\mathrm{H}(3)$ & $1.16(3)$ \\
\hline $\mathrm{C}(12)-\mathrm{P}(1)-\mathrm{C}(21)$ & $108.34(11)$ \\
\hline $\mathrm{C}(12)-\mathrm{P}(1)-\mathrm{C}(27)$ & $102.53(10)$ \\
\hline $\mathrm{C}(21)-\mathrm{P}(1)-\mathrm{C}(27)$ & $105.77(11)$ \\
\hline $\mathrm{C}(12)-\mathrm{P}(1)-\mathrm{B}(1)$ & $122.60(12)$ \\
\hline $\mathrm{C}(21)-\mathrm{P}(1)-\mathrm{B}(1)$ & 107.11(13) \\
\hline $\mathrm{C}(27)-\mathrm{P}(1)-\mathrm{B}(1)$ & $109.35(14)$ \\
\hline $\mathrm{C}(2)-\mathrm{O}(1)-\mathrm{C}(33)$ & $118.1(2)$ \\
\hline $\mathrm{C}(2)-\mathrm{C}(1)-\mathrm{C}(10)$ & $120.1(2)$ \\
\hline $\mathrm{C}(2)-\mathrm{C}(1)-\mathrm{C}(11)$ & $119.6(2)$ \\
\hline$C(10)-C(1)-C(11)$ & $120.20(19)$ \\
\hline $\mathrm{O}(1)-\mathrm{C}(2)-\mathrm{C}(1)$ & $115.1(2)$ \\
\hline $\mathrm{O}(1)-\mathrm{C}(2)-\mathrm{C}(3)$ & $124.4(2)$ \\
\hline$C(1)-C(2)-C(3)$ & $120.4(2)$ \\
\hline$C(4)-C(3)-C(2)$ & $119.8(2)$ \\
\hline $\mathrm{C}(4)-\mathrm{C}(3)-\mathrm{H}(3 \mathrm{~A})$ & 120.1 \\
\hline $\mathrm{C}(2)-\mathrm{C}(3)-\mathrm{H}(3 \mathrm{~A})$ & 120.1 \\
\hline$C(3)-C(4)-C(5)$ & $122.3(2)$ \\
\hline $\mathrm{C}(3)-\mathrm{C}(4)-\mathrm{H}(4 \mathrm{~A})$ & 118.8 \\
\hline $\mathrm{C}(5)-\mathrm{C}(4)-\mathrm{H}(4 \mathrm{~A})$ & 118.8 \\
\hline$C(4)-C(5)-C(6)$ & $123.4(2)$ \\
\hline$C(4)-C(5)-C(10)$ & $117.9(2)$ \\
\hline$C(6)-C(5)-C(10)$ & $118.6(2)$ \\
\hline$C(7)-C(6)-C(5)$ & $121.3(3)$ \\
\hline $\mathrm{C}(7)-\mathrm{C}(6)-\mathrm{H}(6 \mathrm{~A})$ & 119.3 \\
\hline
\end{tabular}




\begin{tabular}{|c|c|}
\hline $\mathrm{C}(5)-\mathrm{C}(6)-\mathrm{H}(6 \mathrm{~A})$ & 119.3 \\
\hline$C(6)-C(7)-C(8)$ & $120.0(2)$ \\
\hline $\mathrm{C}(6)-\mathrm{C}(7)-\mathrm{H}(7 \mathrm{~A})$ & 120.0 \\
\hline $\mathrm{C}(8)-\mathrm{C}(7)-\mathrm{H}(7 \mathrm{~A})$ & 120.0 \\
\hline $\mathrm{C}(9)-\mathrm{C}(8)-\mathrm{C}(7)$ & $120.5(3)$ \\
\hline $\mathrm{C}(9)-\mathrm{C}(8)-\mathrm{H}(8 \mathrm{~A})$ & 119.8 \\
\hline $\mathrm{C}(7)-\mathrm{C}(8)-\mathrm{H}(8 \mathrm{~A})$ & 119.8 \\
\hline$C(8)-C(9)-C(10)$ & $121.3(2)$ \\
\hline $\mathrm{C}(8)-\mathrm{C}(9)-\mathrm{H}(9 \mathrm{~A})$ & 119.4 \\
\hline $\mathrm{C}(10)-\mathrm{C}(9)-\mathrm{H}(9 \mathrm{~A})$ & 119.4 \\
\hline$C(9)-C(10)-C(1)$ & $122.6(2)$ \\
\hline$C(9)-C(10)-C(5)$ & $118.2(2)$ \\
\hline$C(1)-C(10)-C(5)$ & $119.2(2)$ \\
\hline $\mathrm{C}(12)-\mathrm{C}(11)-\mathrm{C}(20)$ & $120.0(2)$ \\
\hline $\mathrm{C}(12)-\mathrm{C}(11)-\mathrm{C}(1)$ & $122.84(19)$ \\
\hline $\mathrm{C}(20)-\mathrm{C}(11)-\mathrm{C}(1)$ & $117.13(18)$ \\
\hline $\mathrm{C}(11)-\mathrm{C}(12)-\mathrm{C}(13)$ & $118.6(2)$ \\
\hline $\mathrm{C}(11)-\mathrm{C}(12)-\mathrm{P}(1)$ & $124.04(17)$ \\
\hline $\mathrm{C}(13)-\mathrm{C}(12)-\mathrm{P}(1)$ & $117.15(16)$ \\
\hline$C(14)-C(13)-C(12)$ & $121.9(2)$ \\
\hline $\mathrm{C}(14)-\mathrm{C}(13)-\mathrm{H}(13 \mathrm{~A})$ & 119.0 \\
\hline $\mathrm{C}(12)-\mathrm{C}(13)-\mathrm{H}(13 \mathrm{~A})$ & 119.0 \\
\hline$C(13)-C(14)-C(15)$ & $120.9(2)$ \\
\hline $\mathrm{C}(13)-\mathrm{C}(14)-\mathrm{H}(14 \mathrm{~A})$ & 119.6 \\
\hline $\mathrm{C}(15)-\mathrm{C}(14)-\mathrm{H}(14 \mathrm{~A})$ & 119.6 \\
\hline$C(16)-C(15)-C(14)$ & $122.0(2)$ \\
\hline$C(16)-C(15)-C(20)$ & $119.7(2)$ \\
\hline $\mathrm{C}(14)-\mathrm{C}(15)-\mathrm{C}(20)$ & $118.31(19)$ \\
\hline$C(17)-C(16)-C(15)$ & $120.5(2)$ \\
\hline$C(17)-C(16)-H(16 A)$ & 119.8 \\
\hline $\mathrm{C}(15)-\mathrm{C}(16)-\mathrm{H}(16 \mathrm{~A})$ & 119.8 \\
\hline$C(16)-C(17)-C(18)$ & $120.4(2)$ \\
\hline $\mathrm{C}(16)-\mathrm{C}(17)-\mathrm{H}(17 \mathrm{~A})$ & 119.8 \\
\hline $\mathrm{C}(18)-\mathrm{C}(17)-\mathrm{H}(17 \mathrm{~A})$ & 119.8 \\
\hline $\mathrm{C}(19)-\mathrm{C}(18)-\mathrm{C}(17)$ & $120.9(2)$ \\
\hline $\mathrm{C}(19)-\mathrm{C}(18)-\mathrm{H}(18 \mathrm{~A})$ & 119.5 \\
\hline
\end{tabular}




\begin{tabular}{|c|c|}
\hline $\mathrm{C}(17)-\mathrm{C}(18)-\mathrm{H}(18 \mathrm{~A})$ & 119.5 \\
\hline$C(18)-C(19)-C(20)$ & $120.5(2)$ \\
\hline $\mathrm{C}(18)-\mathrm{C}(19)-\mathrm{H}(19 \mathrm{~A})$ & 119.8 \\
\hline $\mathrm{C}(20)-\mathrm{C}(19)-\mathrm{H}(19 \mathrm{~A})$ & 119.8 \\
\hline$C(15)-C(20)-C(19)$ & $118.0(2)$ \\
\hline$C(15)-C(20)-C(11)$ & $120.11(19)$ \\
\hline $\mathrm{C}(19)-\mathrm{C}(20)-\mathrm{C}(11)$ & $121.8(2)$ \\
\hline$C(22)-C(21)-C(26)$ & $109.4(2)$ \\
\hline $\mathrm{C}(22)-\mathrm{C}(21)-\mathrm{P}(1)$ & $118.07(17)$ \\
\hline $\mathrm{C}(26)-\mathrm{C}(21)-\mathrm{P}(1)$ & $111.23(17)$ \\
\hline $\mathrm{C}(22)-\mathrm{C}(21)-\mathrm{H}(21 \mathrm{~A})$ & 105.7 \\
\hline $\mathrm{C}(26)-\mathrm{C}(21)-\mathrm{H}(21 \mathrm{~A})$ & 105.7 \\
\hline $\mathrm{P}(1)-\mathrm{C}(21)-\mathrm{H}(21 \mathrm{~A})$ & 105.7 \\
\hline $\mathrm{C}(21)-\mathrm{C}(22)-\mathrm{C}(23)$ & $110.4(2)$ \\
\hline $\mathrm{C}(21)-\mathrm{C}(22)-\mathrm{H}(22 \mathrm{~A})$ & 109.6 \\
\hline $\mathrm{C}(23)-\mathrm{C}(22)-\mathrm{H}(22 \mathrm{~A})$ & 109.6 \\
\hline $\mathrm{C}(21)-\mathrm{C}(22)-\mathrm{H}(22 \mathrm{~B})$ & 109.6 \\
\hline $\mathrm{C}(23)-\mathrm{C}(22)-\mathrm{H}(22 \mathrm{~B})$ & 109.6 \\
\hline $\mathrm{H}(22 \mathrm{~A})-\mathrm{C}(22)-\mathrm{H}(22 \mathrm{~B})$ & 108.1 \\
\hline $\mathrm{C}(24)-\mathrm{C}(23)-\mathrm{C}(22)$ & $112.1(2)$ \\
\hline $\mathrm{C}(24)-\mathrm{C}(23)-\mathrm{H}(23 \mathrm{~A})$ & 109.2 \\
\hline $\mathrm{C}(22)-\mathrm{C}(23)-\mathrm{H}(23 \mathrm{~A})$ & 109.2 \\
\hline $\mathrm{C}(24)-\mathrm{C}(23)-\mathrm{H}(23 \mathrm{~B})$ & 109.2 \\
\hline $\mathrm{C}(22)-\mathrm{C}(23)-\mathrm{H}(23 \mathrm{~B})$ & 109.2 \\
\hline $\mathrm{H}(23 \mathrm{~A})-\mathrm{C}(23)-\mathrm{H}(23 \mathrm{~B})$ & 107.9 \\
\hline$C(23)-C(24)-C(25)$ & $111.1(2)$ \\
\hline $\mathrm{C}(23)-\mathrm{C}(24)-\mathrm{H}(24 \mathrm{~A})$ & 109.4 \\
\hline $\mathrm{C}(25)-\mathrm{C}(24)-\mathrm{H}(24 \mathrm{~A})$ & 109.4 \\
\hline $\mathrm{C}(23)-\mathrm{C}(24)-\mathrm{H}(24 \mathrm{~B})$ & 109.4 \\
\hline $\mathrm{C}(25)-\mathrm{C}(24)-\mathrm{H}(24 \mathrm{~B})$ & 109.4 \\
\hline $\mathrm{H}(24 \mathrm{~A})-\mathrm{C}(24)-\mathrm{H}(24 \mathrm{~B})$ & 108.0 \\
\hline$C(24)-C(25)-C(26)$ & $111.9(2)$ \\
\hline $\mathrm{C}(24)-\mathrm{C}(25)-\mathrm{H}(25 \mathrm{~A})$ & 109.2 \\
\hline $\mathrm{C}(26)-\mathrm{C}(25)-\mathrm{H}(25 \mathrm{~A})$ & 109.2 \\
\hline $\mathrm{C}(24)-\mathrm{C}(25)-\mathrm{H}(25 \mathrm{~B})$ & 109.2 \\
\hline $\mathrm{C}(26)-\mathrm{C}(25)-\mathrm{H}(25 \mathrm{~B})$ & 109.2 \\
\hline
\end{tabular}




\begin{tabular}{|c|c|}
\hline $\mathrm{H}(25 \mathrm{~A})-\mathrm{C}(25)-\mathrm{H}(25 \mathrm{~B})$ & 107.9 \\
\hline $\mathrm{C}(21)-\mathrm{C}(26)-\mathrm{C}(25)$ & $111.1(2)$ \\
\hline $\mathrm{C}(21)-\mathrm{C}(26)-\mathrm{H}(26 \mathrm{~A})$ & 109.4 \\
\hline $\mathrm{C}(25)-\mathrm{C}(26)-\mathrm{H}(26 \mathrm{~A})$ & 109.4 \\
\hline $\mathrm{C}(21)-\mathrm{C}(26)-\mathrm{H}(26 \mathrm{~B})$ & 109.4 \\
\hline $\mathrm{C}(25)-\mathrm{C}(26)-\mathrm{H}(26 \mathrm{~B})$ & 109.4 \\
\hline $\mathrm{H}(26 \mathrm{~A})-\mathrm{C}(26)-\mathrm{H}(26 \mathrm{~B})$ & 108.0 \\
\hline $\mathrm{C}(32)-\mathrm{C}(27)-\mathrm{C}(28)$ & $109.8(2)$ \\
\hline $\mathrm{C}(32)-\mathrm{C}(27)-\mathrm{P}(1)$ & $112.22(16)$ \\
\hline $\mathrm{C}(28)-\mathrm{C}(27)-\mathrm{P}(1)$ & $111.36(16)$ \\
\hline $\mathrm{C}(32)-\mathrm{C}(27)-\mathrm{H}(27 \mathrm{~A})$ & 107.7 \\
\hline $\mathrm{C}(28)-\mathrm{C}(27)-\mathrm{H}(27 \mathrm{~A})$ & 107.7 \\
\hline $\mathrm{P}(1)-\mathrm{C}(27)-\mathrm{H}(27 \mathrm{~A})$ & 107.7 \\
\hline $\mathrm{C}(29)-\mathrm{C}(28)-\mathrm{C}(27)$ & $110.71(19)$ \\
\hline $\mathrm{C}(29)-\mathrm{C}(28)-\mathrm{H}(28 \mathrm{~A})$ & 109.5 \\
\hline $\mathrm{C}(27)-\mathrm{C}(28)-\mathrm{H}(28 \mathrm{~A})$ & 109.5 \\
\hline $\mathrm{C}(29)-\mathrm{C}(28)-\mathrm{H}(28 \mathrm{~B})$ & 109.5 \\
\hline $\mathrm{C}(27)-\mathrm{C}(28)-\mathrm{H}(28 \mathrm{~B})$ & 109.5 \\
\hline $\mathrm{H}(28 \mathrm{~A})-\mathrm{C}(28)-\mathrm{H}(28 \mathrm{~B})$ & 108.1 \\
\hline $\mathrm{C}(30)-\mathrm{C}(29)-\mathrm{C}(28)$ & $111.5(2)$ \\
\hline C(30)-C(29)-H(29A) & 109.3 \\
\hline $\mathrm{C}(28)-\mathrm{C}(29)-\mathrm{H}(29 \mathrm{~A})$ & 109.3 \\
\hline C(30)-C(29)-H(29B) & 109.3 \\
\hline C(28)-C(29)-H(29B) & 109.3 \\
\hline H(29A)-C(29)-H(29B) & 108.0 \\
\hline $\mathrm{C}(29)-\mathrm{C}(30)-\mathrm{C}(31)$ & $110.7(2)$ \\
\hline $\mathrm{C}(29)-\mathrm{C}(30)-\mathrm{H}(30 \mathrm{~A})$ & 109.5 \\
\hline $\mathrm{C}(31)-\mathrm{C}(30)-\mathrm{H}(30 \mathrm{~A})$ & 109.5 \\
\hline $\mathrm{C}(29)-\mathrm{C}(30)-\mathrm{H}(30 \mathrm{~B})$ & 109.5 \\
\hline $\mathrm{C}(31)-\mathrm{C}(30)-\mathrm{H}(30 \mathrm{~B})$ & 109.5 \\
\hline $\mathrm{H}(30 \mathrm{~A})-\mathrm{C}(30)-\mathrm{H}(30 \mathrm{~B})$ & 108.1 \\
\hline $\mathrm{C}(32)-\mathrm{C}(31)-\mathrm{C}(30)$ & $111.5(2)$ \\
\hline $\mathrm{C}(32)-\mathrm{C}(31)-\mathrm{H}(31 \mathrm{~A})$ & 109.3 \\
\hline $\mathrm{C}(30)-\mathrm{C}(31)-\mathrm{H}(31 \mathrm{~A})$ & 109.3 \\
\hline $\mathrm{C}(32)-\mathrm{C}(31)-\mathrm{H}(31 \mathrm{~B})$ & 109.3 \\
\hline $\mathrm{C}(30)-\mathrm{C}(31)-\mathrm{H}(31 \mathrm{~B})$ & 109.3 \\
\hline
\end{tabular}




$\begin{array}{ll}\mathrm{H}(31 \mathrm{~A})-\mathrm{C}(31)-\mathrm{H}(31 \mathrm{~B}) & 108.0 \\ \mathrm{C}(27)-\mathrm{C}(32)-\mathrm{C}(31) & 111.2(2) \\ \mathrm{C}(27)-\mathrm{C}(32)-\mathrm{H}(32 \mathrm{~A}) & 109.4 \\ \mathrm{C}(31)-\mathrm{C}(32)-\mathrm{H}(32 \mathrm{~A}) & 109.4 \\ \mathrm{C}(27)-\mathrm{C}(32)-\mathrm{H}(32 \mathrm{~B}) & 109.4 \\ \mathrm{C}(31)-\mathrm{C}(32)-\mathrm{H}(32 \mathrm{~B}) & 109.4 \\ \mathrm{H}(32 \mathrm{~A})-\mathrm{C}(32)-\mathrm{H}(32 \mathrm{~B}) & 108.0 \\ \mathrm{O}(1)-\mathrm{C}(33)-\mathrm{H}(33 \mathrm{~A}) & 109.5 \\ \mathrm{O}(1)-\mathrm{C}(33)-\mathrm{H}(33 \mathrm{~B}) & 109.5 \\ \mathrm{H}(33 \mathrm{~A})-\mathrm{C}(33)-\mathrm{H}(33 \mathrm{~B}) & 109.5 \\ \mathrm{O}(1)-\mathrm{C}(33)-\mathrm{H}(33 \mathrm{C}) & 109.5 \\ \mathrm{H}(33 \mathrm{~A})-\mathrm{C}(33)-\mathrm{H}(33 \mathrm{C}) & 109.5 \\ \mathrm{H}(33 \mathrm{~B})-\mathrm{C}(33)-\mathrm{H}(33 \mathrm{C}) & 109.5 \\ \mathrm{P}(1)-\mathrm{B}(1)-\mathrm{H}(1) & 107.7(16) \\ \mathrm{P}(1)-\mathrm{B}(1)-\mathrm{H}(2) & 108.3(13) \\ \mathrm{H}(1)-\mathrm{B}(1)-\mathrm{H}(2) & 115(2) \\ \mathrm{P}(1)-\mathrm{B}(1)-\mathrm{H}(3) & 95.6(13) \\ \mathrm{H}(1)-\mathrm{B}(1)-\mathrm{H}(3) & 114.0(19) \\ \mathrm{H}(2)-\mathrm{B}(1)-\mathrm{H}(3) & 114(2) \\ & \\ & \end{array}$

Symmetry transformations used to generate equivalent atoms: 
Table 4. Anisotropic displacement parameters $\left(\AA^{2} \times 10^{3}\right)$ for k11125a. The anisotropic displacement factor exponent takes the form: $-2 \pi^{2}\left[h^{2} a^{* 2} U^{11}+\ldots+2 h k a^{*} b^{*} U^{12}\right]$

\begin{tabular}{|c|c|c|c|c|c|c|}
\hline & $\mathrm{U}^{11}$ & $\mathrm{U}^{22}$ & $\mathrm{U}^{33}$ & $\mathrm{U}^{23}$ & $\mathrm{U}^{13}$ & $\mathrm{U}^{12}$ \\
\hline $\mathrm{P}(1)$ & $38(1)$ & $25(1)$ & $21(1)$ & $-1(1)$ & $3(1)$ & $-6(1)$ \\
\hline $\mathrm{O}(1)$ & $26(1)$ & $29(1)$ & $56(1)$ & $-1(1)$ & $-1(1)$ & $4(1)$ \\
\hline $\mathrm{C}(1)$ & $27(1)$ & $18(1)$ & 19(1) & $2(1)$ & $3(1)$ & $-3(1)$ \\
\hline$C(2)$ & $30(1)$ & $22(1)$ & $27(1)$ & $2(1)$ & $-1(1)$ & $-1(1)$ \\
\hline$C(3)$ & $37(2)$ & $34(1)$ & $34(1)$ & $3(1)$ & $-9(1)$ & $-9(1)$ \\
\hline$C(4)$ & $54(2)$ & $32(1)$ & $26(1)$ & $-4(1)$ & $-5(1)$ & $-15(1)$ \\
\hline$C(5)$ & $50(2)$ & $21(1)$ & $23(1)$ & $-1(1)$ & $7(1)$ & $-8(1)$ \\
\hline$C(6)$ & $67(2)$ & $20(1)$ & $32(2)$ & $-7(1)$ & $14(1)$ & $-6(1)$ \\
\hline$C(7)$ & $66(2)$ & $23(1)$ & $43(2)$ & $6(1)$ & $21(2)$ & $9(1)$ \\
\hline$C(8)$ & $45(2)$ & $32(1)$ & $35(2)$ & $9(1)$ & $12(1)$ & $10(1)$ \\
\hline$C(9)$ & $37(1)$ & $26(1)$ & $25(1)$ & $5(1)$ & $6(1)$ & $1(1)$ \\
\hline$C(10)$ & $35(1)$ & $21(1)$ & $20(1)$ & $3(1)$ & $6(1)$ & $-2(1)$ \\
\hline $\mathrm{C}(11)$ & $26(1)$ & 19(1) & $22(1)$ & $-1(1)$ & $1(1)$ & $2(1)$ \\
\hline$C(12)$ & $32(1)$ & $23(1)$ & $22(1)$ & $-2(1)$ & $2(1)$ & $-2(1)$ \\
\hline $\mathrm{C}(13)$ & $42(2)$ & $30(1)$ & $22(1)$ & $-3(1)$ & $1(1)$ & $-6(1)$ \\
\hline$C(14)$ & $31(1)$ & $25(1)$ & $31(1)$ & $-7(1)$ & $2(1)$ & $-3(1)$ \\
\hline$C(15)$ & $27(1)$ & 19(1) & $30(1)$ & $-2(1)$ & $1(1)$ & $3(1)$ \\
\hline$C(16)$ & $31(1)$ & $23(1)$ & $40(2)$ & $2(1)$ & $-2(1)$ & $-2(1)$ \\
\hline $\mathrm{C}(17)$ & $36(2)$ & $30(1)$ & $40(2)$ & $13(1)$ & $0(1)$ & $-3(1)$ \\
\hline$C(18)$ & $36(1)$ & $37(2)$ & $27(1)$ & $7(1)$ & $0(1)$ & $-1(1)$ \\
\hline$C(19)$ & $30(1)$ & $29(1)$ & $23(1)$ & $2(1)$ & $2(1)$ & $-1(1)$ \\
\hline$C(20)$ & $21(1)$ & 21(1) & $25(1)$ & $3(1)$ & $1(1)$ & $2(1)$ \\
\hline$C(21)$ & $45(2)$ & $24(1)$ & $24(1)$ & $0(1)$ & $6(1)$ & $-6(1)$ \\
\hline$C(22)$ & $53(2)$ & $32(2)$ & $53(2)$ & $-7(1)$ & $-14(2)$ & $1(1)$ \\
\hline$C(23)$ & $58(2)$ & $39(2)$ & $56(2)$ & $-4(1)$ & $-23(2)$ & $1(2)$ \\
\hline $\mathrm{C}(24)$ & $41(2)$ & $39(2)$ & $63(2)$ & $15(1)$ & $4(1)$ & $-3(1)$ \\
\hline $\mathrm{C}(25)$ & $62(2)$ & $37(2)$ & $36(2)$ & $-3(1)$ & $4(1)$ & $8(1)$ \\
\hline$C(26)$ & $69(2)$ & $37(2)$ & $29(1)$ & $2(1)$ & $5(1)$ & $8(1)$ \\
\hline $\mathrm{C}(27)$ & $37(1)$ & $28(1)$ & $22(1)$ & $-2(1)$ & $3(1)$ & $-6(1)$ \\
\hline $\mathrm{C}(28)$ & $46(2)$ & $32(1)$ & $26(1)$ & $-2(1)$ & $9(1)$ & $-8(1)$ \\
\hline \multirow[t]{2}{*}{$C(29)$} & $45(2)$ & $41(2)$ & $26(1)$ & $-3(1)$ & $9(1)$ & $-8(1)$ \\
\hline & & & & 179 & & \\
\hline
\end{tabular}




\begin{tabular}{llllllc}
$\mathrm{C}(30)$ & $38(2)$ & $49(2)$ & $36(2)$ & $-8(1)$ & $3(1)$ & $1(1)$ \\
$\mathrm{C}(31)$ & $45(2)$ & $39(2)$ & $41(2)$ & $0(1)$ & $4(1)$ & $10(1)$ \\
$\mathrm{C}(32)$ & $45(2)$ & $42(2)$ & $32(1)$ & $4(1)$ & $7(1)$ & $1(1)$ \\
$\mathrm{C}(33)$ & $26(1)$ & $47(2)$ & $74(2)$ & $2(2)$ & $-3(1)$ & $6(1)$ \\
$\mathrm{B}(1)$ & $48(2)$ & $32(2)$ & $30(2)$ & $-2(1)$ & $0(1)$ & $-11(2)$ \\
\hline
\end{tabular}


Table 5. Hydrogen coordinates ( $\left.\times 10^{4}\right)$ and isotropic displacement parameters $\left(\AA^{2} \times 10^{3}\right)$ for k11125a.

\begin{tabular}{|c|c|c|c|c|}
\hline & $\mathrm{x}$ & $\mathrm{y}$ & $\mathrm{z}$ & $\mathrm{U}(\mathrm{eq})$ \\
\hline $\mathrm{H}(3 \mathrm{~A})$ & 10877 & 10500 & 10696 & 42 \\
\hline $\mathrm{H}(4 \mathrm{~A})$ & 9461 & 11626 & 10950 & 45 \\
\hline $\mathrm{H}(6 \mathrm{~A})$ & 6849 & 12429 & 10923 & 48 \\
\hline $\mathrm{H}(7 \mathrm{~A})$ & 4114 & 12569 & 10594 & 53 \\
\hline $\mathrm{H}(8 \mathrm{~A})$ & 2824 & 11595 & 9953 & 45 \\
\hline $\mathrm{H}(9 \mathrm{~A})$ & 4275 & 10494 & 9638 & 35 \\
\hline $\mathrm{H}(13 \mathrm{~A})$ & 5890 & 8892 & 7953 & 38 \\
\hline $\mathrm{H}(14 \mathrm{~A})$ & 4490 & 7907 & 8488 & 35 \\
\hline $\mathrm{H}(16 \mathrm{~A})$ & 3767 & 7205 & 9547 & 37 \\
\hline $\mathrm{H}(17 \mathrm{~A})$ & 3734 & 7169 & 10702 & 43 \\
\hline $\mathrm{H}(18 \mathrm{~A})$ & 4908 & 8189 & 11325 & 40 \\
\hline $\mathrm{H}(19 \mathrm{~A})$ & 6190 & 9226 & 10800 & 33 \\
\hline $\mathrm{H}(21 \mathrm{~A})$ & 7391 & 11104 & 7509 & 37 \\
\hline $\mathrm{H}(22 \mathrm{~A})$ & 4535 & 10129 & 7631 & 55 \\
\hline $\mathrm{H}(22 \mathrm{~B})$ & 5914 & 10036 & 7058 & 55 \\
\hline $\mathrm{H}(23 \mathrm{~A})$ & 5277 & 11287 & 6632 & 61 \\
\hline $\mathrm{H}(23 \mathrm{~B})$ & 3609 & 10778 & 6654 & 61 \\
\hline $\mathrm{H}(24 \mathrm{~A})$ & 2723 & 11414 & 7619 & 57 \\
\hline $\mathrm{H}(24 \mathrm{~B})$ & 3167 & 12062 & 7070 & 57 \\
\hline $\mathrm{H}(25 \mathrm{~A})$ & 4287 & 12381 & 8142 & 54 \\
\hline $\mathrm{H}(25 \mathrm{~B})$ & 5705 & 12322 & 7582 & 54 \\
\hline $\mathrm{H}(26 \mathrm{~A})$ & 6628 & 11657 & 8546 & 54 \\
\hline $\mathrm{H}(26 \mathrm{~B})$ & 4981 & 11132 & 8554 & 54 \\
\hline $\mathrm{H}(27 \mathrm{~A})$ & 8135 & 9269 & 7405 & 35 \\
\hline $\mathrm{H}(28 \mathrm{~A})$ & 9582 & 10376 & 6994 & 42 \\
\hline $\mathrm{H}(28 \mathrm{~B})$ & 11101 & 10201 & 7491 & 42 \\
\hline $\mathrm{H}(29 \mathrm{~A})$ & 10086 & 9202 & 6410 & 45 \\
\hline $\mathrm{H}(29 \mathrm{~B})$ & 11755 & 9712 & 6417 & 45 \\
\hline $\mathrm{H}(30 \mathrm{~A})$ & 12869 & 8944 & 7279 & 49 \\
\hline $\mathrm{H}(30 \mathrm{~B})$ & 12318 & 8380 & 6679 & 49 \\
\hline
\end{tabular}




\begin{tabular}{lclll}
$\mathrm{H}(31 \mathrm{~A})$ & 9869 & 8033 & 7247 & 50 \\
$\mathrm{H}(31 \mathrm{~B})$ & 11407 & 7884 & 7739 & 50 \\
$\mathrm{H}(32 \mathrm{~A})$ & 9198 & 8535 & 8309 & 47 \\
$\mathrm{H}(32 \mathrm{~B})$ & 10854 & 9054 & 8315 & 47 \\
$\mathrm{H}(33 \mathrm{~A})$ & 11872 & 8755 & 9817 & 73 \\
$\mathrm{H}(33 \mathrm{~B})$ & 11841 & 9271 & 10484 & 73 \\
$\mathrm{H}(33 \mathrm{C})$ & 12011 & 9685 & 9770 & 73 \\
$\mathrm{H}(1)$ & $9090(40)$ & $11152(16)$ & $9105(15)$ & $63(9)$ \\
$\mathrm{H}(2)$ & $10730(30)$ & $10449(14)$ & $8870(12)$ & $40(7)$ \\
$\mathrm{H}(3)$ & $9980(30)$ & $11178(14)$ & $8229(14)$ & $49(8)$ \\
\hline
\end{tabular}




\section{References:}

1) Hornback, J.M. Organic Chemistry $2^{\text {nd }}$ Edition (Thomson, Belmont, CA, 2005-2006).

2) Bruice, P. Organic Chemistry $5^{\text {th }}$ Edition ( Pearson, Santa Barbara, CA, 2005).

3) IUPAC. Compendium of Chemical Terminology $2^{\text {nd }}$ Edition. Compiled by A.D. McNaught and A. Wilkinson. Blackwell Scientific Publications, Oxford (1997).

4) Grasa, G.A.; Viciu, M.S.; Huang, J.; Nolan, S.P. Amination Reactions of Aryl Halides with Nitrogen-Containing Reagents Mediated by Palladium/Imidazolium Salt Systems. J. Org. Chem. 2001, 66, 7729-7737.

5) Yang, B.H.; Buchwald, S.L.; Palladium-Catalyzed Amination of Aryl Halides and Sulfonates. J. Organomet. Chem. 1999, 576, 125-146.

6) Buchwald, S.L.; Surry, D.S.; Biaryl Phosphane Ligands in Palladium Catalyzed Amination. Angew. Chem. Int. Ed. 2008, 47, 6338-6361.

7) Wolfe, J.P.; Wagaw, S.; Marcoux, J.F.; Buchwald, S.L. Rational Development of Practical Catalysts for Aromatic Carbon-Nitrogen Bond Formation. Acc. Chem. Res. 1998, 31, 805818.

8) Klinkenberg, J.L.; Hartwig, J.F. Catalytic Organometallic Reactions of Ammonia. Angew. Chem. Int. Ed. 2011, 50, 86-95.

9) Hartwig, J.F. Evolution of a Fourth Generation Catalyst for the Amination and Thioetherification of Aryl Halides. Acc. Chem. Res. 2008, 41, 1534-1544.

10) Hartwig, J.F. Carbon-Heteroatom Bond Formation Catalysed by Organometallic Complexes. Nature. 2008, 455, 314-322.

11) Hartwig, J.F. Carbon-Heteroatom Bond Forming Reductive Eliminations of Amines, Ethers and Sulfides. Acc. Chem. Res. 1998, 31, 852-860.

12) Hartwig, J.F. Transition Metal Catalyzed Synthesis of Arylamines and Aryl Ethers from Aryl Halides and Triflates: Scope and Mechanism. Angew. Chem. Int. Ed. 1998, 37, 2047-2067.

13) Guram, A.S.; Rennels, R.A. Buchwald, S.L.; A Simple Catalytic Method for the Conversion of Aryl Bromides to Arylamines. Angwew. Chem. Int. Ed. Eng. 1995, 34, 1348-1350.

14) Louie, J.; Hartwig, J.F. Palladium-Catalyzed Synthesis of Arylamines from Aryl Halides. Mechanistic Studies Lead to Coupling in the Absence of Tin Reagents. Tetrahedron Lett. 1995, 36, 3609-3612.

15) Hartwig, J.F.; Kawatsura, M.; Hauck, S.I.; Shaughnessy, K.H.; Alcazar-Roman, L.M. RoomTemperature Palladium-catalyzed Amination of Aryl Bromides and Chlorides and Extended Scope of Aromatic C-N Bond Formation with a Commercial Ligand. J. Org. Chem. 1999, 64, 5575-5580. 
16) Alcazar-Roman, L.M.; Hartwig, J.F.; Rheingold, A.L.; Liable-Sands, L.M.; Guzei, I.A. Mechanistic Studies of the Palladium-catalyzed Amination of Aryl Halides and the Oxidative Addition of Aryl Bromides to Pd(BINAP)(2) and Pd(DPPF)(2): An Unusual Case of Zeroorder Kinetic Behavior and Product Inhibition. J. Am. Chem. Soc. 2000, 122, 4618-4630.

17) Alcazar-Roman, L.M.; Hartwig, J.F. Mechanistic Studies on Oxidative Addition of Aryl Halides and Triflates to $\mathrm{Pd}(\mathrm{BINAP})(2)$ and Structural Characterization of the Product from Aryl Triflate Addition in the Presence of Amine. Organometallics. 2002, 21, 491-502.

18) Singh, U.K.; Streiter, E.R.; Blacmond, D.G.; Buchwald, S.L. Mechanistic Insights into the Pd(BINAP)-catalyzed Amination of Aryl Bromides: Kinetic Studies Under Synthetically Relevant Conditions. J. Am. Chem. Soc. 2002, 124, 14104-14114.

19) Shakar, S.; Ryberg, P.; Hartwig, J.F.; Mathew, J.S.; Blackmond, D.G.; Streiter, E.R.; Buchwald, S.L. Reevaluation of the Mechanism of the Amination of Aryl Halides Catalyzed by BINAP-Ligated Palladium Complexes. J. Am. Chem. Soc. 2006, 128, 3584-3591.

20) Cundari, T.R.; Ke, Z.; Palladium-Catalyzed C-H Activation/C-N Bond Formation Reactions: DFT Study of Reaction Mechanisms and Reactive Intermediates. Organometallics. 2010, 29, 821-834.

21) Wolfe, J.P.; Wagaw, S.; Buchwald, S.L. An Improved Catalyst System for Aromatic Carbonnitrogen Bond Formation: The Possible Involvement of Bis(phosphine) Palladium Complexes as key Intermediates. J. Am. Chem. Soc. 1996, 118, 7215-7216.

22) Hamann, B.C.; Hartwig, J.F. Sterically Hindered Chelating Alkyl Phosphines Provide Large Rate Accelerations in Palladium-Catalyzed Amination of Aryl Iodides, Bromides, and Chlorides, and the First Amination of Aryl Tosylates. J. Am. Chem. Soc. 1998, 120, 73697370.

23) Wagaw, S., Rennels, R. A. \& Buchwald, S. L. Palladium-Catalyzed Coupling of Optically Active Amines with Aryl Bromides. J. Am. Chem. Soc. 1997, 119, 8451-8458.

24) Frost, C. G. \& Mendonça, P. Palladium Catalysed Mono- $N$-Arylation of Enantiopure Diamines. Tetrahedron: Asym. 1999, 10, 1831-1834.

25) Rossen, K.; Pye, P.J.; Maliakal, A.; Volante, R.P. Kinetic Resolution of rac-4,12Dibromo[2.2]paracyclophane in a Palladium [2.2]PHANEPHOS Catalyzed Amination. $J$. Org. Chem. 1997, 62, 6462-6463.

26) Vyskocil, S.; Smrcina, M.; Kocovsky, P. Synthesis of 2-Amino-2'-diphenylphosphino-1,1'binaphthyl (MAP) and its Accelerating Effect on the $\operatorname{Pd}(0)$-Catalyzed N-Arylation. Tetrahedron Lett. 1998, 39, 9289-9292.

27) Tagashira, J.; Imao, D.; Yamamoto, T.; Ohta, T.; Furukawa, I.; Ito, Y. Optically Active Palladium-Catalyzed Asymmetric Amination of Aryl Halide. Tetrahedron Asymmetry. 2005, 16, 2307-2314.

28) Kreis, M.; Friedmann, C.J.; Brase, S. Diastereoselective Hartwig-Buchwald Reaction of Chiral Amines with rac-[2.2]Paracyclophane Derivatives. Chem. Eur. J. 2005, 11, 7387-7394. 
29) Ranyuk, E.R.; Averin, A.D.; Beletskaya, I.P. One-Step Synthesis of Chiral Azamacrocycles via Palladium-Catalyzed Enantioselective Amination of 1,5-Dichloroanthraquinone and 1,5Dichloroanthracene. Adv. Synth. Catal. 2010, 352, 2299-2305.

30) Ishibashi, K.; Tsue, H.; Takahashi, H.; Tamura, R. Azacalix[4]arene Tetramethyl Ether with Inherent Chirality Generated by Substitution on the Nitrogen Bridges. Tetrahedron Asymmetry. 2009, 20, 375-380.

31) Porosa, L.; Viirre, R.D. Desymmetrization of Malonamides via an Enantioselective Intramolecular Buchwald-Hartwig Reaction. Tetrahedron Lett. 2009, 50, 4170-4173.

32) Porosa, L.; Viirre, R.D.; Lough, A.J.; N,1-Bis(4-chloro-2-methylbenzyl)-3-methyl-2-oxo1,2,3,4-tetrahydroquinoline-3-carboxamide. Acta Cryst. 2009, 65, O3090-U589.

33) Takenaka, K.; Itoh, N.; Sasai, H. Enantioselective Synthesis of $\mathrm{C}_{2}$-Symmetric Spirobilactams via Pd-Catalyzed Intramolecular Double N-Arylation. Org. Lett. 2009, 11, 1483-1486.

34) Kitagawa, O.; Takahashi, M.; Yoshikawa, M.; Taguchi, T. Efficient Synthesis of Optically Active Atropisomeric Anilides through Catalytic Asymmetric N-Arylation Reaction. J. Am. Chem. Soc. 2005, 127, 3676-3677.

35) Kitagawa, O.; Yoshikawa, M.; Tanabe, H.; Morita, T.; Takahashi, M.; Dobashi, Y.; Taguchi, T. Highly Enantioselective Synthesis of Atropisomeric Anilide Derivatives through Catalytic Asymmetric N-Arylation: Conformational Analysis and Application to Asymmetric Enolate Chemistry. J. Am. Chem. Soc. 2006, 128, 12923-12931.

36) Kitagawa, O.; Kurihara, D.; Tanabe, H.; Shibuya, T.; Taguchi, T. Catalytic Enantioselective Synthesis of key Intermediates for NET inhibitors using Atropisomeric Lactam Chemistry. Tetrahedron Lett. 2008, 49, 471-474.

37) Takahashi, M.; Tanabe, H.; Nakamura, T.; Kuribara, D.; Yamazaki, T.; Kitagawa, O. Atropisomeric Lactam Chemistry: Catalytic Enantioselective Synthesis, Application to Asymmetri Enolate Chemistry and Synthesis of key Intermediates for NET inhibitors. Tetrahedron. 2010, 66, 288-296.

38) Uozumi, Y.; Tanahashi, A.; Lee, S.; Hayashi, T. Synthesis of Optically Active 2(Diarylphosphino)-1,1'-binaphthyls, Efficient Chiral Monodentate Phosphine Ligands. J. Org. Chem. 1993, 58, 1945-1948.

39) Hamada, T.; Chieffi, A.; Ahman, J.; Buchwald, S.L. An Improved Catalyst for the Asymmetri Arylation of Ketone Enolates. J. Am. Chem. Soc. 2002, 124, 1261-1268.

40) Xie, X.; Zhang, T.Y.; Zhang, Z. Synthesis of Bulky and Electron-Rich MOP-type Ligands and Their Applications in Palladium-Catalyzed C-N Bond Formation. J. Org. Chem. 2006, 71, 6522-6529.

41) Murata, M.; Buchwald, S.L. A General and Efficient Method for the Palladium Catalyzed Cross-Coupling of Thiols and Secondary Phosphines. Tetrahedron. 2004, 60, 7397-7403.

42) Biscoe, M.R.; Fors, B.P.; Buchwald, S.L. A New Class of Easily Activated Palladium Precatalysts for Facile C-N Cross-Coupling Reactions and the Low Temperature Oxidative Addition of Aryl Chlorides. J. Am. Chem. Soc. 2008, 130, 6686-6687. 
43) Fors, B.P.; Watson, D.A.; Biscoe, M.R.; Buchwald, S.L. A Highly Active Catalyst for PdCatalyzed Amination Reactions: Cross-Coupling Reactions Using Aryl Mesylates and the Highly Selective Monoarylation of Primary Amines Using Aryl Chlorides. J. Am. Chem. Soc. 2008, 130, 13552-13554.

44) Jursic, B.S. Decarbonylation of Tetrasubstituted Barbituric Acids as a Versatile Method for Preparation of $N, N^{\prime}, 2,2-$ Tetrasubstituted Malonamides. Tetrahedron Lett. 2000, 41, 53255328.

45) Bose, A.K.; Garratt, S. A New Synthesis of Barbituric Acids. J. Am. Chem. Soc. 1962, 84, 1310-1311.

46) Alkhouri, B. Synthesis of Enantiopure Chiral Monophosphine Ligands for Use in Asymmetric Buchwald-Hartwig Reactions. Ryerson University BSc. Thesis 2010.

47) Porosa, L. Development of Enantioselective Intramolecular N-Arylation Reactions for the Desymmetrization of Achiral Dinitrogen Malonamides. Ryerson University MSc. Thesis 2008.

48) Vicente, J.; Saura-Llamas, I.; Palin, M.G. Orthometalation of Primary Amines. 4. ${ }^{1}$ Orthopalladation of Primary Benzylamines and (2-Phenylethyl)amine. Organometallics, 1997, 16, 826-833. 